\title{
The February 2004 Landslide Event in Geomorphic Perspective
}

\author{
K.C. Wright
}

Submitted as partial fulfilment

of the requirements for

MSc (Hons) in Physical Geography

School of Earth Sciences

Victoria University of Wellington

2005 


\section{Table of Contents}

Table of Contents........................................................................

List of Figures....................................................................

List of Tables...................................................................

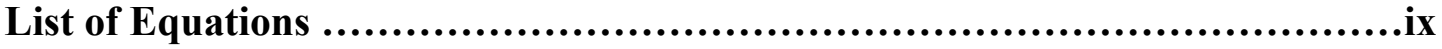

1 Introduction and Background .................................................

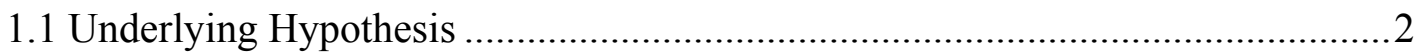

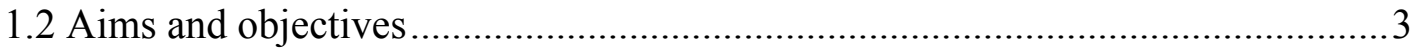

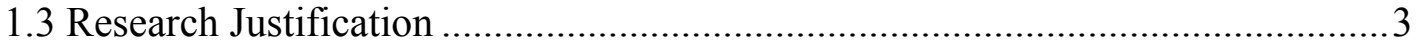

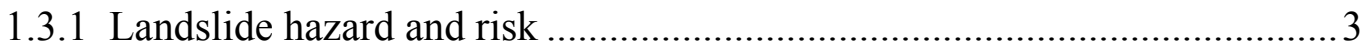

1.3.2 Expansion of existing geomorphic knowledge ....................................... 4

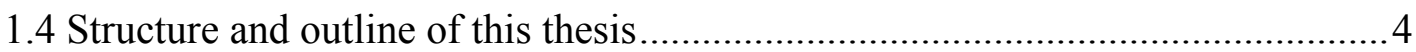

2 Theoretical Framework.................................................................

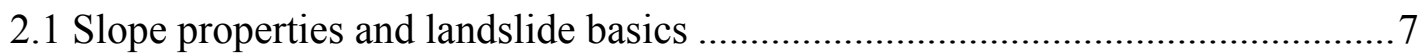

2.1.1 Hillslope processes, properties, and morphology …................................ 8

2.1.2 Landslide Classification, Form, and Behaviour....................................... 16

2.1.3 Landslide triggering factors and pre-conditions ....................................24

2.1.4 Geomorphological impact of landslides on hillslopes .............................25

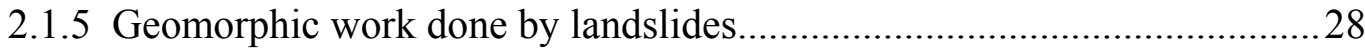

2.1.6 Rainfall-triggered, multiple landslide events in New Zealand .................29

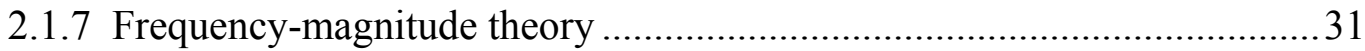

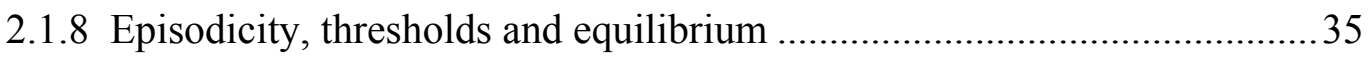

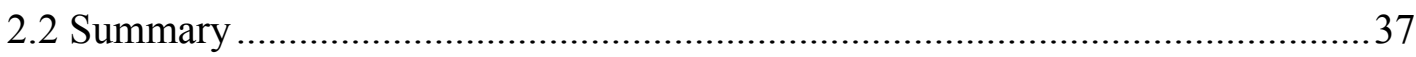

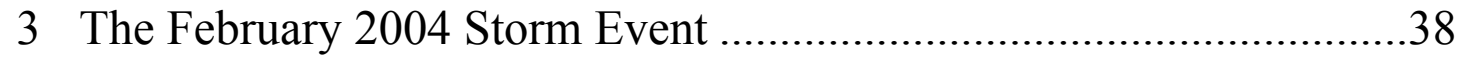

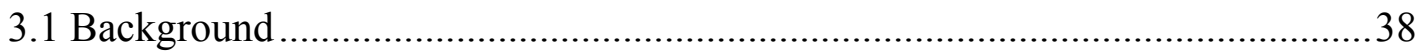

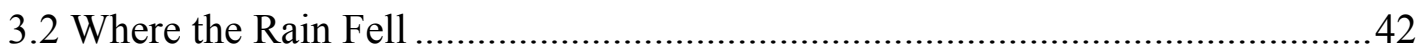

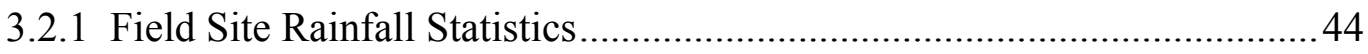

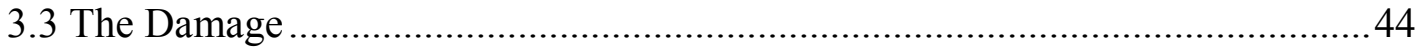

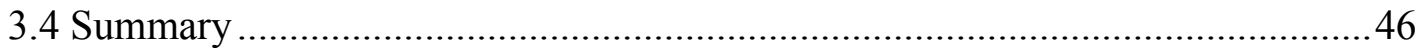

4 Overview of Landslide Damage ............................................4 47

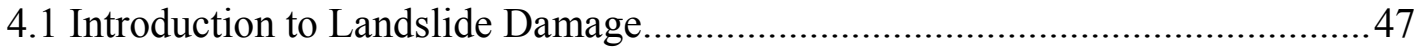

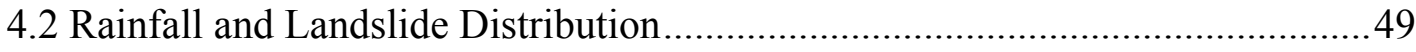


4.3 Immediate Response to Landsliding Damage.................................................50

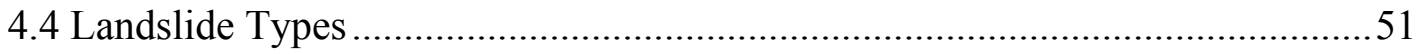

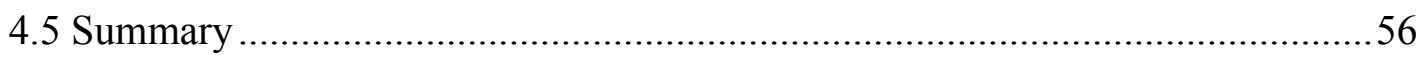

5 Regional Characteristics of the Study Catchment ............................57

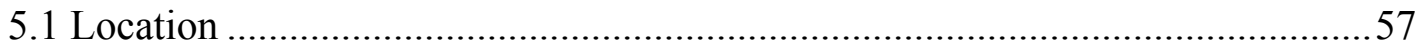

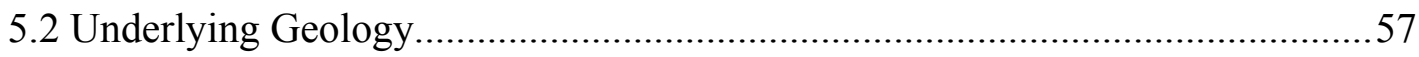

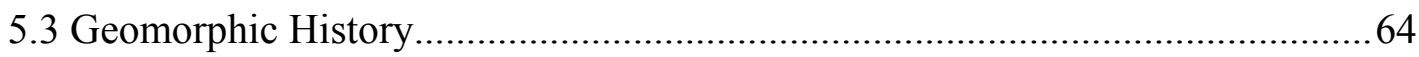

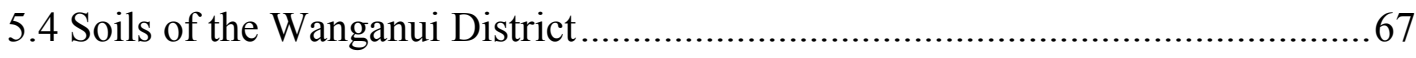

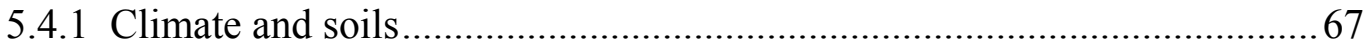

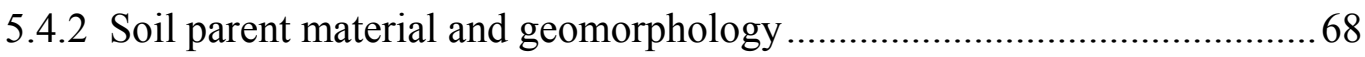

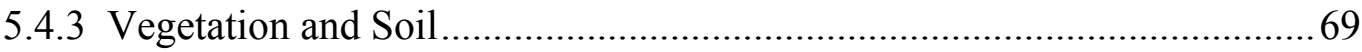

5.4.4 Soil of the Mangawhero River Hill Country............................................ 70

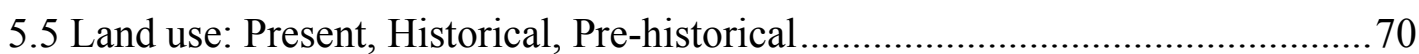

5.5.1 Mangawhero; Road Building and Valley Life........................................ 72

5.5.2 Natural Hazards of Early Wanganui ..........................................................75

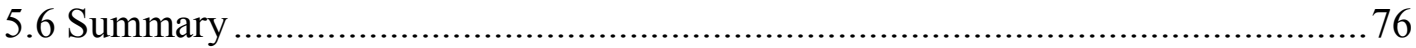

6 Field Study Catchment ............................................................ 77

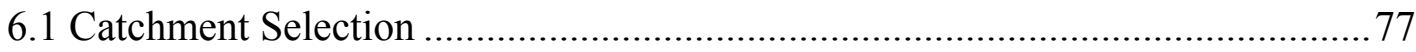

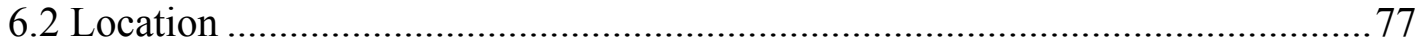

6.3 Lithology, Topography and Geomorphology …............................................. 80

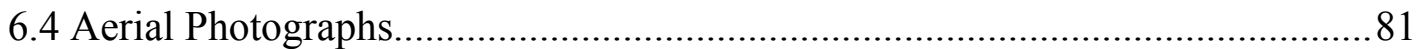

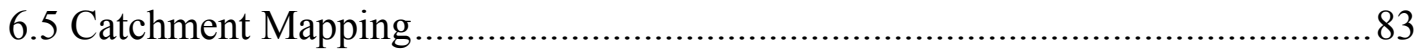

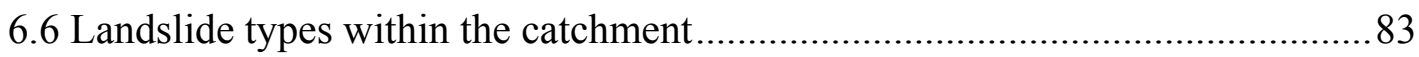

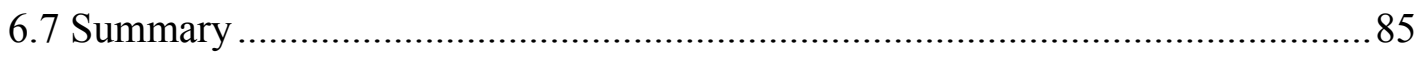

7 Catchment-based Study; Methodology and Results..........................86

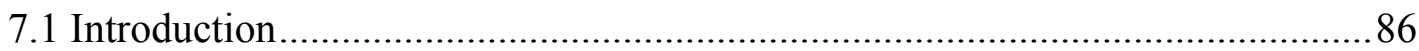

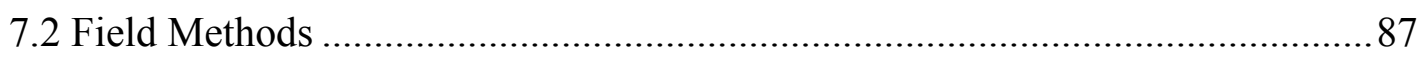

7.2.1 Mapping the Catchment Topography .................................................. 87

7.2.2 Mapping Scar Areas and Runout Areas................................................ 87

7.2.3 Estimating Scar and Runout Depths .......................................................93

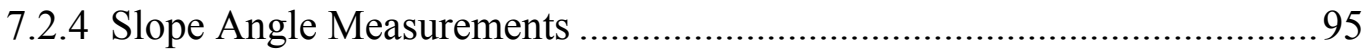

7.2.5 Calculation of scar and runout volumes................................................ 96

7.2.6 Changes to slope angle and slope form, due to landsliding .................... 101 
7.2.7 Slope form and position on slope of landslides

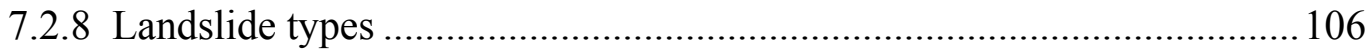

7.3 Summary of Field Catchment Results ........................................................... 108

8 Regional landslide and terrain analysis methods and results ...........109

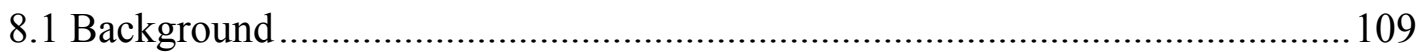

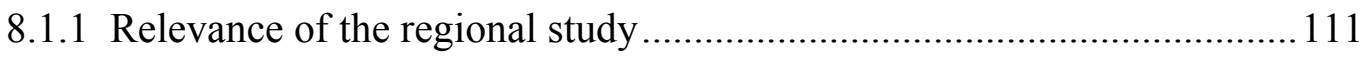

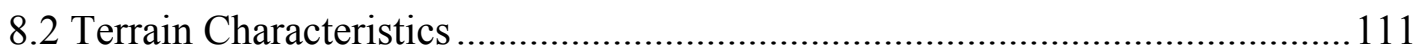

8.2.1 Regional Geology/Lithology ….......................................................... 113

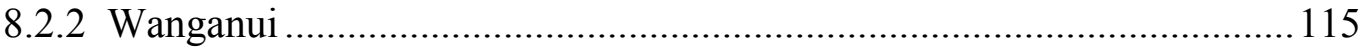

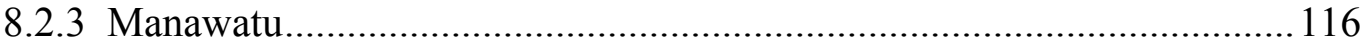

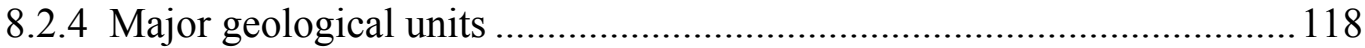

8.2.5 Geological characteristics and erosion susceptibility ............................ 118

8.2.6 Regolith and Soils of the Four Study Regions ......................................... 120

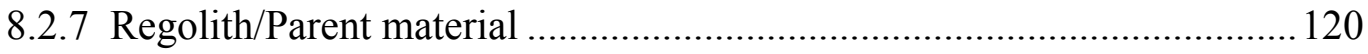

8.2.8 Soils of the Four Study Areas .............................................................. 122

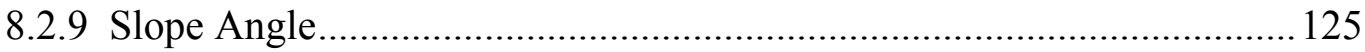

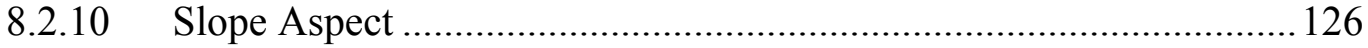

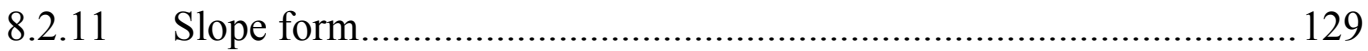

8.2.12 Slope Height................................................................................ 131

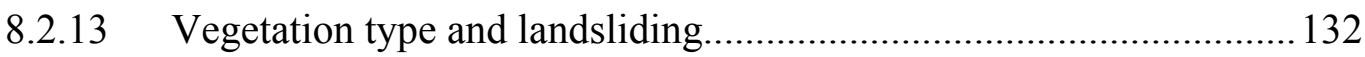

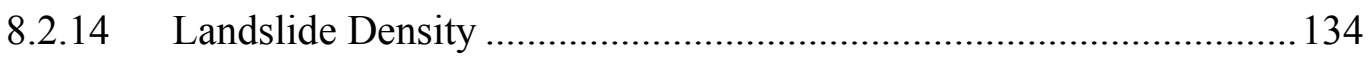

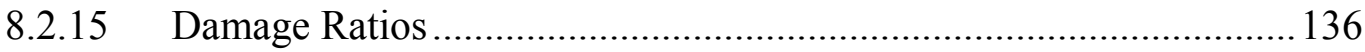

8.2.16 Runout length: Scar length ratios.................................................. 137

8.2.17 Scar Volume Comparisons ............................................................ 139

8.2.18 Error calculation of non-rectified photographs................................ 142

8.3 Summary of the regional terrain and landslide characteristics analysis ........... 142

9 Comparison of rainfall-triggered, multiple landslide events.............148

9.1 Frequency Magnitude Parameters................................................................. 148

9.2 Comparison of frequency and areal extent of landsliding .............................. 148

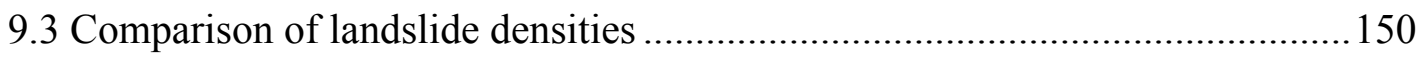

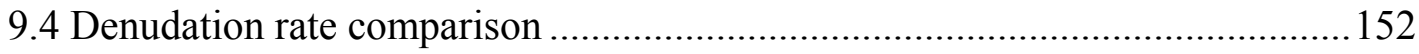

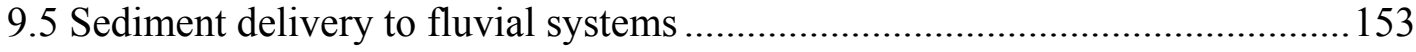

9.6 The Landslide Event Magnitude Scale ......................................................... 153 
9.7 Summary of the landslide event comparisons

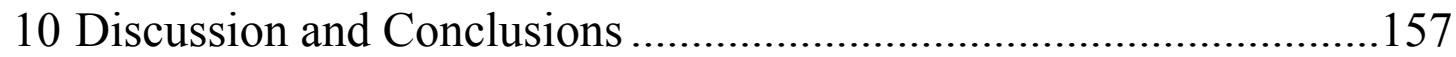

10.1 Geomorphic significance evaluation.................................................... 157

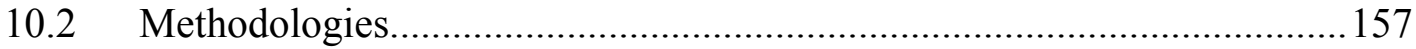

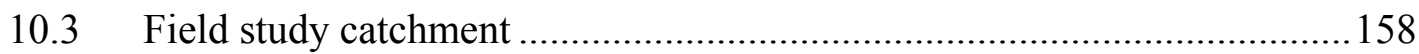

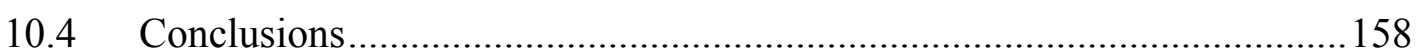

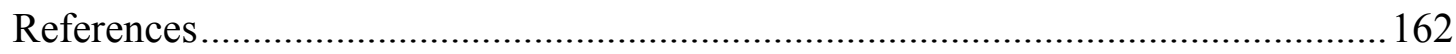

Appendix 1 Study Catchment Landslide Data.......................................................... 167

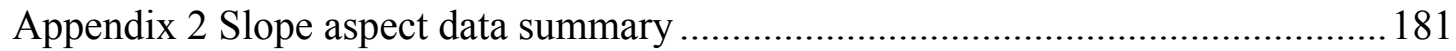

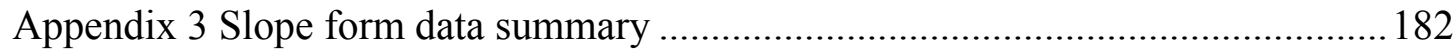

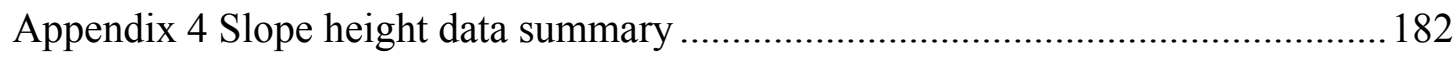

Appendix 5 Vegetation Data summary ............................................................... 183

Appendix 6 Landslide density data summary ..................................................... 183

Appendix 7 Runout length: scar length ratio data summary.................................... 184

Appendix 8 Scar volume data by study area.......................................................... 185

Appendix 9 Vertical aerial photo rectification data summary ................................ 187 


\section{List of Figures}

FIGURE 1-1 VIEW OF LANDSLIDE AFFECTED HILLS IN THE WANGANUI REGION ......................................... 1

FIGURE 2-1 PARTS OF SLOPE USEFUL FOR LANDFORM ANALYSIS ............................................................

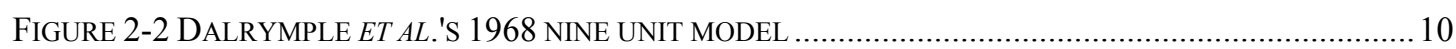

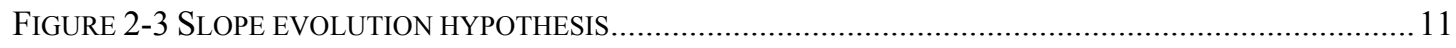

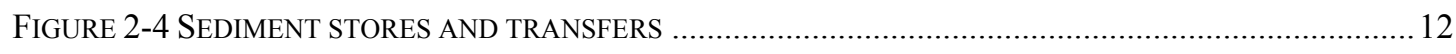

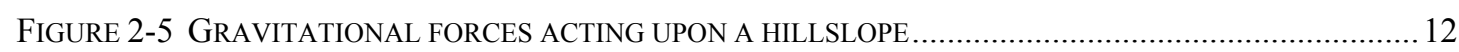

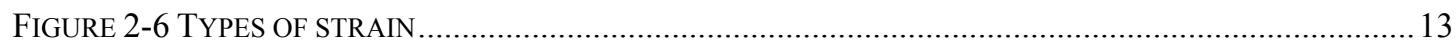

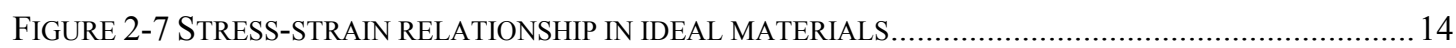

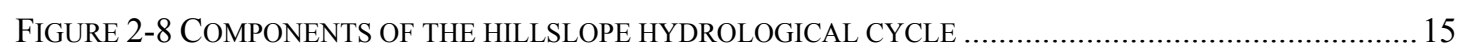

FIGURE 2-9 THE COMPONENTS OF A TRANSLATIONAL LANDSLIDE .......................................................... 19

FigURE 2-10 MULTIPLE TRANSLATIONAL LANDSLIDES IN THE WANGANUI HILL COUNTRY ....................... 19

FIGURE 2-11 THE CROWN/HEADSCARP OF A ROTATIONAL LANDSLIDE, WITH INSET SHOWING BASIC

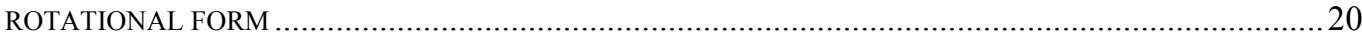

FIGURE 2-12 A LARGE ROTATIONAL SLIDE IN WHICH THE DEPOSIT MATERIAL HAS LOST STRUCTURE......20

FiguRE 2-13 EARTHFLOW OF SATURATED REGOLITH IN THE MANGAWHERO (NORTH-EAST WANGANUI)

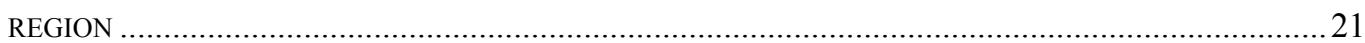

FIGURE 2-14 DRAINAGE CHANNEL EXPANSION WITH TIME _.................................................................22

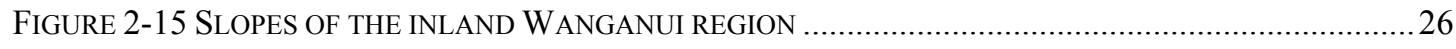

FIGURE 2-16 OVER-STEEPENING OF HILLSLOPE IN SCAR AREA OF ROTATIONAL LANDSLIDE …..................27

FigURE 2-17 THE WAIPAOA RIVER CATCHMENT AREA IN HAWKE'S BAY ................................................2

FIGURE 2-18 STRESS, OR EVENTS OF MAGNITUDE OVER THRESHOLD REQUIRED FOR MOVEMENT .............32

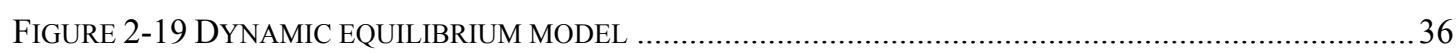

Figure 2-20 COMPARISON OF NEW ZEALAND GEOMORPHIC CHANGE WITH OTHER REGIONS OF THE

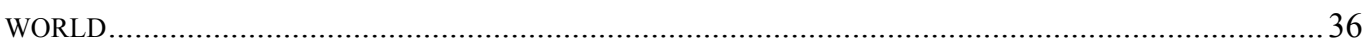

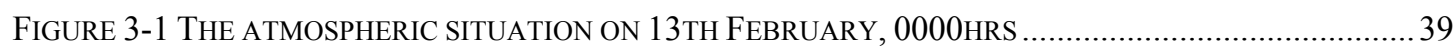

FIGURE 3-2 0000HRS, 14TH FEBRUARY, TWO LOW AIR PRESSURE SYSTEMS MOVE TOWARDS NZ ........... 39

FIGURE 3-3 THE LOWS DEEPEN AND BECOME MORE COMPLEX, 1200HRS 14TH FEBRUARY ....................... 39

FigURE 3-4 FRONTS MOVE OVER THE SOUTHERN NORTH ISLAND, BRINGING HIGH WINDS AND HEAVY

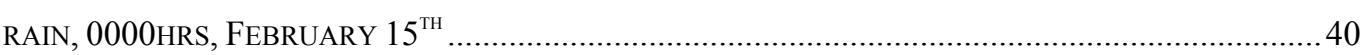

FigURE 3-5 LOW BECOMES SITUATED OFF THE N. I. EAST COAST, 1200HRS, FEBRUARY 15TH, ...............40

Figure 3-6 THE LOW-PRESSURE SYSTEMS STALL OFF THE EAST COAST, 0000HRS, FEBRUARY $16^{\text {TH }} \ldots . . . .40$

FigURE 3-7 THE STORM LOW MOVES SOUTHEAST AS A NEW FRONT APPROACHES FROM THE WEST, 1200HRS, FEBRUARY 16TH

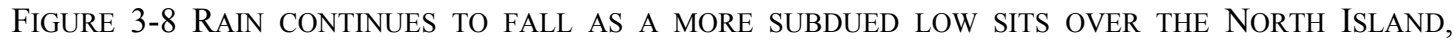
0000HRS, FEBRUARY 17TH.

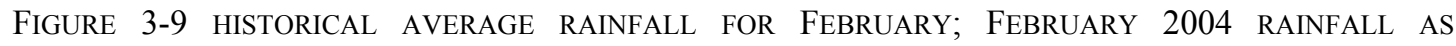
PERCENTAGE OF HISTORICAL AVERAGE; AND TOTAL RAINFALL FOR FEBRUARY 2004 ...................41

FIGURE 3-10 RAINFALL FOR THE DURATION OF THE FEBRUARY 2004 “WEATHER BOMB".........................42 
FIGURE 3-11 ISOHYETAL MAP OF NEW ZEALAND SHOWING PEAK RAINFALL DiSTRIBUTION (MM) AND ATMOSPHERIC PRESSURE ISOBARS FOR THE FEBRUARY $14^{\mathrm{TH}}-18^{\mathrm{TH}}$ STORM EVENT

FIGURE 3-12 A-D VARIOUS EXAMPLES OF DAMAGE FROM THE FEBRUARY 2004 STORM 45

Figure 3-13 EXAMPLE OF THE SEVERE LANDSLIDE DAMAGE RESUlting FROM THE FEBRUARY 2004 STORM EVENT

Figure 4-1 REgIONAL BOUNDARIES, RANGE OF LANDSLIDE DAMAGE, AND LOCATION OF THE FOUR STUDY AREAS EXAMINED IN THIS THESIS

FIGURE 4-2 LANDCARE RESEARCH MAP SHOWING RAINFALL INTENSITY FOR 72 HOUR PERIOD AND LANDSLIDE DENSITY AS RECORDED BY SATELLITE SPOT IMAGERY....

FIGURE 4-3 LARGE, MULTIPLE-HEADED TRANSLATIONAL LANDSLIDE/EARTHFLOW IN MUDSTONE ..........52

FIGURE 4-4 SHALLOW TRANSLATIONAL SLIDING MOSTLY FROM THE UPPER PART OF THE SLOPE............53

FIGURE 4-5 ROTATIONAL SLIDE FORMING A LANDSLIDE DAM AND SMALL LAKE IN THE LOWER TURAKINA RIVER HILL COUNTRY

Figure 4-6 Shallow, translational, multiple-heAded LANDSlides IN THE Pohangina HiLl COUNTRY

FIGURE 4-7 THE "OCTOPUS" LANDSLIDE, A VERY LARGE ROTATIONAL SLIDE AND EARTHFLOW FORMED IN AREA OF DENSE LANDSLIDING IN MUDSTONE IN THE MANGAWHERO HILL COUNTRY 54

FIGURE 4-8 THE LARGEST LANDSLIDE IN THE WELLINGTON REGION .................................................55

FIGURE 4-9 LARGE GREYWACKE BEDROCK LANDSLIDES IN THE MANAWATU GORGE ...........................55

FIGURE 5-1 MAP OF THE WANGANUI REGION IN CONTEXT OF POSITION WITHIN THE NORTH ISLAND ....57

FIGURE 5-2 GRAVITY ANOMALY THAT PRODUCED THE WANGANUI BASIN ….....................................5

Figure 5-3 WANGANUI SUBdiviSION, SHOWING SERIES AND GROUPS .............................................59

FIGURE 5-4 THE MAJOR GEOLOGICAL UNITS OF THE WANGANUI REGION ............................................ 60

FIGURE 5-5 (A) THE HISTORICAL STUDY AND IDENTIFICATION OF WANGANUI BASIN SEDIMENTS ..........6 62

FigurE 5-6 STRATIGRAPHIC COLUMN SHOWING YOUNGEST SEVEN CYCLES OF MANGAWEKA MUDSTONE FORMATION

FIGURE 5-7 LOOKING NORTH TOWARDS MT RUAPEHU ACROSS TYPICAL TERTIARY ROCK HILL COUNTRY WITH A PRESERVED TERRACE IN IMAGE CENTRE

FIGURE 5-8 HILL COUNTRY OF THE MANGAWHERO RIVER SHOWING PALEOSLIDE SLOPE MODIFICATION 66 FIGURE 5-9 MOISTURE RECORDS FOR KARIOI (HILL COUNTRY) AND WANGANUI (COASTAL) .................68 FIGURE 5-10 WANGANUI AND SURROUNDING COUNTIES, MAJOR RIVERS AND SETTLEMENTS .................71 FIGURE 5-11 CLEARING OF HILL COUNTRY IN KAKATAHI (MANGAWHERO RIVER VALLEY), 1926 .........72 FIGURE 5-12 UNSKILLED, POORLY PAID ROAD GANGS WERE USED TO BUILD THE PARAPARA RD ...........74

FIGURE 5-13 SLOPE PROTECTION AND FARM DIVERSIFICATION MEASURES .......................................... 74

Figure 6-1 THE STRUCTURALly WEAK SANDSTONE COUNTRY OF THE POHANGINA HILl COUNTRY, AND THE WEAK, YET MASSIVE MUDSTONE HILL COUNTRY OF MANGAWHERO .................................... 78

FIGURE 6-2 LOCATION MAP OF THE OCTOPUS CATCHMENT …........................................................... 79

FIGURE 6-3 LOOKING SOUTH OVER THE UPPER SLOPES OF THE EAST-FACING 'OCTOPUS CATCHMENT”.. 80 FIGURE 6-4 LOOKING NORTH-WEST INTO THE HEAD OF THE OCTOPUS CATCHMENT. ..............................81

FIGURE 6-5 THE MANGAWHERO STUDY CATCHMENT PHOTOGRAPHED IN 1963 .................................... 82 
Figure 6-6 VERTICAL AERIAL PHOTOGRAPH TAKEN WITHIN 3 MONTHS OF THE FEB. 2004 EVENT .........8 83

FIGURE 6-7 A - H LANDSLIDING AND DAMAGE IN THE MANGAWHERO STUDY CATCHMENT....................84

FigurE 7-1 DEM OF STUDY CATCHMENT PRODUCED FROM COMBINED 20 M CONTOUR DATA AND GPS DATA .89

FIGURE 7-2 TUMONZ PROJECTION OF THE OCTOPUS CATCHMENT 90

FIGURE 7-3 LOCATION AND NUMBER ID OF LANDSLIDES IN THE OCTOPUS CATCHMENT ......................91

FIGURE 7-4 TRUE SCAR (SOURCE) AREAS VISIBLE WITH UN-EVACUATED MATERIAL REMOVED................92

FIGURE 7-5 USING THE SOIL PROBE TO GAUGE RUNOUT/DEPOSIT DEPTH ..............................................99

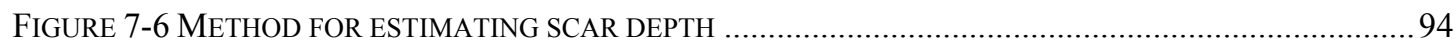

FIGURE 7-7 METHOD FOR USING ABNEY SLOPE ANGLE MEASURING APPARATUS .................................. 95

FIGURE 7-8 LANDSLIDE 15 ON A VERY STEEP SLOPE IN THE UPPERMOST PART OF THE CATCHMENT........ 96

FIGURE 7-9 BLOCKY FLOW MATERIAL FROM LANDSLIDE 18 ........................................................... 98

FIGURE 7-10 LOOKING DOWN AN EARTHFLOW LOBE OF LANDSLIDE 18 ............................................. 98

FIGURE 7-11 BASIC COMPARISON OF RUNOUT VOLUME AS PERCENTAGE OF SCAR VOLUMES FOR ALL LANDSLIDES IN CATCHMENT .99

FIGURE 7-12 THE PERCENTAGE OF SCAR MATERIAL VOLUME NOT PRESENT IN ROUNOUT VOLUME FOR FLUVIALLY COUPLED LANDSLIDES 100

FIGURE 7-13 THE PERCENTAGE OF SCAR MATERIAL VOLUME NOT PRESENT IN RUNOUT MATERIAL VOLUME FOR NON-COUPLED LANDSLIDES 100

FIGURE 7-14 VERY STEEP SCAR FACE AND SHALLOWER RUNOUT SLOPE ON LANDSLIDE 3. .................. 101

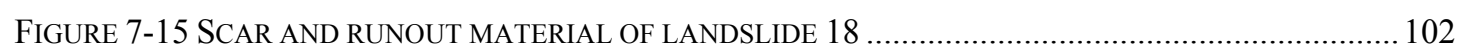

FIGURE 7-16 HIGHLY LIQUID RUNOUT MATERIAL AT THE BASE OF LANDSLIDE 1 ................................ 102

FIGURE 7-17 DIFFERENCES BETWEEN SCAR ANGLES AND ORIGINAL SLOPE ANGLES ........................... 103

FIGURE 7-18 DIFFERENCES BETWEEN RUNOUT ANGLES AND ORIGINAL SLOPE ANGLES ........................ 103

FIGURE 7-19 LANDSLIDE FORMATION ON UPPER SLOPES AND RIDGES AND ON LOWER AND MIDDLE

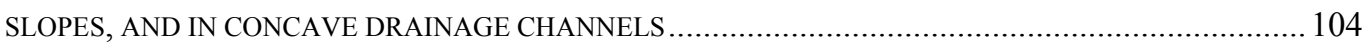

FIGURE 7-20 LANDSLIDE ID NUMBER 3, TRANSLATIONAL SLIDE AND EARTHFLOW.............................. 107

FIGURE 7-21 TRANSLATIONAL SLIDE FORMED IN REGOLITH .......................................................... 107

FIGURE 7-22 TRANSLATIONAL SLIDE SCAR FORMED IN COLLUVIUM ................................................. 107

FIGURE 7-23 THE RUNOUT MATERIAL OF LANDSLIDE ID NUMBER 25 ................................................ 107

FIGURE 7-24 BLOCKY RUNOUT MATERIAL AT THE BASE OF THE LANDSLIDE ID NUMBER 18 SCAR........ 108

FIGURE 7-25 VIEW OF LANDSLIDE ID NUMBER 18 IN WHICH THE EARTHFLOW LOBES ARE SHOWN ........ 108

FIGURE 8-1 LOCATION MAP OF THE FOUR STUDY AREAS DESCRIBED IN THIS THESIS .......................... 110

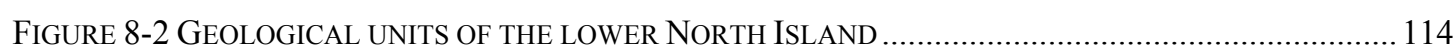

FIGURE 8-3 TYPICAL TERTIARY HILL COUNTRY OF NORTH-EAST WANGANUI REGION ......................... 115

FIGURE 8-4 PRESERVED MARINE TERRACE IN MANGAWHERO HILL COUNTRY. .................................... 116

FiguRE 8-5 DOME FORMATIONS OF THE MANAWATU AND LOWER WANGANUI REGIONS ...................... 117

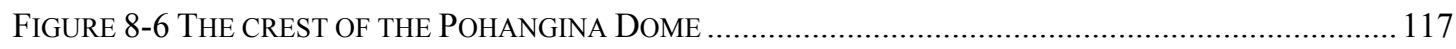

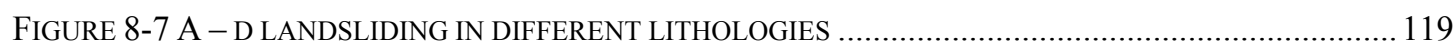

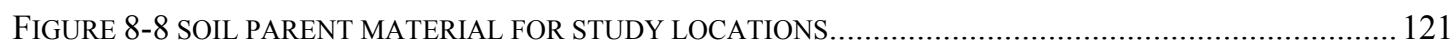


FIGURE 8-9 ASPECT ROSES FOR ALL SLOPES WITHIN THE STUDY AREAS 127

FIGURE 8-10 ASPECT ROSES FOR LANDSLIDE AFFECTED SLOPE PREFERENCE ...................................... 127

FIGURE 8-11 LANDSLIDE AFFECTED SLOPE ASPECT RATIOS AS PERCENTAGE OF ALL SLOPES ................. 128

FIGURE 8-12 PERCENTAGE OF LANDSLIDE AFFECTED SLOPES WITHIN EACH FORM CLASS .................... 130

FIGURE 8-13 PROPORTION OF LANDSLIDE AFFECTED SLOPES DIVIDED BY SLOPE FORM.......................... 130

FIGURE 8-14 SLOPE HEIGHT AND SLOPE FORM COMPARISON ............................................................ 132

FIGURE 8-15 LANDSLIDING SHOWN AS A PERCENTAGE OF LANDSLIDES IN EACH VEGETATION CLASS... 133

FIGURE 8-16 THE VEGETATION TYPE-LANDSLIDING RELATIONSHIP .................................................... 133

FIGURE 8-17 SOME OF THE VERTICAL AERIAL PHOTOGRAPHS USED FOR THIS STUDY ........................... 135

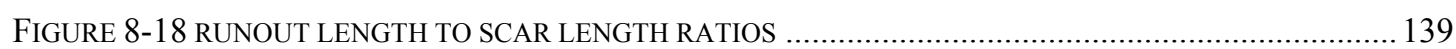

FIGURE 8-19 THE PERCENTAGE OF LANDSLIDES THAT FALL WITHIN EACH SIZE CLASS ......................... 140

FIGURE 8-20 THE PERCENTAGE OF SCAR VOLUME THAT IS REPRESENTED BY EACH SIZE CLASS ............ 141

FIGURE 8-21 BUSH COVERED SLOPES IN COMPARISON WITH PASTURE SLOPES ..................................... 144

FIGURE 8-22 MATURE PINE FOREST, POPLAR PLANTINGS, AND PASTURE COMPARISON ......................... 144

FIGURE 8-23 BUSH/SCRUB VALLEY WITH SEVERAL LANDSLIDES ON THE STEEP UNDERCUT SLOPES ....... 144

FIGURE 8-24 MATURE PINE FOREST (BACKGROUND) AND YOUNG PINES (FOREGROUND) ...................... 144

FIGURE 8-25 POPLARS/WILLOWS PLANTED IN DRAINAGE CHANNELS TO REDUCE SOIL SATURATION...... 144

FIGURE 9-1 THE EYLES AND EYLES (1982) MAP ADAPTED BY HANCOX............................................... 149

Figure 9-2 THE CHRONOLOGY OF LANDSLIDE EPISODES FOR THE PERIOD 1880 TO 1980, FOR THE EASTERN WAIRARAPA HILL COUNTRY 150

FIGURE 9-3 LANDSLIDE EVENT MAGNITUDE IN COMPARISON WITH TOTAL LANDSLIDE AREAS, VOLUMES, AND NUMBER OF LANDSLIDES 155 


\section{List of Tables}

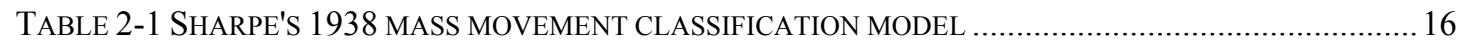

TABLE 2-2 VARNES' 1958 SLOPE MOVEMENT MODEL, WHICH INTRODUCED "FALLS" ................................ 16

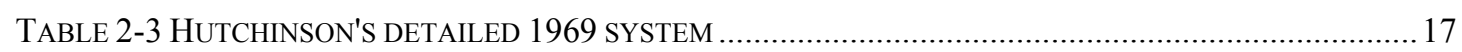

TABLE 2-4 VARNES' WIDELY -USED, REVISED 1975 CLASSIFICATION MODEL ……………...................... 17

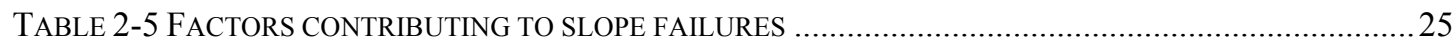

TABLE 2-6 RAPP'S RESULTS FROM THE 1960 SCANDINAVIAN MOUNTAIN STUDY ....................................34

TABLE 3-1 24-HOUR RAINFALL TOTALS FROM 9AM $15^{\text {TH }}$ TO 9AM $16^{\text {TH }}$ FOR LOWER N. I. AREAS .................43

TABLE 3-2 RAINFALL FOR JANUARY AND FEBRUARY 2004, MANGAWHERO FIELD STUDY SITE ................44

TABLE 5-1 IDENTIFIED NATURAL HAZARDS OF THE MANAWATU-WANGANUI REGION ............................. 75

TABLE 7-1 Volume CALCULATIONS, INCLUding total AND PERCENTAGe MATERIAL LOST FROM

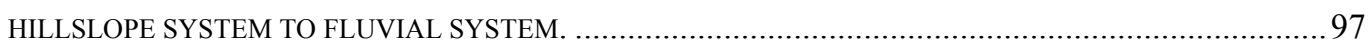

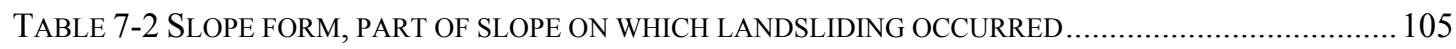

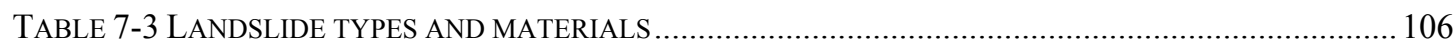

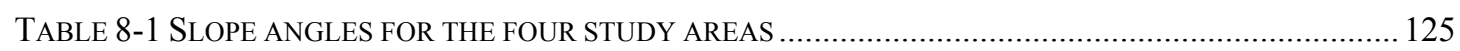

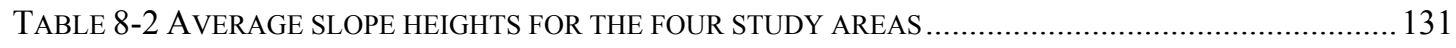

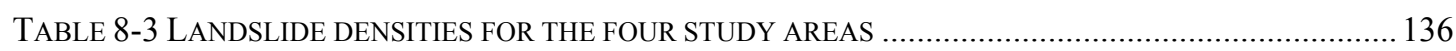

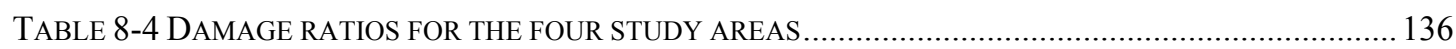

TABLE 8-5 AVERAGE OF ALL RUNOUT LENGTH: SCAR LENGTH RATIOS FOR EACH SAMPLE AREA ............138

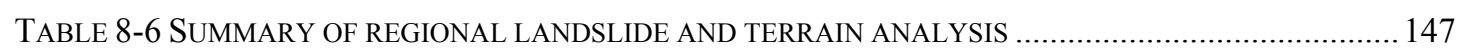

TABLE 9-1 LANDSLIDE DENSITIES FOR THE STUDY CATCHMENT AND REGIONAL STUDY AREAS .............. 150

TABLE 9-2 LANDSLIDE DENSITY COMPARISONS OF NEW ZEALAND (AND FiJIAN) RAINFALl TRIGGERED EVENTS 151

TABLE 9-3 DENUDATION RATES FoR THE FEBRUARY 2004 LANDSLIDE EVENT ...................................... 152

TABLE 9-4 LANDSLIDE EVENT MAGNITUDES FROM MALAMUd ET AL. (2004) AND THIS STUDY ............... 154

\section{List of Equations}

EQUATION 2-1 EQUATION FOR DETERMINING WHETHER HORTONIAN OVERLAND FLOW WILL OCCUR ....23 EQUATION 2-2 MANNING'S EQUATION FOR TURBULENT FLOW VELOCITY .23

EQUATION 2-3 SEDIMENT BUDGET EQUATION FOR MEASURING HILLSLOPE MATERIAL INPUT TO FLUVIAL SYSTEMS

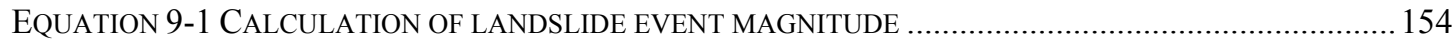

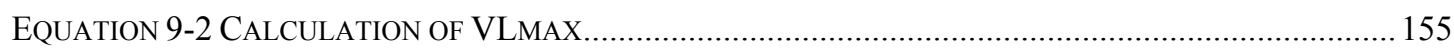




\begin{abstract}
In February 2004 a severe storm impacted the lower half of the North Island, New Zealand. Intense rainfall during the storm triggered extensive landsliding throughout the Tertiary hill country of Wanganui, Manawatu, and Wairarapa. The storm event also produced floods estimated to have a return period of 100 years. Flooding impacted on many communities, destroying homes, drowning livestock, and ruining crops. Because the effects of flooding were more immediate, and affected a greater number of people, landsliding damage received little coverage in the news media. However, the importance of these large rainfall-triggered, multiple landslide events that occur periodically in New Zealand should not be underestimated. New Zealand is losing valuable hillslope soil through erosion processes at a rate far in excess of the development of new soil. Landsliding is the most obvious and active hillslope erosion process operating in the hill country of New Zealand today.
\end{abstract}

This study examines the impact of the February 2004 landslide event from a geomorphic perspective, addressing questions such as: what changes to landforms were produced by this event, and, how much geomorphic work (volume of material, moved a given distance in a given time) was done by landsliding during the event. The proposition underlying this study is that it is not just the magnitude of the triggering event that determines the geomorphic response in terms of landform change and work done, but also that the nature of the terrain influences the magnitude (e.g. landslide densities, volumes, areal extent) of the landsliding produced. In order to test this hypothesis the study was undertaken in two parts. The first, a catchment-based study using mostly field methods to produce a sediment budget and landform change measurement. Secondly, a regional analysis of four areas which experienced the most severe landslide damage were analysed in terms of terrain and landslide characteristics. From the methodologies employed in these studies it is demonstrated that terrain characteristics are highly influential in determining the type and severity of landsliding.

To determine the geomorphic significance of the event in terms of the history of similar New Zealand landslide events, a frequency-magnitude analysis comparison was conducted, and the results compared with studies of previous rainfall-triggered, multiple landslide events.

The results of the catchment-based study, the regional study, and the frequencymagnitude analysis show that the February 2004 event is likely to be the most geomorphically significant event of its type (rainfall-triggered) to have occurred in New Zealand over the past 100 years. The area affected $\left(16,000 \mathrm{~km}^{2}\right)$ and number of landslides produced $(\sim 70,000)$ are greater than previously documented events. Landslide densities are also amongst the highest recorded in New Zealand. Although the majority of landslides were shallow regolith failures, large scars from deep-seated, rotational landslides will be visible in the landscape for hundreds of years. Material eroded from hillslopes during the event is estimated (conservatively) to be in excess of 20 million tonnes. While the majority of this eroded material remains within the hillslope system (depositional slopes and fans), a considerable proportion (an average of $25 \%$ in the study catchment) is transferred to fluvial systems via fluvial coupling and removed from hillslopes permanently. 


\section{Introduction and Background}

This study investigates the geomorphic significance of the February 2004 landsliding event, which was triggered by a severe storm that impacted the lower half of the North Island, New Zealand, between February $14^{\text {th }}$ and $16^{\text {th }}$ 2004. Landslide damage was extensive and severe in the Tertiary hill country east of Wanganui (Figure 1-1); a region that exhibits previous historic and prehistoric landslide damage.

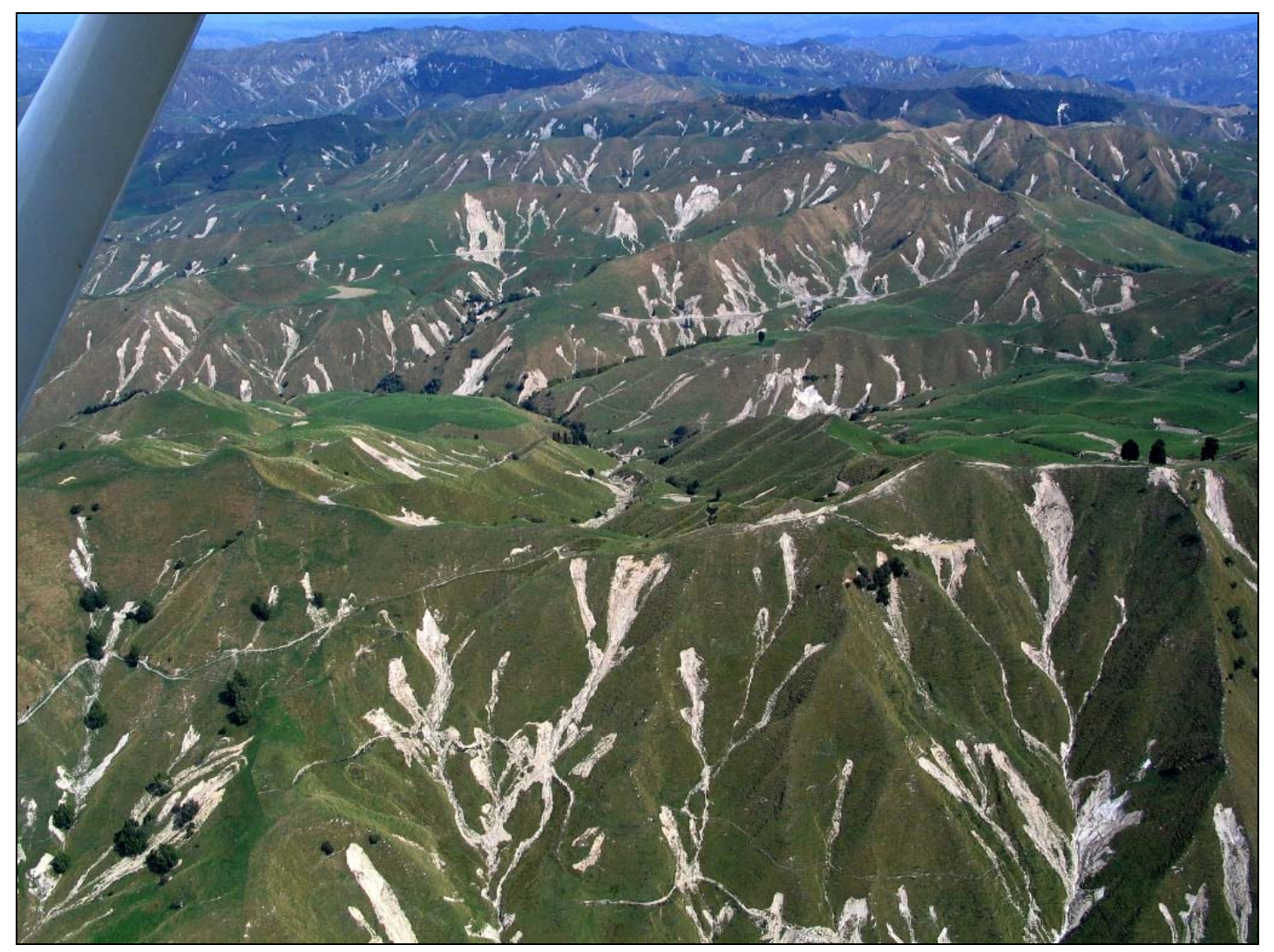

Figure 1-1 View of landslide affected hills in the Wanganui region, photograph Hancox 2004

The geomorphic significance of an event such as this can be determined by two measures:

- How much geomorphic work is done, i.e. how much material is moved, and over what distance, in a given time; and

- What are the landform changes that result from the event, i.e. how are hillslopes 'modified by material removal and deposition, and how durable are the changes. 
The February 2004 event can also be classified in terms of frequency-magnitude event classification. These types of studies are useful for comparing different events of a similar triggering mechanism and geomorphic response, i.e. in this instance other New Zealand, rainfall-triggered, multiple landslide events.

\subsection{Underlying Hypothesis}

That the geomorphic significance of multiple-occurrence landslide events is determined not only by the size of event but the nature of the catchment/area affected.

By examining the nature of the area affected as well as the nature of the event itself, it is possible to achieve a better understanding of how landscapes respond geomorphically to landslide events.

Factors that affect the magnitude of geomorphic response (number, areal extent, density and volume of landslides) of a hillslope system to triggering energy are:

- The lithology of the hillslope (bedrock type affects strength and drainage);

- The thickness of regolith;

- Hydrological hillslope properties (drainage, pore water pressures etc);

- The energy provided by the triggering mechanism (e.g. rainfall, earthquake) including magnitude and duration the trigger is active;

- Slope angle;

- Vegetation cover;

- Previous landslide events and the resulting loss of vulnerable material;

- Whether the hillslope has been anthropogenically modified or undercut by a river; and,

- The degree of fluvial coupling between hillslopes and river systems.

This study will examine the February 2004 landslide event impact from both a broad (regional) and more detailed (catchment-based) perspective. For the regional analysis, the extent of landslide damage, the types of landslides present, the density of landsliding, and regional characteristics will be examined. For the catchmentbased study, a detailed Digital Elevation Model (DEM) will be created, the individual 
landslides within the catchment mapped using Geographic Positioning System (GPS) technology, and a sediment budget produced using measured landslide areas and depths. Changes to slope morphology measured in the field will also be presented.

This quantification of the February 2004 event using the characteristics listed above allows comparison with other rainfall-triggered, multiple landslide events. This multiple landslide event, triggered by a storm termed a "one in one hundred year event" can then be compared in terms of geomorphic significance with historic rainfall-triggered, and pre-historic earthquake-triggered, landslide-affected slopes.

\subsection{Aims and objectives}

This study is undertaken to:

a) Characterise the February 2004 landslide event both regionally, and on a single catchment level;

b) Describe landslide type, density, runout (debris tail) properties, and volume and extent induced by a "one in one hundred year storm event";

c) Determine the frequency-magnitude status for the February 2004 landslide event;

d) Rank and compare this event with other New Zealand rainfall-triggered landslide events;

e) Determine the geomorphic significance (work done and landform change) arising from the February 2004 event; and,

f) Increase existing knowledge regarding New Zealand rainfall-triggered multiple landslide events.

\subsection{Research Justification}

\subsubsection{Landslide hazard and risk}

While this study does not deal directly with hazard and risk, it examines in detail a common type of hazardous event and the nature of its impact. Thus it aims to provide a scientific underpinning for hazard and risk studies of rainfall-triggered landslides. Landslides create a significant hazard in New Zealand hillslope areas. The risk is greatest where there is higher population density, such as when hillslope residential 
development occurs in urban areas on potentially unstable slopes, however rural communities are also at risk. In the rural sector the hazard from these sorts of events is represented largely by loss of productive soil, decrease in primary productivity, and destruction of rural infrastructure. Expansion of knowledge in the field of how landslides behave in certain terrains and lithologies assists with hazard planning, slope modification planning, and land use planning. Planning in high risk areas may include "avoidance zones", or changes in land use on unstable slopes. Whether slope modification is appropriate for given hillslopes is a function of a slopes stability based on endogenic and exogenic slope factors. The potential for landsliding is often considered in probabilistic terms. Quantification of actual landslide events provides greater data for landslide hazard and risk models.

\subsubsection{Expansion of existing geomorphic knowledge}

The study of landslides is not a new science; however the way in which these phenomena are studied has evolved, from basic classification studies (e.g. Sharpe 1938, Varnes 1958 and 1975), to studies of triggering factors and thresholds (e.g. Hicks 1991, and Crozier 1991 and 1999), to studies of frequency-magnitude modelling and classification (e.g. Page et al. 1994, Crozier and Glade 1999) and also geomorphic response and impact studies (e.g. Crozier and Pillans 1991, Brunsden and Chandler 1996).

This study aims to build on existing knowledge of landslides and slope stability in the Tertiary hill country of New Zealand, particularly with respect to magnitudefrequency, and geomorphic significance (magnitude of response). By increasing understanding of hillslope processes that have occurred, and are currently occurring, knowledge of how anthropogenic activity affects hillslope response to triggering factors is in turn increased. Conclusions may then be drawn regarding the suitability of differing land usages and hillslope modification in marginally stable areas.

\subsection{Structure and outline of this thesis}

This introductory chapter is followed by Chapter Two "Theoretical Framework" which addresses the concepts underpinning the research undertaken. This chapter includes a brief history of hillslope studies, framed within topics such as: slope 
processes, properties and morphology; landslide classification; landslide behaviour and triggering factors; geomorphic work done by landslides; frequency-magnitude theory; and episodicity and thresholds.

Chapter Three "The February 2004 Storm Event" describes the atmospheric conditions leading up to and during the 'weather bomb' which impacted the lower half of the North Island between February $14^{\text {th }}$ and $16^{\text {th }}, 2004$. Data on the amount and location of rainfall for the event is also presented as well as a brief overview of some of the impacts of the storm.

In Chapter Four "Overview of Landslide Damage" the extent and severity of damage is generally described for the Wanganui-Manawatu region. Reconnaissance images of the event are presented and a summary of reports characterising the storm event and resulting damage will be included. The initial impetus for this study will also be explained within this chapter.

The next chapter "Regional Characteristics" describes the geology, geomorphology, topography, soils, land use, historical settlement, and natural hazards of the east Wanganui hill country, and introduces the location of the detailed study catchment; the Mangawhero River Valley hills.

Chapter Six "Field Study Catchment" provides more detailed information on location, morphology and drainage of the field study area. Vertical aerial and oblique aerial photographs of the catchment will be presented as well as ground photographs of the study area. The chapter concludes with a summary of catchment characteristics.

A description of the methodologies employed in the catchment-based study and the results these methodologies produced is covered in Chapter Seven. This chapter, "Catchment-Based Study; Methodology and Results" describes the methodologies employed in the collection and analysis of field data for the catchment-based study, and provides a summary of these results, which are used for comparison with the regional study and with other events in later chapters. 
Chapter Eight outlines the methods used for regional analysis of the event, and the results of this analysis. This analysis includes detailed study of the terrain and landslide characteristics of four regional study areas severely affected during the February 2004 event. This chapter concludes by comparing and combining the results of the catchment-based study and the regional study to determine the geomorphic significance of the event in terms of work done, and changes to landforms. A brief discussion of these results is also included.

Chapter Nine introduces other New Zealand rainfall-triggered multiple landslide events in more detail. Following from the results presented in Chapter Eight, the frequency-magnitude status of the February 2004 event will be determined and then ranked and compared with these other events.

"Discussion and conclusions", the final chapter, reiterates the main findings arising from the results of the regional, catchment and comparison studies, with emphasis on the underlying hypothesis upon which this thesis is based. This chapter also suggests further areas of interest for research into this event, identified by, and related to, this study but not able to be included. 


\section{Theoretical Framework}

\subsection{Slope properties and landslide basics}

"Landslides are the most obvious and important processes acting upon hillslopes in New Zealand. Instability is a common feature of mountains and hills because of the combinations of geological and climatic phenomena which characterise these islands...." (Crozier et al. 1982).

The New Zealand hill country, particularly in the North Island, is relatively susceptible to landsliding processes. Rainfall-triggered landslides are initiated when soil and/or bedrock becomes saturated and loses strength. When stresses acting upon the hillslope outweigh the material strength of hillslope components (regolith, colluvium or bedrock), movement of the material ensues (see Section 2.1.1). Mass wasting of hillslope material can take many forms, depending on: lithological hillslope units; regolith thickness; material properties; degree of slope saturation; vegetation cover; anthropogenic slope modification; and the triggering factor(s) initiating movement. Mass movement may be slow and seemingly continuous (depending on time scale), or rapid and discrete. Several landslide classification systems have been promulgated since Sharpe's early attempt in 1938 (Selby 1982). Attempts at clarification and refinement of Sharpe's (1938) initial system are discussed in Section 2.1.2.

Triggering factors for landslides in New Zealand include: prolonged or intense rainfall; earthquakes; and slope modification. New Zealand's moist maritime climate and orographic rainfall patterns provide rainfall events of high intensity and/or prolonged duration. In the North Island, the combination of frequent intense and/or prolonged rainfall in the hill country (where evapotranspiration rates are generally lower due to altitudinal temperature gradients), and weak Tertiary rock forming steep hills with mostly pasture cover, provides an environment where landsliding is common.

Landsliding plays an important part in the formation of slope morphology, and sediment redistribution. Slopes achieve a maximum angle of repose, dependent on the material from which they are formed and the behaviour of the groundwater system. 
The process of landslide sediment redistribution is most effective where slopes are steep. Landslides play an important part in reducing high relief to lower elevations, and creating gentler slopes (Crozier et al. 1982). Because New Zealand is a relatively young landmass, and has experienced periods of rapid tectonic uplift (termed orogenic or mountain-building stages), the New Zealand hill country terrain has not achieved the smoothing and lowering of a mature landscape, except in a few areas. In general, where rounding and smoothing of the New Zealand hill country occurs, it results from depositional agents such as loess or volcanic ash deposit, rather than as the product of millennia of denudational processes.

\subsubsection{Hillslope processes, properties, and morphology}

The majority of the Earth's landscape consists of erosional valley slopes. Other less common landscape features are erosion-surface remnants and depositional areas (dunes, floodplains), (Young, 1972). Three classes of slope have been identified by Young (1972) as the basic units for landform analysis. After identifying watersheds, the units are classified as: valley heads, spur-ends, and valley sides (Figure 2-1).

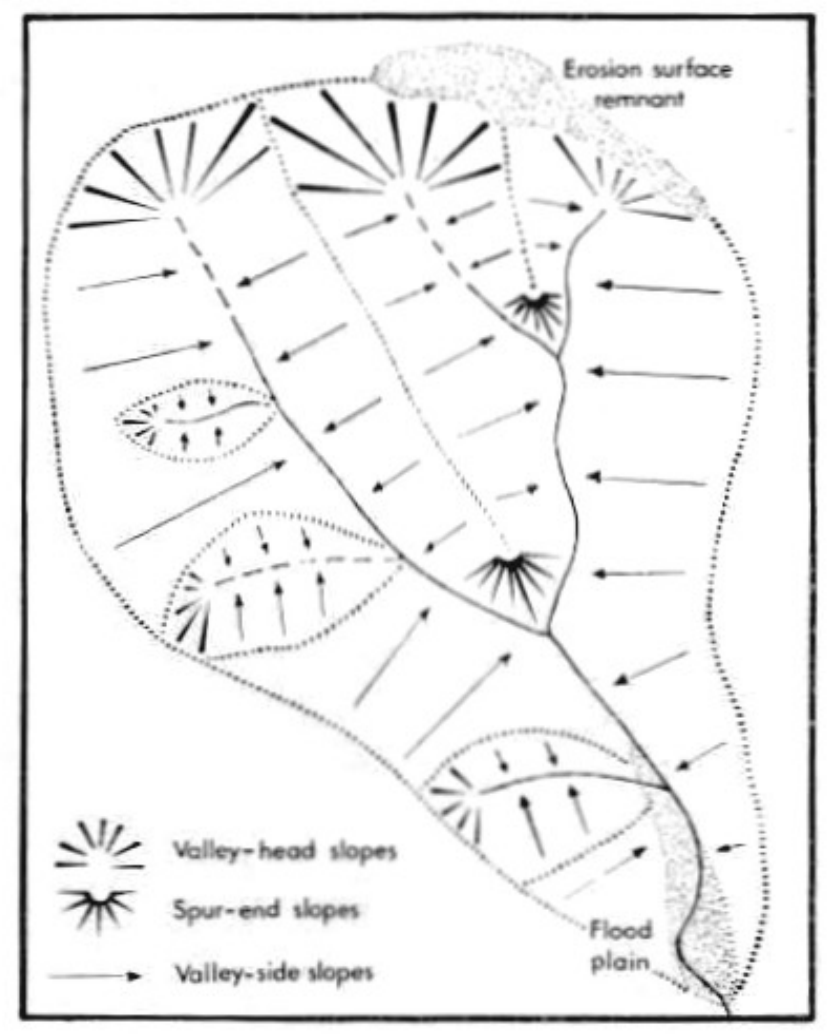

Figure 2-1 Parts of slope useful for landform analysis from Young 1972 
Selby (1982) states that traditionally slopes have been examined from long profile ridge top to valley floor (as in the Young 1972 model), but that many complex forms and variations occur across slopes, and along contours, and this must be considered when studying slope processes and morphology. Both views of slope study have merit, therefore when studying slope processes, particularly for a small catchment basin as in this study (see Chapter 6), both downslope and across-slope processes should be considered.

When characterising the nature of a slope to understand its geomorphic behaviour, the following endogenic and exogenic characteristics and processes are important:

- Slope angle- a major factor in land use classification and significant control on slope stability;

- Whether the slope form is concave or convex- this will dictate the pattern of drainage;

- Is the slope a denudation slope (losing material), accumulation slope (gaining material), or transportation slope (material losses equal gains);

- Underlying geology and surface regolith properties;

- Climate;

- Vegetation cover, and;

- The processes acting on and within the slope- weathering, mass wasting, soil creep, surface wash, subsurface piping.

Slope form, component parts, and processes have been identified in Dalrymple et al.'s 1968 “Nine unit land surface model” (Figure 2-2) (Selby 1982, and Young 1972). Not all units need to be present for a slope to fit the model; individual units may be repeated throughout the slope and some units may be absent. The nine units are possible slope components only, and describe material involved in hillslope processes as well as the type of process present for each part of any given slope. Movement of material and water through the profile as well as along the profile is shown. When used in mapping the model is designed to give a complex, 3-D explanation of how slopes operate from the drainage divide to the channel bed (Selby 1982). It must be noted that this is a simplistic model that has validity only when referenced to a 
particular time scale. For example, slopes that at one time act as transportations slopes may at another time operate as denudational or depositional slopes.

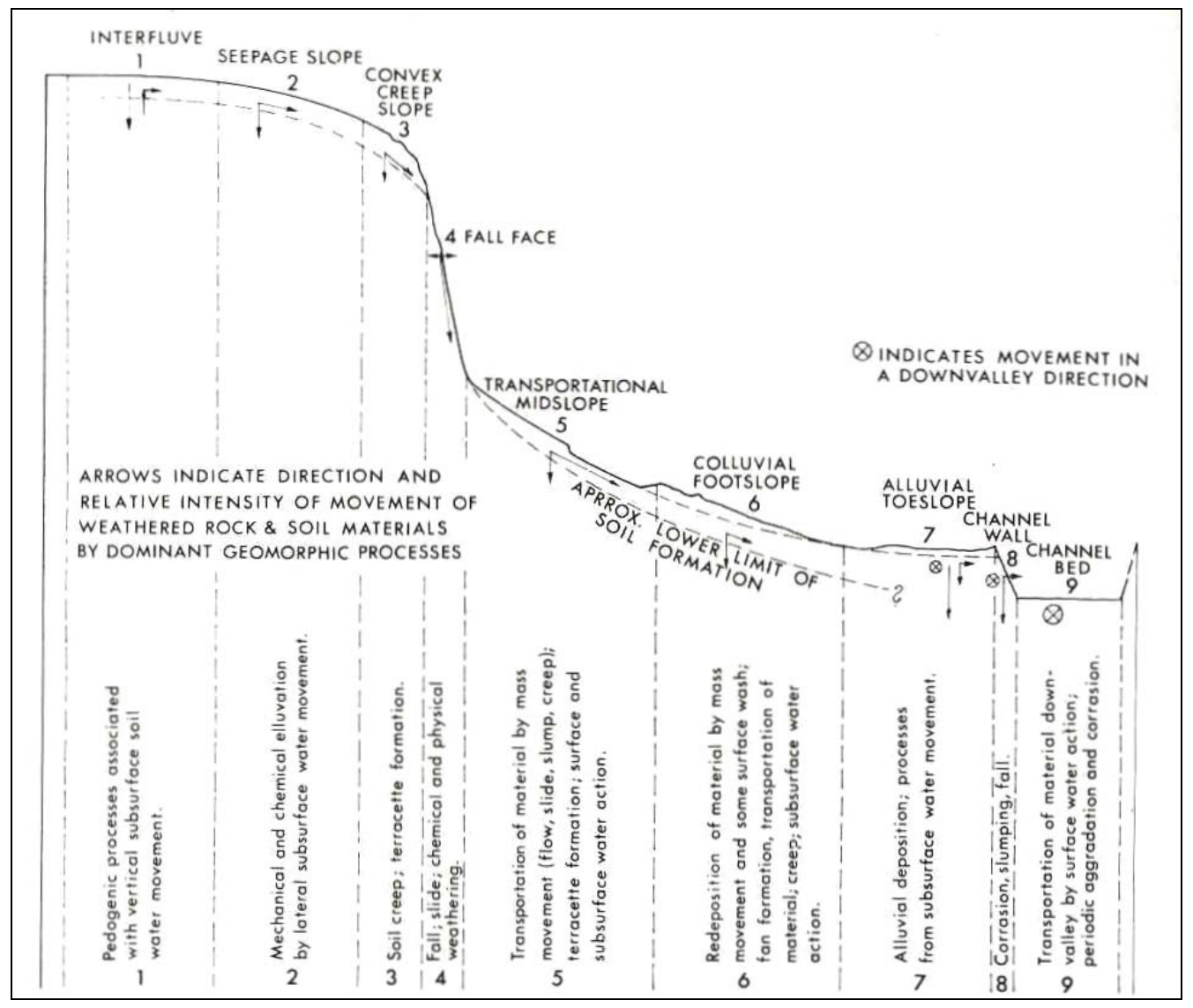

Figure 2-2 Dalrymple et al.'s 1968 nine unit model, from Selby 1982

By considering the various factors affecting slope development, slope evolution with time may be proposed, including whether slopes are steepening, becoming gentler, or retaining their form. Several types of slope long profile evolution may be seen in one catchment (Figure 2-3) including:

- slope decline- whereby the steepest part of the slope progressively decreases in angle, accompanied by the development of concavity and convexity;

- slope replacement- the maximum angle of the slope decreases through replacement by below from gentler slopes, and a greater part of the profile is in concave form;

- parallel retreat- where there is constraint on the maximum angle formed;

- slope enhancement- whereby the upper slope is over-steepened due to masswasting processes (not included in Young's 1972 evolution theory);

- slope denudation- the lowering of ground surface by removal of sediment from a catchment (Young and Saunders 1986) can be characterised by two 
aspects: the mechanism process and how it operates, including forces and agents, and the interrelations between them; and the manner of action, the way in which the processes affects hillslope form (Young 1972).

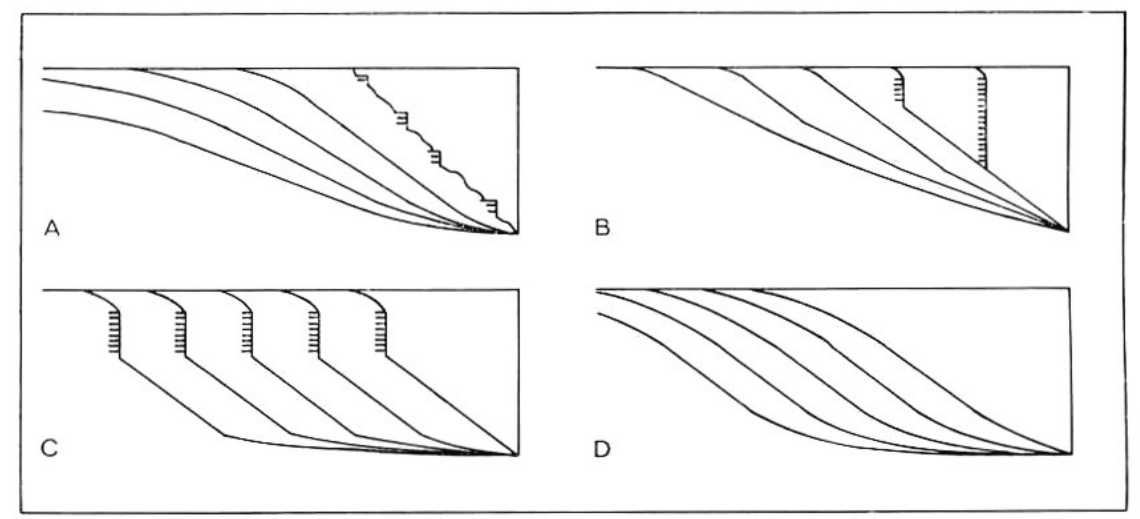

Figure 2-3 Slope evolution hypothesis: $\mathrm{A}=$ slope decline, $\mathrm{B}=$ slope replacement, $\mathrm{C}=$ parallel retreat with free face, $D=$ parallel retreat without a free face, from Young 1972

Slope evolution as hypothesised above involves long periods of geological time, and this present study cannot hope to evaluate these models. However the results of this study may be assessed in terms of their consistency with various approaches proposed.

Slopes can be considered as sediment storage and transport systems. Selby (1982) has graphically portrayed the system of stores and transfers on a soil-covered hillslope system for ridge slopes and gully slopes (Figure 2-4).

Natural hillslopes generally fail when strength is reduced to the degree that it is outweighed by internal shear stresses. However, some slopes fail in response to an increase in shear stress (e.g. after a period of undercutting by a river) while the strength of the material remains constant. The reduction of strength may be due to internal (e.g. pore water pressure changes) or external (e.g. removal of support) factors. Stress is the force acting on a body, including gravitational force (external), molecular force (internal) and biological force. Strain is the resulting movement of the entire body or some part of the body (Young 1972). Gravitational stresses (Figure 2-5) produce a net downslope stress parallel to the ground surface on a body, as downwards movement of the body (normal force and pure gravitational force towards the earth's centre) is constrained by the underlying bedrock. 


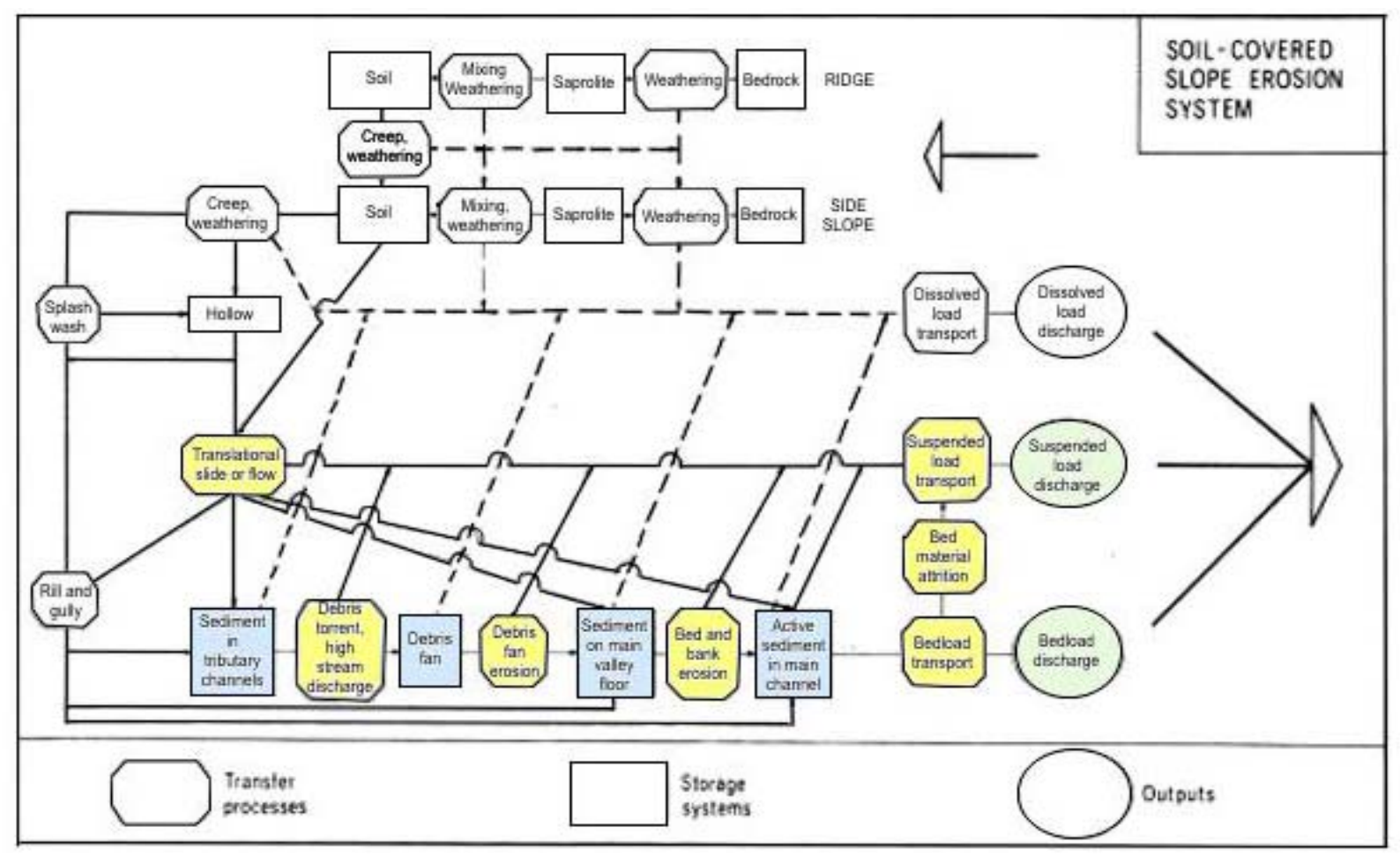

Figure 2-4 Sediment stores and transfers, from Selby 1982; coloured polygons represent stores, processes and outputs related to this study

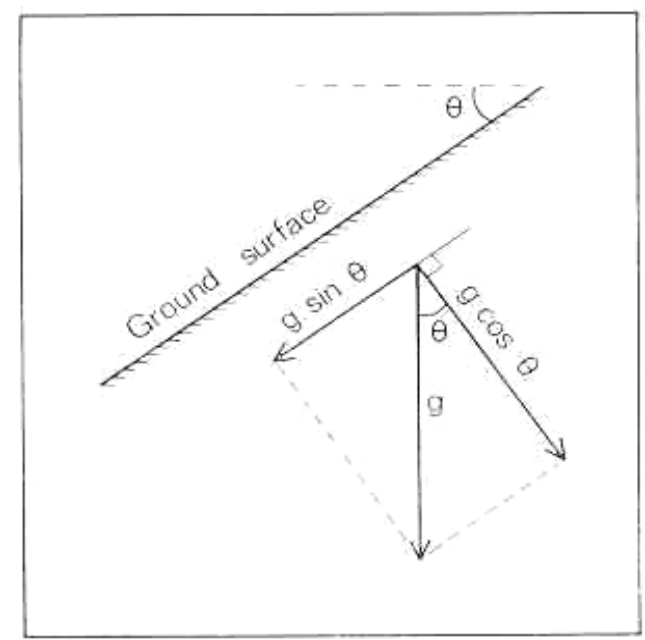

Figure 2-5 Gravitational forces acting upon a hillslope: $g \cos \theta$ is the normal force, $g$ direct force of gravity, and $\mathrm{g} \sin \theta$ the resultant net stress produced, from Young 1972

Molecular stress originates from the shrinking and swelling of colloids (clay particles) on wetting and drying, thermal expansion and contraction, and from the formation of ice crystals within the soil. Biological stress is the product of plant root growth and soil animal movement. Strain, or the movement produced when the stresses outweigh the strength of the body, may manifest on a hillslope in several ways: 
- Fracture, strain takes place entirely upon a plane. Fracture includes shear fracture (along a slip plane), and tensional fracture (material on either side of the plane becomes separated (Figure 2-6A);

- Laminar flow, where strain is distributed throughout the material as if on an infinite number of parallel slip planes (Figure 2-6B);

- Turbulent flow, irregularly distributed deformation of entire material, including mixing of material and movement in all directions; this type of flow is confined to liquids, e.g. rivers or overland flow (Figure 2-6C);

- Net shear, movement by shear and tensional fracture along many irregularly distributed planes (Figure 2-6D).

In theory landslides and landslide material exhibit some of these different movement mechanisms; in practice some of these mechanisms (e.g. fracture, turbulent flow) were observed in the field catchment study.

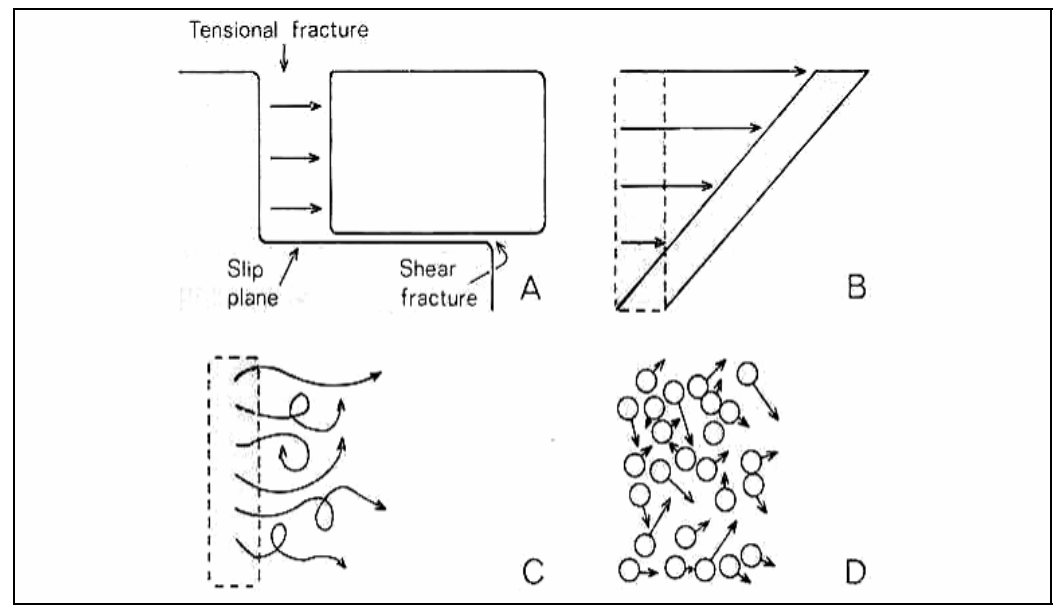

Figure 2-6 Types of strain: A - fracture, B - laminar flow, C - turbulent flow, D - net shear, from Young, 1972

The relationship between stress and strain determines how a material will behave; whether as a rigid solid, elastic solid, plastic solid, fluid, or as particulate matter (Figure 2-7). The properties of these behaviours under idealised conditions are as follows (Young 1972):

- A rigid solid will experience no strain (movement) until the strength of the material is exceeded, when fracture will occur.

- An elastic solid will undergo slow, discontinuous deformation in proportion to the stress applied, prior to fracturing. 
- A plastic solid possesses a finite strength (the yield limit), deformation rates are proportional the amount stress exceeds the yield limit.

- Fluids have no strength and deform proportionately with stress applied and in inverse proportion to their viscosity.

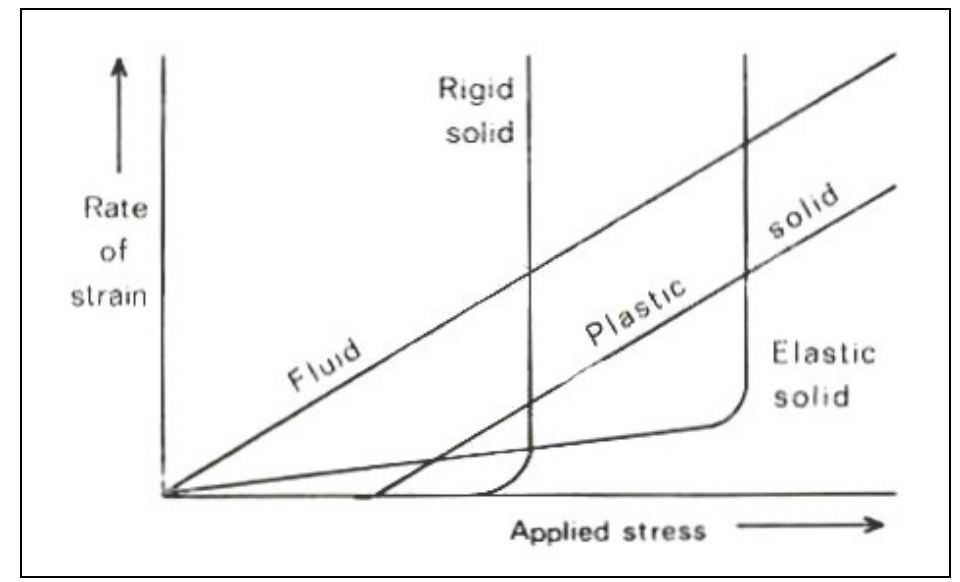

Figure 2-7 Stress-strain relationship in ideal materials, from Young 1972

Many natural materials possess more complex relationships between stress and strain, and for regolith the relationship is likely to alter with degree of saturation. Regolith contains a mixture of solid particles, colloidal clay, and water. The majority of landslides treated in this study have regolith as their main component. This mixture of particle sizes and material properties within the regolith can produce fluidal behaviour of the material when saturated, and complex plastic and elastic solid behaviour when in the moist or dry state (Young 1972). The difficulty in classifying regolith behaviour under stress has resulted in Young (1972) using the term particulate matter to provisionally describe the regolith stress-strain relationship. Painter (1981) described the behaviour of regolith as not that of an elastic solid such as a block of rubber, nor that of a fluid like water. He concluded that sometimes regolith behaves elastically, sometimes viscously, and often as a plastic solid, continuing to deform with little change in stress applied, after yield limit stress is reached, and that the resulting deformation is not recovered when stress is removed.

Hillslope hydrological processes control the degree of saturation of slope material. The various processes of precipitation, evapotranspiration, interception, infiltration, throughflow and surface runoff operate upon the hillslope system to determine regolith and bedrock moisture levels (Figure 2-8). 


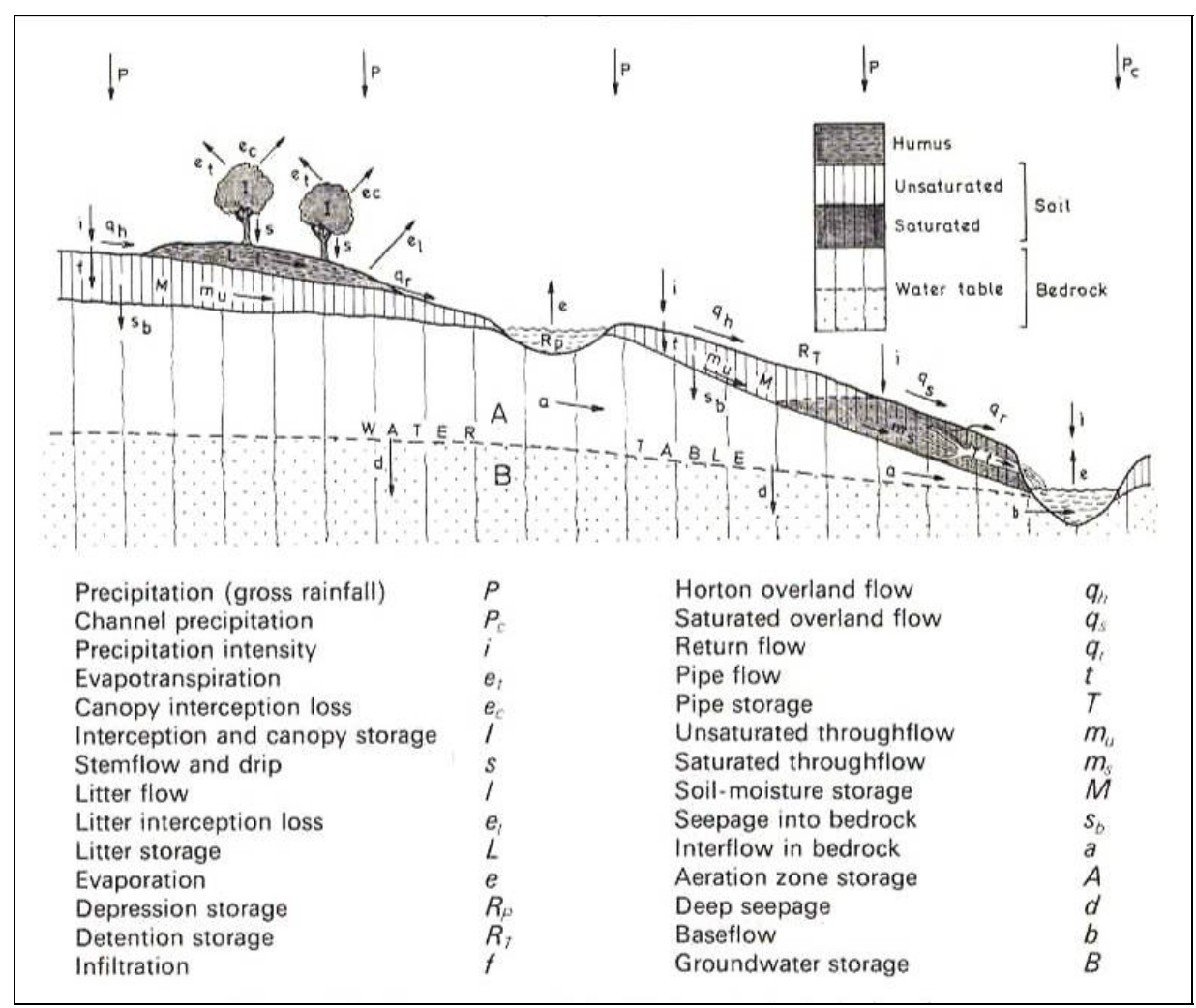

Figure 2-8 Components of the hillslope hydrological cycle, from Chorley, 1978

The material properties of hillslope materials, climate, vegetation, and slope angle play key roles in determining whether a soil will drain freely or frequently reach saturation point. A saturated hillslope loses material strength through loss of cohesion, reduction of frictional stress, and an increase in pore water pressure throughout the soil profile. Hillslopes may fail when unsaturated, for example during large earthquake events, such as the Fiordland M7.2 August 2003 event. During this event hundreds of regolith and bedrock failures were initiated (Hancox, 2004). However, the majority of failures in New Zealand are rainfall-triggered and due to the increase in pore water pressure within the soil that results from prolonged or intense rainfall events. Hillslope failure may be abrupt and discrete (e.g. translational slides) or seemingly continuous and difficult to quantify (e.g. earthflow and soil creep).

Different parts of a slope comprised of the same material may exhibit different failure mechanisms and runout behaviour purely because the degree of material saturation differs down the slope profile, or because localised vegetation effects reduce precipitation inputs to the system and increase soil strength through root support. To quantify and compare a large rainfall-induced, multiple landslide event, an 
understanding of different hillslope erosion processes and their triggering factors is required. In Section 2.12 hillslope failures types and processes will be discussed.

\subsubsection{Landslide Classification, Form, and Behaviour}

Mass wasting is the general term used to describe all types of hillslope erosion. The term now covers all scales both temporal and spatial. Mass movement upon a hillslope is a type of mass wasting. Specific mass movement classification based on form and process became widely accepted with Sharpe in 1938 (Table 2-1). Sharpe differentiated between flows and slides and classed movement according to rapidity and degree of water/ice content, including fluvial mass movement in his system. The widely accepted current landslide classification system is based upon an adaptation of Varnes' 1958 model (Table 2-2) which identifies three types of landslide movement: falls, slides, and flows. His initial model did not include solifluction or soil creep processes (Selby 1982).

Table 2-1 Sharpe's 1938 mass movement classification model, from Selby 1982

\begin{tabular}{|c|c|c|c|c|c|c|}
\hline \multirow{2}{*}{ 혼 } & $\begin{array}{l}\text { Nature and rate } \\
\text { of movement }\end{array}$ & \multirow{4}{*}{ 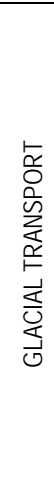 } & $\begin{array}{l}\text { With Increasing } \\
\text { Ice Content }\end{array}$ & Rock or Soil & $\begin{array}{r}\text { With Increasing } \\
\text { Water Content }\end{array}$ & \multirow{4}{*}{ 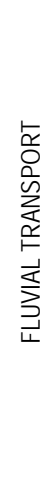 } \\
\hline & imperceptible & & SOLIFLUCTION & $\begin{array}{l}\text { CREEP } \\
\text { (Rock creep } \\
\text { Soil Creep) }\end{array}$ & $\begin{array}{c}\text { SOLIFLUCTION } \\
\Omega^{-1}\end{array}$ & \\
\hline \multirow{2}{*}{$\begin{array}{l}\text { 岁 } \\
\text { ळ }\end{array}$} & $\begin{array}{l}\text { slow } \\
\text { to } \\
\text { rapid }\end{array}$ & & $\begin{array}{l}\text { DEBRIS } \\
\text { AVALANCHE }\end{array}$ & $V$ & $\begin{array}{l}\text { EARTHFLOW } \\
\text { MUD FLOW } \\
\text { DEBRIS } \\
\text { AVALANCHE }\end{array}$ & \\
\hline & $\begin{array}{l}\text { slow } \\
\text { to } \\
\text { rapid }\end{array}$ & & & $\begin{array}{l}\text { SLUMP } \\
\text { DEBRIS-SLIDE } \\
\text { DEBRIS-FALL } \\
\text { ROCKSLIDE } \\
\text { ROCKFALL }\end{array}$ & & \\
\hline
\end{tabular}

Table 2-2 Varnes' 1958 slope movement model, which introduced "falls", from Selby 1982

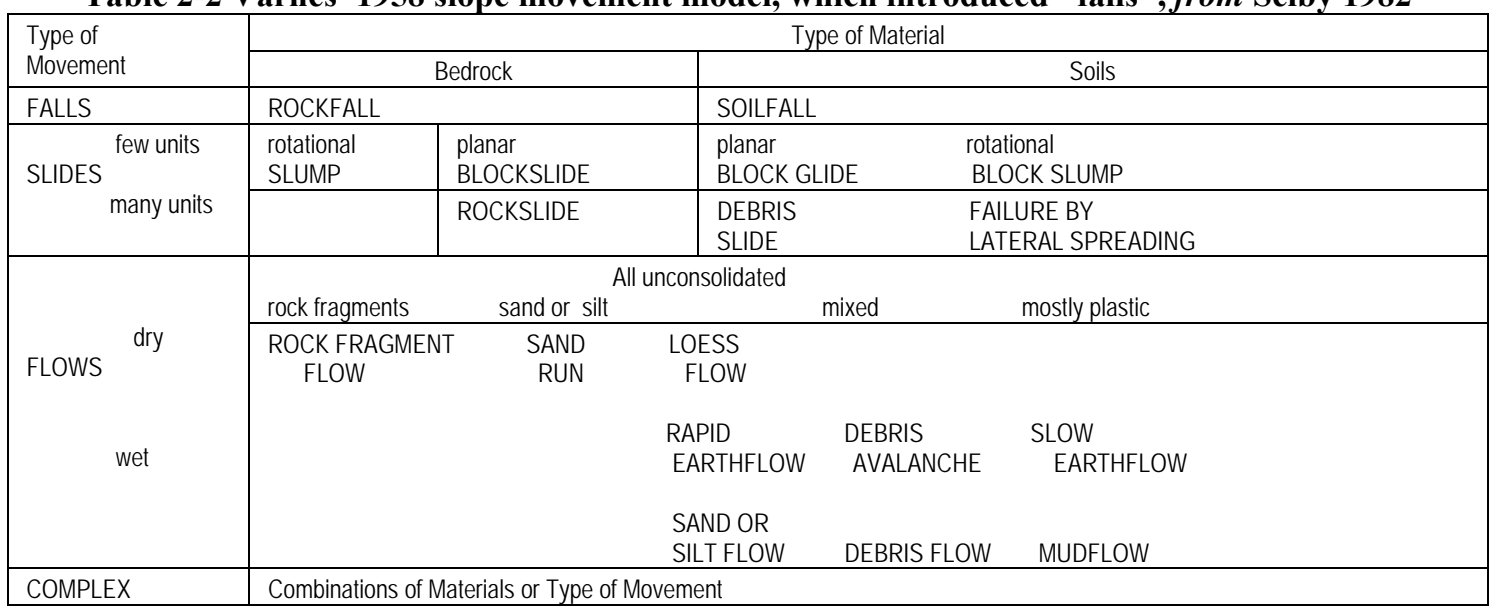


In 1969 Hutchinson proposed a new, more detailed classification system (Table 2-3). Hutchinson's model, while an improvement on earlier models in terms of thoroughness of movement types (it included more detailed periglacial processes) used the term flow slides for two separate classes. The term mudflow is also used in a confusing manner as it includes volcanic mudflow (lahar), which would include particle sizes far larger than those technically included in the mud range of silts and clays $(<0.62 \mu$ or $>4 \varnothing)$. Confusion over terminology differences and usage led Varnes to incorporate the mudflow and earthflow terms into one unit and revise his original 1958 classification system in 1975 (Table 2-4).

Table 2-3 Hutchinson's detailed 1969 system, from Selby 1982

\begin{tabular}{|c|c|c|}
\hline CREEP & $\begin{array}{l}\text { (2) } \\
\text { (3) }\end{array}$ & $\begin{array}{l}\text { Shallow, predominantly seasonal creep; } \\
\text { (a) Soil creep } \\
\text { (b) Talus creep } \\
\text { Deep-seated continuous creep; mass creep } \\
\text { Progressive creep }\end{array}$ \\
\hline $\begin{array}{l}\text { FROZEN } \\
\text { GROUND } \\
\text { PHENOMENA }\end{array}$ & (4) & $\begin{array}{l}\text { Freeze-thaw movements } \\
\text { (a) Solifluction } \\
\text { (b) Cambering and valley bulging } \\
\text { (c) Stone streams } \\
\text { (d) Rock Glaciers }\end{array}$ \\
\hline LANDSLIDES & (7) & $\begin{array}{l}\text { Translational Slides } \\
\text { (a) Rock slides; block glides } \\
\text { (b) Slab, or flake slides } \\
\text { (c) Detritus, or debris slides } \\
\text { (d) Mudflows } \\
\text { (i) Climatic mudflows } \\
\text { (ii) Volcanic mudflows } \\
\text { (e) Bog flows; bog bursts } \\
\text { (f) Flow failures } \\
\text { (i) Loess flows } \\
\text { (ii) Flow slides } \\
\text { Rotational Slips } \\
\text { (a) Single rotational slips } \\
\text { (b) Multiple rotational slips } \\
\text { (i) In stiff, fissured clays } \\
\text { (ii) In soft, extra-sensitive clays; clay flows } \\
\text { (c) Successive or stepped rotational slips } \\
\text { Falls } \\
\text { (a) Stone and boulder falls } \\
\text { (b) Rock and soil falls } \\
\text { Sub-aqueous slides } \\
\text { (a) Flow slides } \\
\text { (b) Under-consolidated clay slides }\end{array}$ \\
\hline
\end{tabular}

Table 2-4 Varnes' widely -used, revised 1975 classification model, from Selby 1982

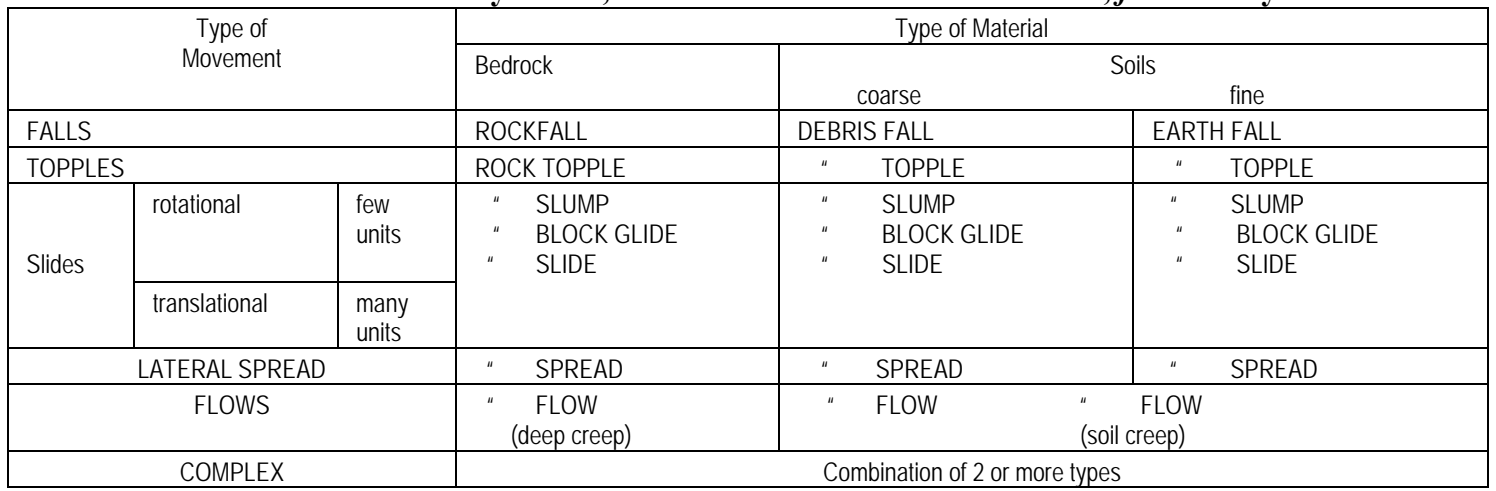


Varnes' 1975 model is now widely used for landslide classification internationally. It differentiates by type of movement and type of material, as well as including a category for landslides that exhibit more characteristics of more than one class. The Varnes' model has been modified (Cruden and Varnes 1996) however it still presents the preserves the principle elements used by Varnes (1975) applicable to landslide classification.

This study is mostly concerned with slides and flows, the types of movements that are associated with rainfall-triggered failure events. Also to be discussed is the process of overland flow, which is another avenue of hillslope material removal that occurs during rainfall events. Types of landslides and flows discussed later in this study are described and illustrated in Figure 2-9 to Figure 2-13 (see also Chapters 4 and 7).

Differentiation of the various types of movement involves factors such as the type of material removed, transported, and deposited, and the form the failure takes on the hillslope surface. It is possible for a failure to exhibit more than one type of movement. These failures are termed "complex" movements, for example a movement may initiate as a slide, and then downslope with increased moisture content, behave as a flow.

\section{Translational slides}

Translational slides are the most common form of soil landslide (Selby 1982 and Crozier et al. 1982). Movement occurs along a discrete failure surface parallel to the hillslope surface (Young 1972). There may be curvature of the slip surface towards the crown where some rotational movement may occur. The landslide runout (deposit material) may be totally absent from the scar (source) area or only partially evacuated, with material in both the runout zone and the scar area. The components of an ideal translational landslide are shown in Figure 2-9. An example of freshly-formed translational landslides in the New Zealand hill country is shown in Figure 2-10. 


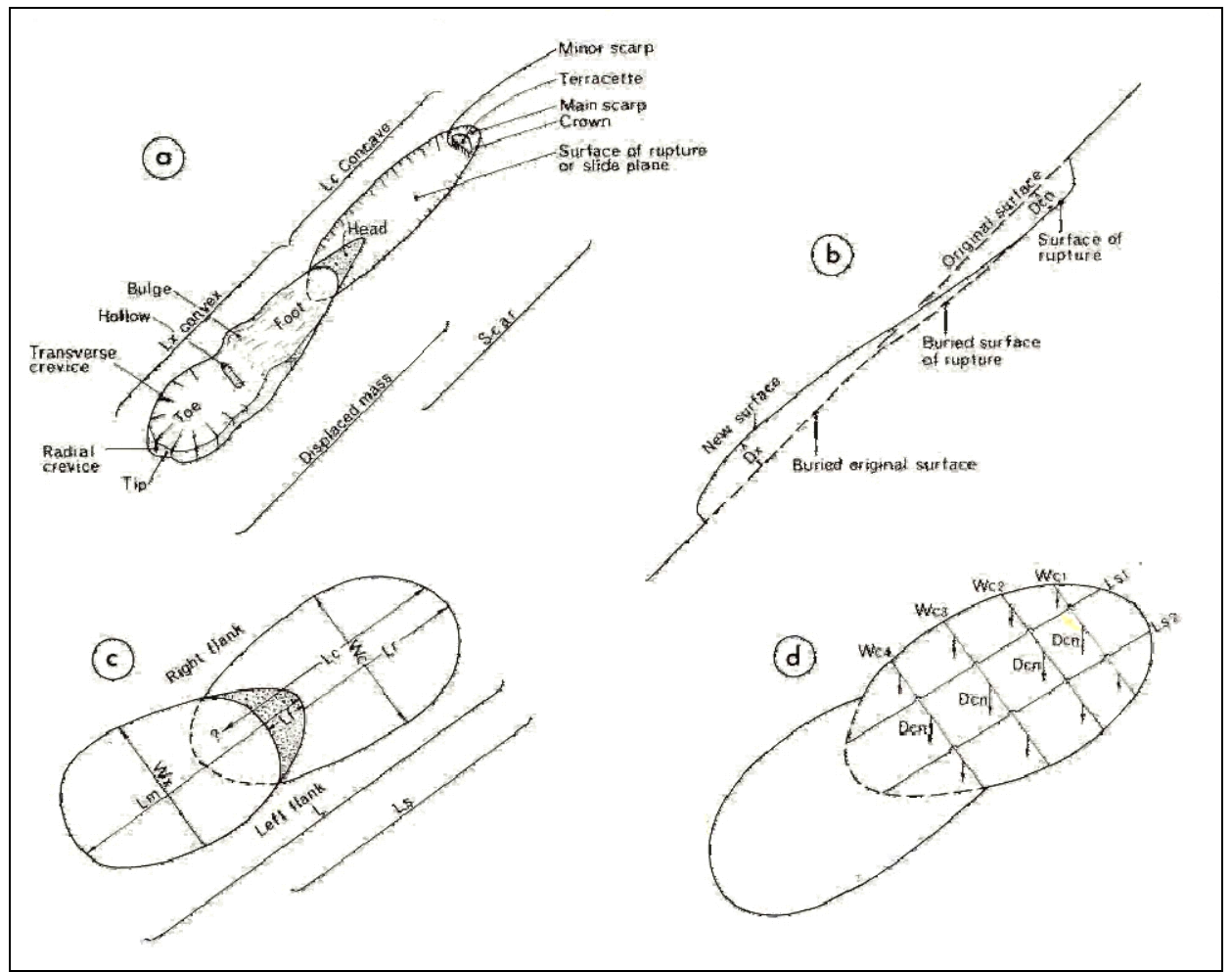

Figure 2-9 The components of a translational landslide, from Selby 1982

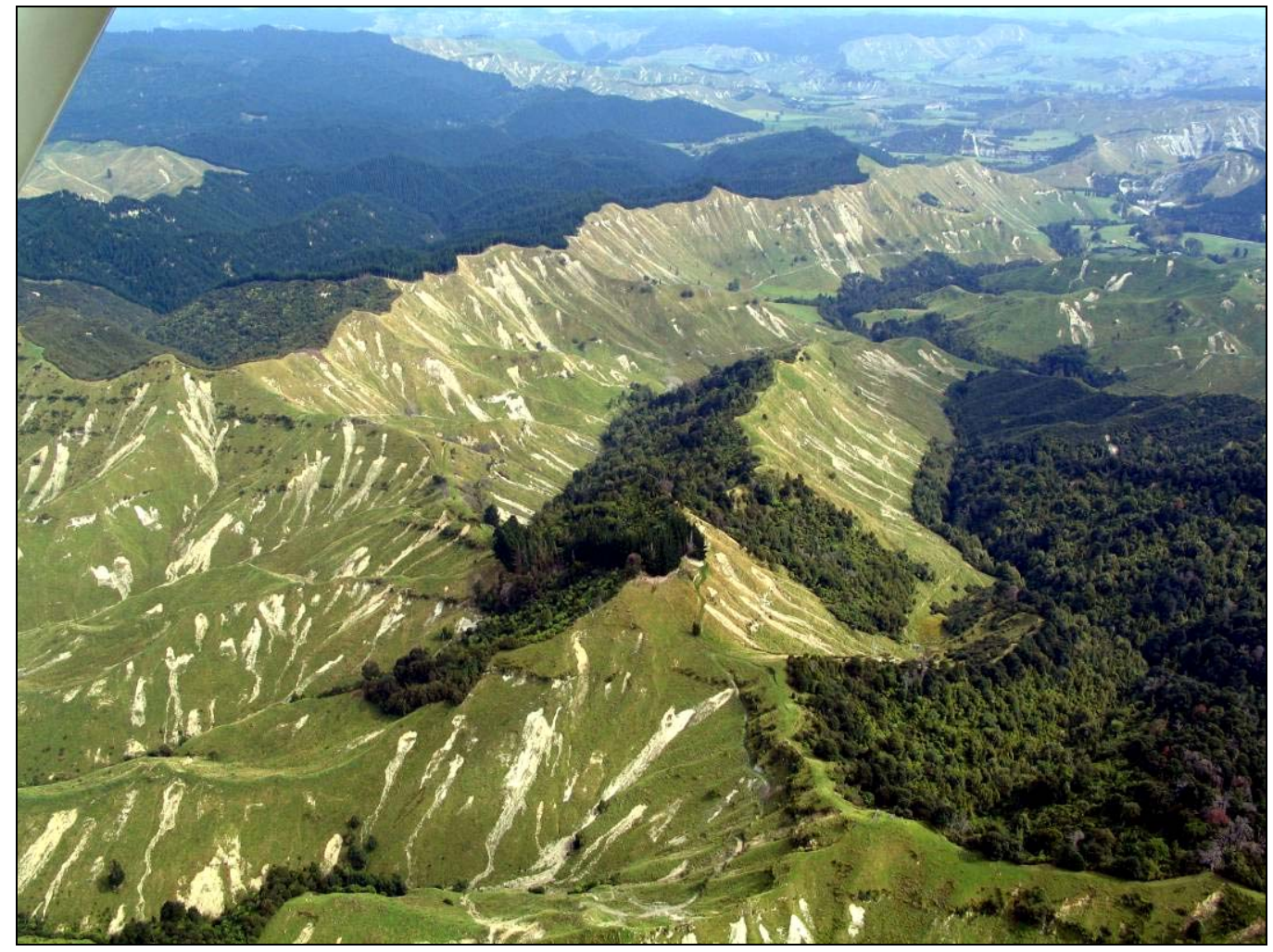

Figure 2-10 Multiple translational landslides in the Wanganui hill country, photograph Hancox 2004 


\section{Rotational Slides}

When material is homogenous, and given sufficient angle and slope height, failure may occur along a curved surface, concave to the slope (Figure 2-11) (Young 1972). Deep-seated bedrock failures in Tertiary mudstone often take the form of rotational slides (Figure 2-12). The material remains largely unbroken in comparison with translational slide failures.

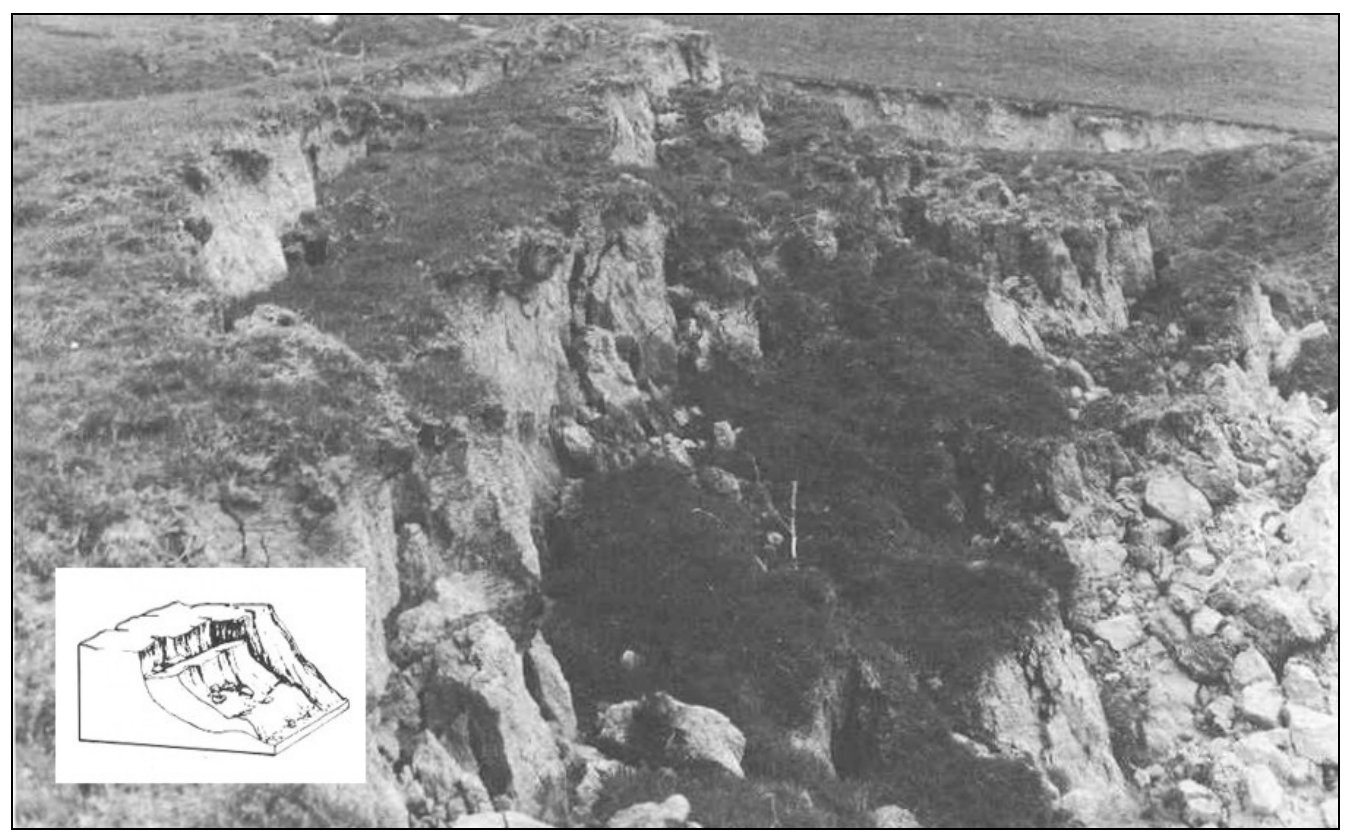

Figure 2-11 The crown/headscarp of a rotational landslide, with inset showing basic rotational form, adapted from Selby 1982

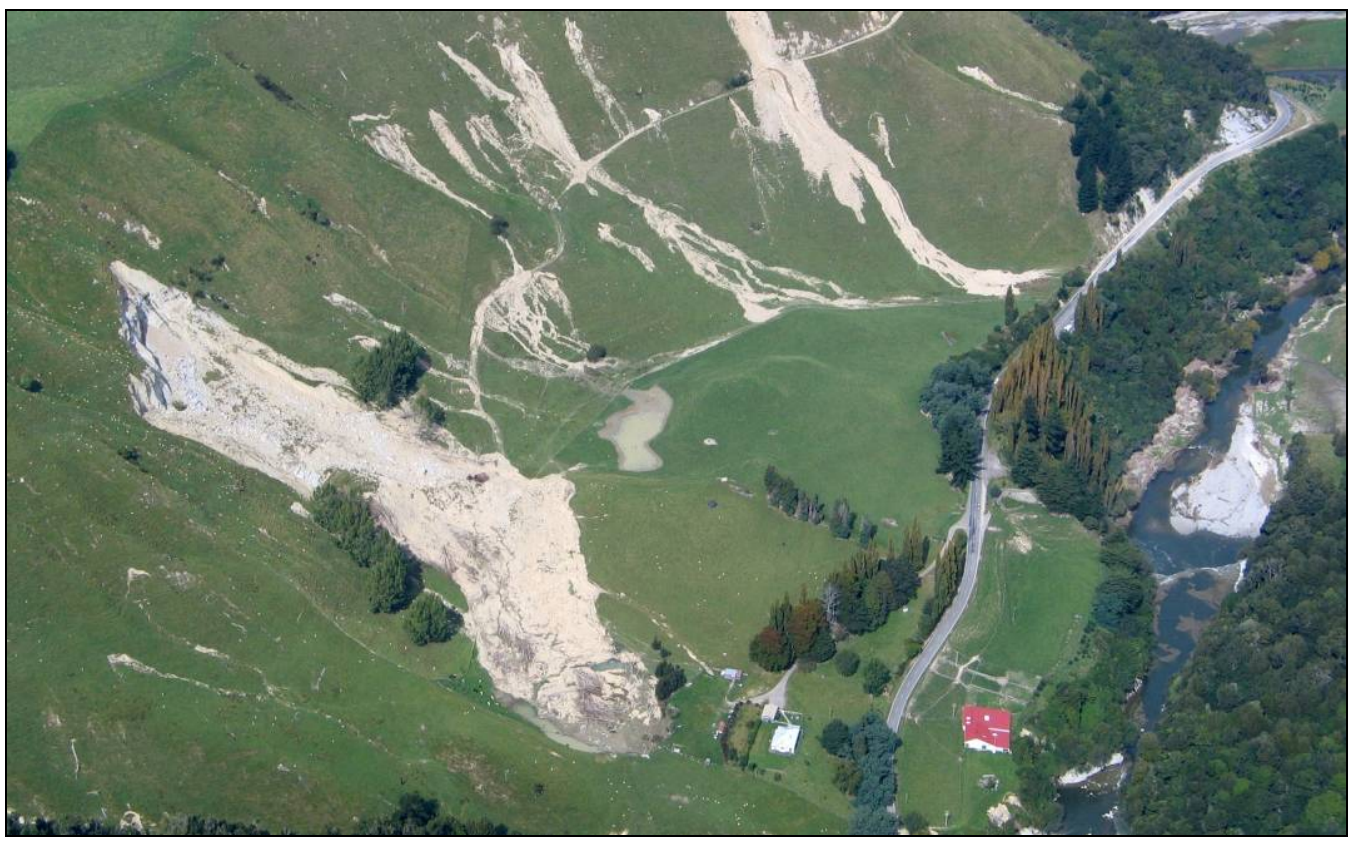

Figure 2-12 A large rotational slide in which the deposit material is so liquefied it has lost structure. Note the concave headscarp, photograph Hancox 2004 


\section{Earthflow}

When material becomes saturated it may behave as a liquid, losing particle cohesion and flow rapidly downslope (Figure 2-13). As the water table rises, pore-water pressures within the soil increase, reducing shear strength. Materials with high percentages of clay are susceptible to becoming flows during rainfall-triggered landslide events. The degree to which a material is susceptible to flow is determined by its Atterburg Liquid Limit; the lower a material's liquid limit, the more likely it is to form a flow (Young 1972, Selby 1982).

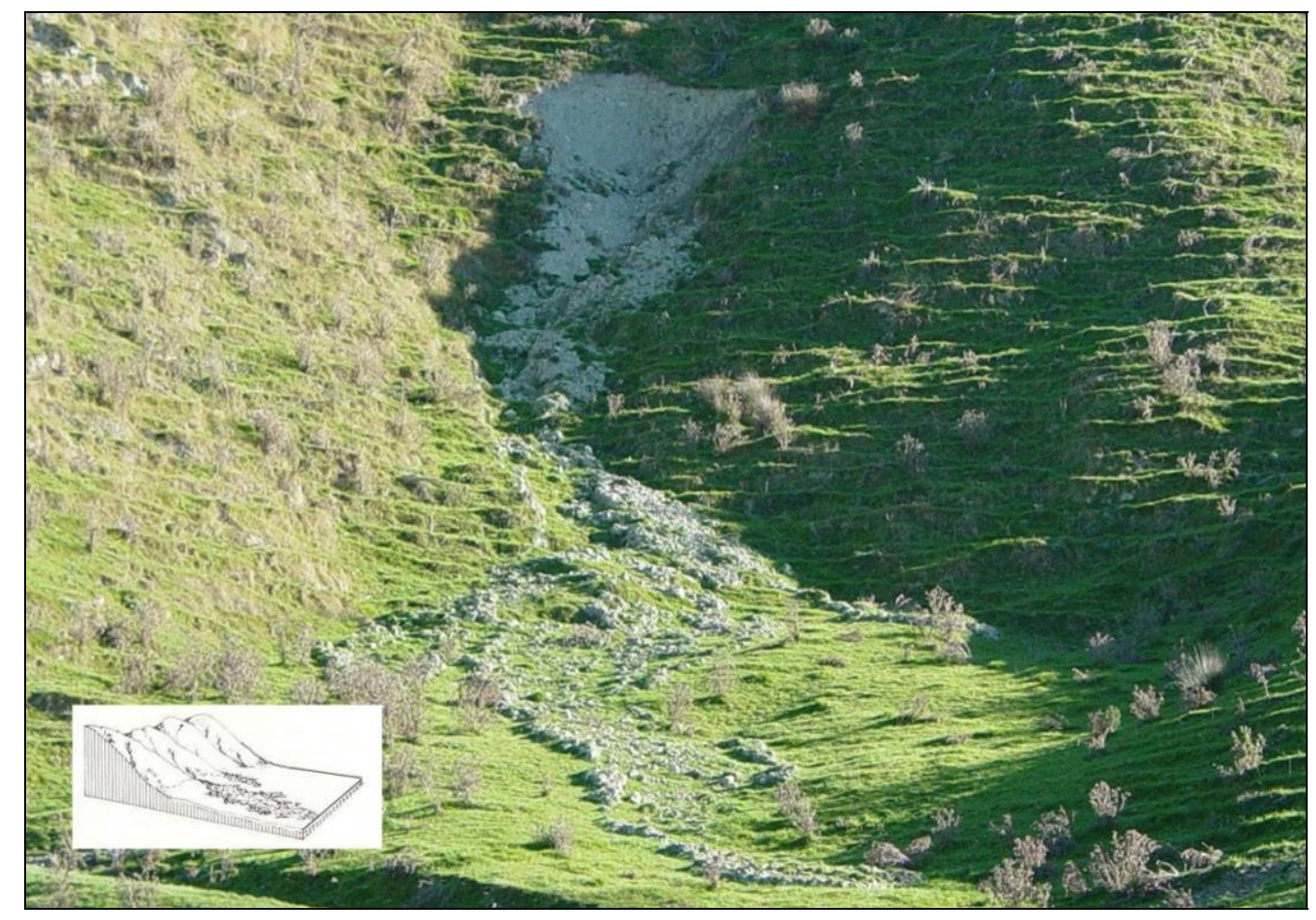

Figure 2-13 Earthflow of saturated regolith in the Mangawhero (north-east Wanganui) region

In many New Zealand steeplands landsliding and flows are the most important erosion processes (Painter 1981). Material is redistributed downslope, or in the case of fluvial coupling of landslide and flow runouts, material is permanently removed to waterways, and ultimately offshore. However during intense or prolonged rainfall events other erosion processes can play a significant role in removing material. Fluvial coupling may be enhanced during storm events because effective drainage channel area increases (Figure 2-14) as soil becomes saturated and infiltration decreases (Chorley 1978). 
The degree of fluvial coupling of hillslope systems and drainage systems affects the over all geomorphic response. A hillslope system may exhibit high 'terrain coupling' (steep narrow valleys with minimum distance for hillslope sediment inputs to reach the fluvial system) Although, this does not mean that a high degree of actual fluvial coupling or 'event coupling' will necessarily occur. When hillslope sediment becomes mobilised and travels downslope it may or may not reach fluvial systems regardless of the degree of terrain coupling. Hillslope material that readily deforms into a flow will have increased likelihood of reaching the fluvial system, as will material that fails in a position on the slope which is closer to active drainage channels. Where fluvial systems are coupled to landslide material, an increase in permanent sediment removal from the hillslope system is predicted. The degree to which a hillslope can recover from an event (produce replacement regolith, soil, and vegetation, and undergo hillslope adjustment to more stable forms) is based on the type of damage, the volume and area of landslide material, and the physical and environmental characteristics of the hillslopes affected.

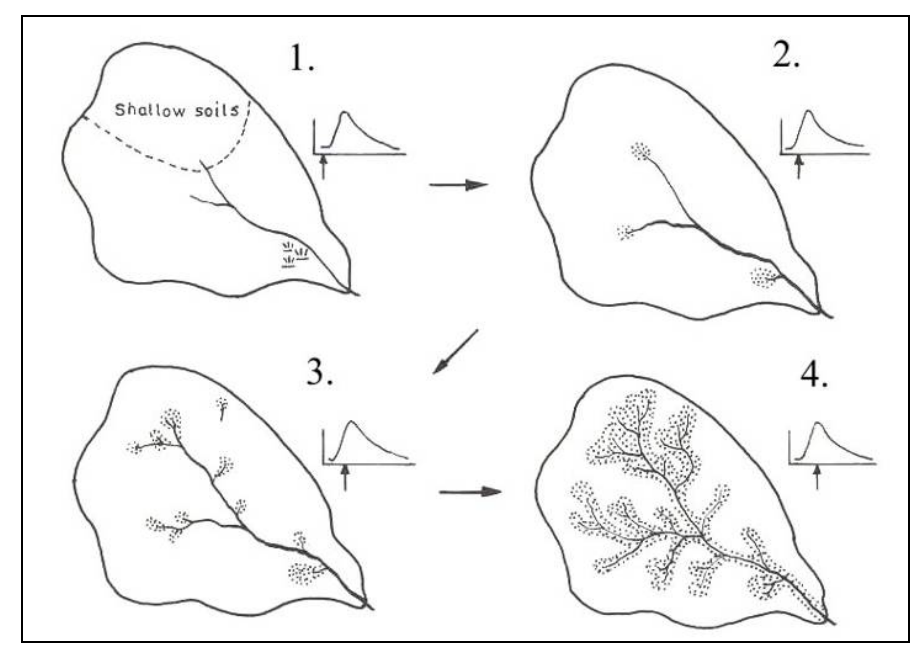

Figure 2-14 Drainage channel expansion with time, from Chorley 1978

\section{Other erosional processes - Overland flow}

During an intense rainstorm event, on hillslopes comprised of fine sediments such as clays, some erosion will be attributable to overland flow erosion. For the catchmentbased study it is assumed that some portion of dislodged landslide material will be entrained and removed by overland flow processes, and also that there will be losses not included in the sediment budget directly from the undisturbed hillslope surface. 
This process was first observed and described by McGee in 1897 (Young 1972). Overland flow erosion occurs when the impact of raindrops dislodges fine soil particles, which are then transported downslope as water travels down the hillslope surface. The impact of the raindrops is a more powerful detachment agent than overland flow, but less important for transport, though some movement occurs when the particles are dislodged. Overland flow is rare under natural vegetation and occurs more readily on bare soil or pastured slopes. Hortonian overland flow is the result of rainfall intensities higher than soil infiltration rates. The basic equation (Equation 2-1) for whether Hortonian overland flow will occur is:

Equation 2-1 Equation for determining whether Hortonian overland flow will occur

$$
\sigma=i-f
$$

Where $\sigma$ is supply rate of delivered overland flow eroded sediment, $i$ is rainfall intensity, and $f$ is soil infiltration capacity. Soil may become saturated due to low transmission rates through moisture excess in the lower horizons, rather than an excess of rainfall over infiltration capacity. When this occurs a gradient develops whereby overland flow susceptibility increases in a downslope direction as the velocity of surface flow increases. Under these circumstances the Manning's equation for turbulent flow (Equation 2-2) applies to sediment eroded:

Equation 2-2 Manning's equation for turbulent flow velocity

$$
v_{x}=\frac{I}{R} \times d^{2 / 3} \times S^{1 / 2}
$$

Where $I / R$ is the roughness coefficient of the surface, water depth (d) replaces hydraulic radius (original Mannings equation), $\mathrm{s}$ is slope angle and $v$ is velocity. Velocity increases downslope due to gravity, and in turn overland flow erosion varies with 0.6 power of the distance from the slope crest. Lowering of the land surface via overland flow varies directly with slope angle $(\theta)$; there is a linear proportional increase in sheet wash with sine $\theta$ the best approximation of proportional increase (Young 1972). Saturated overland flow and return flow occur when the water table within the slope rises and intersects the ground surface. 
If the transport agent (overland flow) is sufficient to remove all dislodged particles, loss of sediment is determined by detachment rate. If the supply of dislodged sediment outweighs the carrying capacity of the transport agent loss is determined to be controlled by transport. The effectiveness of overland flow erosion increases during a storm event in four ways, when:

- raindrops are larger, therefore can dislodge particles more easily,

- infiltration capacity is more likely to be exceeded,

- the water table is more likely to rise to the surface, and,

- the rate of transport increases more than linearly with flow (Young and Saunders 1986).

\subsubsection{Landslide triggering factors and pre-conditions}

Stable hillslopes comprised of cohesive material have an upper limit on the height and angle they can achieve. When the limits are reached, gravitational shear stresses approach or exceed slide-resisting stresses within the material and landsliding may result (Crozier et al. 1982). Resisting stresses are partly dependent on material strength, so some types of rock will achieve steeper, higher slopes than others without failing. Pre-conditioning and triggering factors that contribute to increased shear stress and reduced shear strength are shown in Table 2-5.

Three main triggering factors have been associated with the initiation of landslides in the New Zealand hill country:

- Steepening of slopes by basal erosion,

- Earthquakes,

- Heavy or prolonged rainfall (Young, 1972).

This study focuses on rainfall-triggered landslides, which are common in the soft Tertiary rock hill country of New Zealand's North Island (Crozier et al. 1986). Weathered mudstones in particular produce unstable slopes more rapidly than in hard rocks, after incision by stream cutting into the basal zone. A commonly held view is that rainfall-triggered landslides are entirely the result of deforestation of the landscape for pasture production. Crozier et al. (1986) dispute this while noting that the removal of native vegetation in the upland areas of the country (New Zealand) has greatly increased the incidence of shallow landsliding. 
Table 2-5 Factors contributing to slope failures, from Selby, 1982

\begin{tabular}{|c|c|}
\hline \multicolumn{2}{|c|}{ A. Factors contributing to high shear stress } \\
\hline Types & Major Mechanisms \\
\hline 1. Removal of lateral support & $\begin{array}{l}\text { (a) Stream, water, or glacial erosion } \\
\text { (b) Subaerial weathering, wetting, drying, and frost action } \\
\text { (c) Slope steepness increased by mass movement } \\
\text { (d) Manmade quarries and pits, or removal of toe slopes }\end{array}$ \\
\hline 2. Overloading by & $\begin{array}{l}\text { (a) Weight of rain, snow, talus } \\
\text { (b) Fills, wastepiles, structures }\end{array}$ \\
\hline 3. Transitory stresses & $\begin{array}{l}\text { (a) Earthquakes - ground motions and tilt } \\
\text { (b) Man-made vibrations }\end{array}$ \\
\hline 4. Removal of underlying support & $\begin{array}{l}\text { (a) Undercutting by running water } \\
\text { (b) Subaerial weathering, wetting, drying and frost action } \\
\text { (c) Subterranean erosion (eluviation of fines or solution of salts) } \\
\text { (d) Mining activities }\end{array}$ \\
\hline 5. Lateral pressure & $\begin{array}{l}\text { (a) Water in interstices } \\
\text { (b) Freezing of water } \\
\text { (c) Swelling by hydration of clay }\end{array}$ \\
\hline \multicolumn{2}{|c|}{ B. Factors contributing to low shear strength } \\
\hline 1. Composition and texture & $\begin{array}{l}\text { (a) Weak materials such as volcanic tuff and sedimentary clays } \\
\text { (b) Loosely packed materials } \\
\text { (c) Smooth grain shape } \\
\text { (d) Uniform grain sizes }\end{array}$ \\
\hline 2. Physio-chemical reactions & $\begin{array}{l}\text { (a) Cation (base) exchange } \\
\text { (b) Hydration of clay } \\
\text { (c) Drying of clays }\end{array}$ \\
\hline 3. Effects of porewater & $\begin{array}{l}\text { (a) Buoyancy effects } \\
\text { (b) Reduction of capillary tension } \\
\text { (c) Viscous drag of moving water on soil grains }\end{array}$ \\
\hline 4. Changes in structure & (a) Spontaneous liquefaction \\
\hline 5. Vegetation & (a) removal of trees (i) reducing normal loads; (ii) removing apparent cohesion of tree roots \\
\hline
\end{tabular}

\subsubsection{Geomorphological impact of landslides on hillslopes}

Landslides are agents of sediment transport and redistribution. Shallow regolith landslides may produce short-term changes to landforms such as altering slope angles and creating depositional surfaces, however larger, deep-seated slides create more lasting changes to the land surface. Topographic maps of the Wanganui hill country show pre-historic landslide features visible in the landscape today. The largest landslide modified features are deep-seated slumps (Figure 2-15), dissimilar from the rain-induced landslides active in historical times, and which are commonly accepted as being earthquake-induced (Crozier and Pillans 1991). These pre-historic formations or paleoslides alter the nature of the landscape in this area considerably, reducing elevation, often creating lakes, and are distinctively "porridgey-looking" from the air or on topographic maps. Three pre-historic periods of seismically induced landslides have been identified by Crozier (cited in Crozier and Pillans 1991). Carbon dating and the degree of land smoothing after disturbance have provided dates of 1,400 yr BP, $12,000 \mathrm{yr} \mathrm{BP}$, and 31,000 yr BP for this activity. Two historic earthquakes in the 
Wanganui region (in 1838 and 1843) are known to have caused large landslides. Earthquakes in the Wanganui region are frequent occurrences; however earthquakes providing the required shaking intensity of $\mathrm{MM} \geq \mathrm{VIII}$ for landsliding to be induced are rare (Crozier and Pillans 1991).

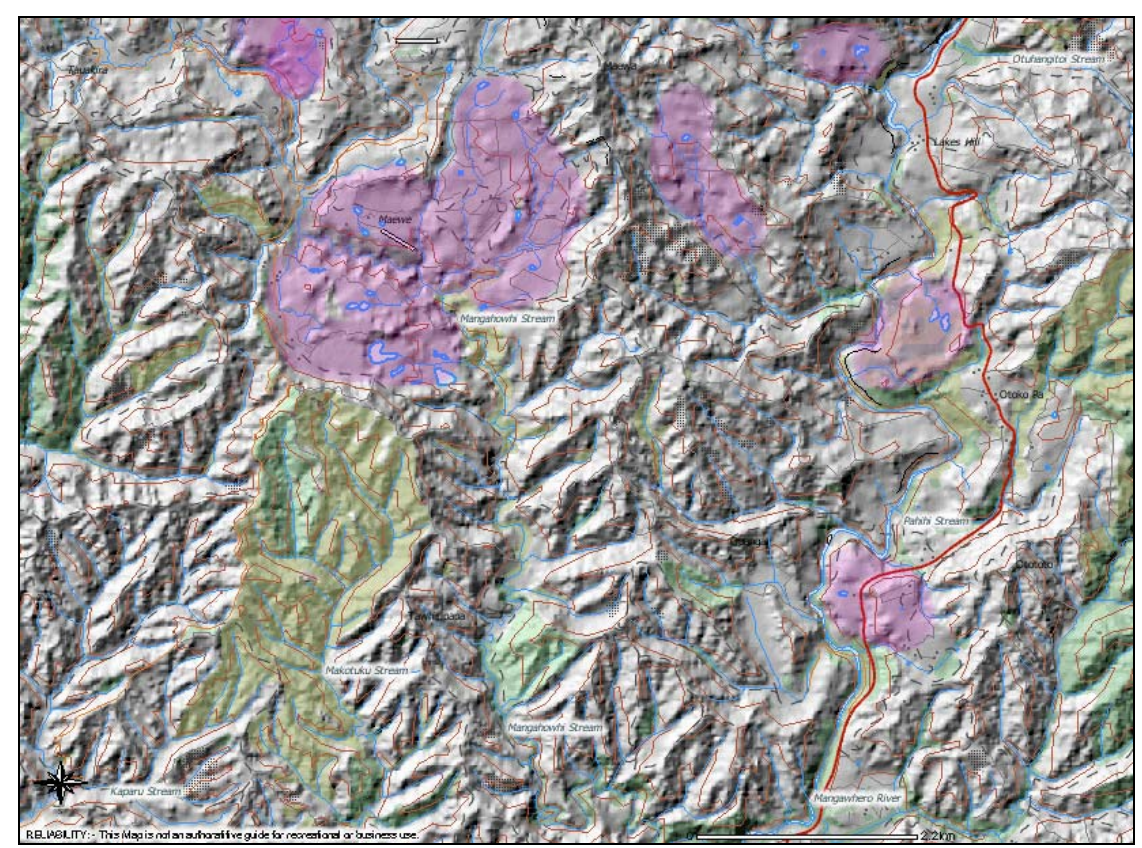

Figure 2-15 Slopes of the Wanganui region; unmodified form can be seen in the west and south of selected area; mauve shaded areas show typical paleoslide form, including loss of elevation, hill smoothing and lake formation, adapted from a topographic base map DOC 2004

As these relict forms are still visible in the landscape today, they are able to be compared with recent landsliding events in the region which have been induced by excess soil moisture. The rainfall-triggered landslides observed in the last 150 years have had different forms than the paleoslides. They are degrees of magnitudes smaller in volume and area, as there is much less visible landform modification except at the localised level. What is important in terms of changes to landforms brought about by current landslide activity is the durability of the changes; i.e. will they be present in 10, 20, 100, or even 1000 years time? How important landslides have been in forming hillslopes can be surmised from how bumpy and scarred slopes appear. Rounded, smoothed slopes suggest small-scale, continuous processes are dominant (Young and Saunders 1986). However, in the steeply sloping and dissected hill country of eastern Wanganui, the smoothing and lowering of slopes can be mostly attributed to massive earthquake-induced paleoslide events. 
Modification of landforms is visible on a reduced and more localised level for historic rainfall-triggered landslides. The majority of slides of this type are shallow, translational slides, which may over-steepen slopes where source material is lost from the scar. These slides rarely exceed two metres in depth, causing little long-term modification to landforms (Crozier et al. 1986). During very large rainfall events much larger failures may be initiated (Figure 2-16). The endurance of the impact of these larger, usually rotational slides in Tertiary mudstone is yet to be determined. Scar areas with exposed bedrock take longer to recover (i.e. produce topsoil and vegetation cover) than runout deposits, or shallow scars in regolith only (Painter, 1981).

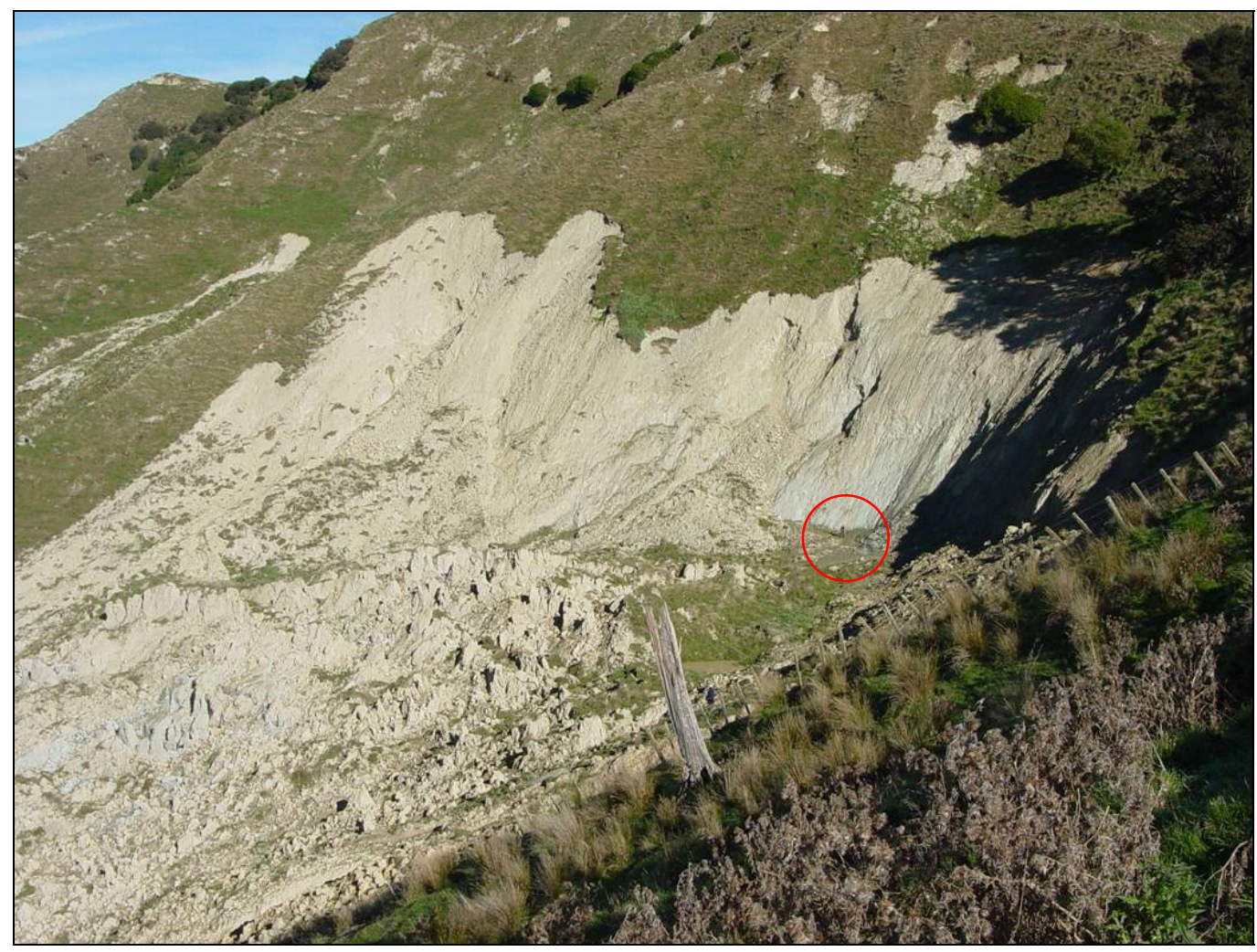

Figure 2-16 Over-steepening of hillslope in scar area of rotational landslide, Mangawhero region. Note the circled figure for scale, photograph Crozier 2004

Storm events of sufficient intensity and/or duration to produce deep-seated $(>10 \mathrm{~m}$ depth) scars are infrequent. Events of this nature such as the Cyclone Bola Event of 1988 that have been studied are too recent to determine how long the land will take to recover from deeper slides. This event caused thousands of shallow regolith slides in the Hawke's Bay hill country, and some deeper bedrock slides (Figure 2-17). By 2004 slopes had re-grassed on areas severely impacted by shallow regolith landslides however, it was observed that the scar areas and tracks of flow paths below the 
pasture cover. The long-term net geomorphological effect of landslides is to reduce slopes to angles at which they possess long term stability; individual landslides may not always produce gentler slopes but often where a slope is steepened its overall height is reduced (Young 1972).

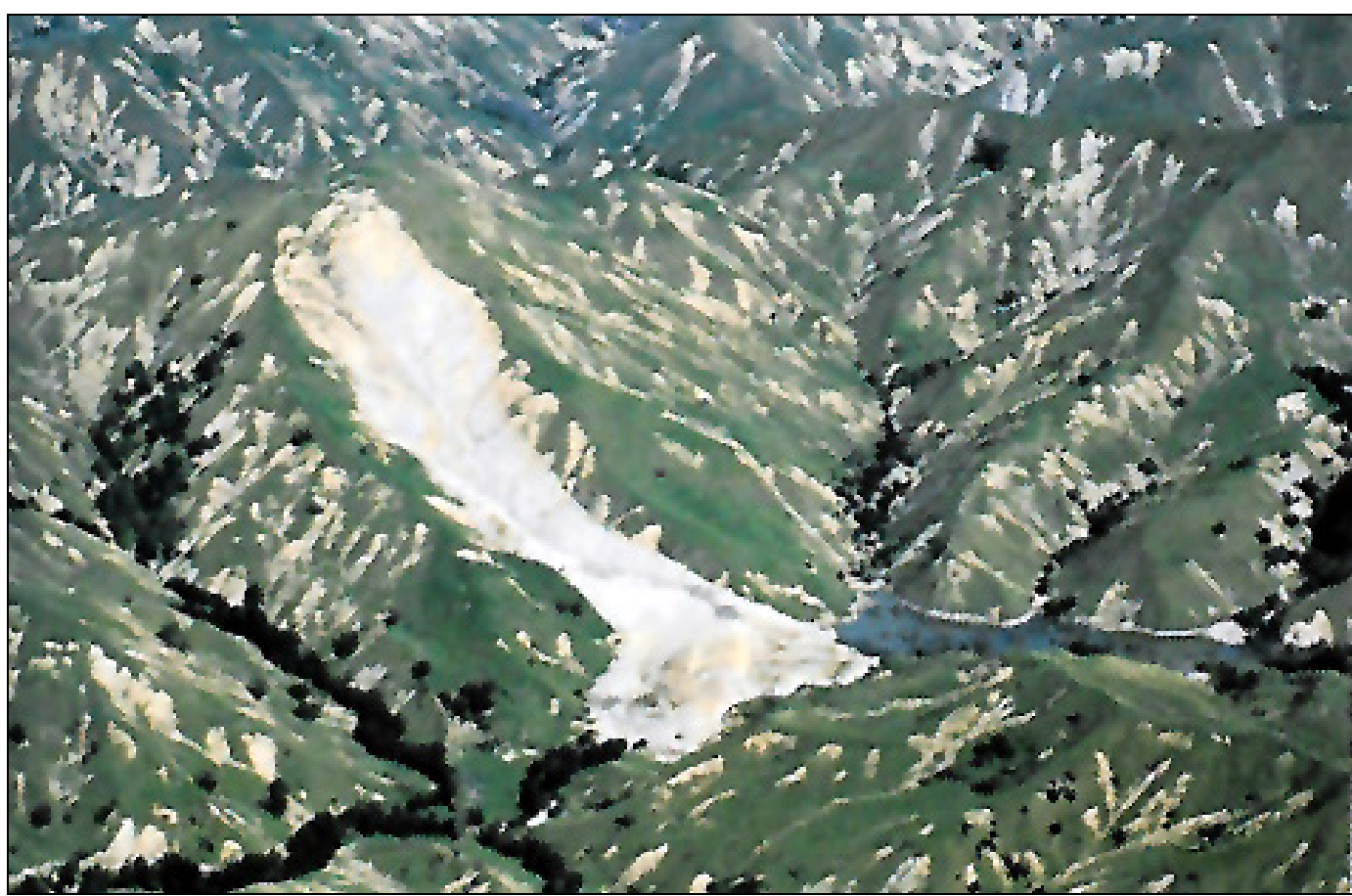

Figure 2-17 The Waipaoa River catchment area in Hawke's Bay, which was severely affected by thousands of shallow, and many bedrock failures during Cyclone Bola, 1988 photograph Trustrum, 1988

\subsubsection{Geomorphic work done by landslides}

Geomorphic work is defined as a given amount of material transported a certain distance over a specified time. The work that landslides do is the removal, transportation, and deposition of hillslope material. It can also involve delivery of this material to waterways where there is coupling between fluvial systems and landslide material. The significance of work done during rainfall-triggered, multiple landslide events has been the subject of many New Zealand studies (e.g. Bell 1976, Hicks 1991, Crozier 1991, Crozier and Pillans 1991, Page et al. 1994, Luckman et al 1999, Kasai et al. 2001, Brooks et al. 2002,) (see also Section 2.16) and overseas studies (e.g. Rapp 1960, Haneburg 1991, Slattery and Burt 1996, Terlien et al. 1996, Borga et al. 2002, Casadei 2003). In earlier New Zealand studies (1970s - mid 1990s) the primary motivation for work of this nature was the investigation of productivity loss from pastureland which had experienced the removal of vegetation, regolith, and 
sometimes bedrock during storm events. In addition, work over this period involved determining the triggering rainfall threshold and return period of events. More recent studies have begun to focus more on the geomorphic significance of these events; how are these events changing the landscape, where is sediment being removed from and where is it transported to? Is sediment staying within the hillslope/catchment system or being transported out of the system due to fluvial or lacustrine coupling? The production of a sediment budget provides the basis for the assessment of geomorphic work done by landslides. Sediment budgets are calculated by determining the volume of material removed from the source area (scars) of landslides within a given study area, for a particular event. When this volume is known, the volume of material deposited on the hillslopes within the study area is subtracted from scar volume to determine the volume of material transported out of the system. Page et al (1994) used a comprehensive sediment budget of the Lake Tutira catchment in Hawke's Bay to determine the geomorphic work done by Cyclone Bola in 1988. They based their budget on the following equation (Equation 2-3):

Equation 2-3 Sediment budget equation for measuring hillslope material input to fluvial systems

Sediment generation $=$ sediment stored + sediment discharged

In this study a similar approach is taken, in that a sediment budget is calculated, however the method differs from the broad scale of Page et al. (1994). For this study a handheld GPS device is used to trace the areas of sediment removal (scars) and deposits, for a selected drainage basin. Volumes are calculated using average depths for each landslide scar and deposit area, which were assessed in the field, and used to produce a sediment budget (see Chapter 7).

\subsubsection{Rainfall-triggered, multiple landslide events in New Zealand}

New Zealand is an optimal location for the study of rainfall-triggered, multiple landslide events. Orographically driven rainfall and the moist maritime climate, produces rainfall events of sufficient magnitude to periodically initiate landsliding in the weak Tertiary rock hill country of the North Island. Coupled with the deforestation of the hill country, which has reduced interception and soil support, events of this nature are not infrequent (Crozier et al. 1982, Hicks, 1991). Several 
studies of rainfall-triggered, multiple landslide events will be examined and compared with data from the February 2004 storm event. Comparing these large events and ranking the geomorphic significance is a complex task; the nature of the terrain, and magnitude of the storm must be considered, as well as comparing the magnitude of the geomorphic work done and geomorphological changes to terrain.

Events to be compared to and ranked against the February 2004 landslide event are:

- The 1988 Cyclone Bola event studies in the Waipaoa and Lake Tutira catchments (Page et al. 1994);

- Gisborne 2002 storm event (Preston 2003);

- Wellington 1974 and 1976 storm events (Eyles, et al 1982);

- 1977 Wairarapa storm event (Crozier et al. 1982), and ;

- Hawke's Bay 1971 storm event (Eyles 1971).

Each of these events is to be quantified in terms of magnitude (for ease of comparison landslide densities, areal extents, and sediment budgets if available are used), and frequency (how often an event of this magnitude is likely to occur and the duration of the event itself; i.e. is it a one in one hundred year event? a one in twenty year event?).

At a catchment or basin level studies often involve field measurement. For these studies it is also useful to determine the record of landslide activity in the study area. Crozier and Glade (1999) sum up the approaches taken when recording pre-historic and historic landslide activity (this includes slow moving deep-seated slump activity analysis as well as shallow, multiple landslide events):

- Direct monitoring of hillslopes and existing landslides. This method is generally used to record reactivation rather than first-time failures and involves the use of sophisticated sensors such as strain gauges, inclinometers, and precise survey of surface and subsurface positional indicators.

- Survey and direct field dating of actual landslide remnants. Many standard relative and absolute dating techniques have been successfully applied to landslides.

- The use of documentary sources, including sequential air and ground photo coverage. 
- Surrogate histories of landslide activity built up indirectly from records of associated infrastructural damage.

- Techniques which provide indirect physical evidence of movement e.g. dendrogeomorphological studies of debris impacts on trees, (Crozier and Glade, 1999).

When the landslide history of a basin, catchment, or region is known it assists with interpretation of new landslide event data. Previous removal of hillslope material can reduce the impact of future storm events of increased magnitude by reducing the amount of potentially landslide-susceptible regolith. Traditionally in New Zealand south-facing slopes are wetter and more vulnerable to slipping due to lower evapotranspiration rates. A landslide event that is dominated by failures on northfacing slopes could be attributed to a storm approaching from the north, which is so intense the north-facing slopes achieve saturation before slopes of other aspects, or as in the case of the Wairarapa 1977 storm, it was found by Crozier (1980) that previous stripping of regolith on the wetter south-facing slopes had rendered them less susceptible to failure during this storm event.

\subsubsection{Frequency-magnitude theory}

Selby (1982) defines the geomorphic importance of an erosional event as being governed by the magnitude of the energy it expends in the environment and the frequency with which it occurs. Early geomorphic frequency-magnitude studies were based mostly upon fluvial systems, or depositional landforms (Wolman and Millar 1960). In their seminal work on frequency-magnitude, Wolman and Millar (1960) found that the majority of geomorphic work and landform changes were the result of small frequent events rather than infrequent catastrophic events. The underlying basis for frequency-magnitude studies is that a certain magnitude of energy must be present, i.e. a threshold must be reached, before work is able to be done. How often this threshold is exceeded and by how much it is exceeded determines the relative frequency and magnitude of an individual event. Wolman and Millar (1960) concentrated on studying geomorphic work done by looking at material transport and deposition in river channels, and landform change by looking at formation of beach profiles, and aeolian transport and deposition within dune systems. For the fluvial studies they examined suspended load only. A common theme of these three types of studies is that the variation in sediment size is not great. Fluvially suspended particles 
have a maximum mass that alters with available transport energy; however the majority of coarse sediment travels as bedload. Dune sand must be able to be carried directly in the wind or by bouncing along the land surface by saltation; again a maximum mass controls the range of sediment in the study. Beach sediments can contain a range of sizes from fine sands and silts to cobbles (and occasionally boulders, depending on available source material from nearby rivers). While providing a greater range of transported sediment for study, the range is still extremely limited compared with erosional landform processes such as landslides, lahars, and rock and ice avalanches.

The outcome of the Wolman and Millar study is that a maximum product of frequency and magnitude dominates the work done within a system (Figure 2-18). For their fluvial studies they calculated that $90 \%$ of work was done by events that occurred at least once every five years. They presumed that large floods are so rare that their sediment transport work becomes insignificant in comparison with smallscale frequent events (Wolman and Millar 1960), however their dataset was only approximately ten years in duration (3056 days) so may not have included any events of extreme magnitudes. Also, the "freak" nature of catastrophically large events makes them difficult to fit to any rating curve to determine frequency from magnitude values. These events are naturally outliers.

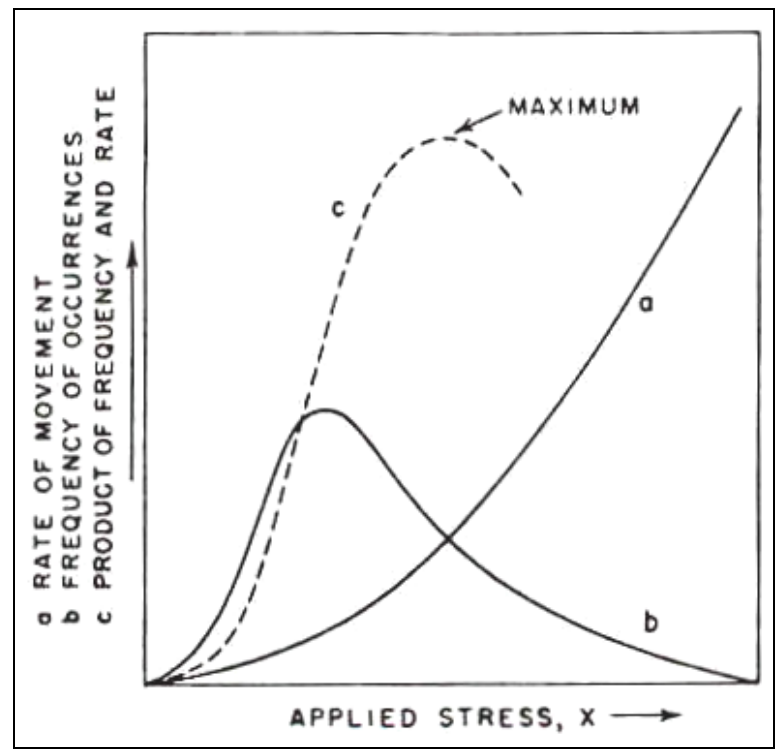

Figure 2-18 (a) Stress or events of magnitude over threshold required for movement- log normal, (b) frequency, (c) maximum product of stress and frequency, from Wolman and Millar 1960 
The Wolman and Millar (1960) studies of landform change and frequency-magnitude identified that differing magnitudes were required to form separate parts of the beach profile, and that typically only very large floods can change the overall position of a river channel (channel avulsion). They do conclude that gully erosion and landsliding are largely the result of catastrophic events and endure in the landscape for sufficient time to alter drainage patterns and topography (Wolman and Millar 1960); however this is theoretical and not based on empirical studies.

A similar frequency-magnitude study of fluvial sediment delivery was undertaken by Slattery and Burt (1996), in the Cotswold regions of England. Their short-term study (one year) examined the coupling of soil erosion and sediment yield within a basin. Their study concluded that it was larger events within the period of study rather than average flow rates that were responsible for most erosion. They found that nine storms throughout the year were responsible for $57 \%$ of total sediment yield. This result seems to disprove Wolman and Millar's (1960) theories on magnitude and frequency; however it is difficult to compare studies of differing duration.

The variance in results does however indicate that transference of frequencymagnitude theory from the Wolman and Millar (1960) depositional landform and fluvial studies to erosional studies must therefore be questioned (Crozier and Glade 1999). Rapp also undertook a frequency-magnitude study in 1960; however the focus of the study was erosional - slope development in Scandinavia. Rapp's study of a 15 $\mathrm{km}^{2}$ area outside the glacial hillslope area of the Scandinavian mountains was undertaken to determine the types of movement operating within the system and their importance. The single most important erosional factor in the system was found to be chemical weathering, followed by earthslides and mudflows (Table 2-6).

Rapp's (1960) study was based on sediment delivery from the hillslope system to the valley floor and fluvial system. In this unstable area earthslides and mudflows (Rapp's nomenclature) were ranked second, despite the large volume of material transported because very none of the material reached the valley floor. The landslide deposits added to existing alluvial fans in the lower slopes or in the upper slopes in sheltered areas of talus deposition. Some of these talus deposits were found to be mobilised by landslides and continued downslope as mudslides. Rapp concluded that 
if the study area was subject to more frequent, heavy rainfall earthflows would be much more important within the system (Rapp 1960).

Table 2-6 Rapp's results from the 1960 Scandinavian mountain study

\begin{tabular}{|c|c|c|c|c|c|c|c|}
\hline Process & $\begin{array}{c}\text { Volume } \\
\left(\mathrm{m}^{3}\right)\end{array}$ & Density & $\begin{array}{c}\text { Tons } \\
(\mathrm{t})\end{array}$ & $\begin{array}{c}\text { Tons } \\
\text { per } \mathrm{km}^{2}\end{array}$ & $\begin{array}{l}\text { Average } \\
\text { Movement } \\
(\mathrm{m})\end{array}$ & $\begin{array}{c}\text { Average } \\
\text { gradient }\end{array}$ & $\begin{array}{c}\text { Ton-metres } \\
\text { (vertical) }\end{array}$ \\
\hline $\begin{array}{l}\text { Rockfalls } \\
\text { Pebble-falls.................... } \\
\text { Small boulder falls............ } \\
\text { Big boulder falls............. }\end{array}$ & $\begin{array}{r}5 \\
10 \\
35 \\
\end{array}$ & $\begin{array}{l}2.6 \\
2.6 \\
2.6 \\
\end{array}$ & $\begin{array}{l}13 \\
26 \\
91 \\
\end{array}$ & $\begin{array}{l}1.0 \\
1.7 \\
6.0 \\
\end{array}$ & $\begin{array}{r}90 \\
225 \\
225 \\
\end{array}$ & $\begin{array}{l}45^{\circ} \\
45^{\circ} \\
45^{\circ} \\
\end{array}$ & $\begin{array}{r}845 \\
4,160 \\
14,560 \\
\end{array}$ \\
\hline 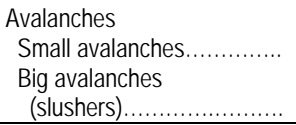 & $\begin{array}{r}8 \\
80 \\
\end{array}$ & $\begin{array}{l}2.6 \\
2.6 \\
\end{array}$ & $\begin{array}{r}21 \\
208 \\
\end{array}$ & $\begin{array}{l}1.4 \\
1.4 \\
\end{array}$ & $\begin{array}{l}100 \\
200 \\
\end{array}$ & $\begin{array}{l}30^{\circ} \\
30^{\circ} \\
\end{array}$ & $\begin{array}{r}1,050 \\
20,800 \\
\end{array}$ \\
\hline $\begin{array}{l}\text { Earth-slides etc. } \\
\text { Bowl-slides..................... } \\
\text { Sheet-slides.................. } \\
\text { Sheet-slides + mudflows..... } \\
\text { Other mudflows.............. }\end{array}$ & $\begin{array}{r}170 \\
190 \\
150 \\
70 \\
\end{array}$ & $\begin{array}{l}1.8 \\
1.8 \\
1.8 \\
1.8 \\
\end{array}$ & $\begin{array}{l}300 \\
340 \\
270 \\
126 \\
\end{array}$ & $\begin{array}{c}20 \\
23 \\
18 \\
8.4 \\
\end{array}$ & $\begin{array}{r}0.5 \\
12-420 \\
70-600 \\
100 \\
\end{array}$ & $\begin{array}{l}30^{\circ} \\
30^{\circ} \\
30^{\circ} \\
30^{\circ} \\
\end{array}$ & $\begin{array}{r}75 \\
20,000 \\
70,000 \\
6,300 \\
\end{array}$ \\
\hline $\begin{array}{l}\text { Creep } \\
\quad \text { Talus creep } \ldots \ldots \ldots \ldots \ldots \ldots \ldots \\
\text { Solifluction } \ldots \ldots \ldots \ldots \ldots \ldots \ldots \ldots\end{array}$ & $\begin{array}{l}300,000 \\
550,000 \\
\end{array}$ & $\begin{array}{l}1.8 \\
1.8 \\
\end{array}$ & - & - & $\begin{array}{l}0.01 \\
0.02\end{array}$ & $\begin{array}{l}30^{\circ} \\
15^{\circ}\end{array}$ & $\begin{array}{l}2,700^{d} \\
5,300^{e}\end{array}$ \\
\hline $\begin{array}{l}\text { Running water } \\
\quad \text { Dissolved salts.............. } \\
\text { Slope wash................. }\end{array}$ & $\begin{array}{r}150 \\
?\end{array}$ & 2.6 & 390 & $\begin{array}{c}26 \\
?\end{array}$ & 700 & $30^{\circ}$ & $\begin{array}{r}136,500 \\
?\end{array}$ \\
\hline
\end{tabular}

Frequency-magnitude studies relating to landslides have progressed significantly since the study of Rapp (1960). These studies are now the basis of characterising landslide hazard, assessing rates of geomorphic work, and identifying significant change over time of environment factors which affect landsliding (Crozier and Glade 1999). The biggest issue in studying the frequency and magnitude of landslide events is access to sufficient, good quality data. In New Zealand long-term records are not available, and studies are not undertaken in a uniform way. Worldwide, insufficient records from many regions make determining return periods for very large events difficult (Selby 1982). Earlier studies of landsliding had the loss of soil productivity as the primary focus (e.g. Page et al. 1994), with more recent studies focussing on geomorphic significance, and landslide hazard and risk (Crozier and Glade 1999). Systems for recording landslide activity are not standardised, as agreement on which landslide describing parameters are most important has not been reached by the different agencies concerned with studying landslides (e.g. government departments, local bodies, crown research institutes, academic institutions).

To undertake a study of landslide frequency and magnitude the two terms must be defined. When considering a rainfall-triggered, multiple-landslide event, the term landslide frequency is concerned not only with how often the events occur but also the 
duration of the event. Landslide magnitude includes the aerial extent of landsliding, the proportion of hillslopes affected, and the volume of material removed, transported and deposited. New Zealand is one of the world's regions that experience an average of five to ten extreme landsliding events per century (Selby 1982). However this statement is somewhat ambiguous as no worldwide definition of extreme landsliding is available. In a 100 year period, damaging landsliding events in this country are such that denudation of hillslopes by landsliding greatly exceeds the denudation arising from low intensity, high frequency processes (Selby 1982). The rate of storm-induced landsliding in New Zealand has increased over the last 150 years as original vegetation has been cleared and converted to pasture. Under original vegetation cover (forest) hillslopes over $20^{\circ}$ were subject to landsliding during large storms only once in every 100 years. Since land clearing the rate is now approximately once every thirty years (Selby 1982).

\subsubsection{Episodicity, thresholds and equilibrium}

Studying complex dynamic systems such as hillslopes becomes simpler when the concept that landforms change episodically is taken as a fundamental approach (Brunsden and Chandler 1996). Formative events can be identified which have created, or are in the process of creating, landforms and deposits which persist in the landscape. After each event (the period of activity of a process during which landform change occurs) there is a "relaxation process" during which the system adjusts and a new characteristic form is produced in the landscape (Selby 1982, Brunsden and Chandler 1996). When a system is periodically disturbed by triggering events above the threshold, and consequently readjusting to a relatively stable new form between events the system is determined to be in dynamic equilibrium (Figure 2-19). For the New Zealand landscape the relaxation time between landslide events may not be sufficient for the landform to adjust to a new and more stable form; reactivation of existing landslides is a common occurrence. Crozier and Pillans (1991) suggest that for much of the New Zealand hill country the natural state of the landscape is one of constant adjustment. 


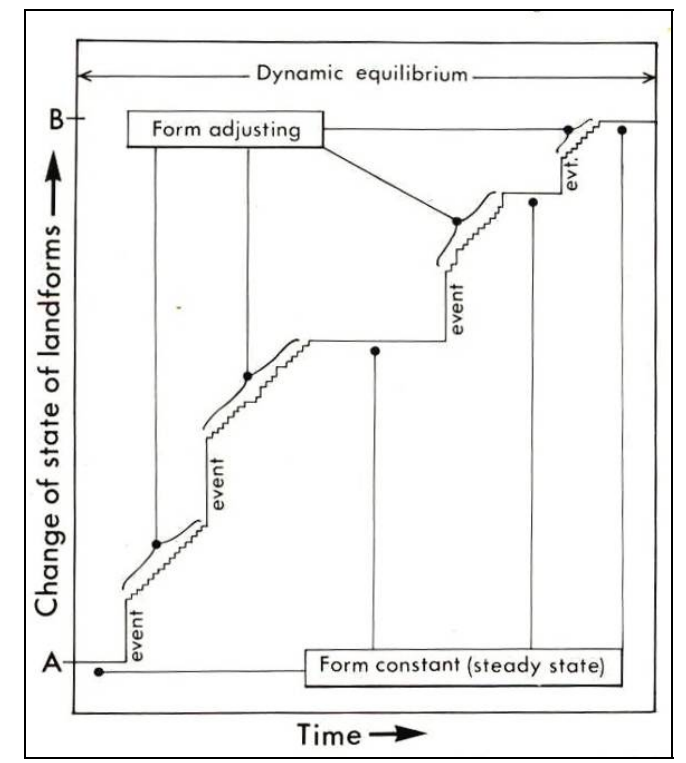

Figure 2-19 Dynamic equilibrium model from Selby 1982

A comparison of New Zealand geomorphic change rates and magnitude frequency with other regions shows New Zealand to be relatively active. The moist climate and tectonically active landscape provide the conditions for reasonably frequent geomorphic system adjustment when compared with other regions around the world such as Europe (Selby 1982).

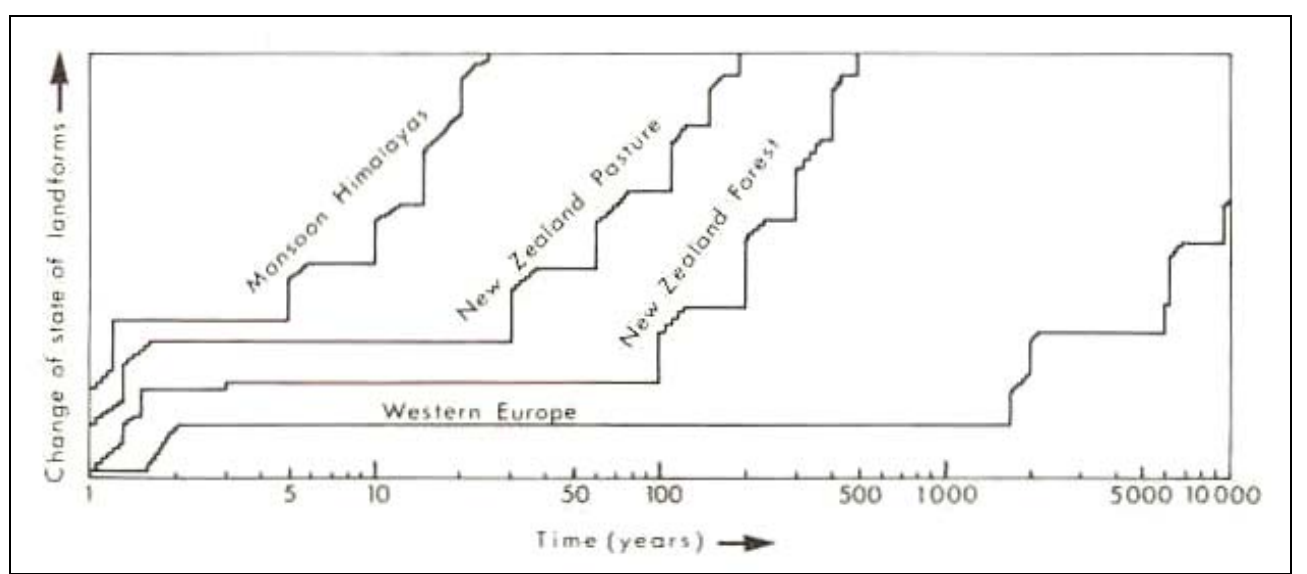

Figure 2-20 Comparison of New Zealand geomorphic change with other regions of the world from Selby 1982

For a geomorphic change to be produced in the landscape a given magnitude of event must occur. The threshold for change is not a static value as changes brought about by previous events may render the system less susceptible (e.g. removal of available regolith to bedrock surface resulting in no material available for future failure), or more likely to fail (e.g. over-steepening of slopes increasing internal stresses). When 
the threshold for initiating geomorphic response is reached, system change occurs. The magnitude of the energy for change or forcing process will determine the magnitude of the geomorphic response (Crozier 1999).

\subsection{Summary}

This chapter has introduced the theory of slope process and slope development. It has highlighted those factors and approaches that have proved useful in understanding the geomorphic behaviour of slopes. Concepts of particular value to the interpreting of damage from high magnitude rainfall events are: the factors that combine to produce instability on hillslopes; the types of erosional mass movement that can be induced by these events (e.g. landslides, overland flow erosion); and, the classification of landslides by material and movement type. With the background provided in this chapter the nature of the February 2004 landslide event may be examined. The following chapter introduces the event in more specific terms by covering the February 2004 storm event. Subsequent chapters examine the nature of the terrain affected and the landsliding caused by this storm event. 


\section{The February 2004 Storm Event}

\subsection{Background}

In February 2004 New Zealand experienced an exceptional climate pattern; an unusually high number of depressions (low-pressure systems) occurred to the south of the South Island (National Institute of Water and Atmosphere (NIWA) 2004). These depressions often gained in intensity as they moved over the country. In combination with the unusually low-pressure conditions that dominated February's weather patterns, there was an absence of the summer anticyclones (high-pressure systems) usually experienced over much of New Zealand in February (NIWA 2004).

The most damaging and intense storm event resulting from the unusual weather conditions arose from a depression moving rapidly from the Tasman Sea in an eastsoutheast direction across New Zealand on Saturday, February $14^{\text {th }}$. The depression lost pressure rapidly as it travelled, with a drop in pressure of $22 \mathrm{hPa}$ over 24 hours, to reach $983 \mathrm{hPa}$ by midday February $14^{\text {th }}$. A pressure drop such as this is commonly referred to as a 'weather bomb'. The front associated with the low pressure system travelled over the North Island on February $14^{\text {th }}$ and $15^{\text {th }}$, bringing gale-force winds and heavy rain to many areas. By midday February $15^{\text {th }}$, the front was situated over eastern Bay of Plenty, where its progress was stalled by interaction with a northwardmoving southerly change (Figure 3-1 to Figure 3-8) and with a tropical depression north-northeast of the country (Metservice 2004).

The combination of fronts produced lower than average temperatures and resulted in snowfall in alpine areas of both Islands (unusual for February), and heavy rainfall over much of the North Island, particularly the southern half. February rainfall totals for the south and west of the North Island ranged between $400 \%$ and $600 \%$ of the February average (Figure 3-9). The low-pressure system also contributed to high sea levels during the period with many areas at risk from storm surge waves (Metservice 2004). 


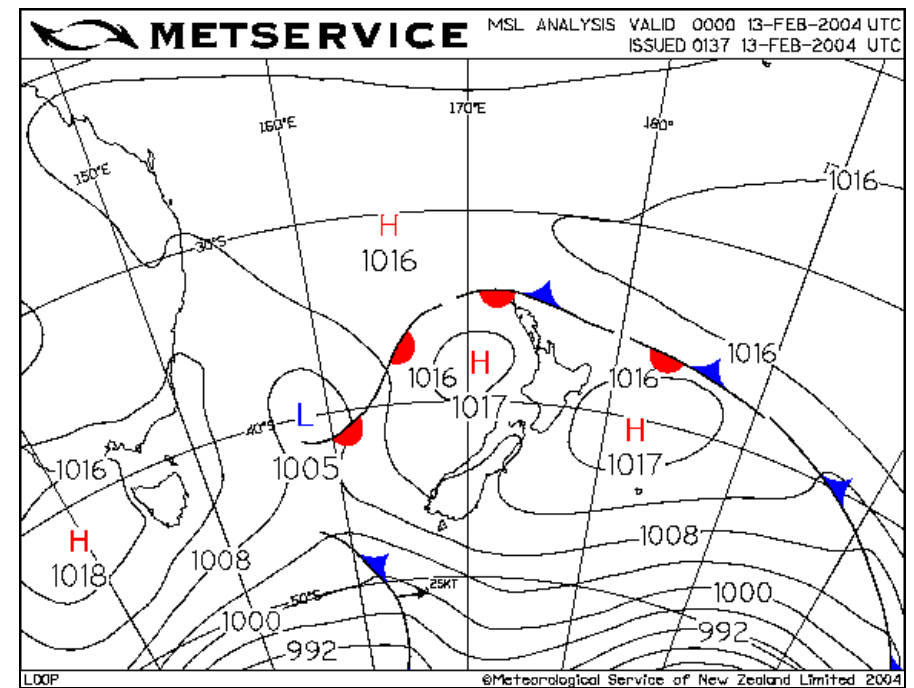

Figure 3-1 The atmospheric situation on 13th February, 0000hrs, from Metservice 2004

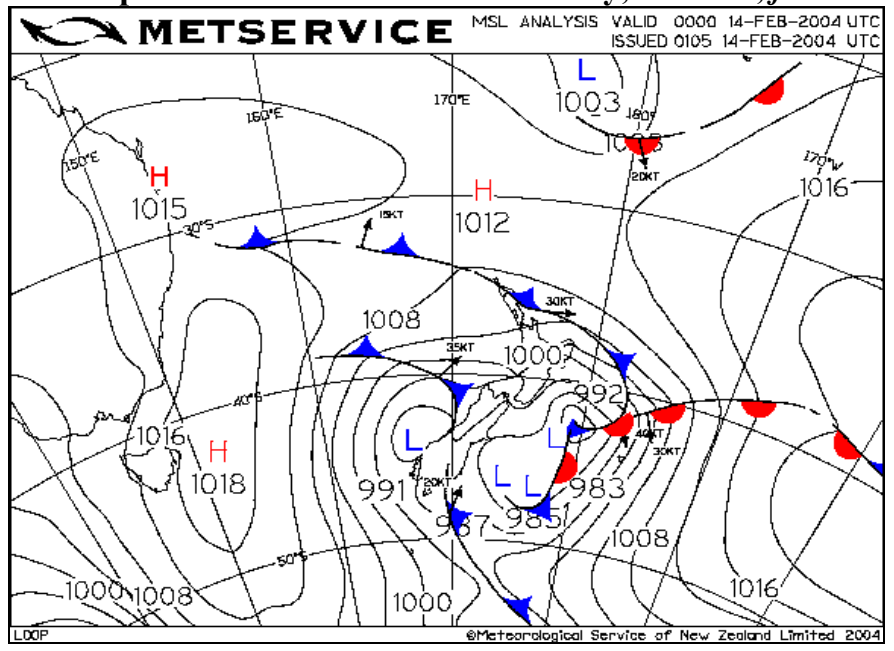

Figure 3-2 0000hrs, 14th February, two low air pressure systems move towards NZ, from Metservice 2004

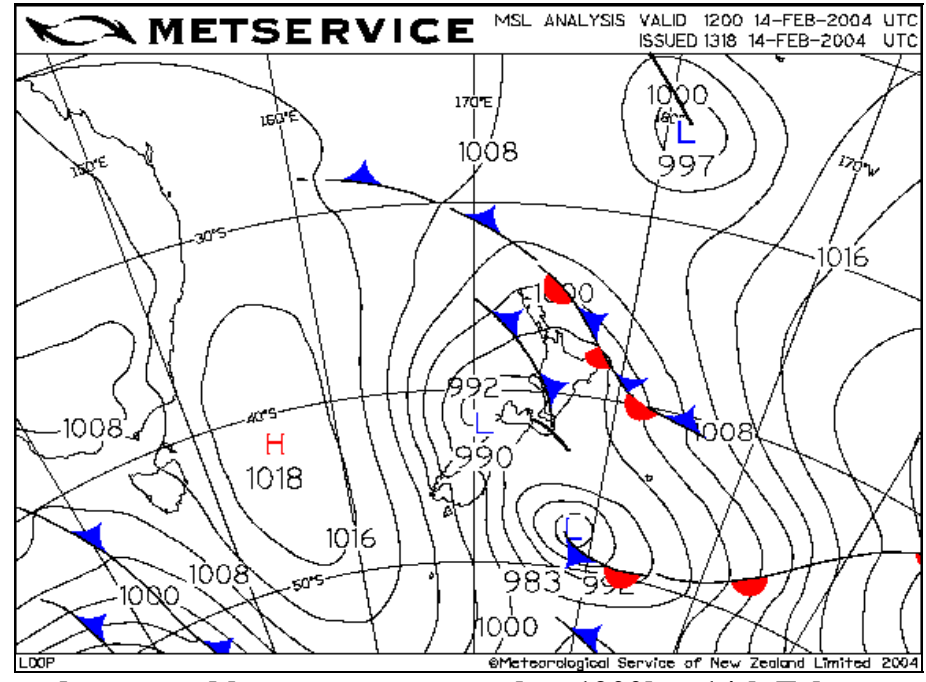

Figure 3-3 The lows deepen and become more complex, 1200hrs 14th February, from Metservice 2004 


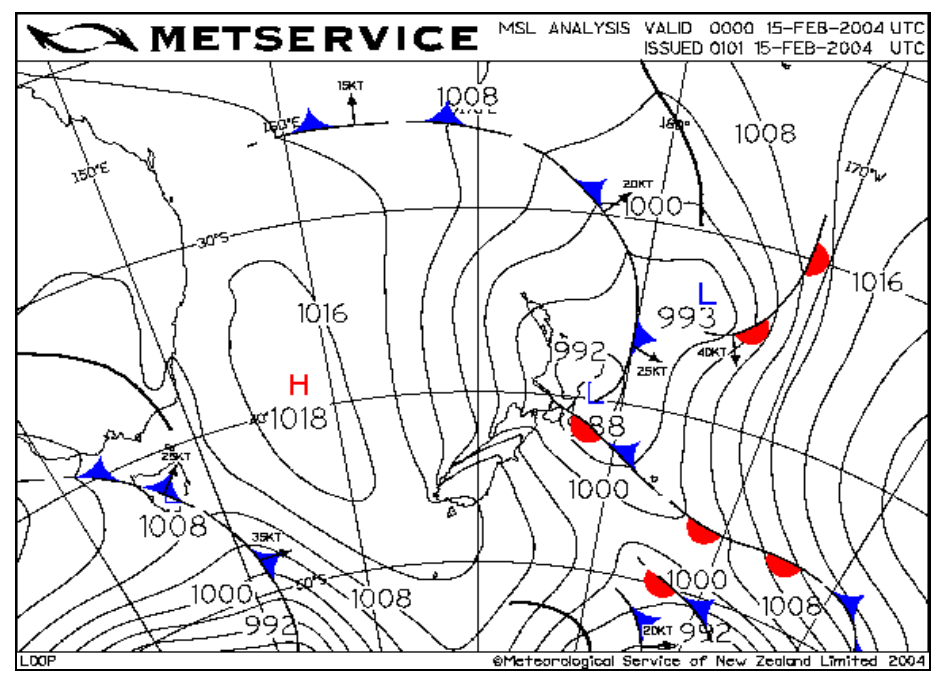

Figure 3-4 Fronts move over the southern North Island, bringing high winds and heavy rain, 0000hrs, February $15^{\text {th }}$, from Metservice 2004

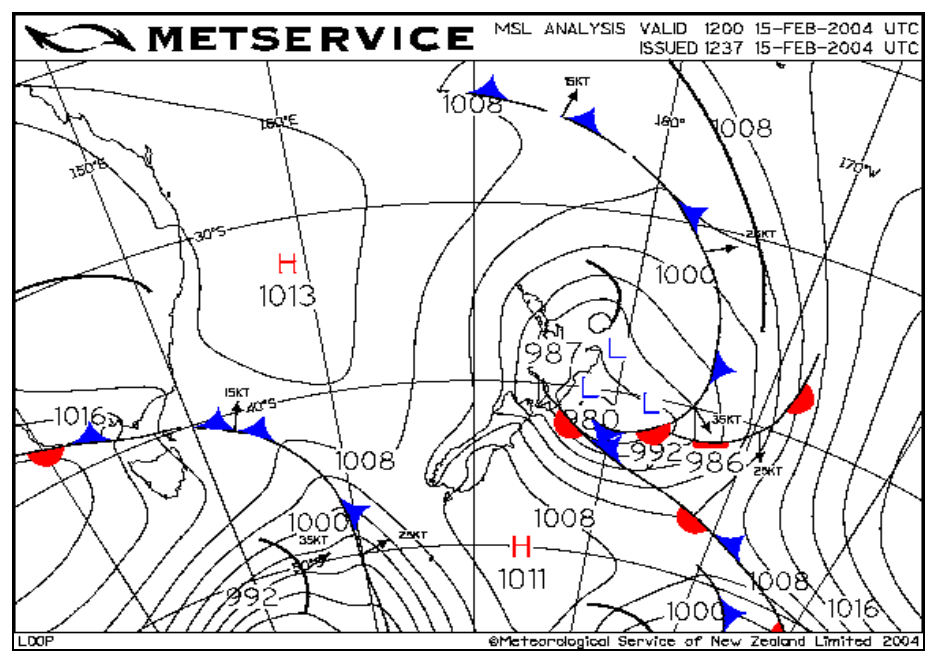

Figure 3-5 Low becomes situated off the North Islands east coast, 1200hrs, February 15th, from Metservice 2004

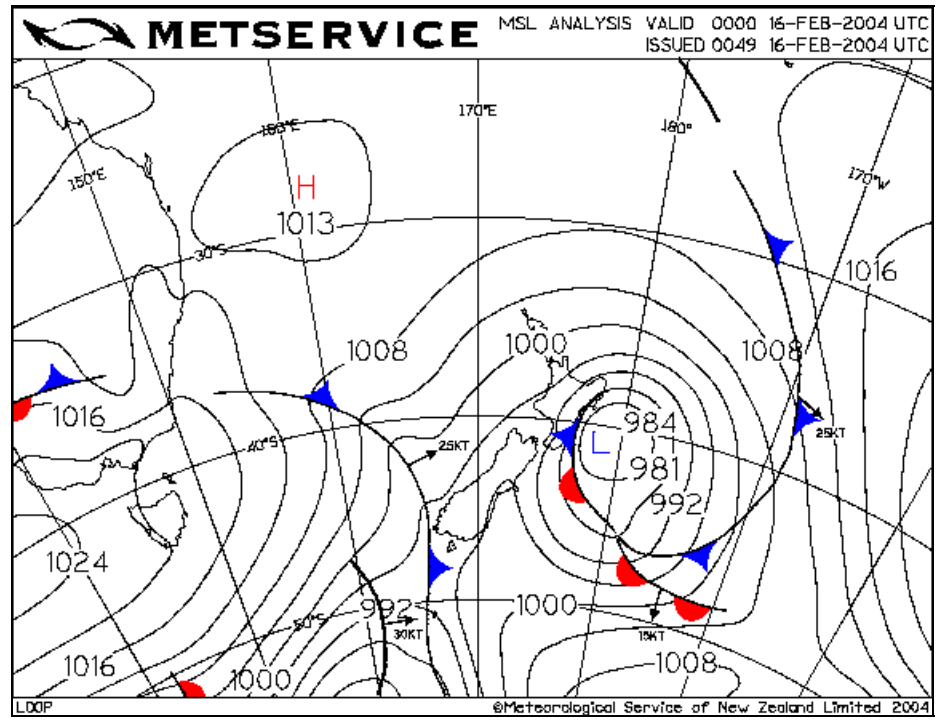

Figure 3-6 The low-pressure systems stall off the East Coast, 0000hrs, February $16^{\text {th }}$, from Metservice 2004 


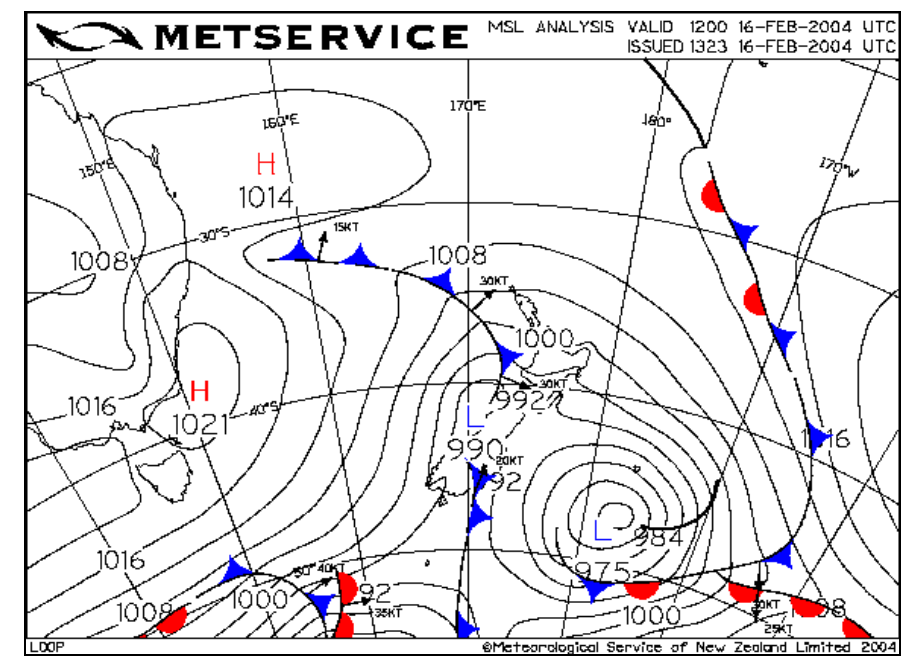

Figure 3-7 The storm low moves southeast as a new front approaches from the west, 1200hrs, February 16th, from Metservice 2004

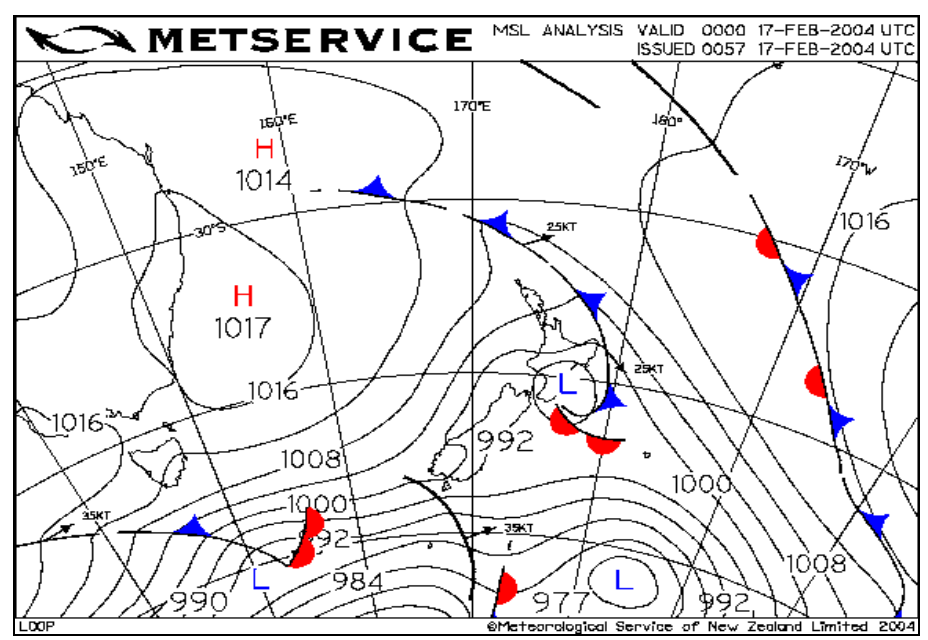

Figure 3-8 Rain continues to fall as a more subdued low sits over the North Island, 0000hrs, February 17th, from Metservice 2004

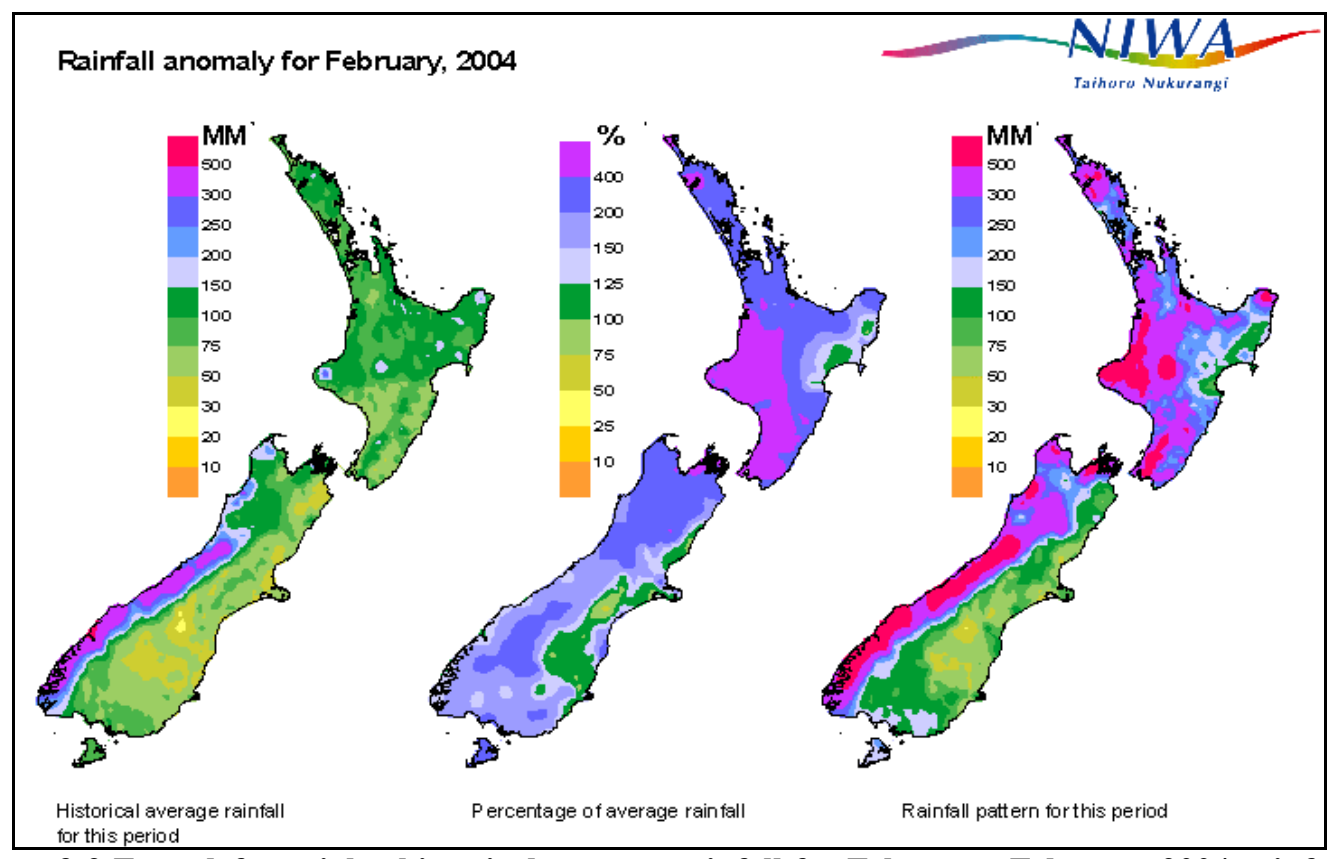

Figure 3-9 From left to right: historical average rainfall for February; February 2004 rainfall as percentage of historical average; and total rainfall for February 2004, from NIWA, 2004 


\subsection{Where the Rain Fell}

Between February $14^{\text {th }}$ and $18^{\text {th }}$ the weather pattern anomaly impacted on the Lower North Island. Figure 3-10 shows the distribution of total rainfall for the 'weather bomb' event. Maximum rainfall for the event was recorded for the 24 hours between 9am February $15^{\text {th }}$ and 9am February $16^{\text {th }}$ (Figure 3-11). The intense rainfall resulted in severe flooding of low-lying areas in the Wanganui, Rangitikei, Manawatu, Wairarapa, and Lower Hutt areas. The magnitude and extent of flooding has been described as the worst in 100 years of flood records for some of the affected areas (Metservice (NZ) Ltd., 2004).

Hundreds of people were evacuated from their homes in the affected areas, rivers burst their banks, the Motua floodway on the Manawatu River was breached, and in Feilding, Marton and Tangimoana States of Civil Emergency were declared (Metservice 2004). Cook Strait ferries were cancelled due to high seas, Wellington Airport was closed, and major road and rail transport routes throughout the southern North Island were disrupted.

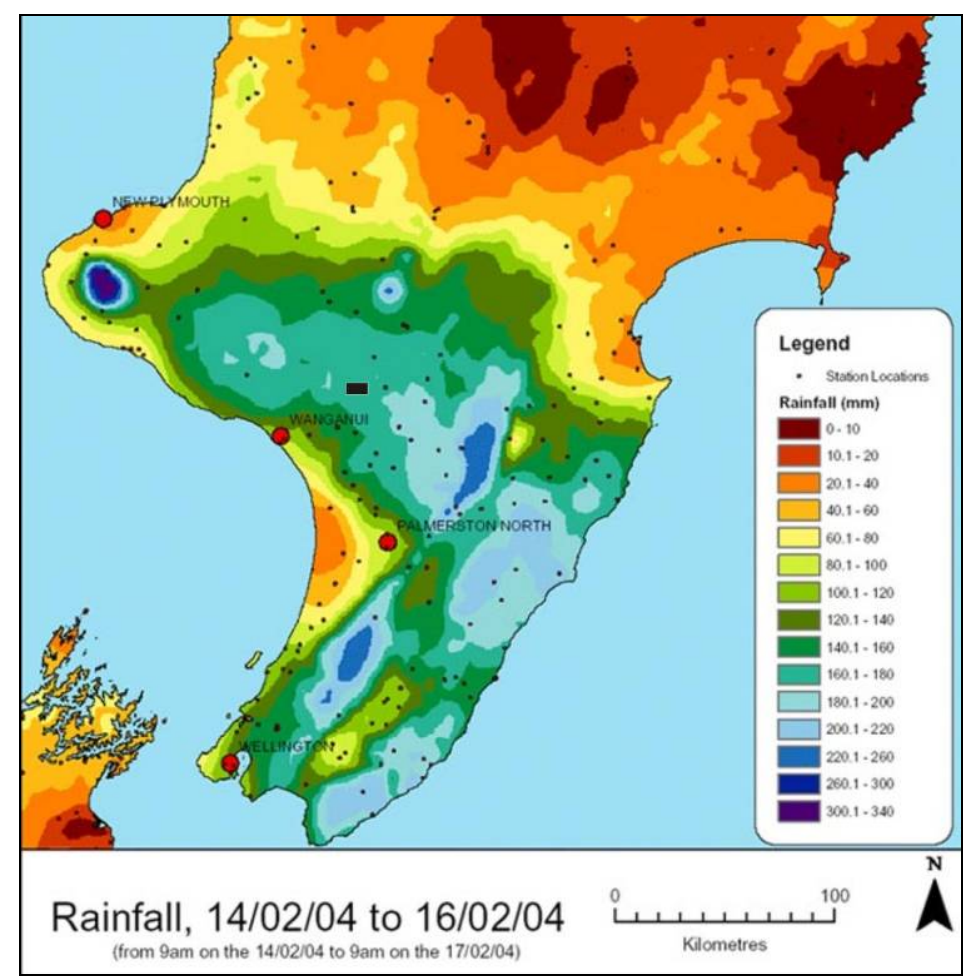

Figure 3-10 Rainfall for the duration of the February 2004 'weather bomb', the Mangawhero field study area is indicated by the black box northeast of Wanganui, from NIWA 2004 


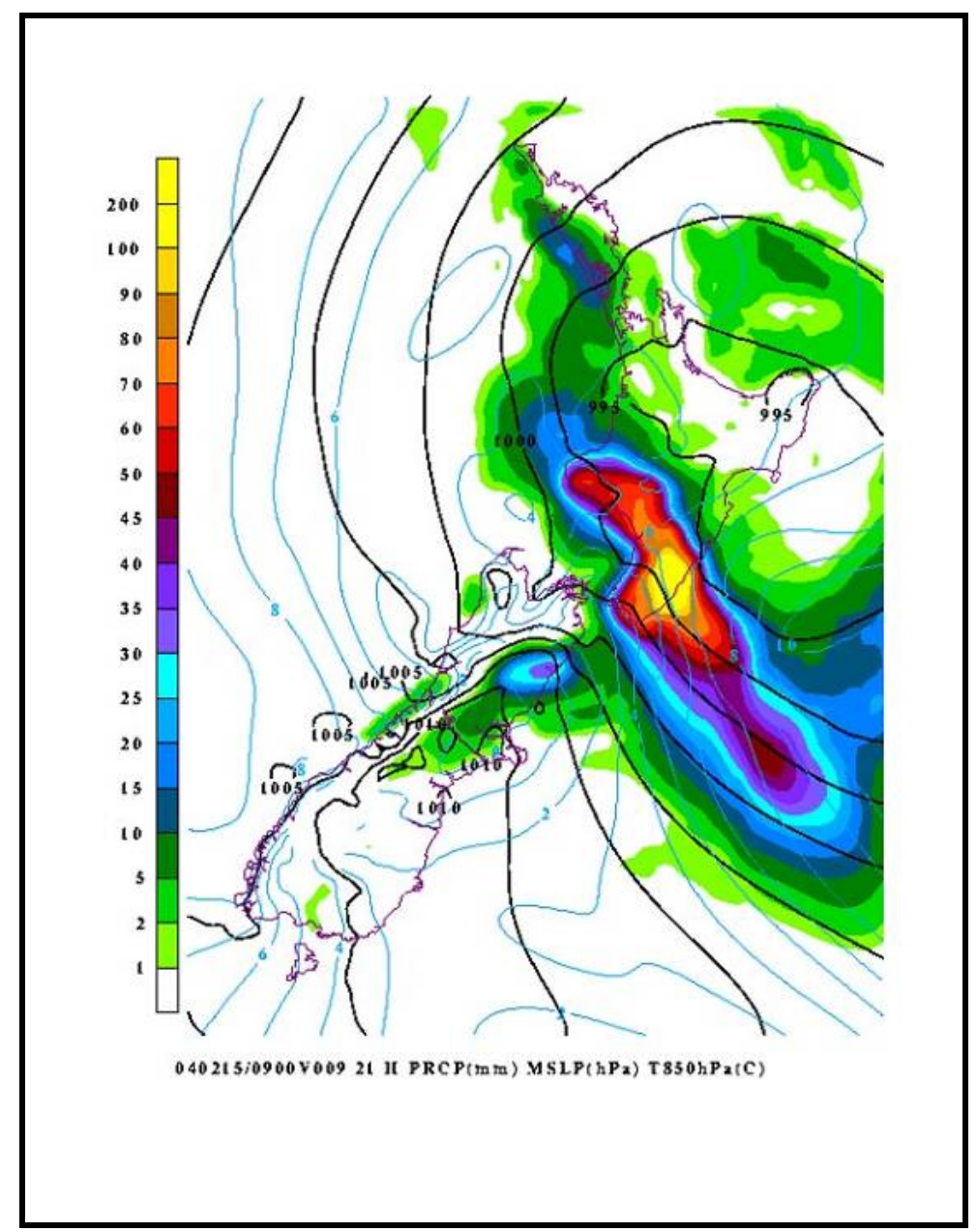

Figure 3-11 Isohyetal map of New Zealand showing peak rainfall distribution (mm) and atmospheric pressure isobars for the February $14^{\text {th }}-18^{\text {th }}$ storm event. The New Zealand isohyetal map shows the distinct northeast-southwest band of heavy rain that impacted the North Island of New Zealand. The concentrated stationary low pressure zone off the East Coast of the North Island prevented the rainfront from travelling eastwards and into the Pacific Ocean for two days, Source: NIWA, 2004

Rainfall was highest in the ranges of the southern North Island. Table 3-1 lists rainfall amounts recorded in the 24 hour period between $9 \mathrm{am}$ on the 15 th and $9 \mathrm{am}$ on the $16^{\text {th }}$ of February for some affected areas. From the figures it can be seen that hill country recordings (Mangawhero River, Waiouru) are considerably higher than those of lower altitude (Wanganui, Masterton).

Table 3-1 24-hour rainfall totals from 9am $15^{\text {th }}$ to $9 \mathrm{am} 16^{\text {th }}$ for lower North Island areas (all data from official Metservice stations unless marked*), adapted from Metservice 2004

\begin{tabular}{|c|c|c|c|c|c|l|}
\hline Location & Waiouru & Wanganui & Masterton & Mangawhero* & Wainuiomata* & $\begin{array}{l}\text { Karori }^{\star} \\
\text { (Wellington) }\end{array}$ \\
\hline $\begin{array}{c}\text { Rainfall } \\
(\mathbf{m m})\end{array}$ & 134 & 51 & 75.4 & 140 & 200 & 78 \\
\hline
\end{tabular}




\subsubsection{Field Site Rainfall Statistics}

A major part of this study focuses on a catchment in the Mangawhero River Valley, State Highway 4, on the Truebridge farm. Terrain and lithology are similar to that shown in Figure 3-13. Rainfall data collected by John Medlicott, the farm manager during the storm event is given for January and February in Table 3-2.

Table 3-2 Rainfall for January and February 2004, field study site Mangawhero River Valley, source Medlicott, 2004

\begin{tabular}{|l|c|c|}
\hline Date & Rainfall $(\mathrm{mm})$ \\
\hline Jan & 22 & 52 \\
\hline & 28 & 6 \\
\hline & 31 & 32 \\
\hline Feb & 3 & 10 \\
\hline & 6 & 18 \\
\hline & 12 & 20 \\
\hline & 15 & 25 \\
\hline & 16 & 140 \\
\hline & 17 & 28 \\
\hline & 18 & 32 \\
\hline
\end{tabular}

\subsection{The Damage}

For low-lying areas in the storm path flood inundation was the most common hazard experienced, and the most reported in the media. At least one house was swept away, and many others were irreparably damaged by floodwaters from overflowing rivers. Bridges loaded with flood-borne debris were washed out in several areas, cutting off access to affected areas and causing major economic losses for communities dependent on through-traffic for their livelihoods. Other roads and rail routes were blocked or disrupted by landslides; the Manawatu Gorge was closed for nearly three months due to a series of very large slips. One house in Karaka Bay Wellington was completely destroyed by a large slip, and several others in the Eastbourne and Stokes Valley areas were severely damaged by landslides (Figure 3-12 A-D). 


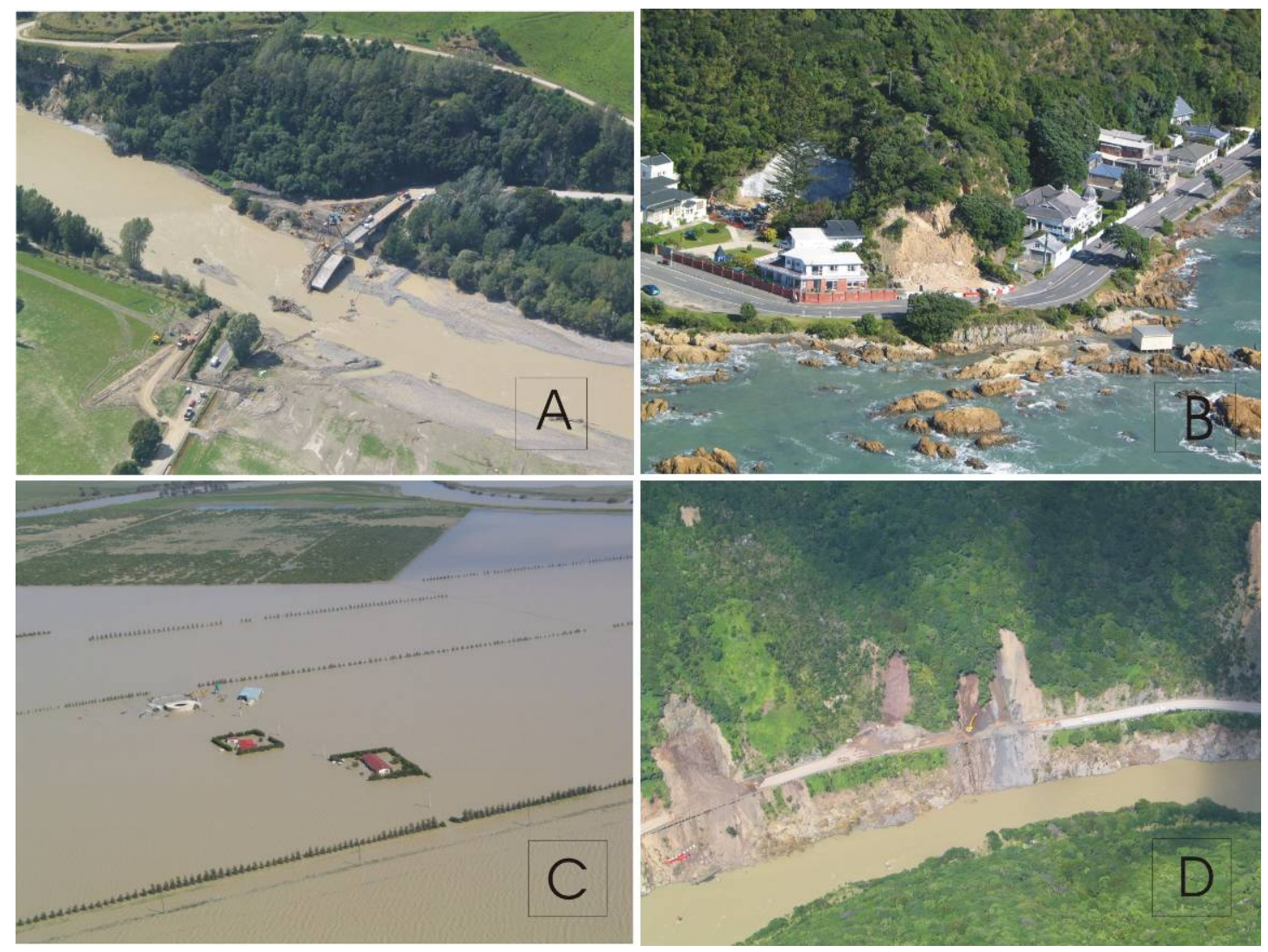

Figure 3-12 A -The Ashhurst Bridge east of Palmerston North, B - The Manawatu Gorge Road, the slip on the left failed again to encompass the brighter green area on the hill face, $\mathrm{C}$ - Houses on the Manawatu floodplain 10 days after the storm event. D - Karaka Bay slip site, the house has been removed after the landslide caused irreparable damage, houses nearby were protected by retaining walls, photographs Hancox 2004

At the end of February the economic losses reported from the storm event were estimated to be near to $\$ 300$ million (Hancox 2004). Severe and widespread landsliding occurred during the event in the Wanganui, Manawatu, and Wairarapa hill country (Figure 3-13). However, as these areas are sparsely populated and the effects were not immediately life threatening there was little recognition by the New Zealand news media of this damage.

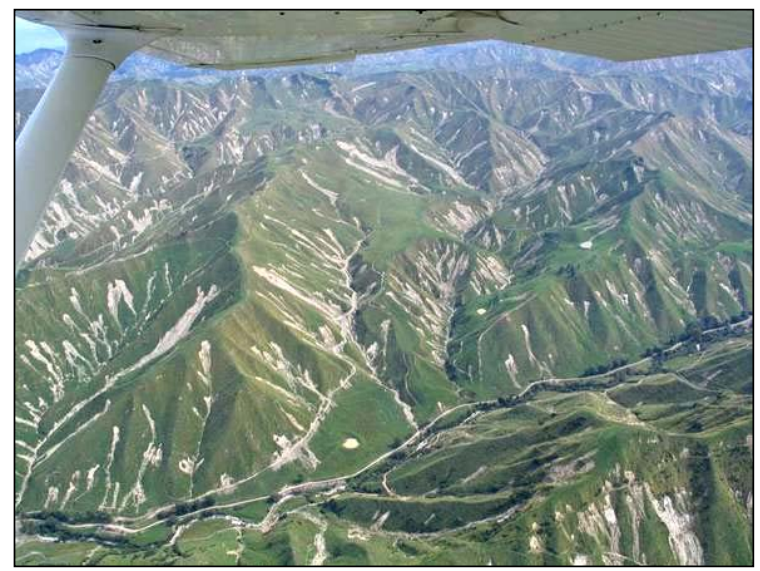

Figure 3-13 An example of the severe landslide damage resulting from the February storm event; the location is the Tertiary Mudstone (Papa) hill country north-east of Wanganui, photograph Hancox 2004 


\subsection{Summary}

The February 2004 'weather bomb' brought heavy rain to the lower half of the North Island, New Zealand, in a month that is usually the driest for the year in this part of the country. The intense rainfall resulted in widespread flooding of low-lying areas throughout the Wellington-Manawatu region, and widespread and severe landslide damage in the Wanganui-Manawatu hill country. As well as the direct effects of inundation of property and infrastructure damage, indirect costs from the event included: transport disruption; productivity losses; loss of access to local suppliers; and ongoing economic losses from lack of travellers (particularly for towns along State Highway 3, the Manawatu Gorge Road). A more detailed explanation of damage from the event is given in Chapter 4. 


\section{Overview of Landslide Damage}

\subsection{Introduction to Landslide Damage}

Landslide damage from the February 2004 storm ranged over an extensive area of approximately $16,000 \mathrm{~km}^{2}$ (Figure 4-1). Worst affected were the hill country of Wanganui, Manawatu $\left(\sim 8,000 \mathrm{~km}^{2}\right)$, the inland Wairarapa hill country $\left(\sim 7000 \mathrm{~km}^{2}\right)$, and some of the hills surrounding Wellington city and the Hutt Valley $\left(\sim 1000 \mathrm{~km}^{2}\right)$ (Hancox and Wright 2005a). An in-depth study of four of the most severely affected regions was undertaken by Hancox and Wright (2005b). Areas of extreme landslide damage (Mangawhero, Whangaehu, Turakina, and Pohangina) were identified from vertical aerial photographs, and within those areas sample areas were selected, depending on the characteristics being examined (e.g. vegetation effects on landsliding, landslide density) The nature of the terrain (slope angle, aspect, and form, geology and soil types, and vegetation cover) and the nature of landsliding (scar volumes, scar length to runout length ratios, fluvial coupling of landslides and river systems, damage ratios, and landslide density) were examined. The findings of this regional study are discussed in Chapter 8 , following the findings of the Mangawhero catchment-based study (Chapter 7).

Observed landslide types for this event included translational slides of varying depths and volumes, large deep-seated rotational slides, and earth flows. For the WanganuiManawatu study areas (Mangawhero, Whangaehu, and Turakina) landslide types present were controlled largely by underlying geology, and to a lesser degree by slope form (height and angle) (Hancox and Wright, 2005). The study identified that areas of Pliocene age rocks dominated by sedimentary mudstones and relatively hard sandstones were susceptible to both deep-seated rotational slides and translational slides of varying depths and volumes. The Manawatu study area (Pohangina) in younger Pleistocene sediments of weakly compacted sandstone, gravels and pumice layers, exhibited shallow translational landsliding only. The areas also differed in topographic form with the Wanganui study areas comprised of steeply dissected, often rectilinear, slopes of high elevation and longer slope profile than the slopes of the Manawatu study area which are at lower elevations, and have a shorter profile and more rounded form (Hancox and Wright 2005). 


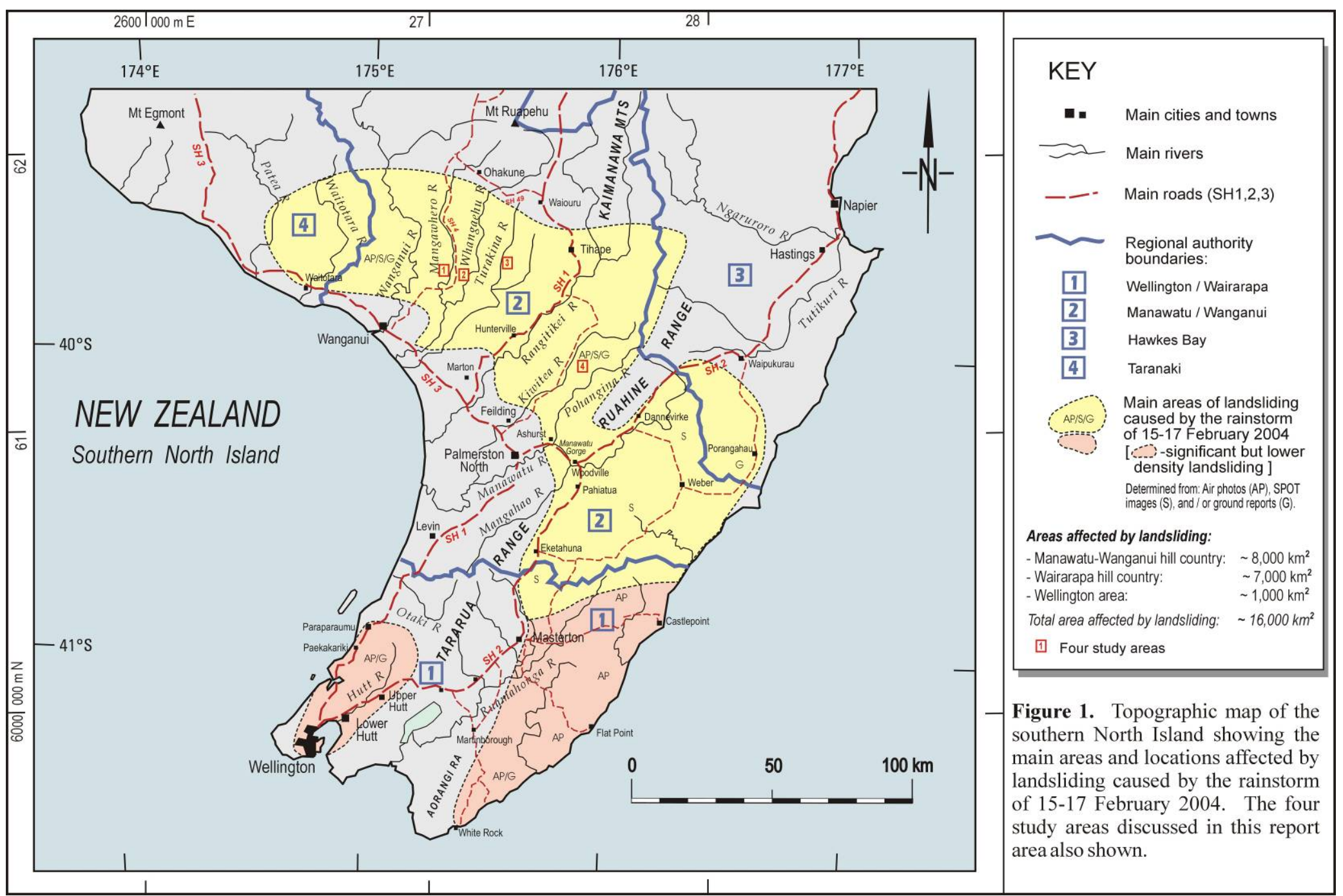

Figure 4-1 Regional boundaries, range of landslide damage, and the location of the four study areas examined in this thesis, from Hancox and Wright 2005a 


\subsection{Rainfall and Landslide Distribution}

Landsliding is one type of geomorphic response to a trigger, or forcing factor (Crozier and Glade 1999). In the case of the February 2004 storm event, the trigger was intense rainfall over a three day period producing saturated slopes. During this storm, rainfall was estimated to have return periods of up to 150 years in the storm centre, and between 100 to 150 year return periods were estimated for areas of most severe landslide damage including the areas under study in Chapter 7 "Methodology and results" (Horizons Regional Council 2004). Figure 4-2 adapted from Landcare Research's summary map of landsliding as detected by SPOT satellite imagery relates rainfall contours to landsliding density.

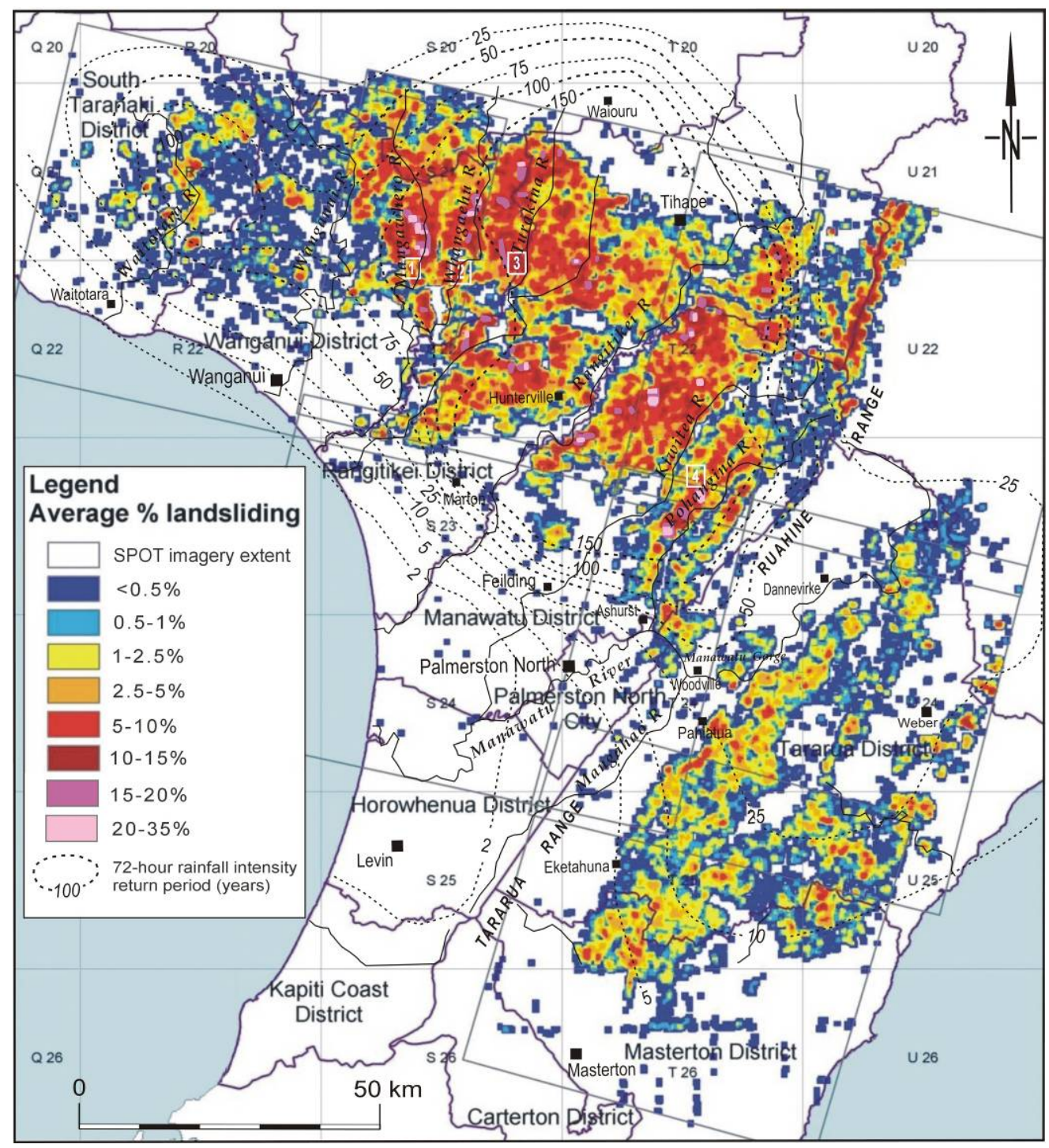

Figure 4-2 Landcare research map showing rainfall intensity for 72 hour period and landslide density as recorded by satellite SPOT imagery, from Dymond et al. 2004 
The rainfall data are understandably generalised to produce average contours, however data collected within the catchment-based study area (see Chapter 7) by local farmers suggests isolated pockets of slightly higher (but consistent with) rainfall amounts than those shown by the contours in Figure 4-2. For example, in the Mangawhero region a total of $193 \mathrm{~mm}$ for the three day period was recorded at one farm with $140 \mathrm{~mm}$ recorded on 16 February responsible for one very large landslide (pers. comm., John Medlicott 2004). These extreme rainfall conditions produced severe and widespread landsliding throughout the Wanganui-Manawatu region generally consistent with the rainfall distribution, and also vegetation and land use (Hancox, 2004; Dymond et. al., 2004; Hancox and Wright, 2005). However, since regional variations in landsliding response cannot be attributed entirely to variance in rainfall or unreservedly to variance in rainfall or vegetation, an examination some of the worst affected areas was undertaken to see if terrain characteristics (for example, rock and soil types, slope angle and aspect) were responsible or contributed to differences in landslide density and damage (Hancox and Wright 2005b). The total number of landslides from the event is estimated to be at least 70,000 (Hancox and Wright 2005a).

\subsection{Immediate Response to Landsliding Damage}

The Wellington region was surveyed by ground reconnaissance of reported landslides, during which NZ MS260 map series grid locations for individual landslides were recorded, as well as information on any structural damage resulting from landslide activity, landslide material type (colluvium, bedrock, regolith), and volume. This information collected by N. Perrin of the Institute of Geological and Nuclear Sciences (IGNS) and K. Wright (summer student under contract to IGNS) was added to the New Zealand large landslide database. Although landslide damage in the Wellington Region was generally more damaging in terms of people immediately affected (for example one dwelling at Karaka Bay had to be demolished following a bedrock failure, other dwellings were threatened or partially damaged, and many roads were blocked), the density of landsliding was far lower than for the hill country of the Wairarapa, Manawatu, and Wanganui regions. Reports of severe landsliding from landowners in the Waitotara (North Wanganui), Taihape (Northeast Wanganui), and Pohangina (Manawatu) regions suggested widespread and intense landslide damage worthy of aerial investigation. 
During five days (late February and early March. 2004) of aerial reconnaissance by G. Hancox (IGNS) and K. Wright (IGNS contracted summer student) of the Wanganui Manawatu hill country, hundreds of oblique aerial photographs were taken by G. Hancox. This reconnaissance identified severe and widespread damage over much of the agricultural hill country in these regions. In response to immediate reports on the damage by Hancox et al. 2004, local members of Federated Farmers and also Regional Council workers, Government agencies and local bodies (Ministry of Civil Defence and Emergency Management, Horizons Regional Council) commissioned vertical aerial photograph runs and SPOT satellite imagery of the affected areas. These images complemented those taken by G. Hancox, and assisted with identification of areas of most severe damage (e.g. greatest landslide scar areas and volumes, highest density).

Aerial reconnaissance of the landslide damage from this event provided the impetus for this study. The field study catchment selected in the Mangawhero River Valley hill country contained a particularly large and eye-catching landslide, informally dubbed "the Octopus". This intriguing landslide occurred in a manageable sized catchment $\left(0.7 \mathrm{~km}^{2}\right)$ containing over 25 landslides of varying volumes, types, and positions on hillslopes. This catchment was chosen to carry out field analysis of the February 2004 landslide event (see Chapters 6 and Chapter 7).

\subsection{Landslide Types}

As mentioned in Section 4.1, varying types of landslides resulted from the February 2004 storm event. The dominant types for this event are translational slides, rotational slides (slumps) and earthflows. Many slides exhibited a more complex form in that they may have a landslide scar in the form of a rotational or translational slide but the runout material has become liquefied and formed an earthflow. Thus many of the landslides would be classified by Varnes (1975) as rapid earthflows.

The basic landslide types may be further separated into classes depending on which landslide characteristic is being examined. Translational slides can be further categorised into multiple-headed (common particularly in the Pohangina hill country) or single-headed slides. Slides can also be grouped by fluvial coupling (whether some 
part of the landslide connects with the fluvial drainage network). Another method of differentiating landslides is by slope position, whether they occur on the (generally drier) upper part of a slope, the mid-slope or the lower part of the slope. In some areas landslides appear to coincide with drainage channel networks and runout material curves around and down hillslopes; in others landslides appear to travel directly downslope with no apparent influence from hillslope drainage channels. Slides can also be described by volume or area. Examination and comparison of landslides for four severely affected areas based on some of these characteristics is the basis of the regional landslide analysis in Chapter 7 "Methodology and Results". For the catchment-based field study landslide type, material, volume, fluvial coupling and position on slope were recorded for each slip. Example of different landslides types and characteristics are shown in Figure 4-3 to Figure 4-9.

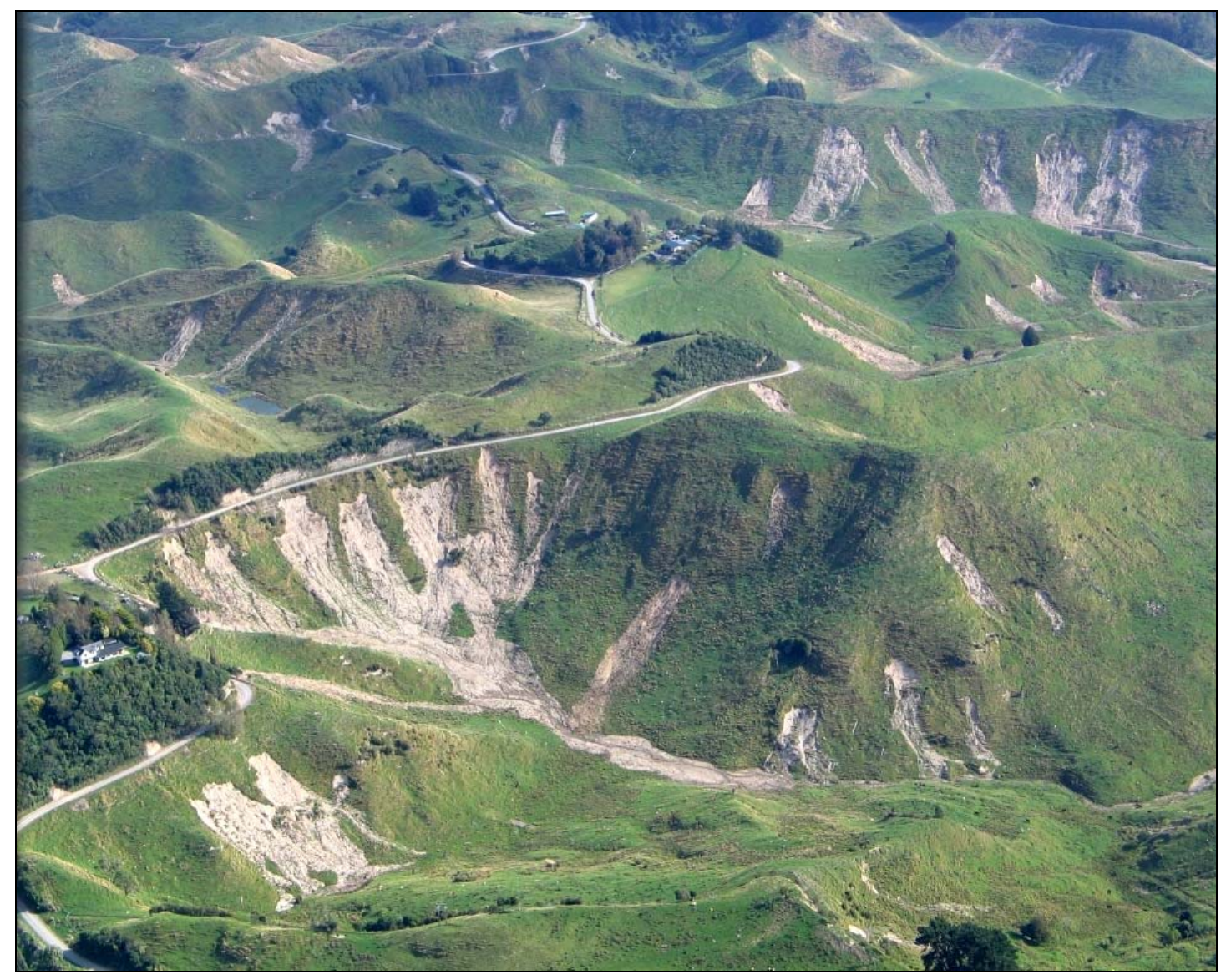

Figure 4-3 Large, multiple-headed translational landslide/earthflow in mudstone (from ridge road), and single-headed translational slides in mudstone (background) near Taihape; in the left foreground is a rotational slump with debris mostly in situ, photograph Hancox 2004 


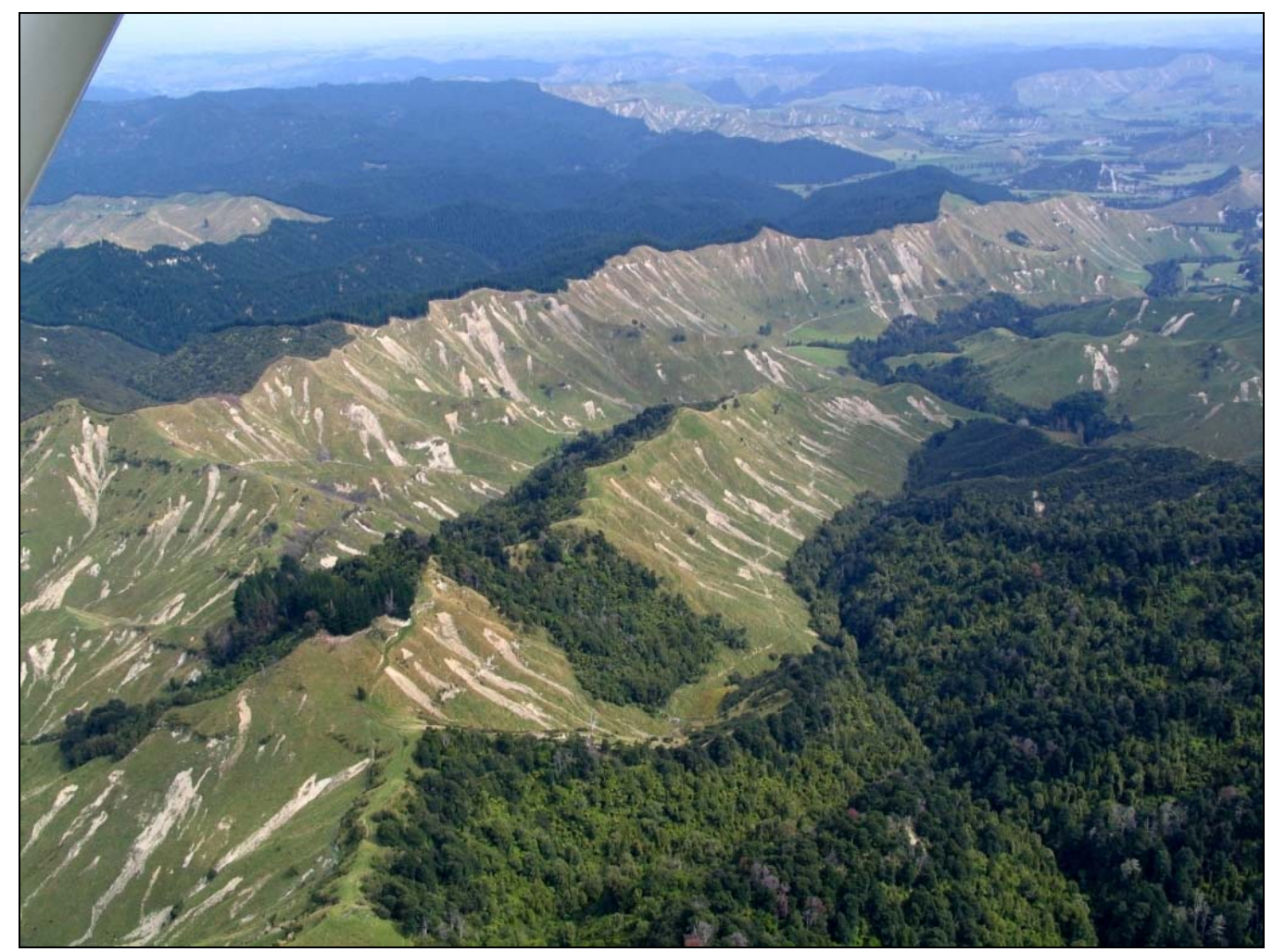

Figure 4-4 Shallow translational sliding mostly from the upper part of the slope, landsliding does not appear to follow drainage channels, photograph Hancox 2004

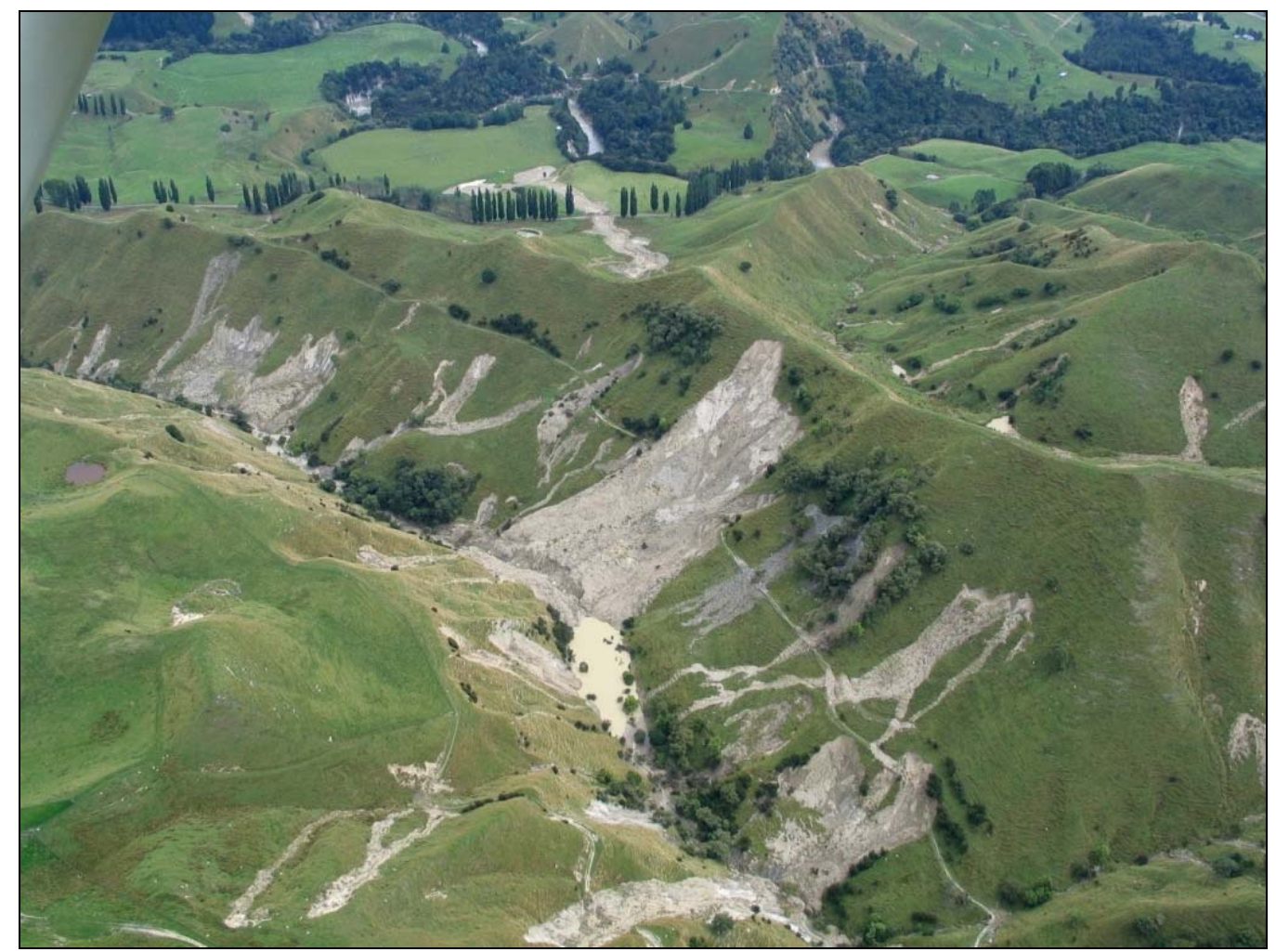

Figure 4-5 Rotational slide forming a landslide dam and small lake in the lower Turakina River hill country; the underlying geology is mudstone, photograph Hancox 2004 


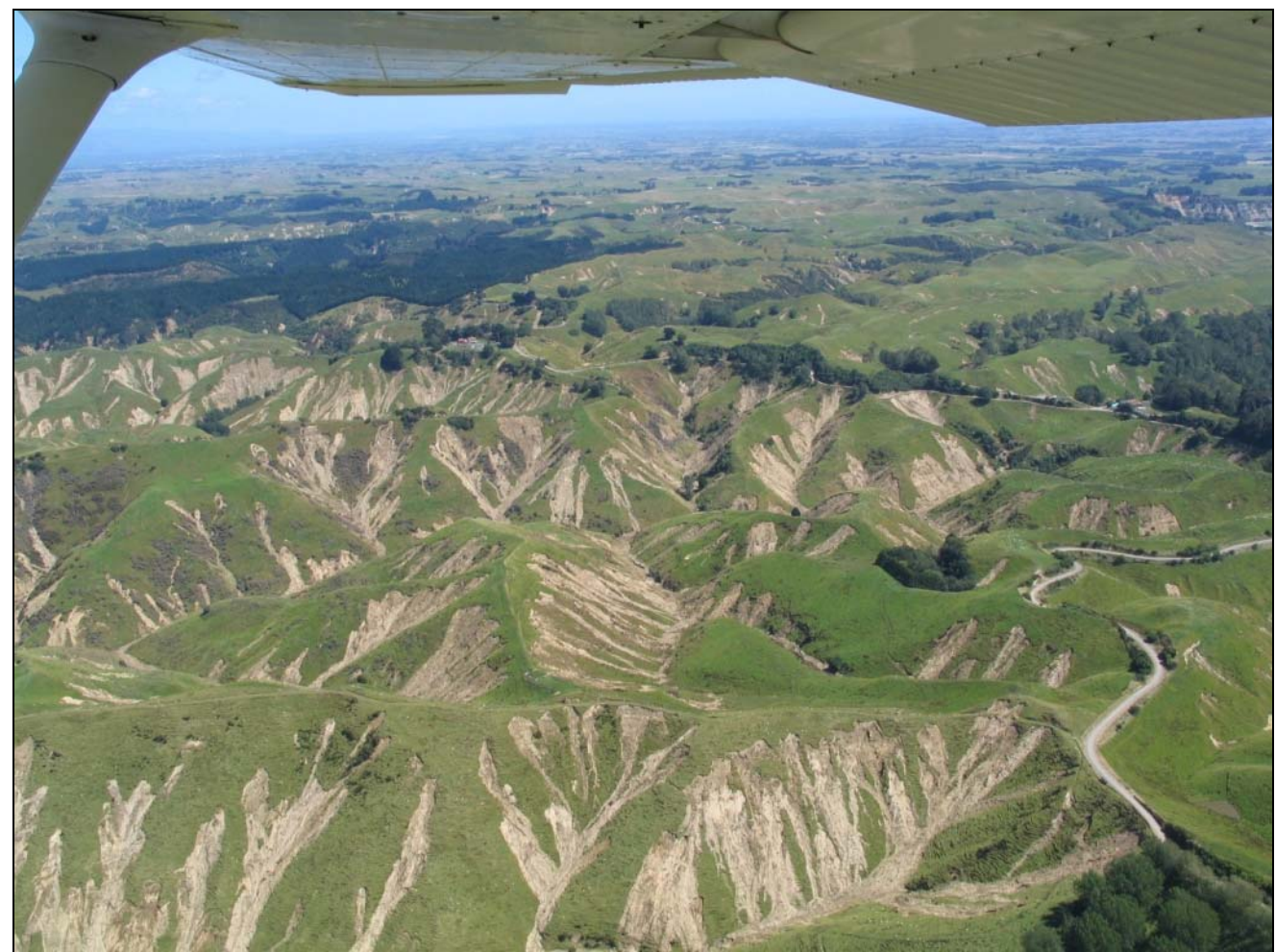

Figure 4-6 Shallow, translational, multiple-headed landslides in the Pohangina hill country. The underlying geology is weak sandstone with interbedding of pumice and gravels, photograph Hancox 2004

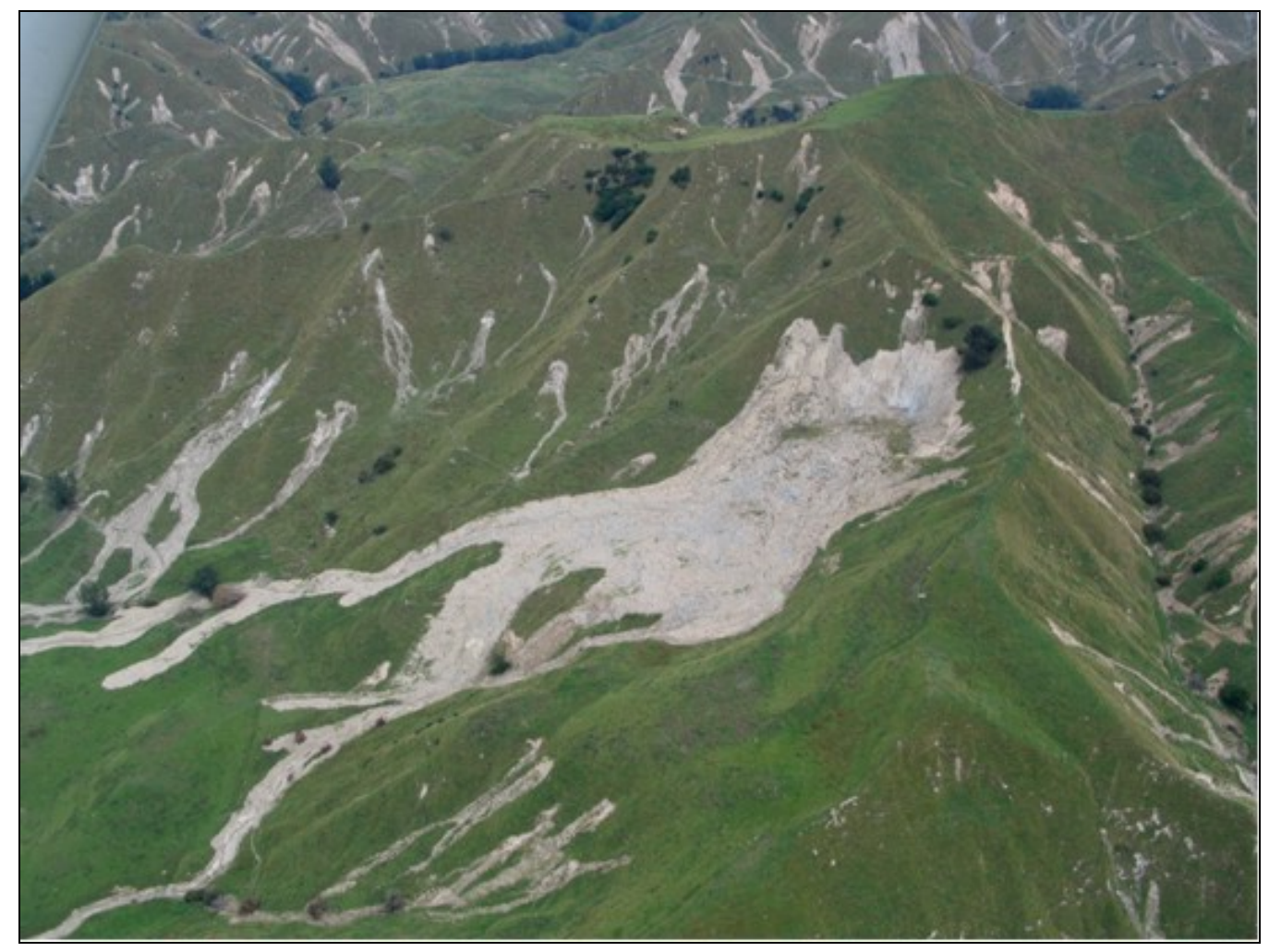

Figure 4-7 The "Octopus" landslide, a very large rotational slide and earthflow formed in area of dense landsliding in mudstone in the Mangawhero hill country, photograph Hancox 2004 


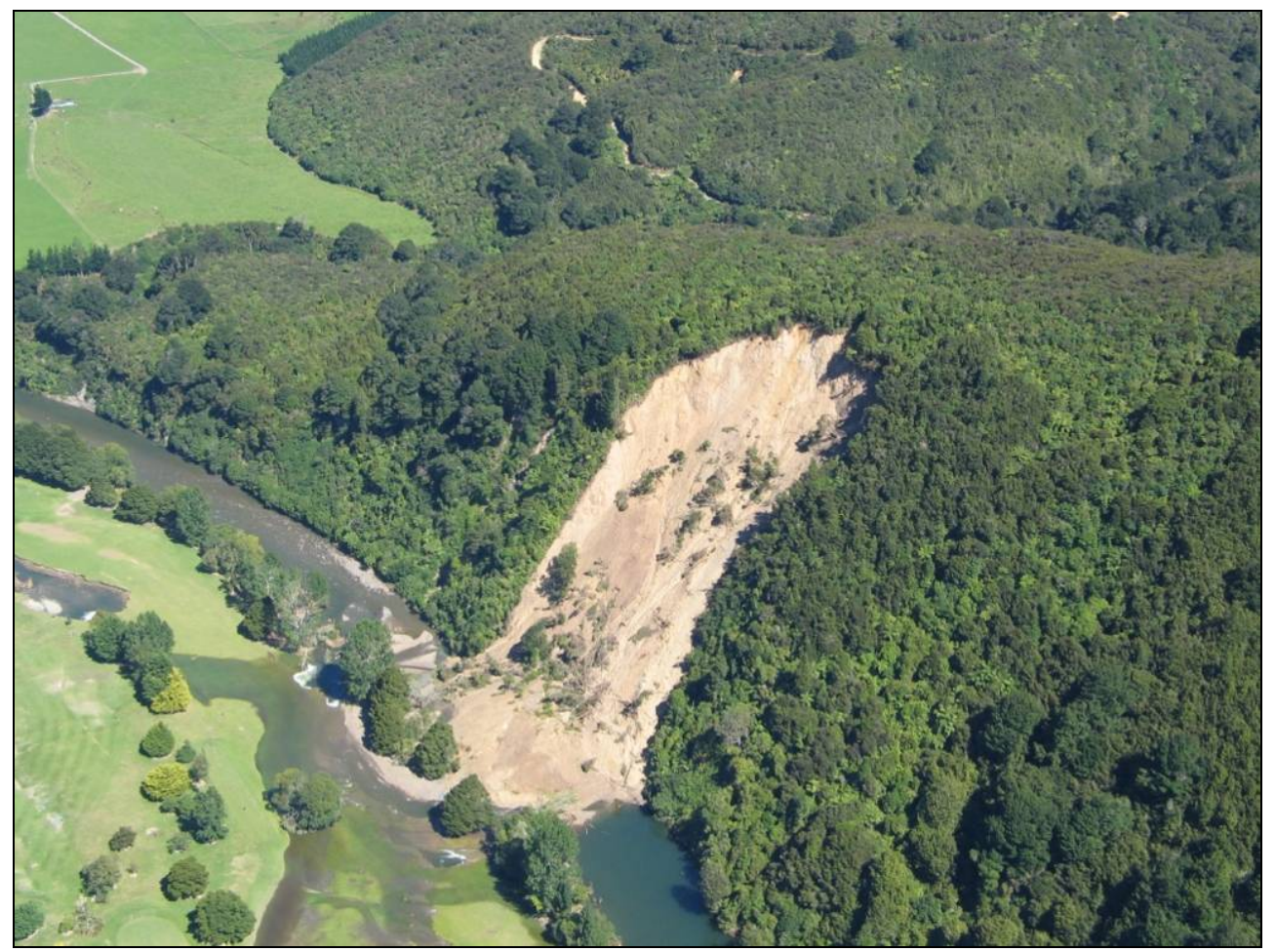

Figure 4-8 The largest landslide in the Wellington region which temporarily diverted the Hutt River through a golf course; this translational landslide is formed in greywacke bedrock, photograph Hancox 2004

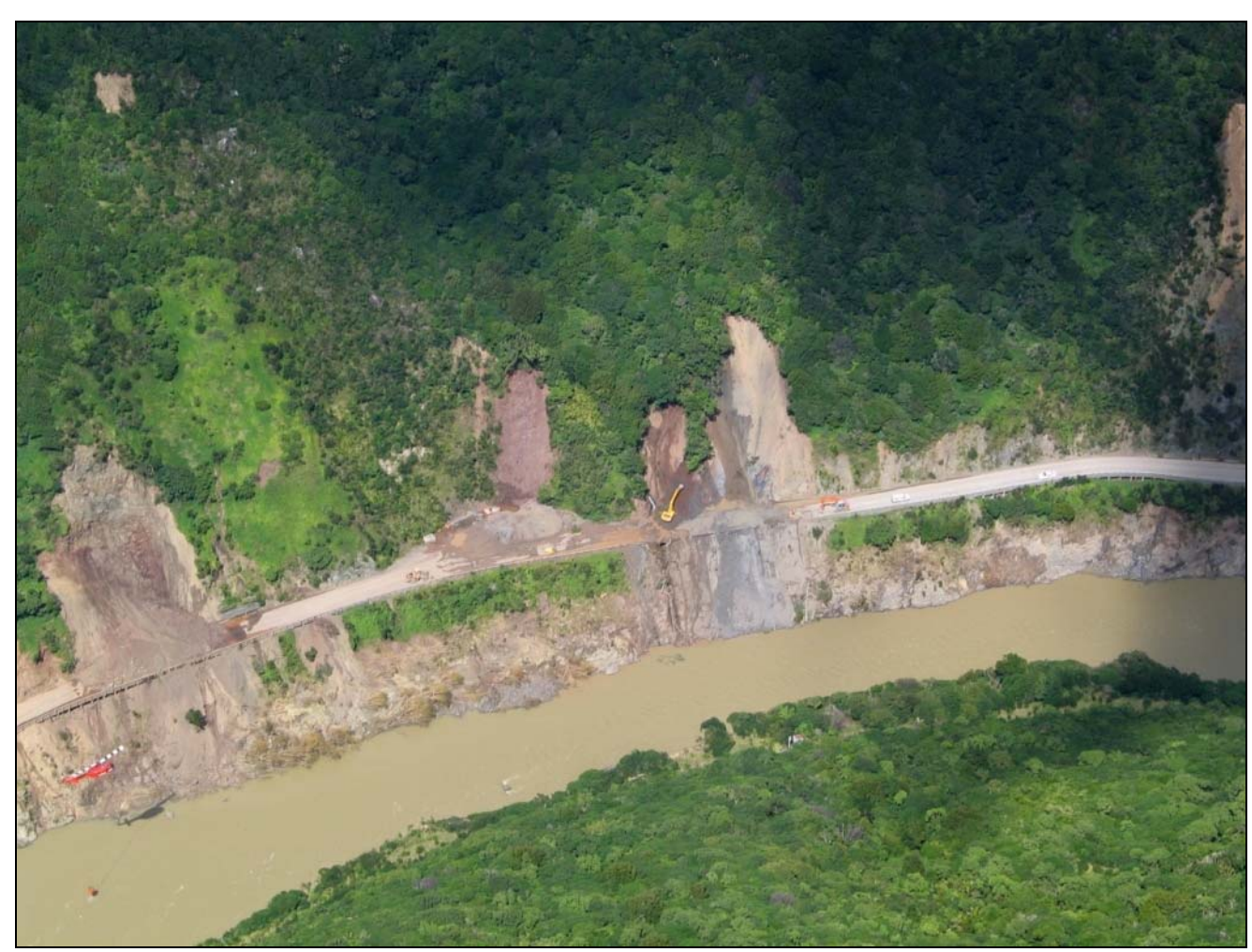

Figure 4-9 Large greywacke bedrock landslides in the Manawatu Gorge; the gorge road (State Highway 3) was closed for two months, photograph Hancox 2004 


\subsection{Summary}

Landsliding from the February 2004 storm ranged over a large area of the southern North Island. Worst affected were the hills of Wanganui, Manawatu, and Wairarapa regions, with isolated landsliding in parts of Wellington region also. The extent of landsliding is estimated at $16,000 \mathrm{~km}^{2}$, with at least 70,000 landslides being identified from SPOT image mapping of the event. From aerial reconnaissance it could be seen that the majority of landslides consisted of shallow translational regolith failures, however deep seated rotational landslides and landslide dammed lakes were also seen. Many landslides were seen to form extensive earthflow runout lobes. Through examination of vertical aerial photographs and air reconnaissance areas of detailed investigation were selected. A catchment was selected for field study of the event (Mangawhero area) and four larger areas of severe damage chosen for regional comparisons of terrain and landsliding relationships (Mangawhero, Whangaehu, Turakina and Pohangina). 


\section{Regional Characteristics of the Study Catchment}

\subsection{Location}

The study catchment is located in the Wanganui Region, which lies on the western side of the North Island of New Zealand (Figure 5-1). Main topographic features of the region are: the Ruahine ranges to the East; and the volcanoes, Ruapehu, Ngauruhoe, and Tongariro to the north. The northwestern boundary of Wanganui region is dominated by Mt. Taranaki, also volcanic. The Wanganui Basin is a lowlying area surrounded by these mountains; the north and eastern margins of the Basin have been compressed into steeply dissected hill country through tectonic uplift.

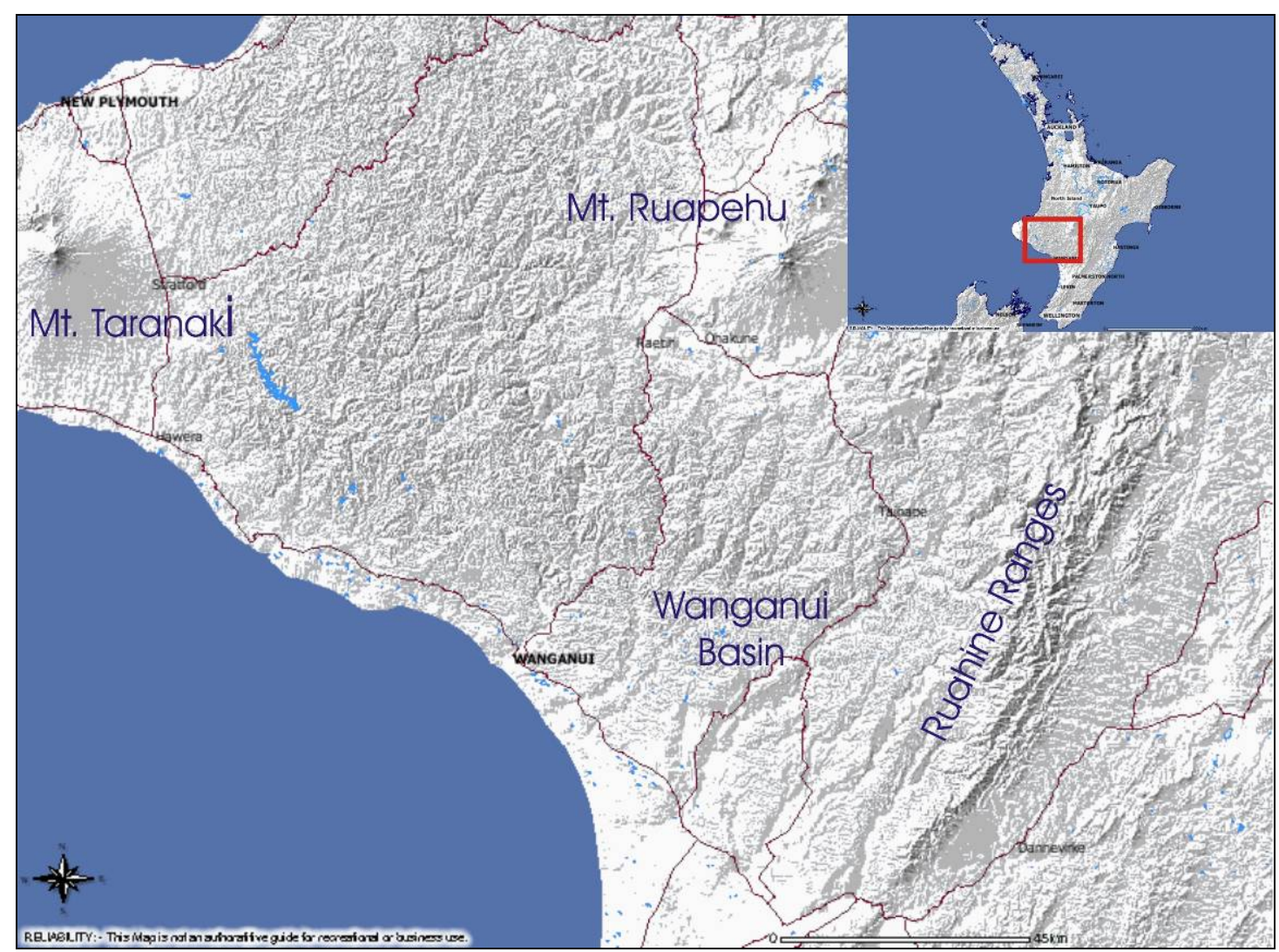

Figure 5-1 Map of the Wanganui region in context of position within the North Island (inset); main topographic features are identified, adapted from DOC 2004

\subsection{Underlying Geology}

The hill country east of Wanganui is comprised of Upper Tertiary and Lower Quaternary marine mudstones, sandstones and minor limestone deposits (Fleming 1953). Sedimentary rocks such as sandstones and mudstones are formed during the deposition of medium (sandstone) or fine (mudstone) grained marine or fluvial sediments. As the sediments are laid down the weight of overlying sediment deposits 
creates compaction on layers below until moisture is forced from the layers and the sediment is consolidated into rock (Walton 1993, Press and Seiver 2000). During periods of inundation and retreat of marine or lacustrine bodies, sedimentation rates vary and layers of differing thicknesses and organic content (carbonates) are produced. From the stratigraphic fossil record, ages of different layers can be found. From the thickness and sediment type of layers (Groups and Series), deposition conditions such as availability of material, climate and volcanic input can be determined. Ages and types of sediments in the Wanganui Region have been extensively studied and identified, as the downwarping, deposition and uplift processes occurring in the Wanganui Basin have left an excellent record (Fleming 1953). The Wanganui Basin is defined as the entire Tertiary basin east of the Taranaki Fault, from Te Kuiti in the north to Palmerston North in the south (Collen 1977).

The location of the Gravity Anomaly that created the conditions for downwarping of the basin area is shown in Figure 5-2. The geoid (actual earth surface including surface of the ocean) is not uniform, exhibiting positive and negative anomalies, which produce geographic features on land and variation in sea level around the world.

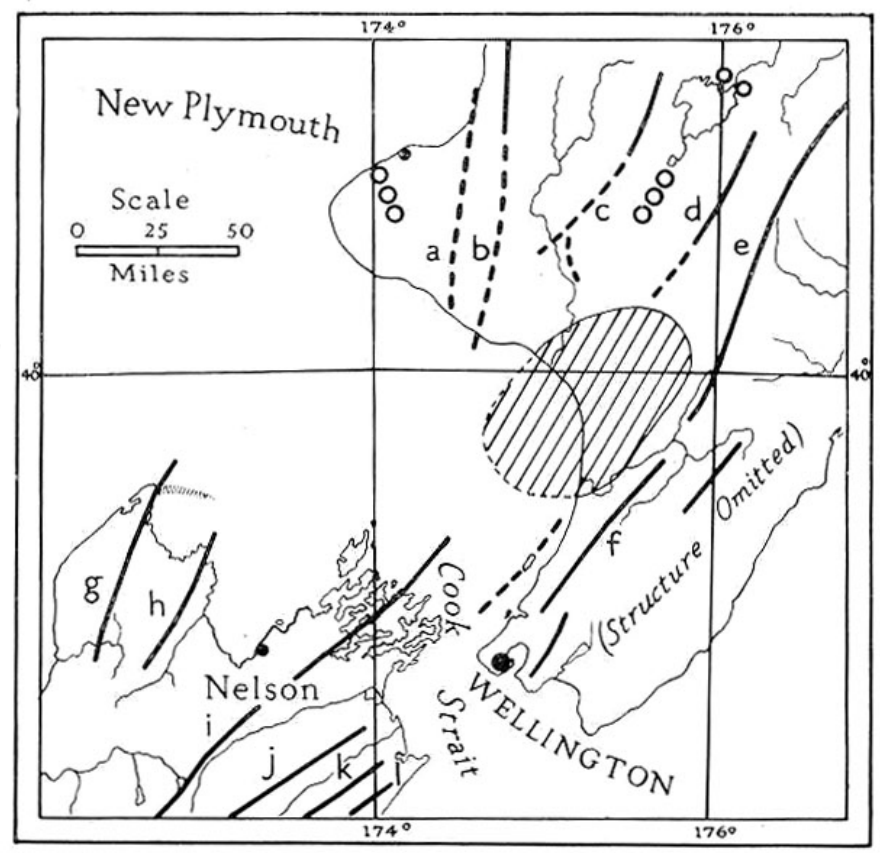

Figure 5-2 Gravity Anomaly (shaded) that produced the Wanganui Basin; circles are volcanoes, lines are major and minor (broken lines) anticlinal structures, from Fleming, 1953 
Tertiary sedimentary deposits fill the geosynclinal Wanganui Basin (Figure 5-3). During the Wanganui Series three stages of deposition occurred; the oldest sediments, the Waitotaran stage of the Wanganui series, were laid down during the early part of the Pliocene Epoch. The second depositional stage is the Nukumaru stage, and the third and younger sedimentary stage is the Castlecliffian. During Pliocene times the Wanganui Basin experienced intermittent geosynclinal sinking and marine infilling of the basin occurred (Fleming 1953).

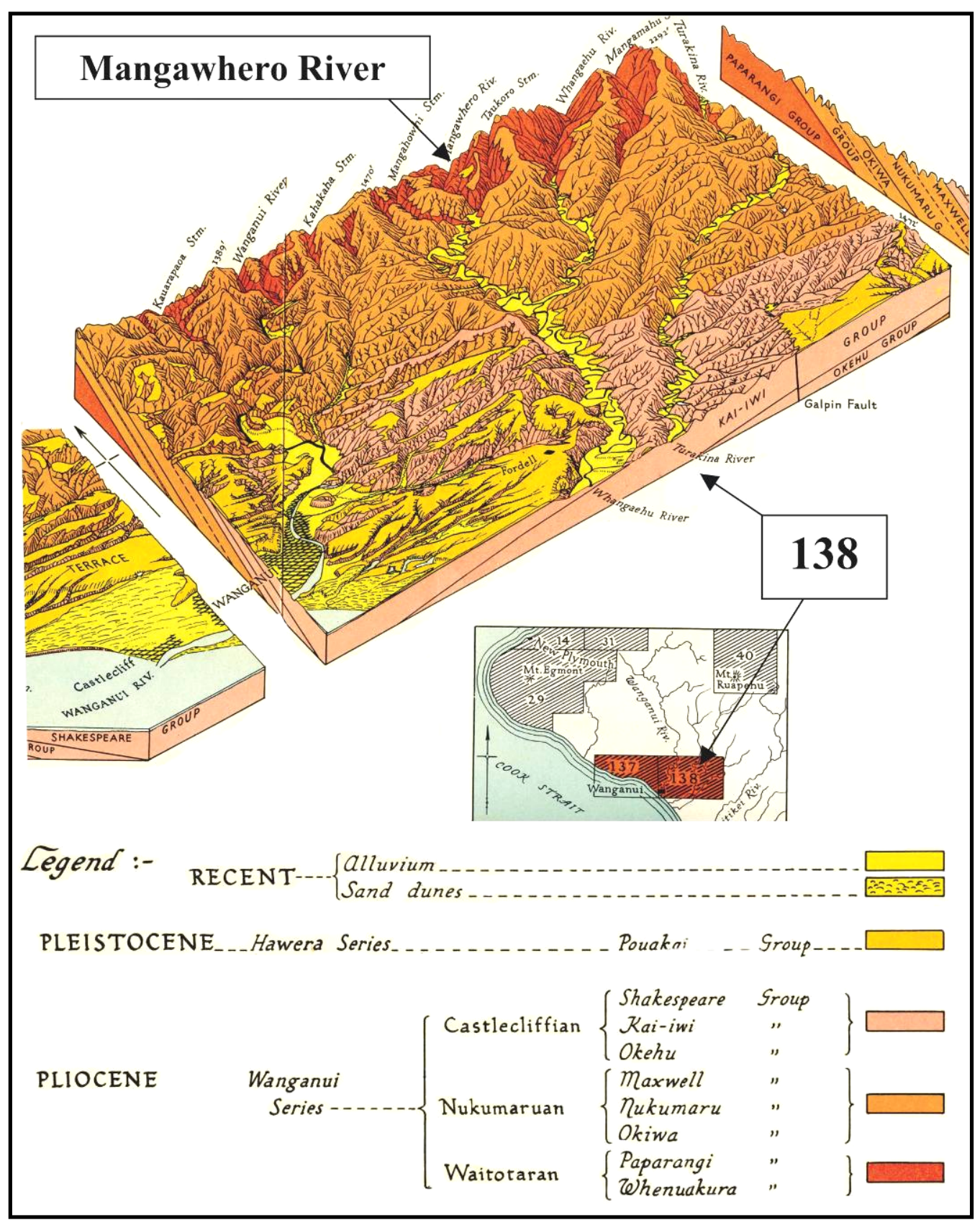

Figure 5-3 Wanganui Subdivision, showing Series and Groups, adapted from Fleming, 1953 
During the early part of the Wanganui Epoch, the Waitotaran Age, sediments were thickly laid down, partly sourced from older tertiary Rocks from north Taranaki and partly from granite rocks thought to be an extension of the Tasman Range - Cape Farewell anticline (Fleming 1953). The Waitotaran deposits show little input from volcanic sources, though rhyolitic eruptions had occurred in the Central Volcanic Zone prior to this deposition period. As a result of uplift and erosion process (see also Section 5.3) exposed sediments are progressively younger towards the west. The Basin formed as sedimentation occurred in an eastward direction from the central North Island direction during Pliocene-Early Quaternary time (Fleming 1978). Anticlinal basement rocks separated the Hawkes Bay-Wairarapa Sea from the western Taranaki Seas; these basement rocks are at the centre of the Wanganui Basin today (Figure 5-4). The sea transgressed this anticline during Pliocene times, and the Wanganui-Manawatu region became differentiated between an area of uplift in the east (Ruahine and Tararua anticlines) and an area of subsidence in the west; the Wanganui Basin. The Tararua and Ruahine ranges are comprised of Mesozoic sediments, which began to emerge in the Pliocene through geosynclinal processes. Thereafter these anticlinal structures influenced sedimentation in the Wanganui Basin by providing the eastern boundary of marine transgression (Collen 1977).

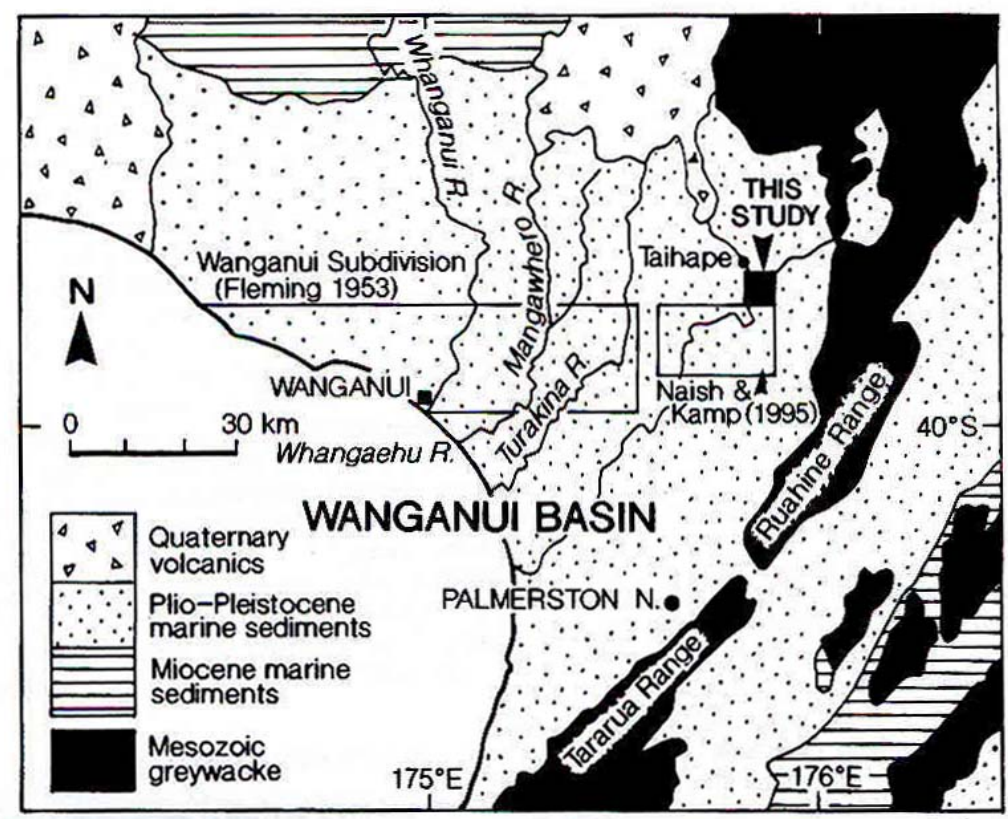

Figure 5-4 Journeaux et al.'s 1996 study area and the major geological units of the Wanganui region, from Journeaux et al. 1996 
The rising areas had uplifted to the point of no marine transgression by the midQuaternary (Fleming 1978). During the deposition of sediments that were to form Mangaweka Mudstone and Paparangi Sandstone units, the coast probably extended as far north as Taihape and as far south as Palmerston North (Fleming, 1953). The Wanganui basin is the largest area of Plio-Quaternary sedimentation in New Zealand (Collen 1977). The Basin is comprised of a thick succession of Pliocene and Pleistocene terrigenous sediments up to $5 \mathrm{~km}$ thick. The older (Pliocene) strata are exposed in belts orientated east-west along the northern margin of the basin (Journeaux et al. 1996). In the eastern extremes of sediment deposition, at the base of the Ruahine Range, sediments contained more limestone and shell deposits indicating the presence of the shoreline during this time. The Mangaweka Mudstone sediments were deposited and consolidated at considerable depth offshore, while Paparangi Sandstone formed in shallower eastern waters. Eleven major cycles of deposition have been identified by Journeaux et al. (1996) as contributing to the Mangaweka Mudstone formation. The Mudstone unit was first described as "the Mangaweka Horizon" in the 1943 Superior Oil Company's "Geology of Palmerston North and Wanganui Basin" (Figure 5-5). This report was the first significant reference to the geology of the Utiku and Mangaweka region (Journeaux et al. 1996). The younger coastal deposits form the Castlecliffian unit and are not present in the inland regions of Mangaweka and Utiku (see Figure 5-3). The name Mangaweka Mudstone applies to all strata between the upper contact of the Utiku Group and the basal contact of the younger, Rangitikei Group (Journeaux et al. 1996).

Journeaux et al. (1996) re-defined the Mangaweka Mudstone unit into 11 identifiable sedimentary cycles. The lower four sand-dominated cycles belong to the Utiku Group, the upper seven silt-dominated cycles form the Paparangi Group. A stratigraphic column of the top seven cycles is shown in Figure 5-6. The Mudstone formation comprises a basal sandstone member, two tephra members, and the massive siltstone member (Journeaux et al. 1996). The sediments of the Wanganui Basin exhibit subdued folding. Within the Basin strata get progressively younger towards the south, with the older northern rocks more homogeneous and massive. The Mangaweka Mudstone unit underlies the majority of the hill country affected during the February 2004 event. Failures occurred infrequently in the bedrock layer but these failures were significant in size and effects (e.g. landslide dam formation). Regolith failures were 
more frequent but as can be seen from later sections in this chapter, and in more detail in Chapter Eight, the nature of underlying bedrock material has a strong control on regolith and soil in the Wanganui-Manawatu hill country so is of considerable importance when examining landslide behaviour in these areas.

\begin{tabular}{|c|c|c|c|c|c|c|c|}
\hline \multicolumn{2}{|c|}{$\begin{array}{c}\text { SUPERIOR OIL COMPANY } \\
\text { OF N.Z. (1943) }\end{array}$} & \multicolumn{2}{|r|}{ TE PUNGA } & \multicolumn{2}{|c|}{$\begin{array}{c}\text { FLEMING (1953) } \\
\text { WANGANUI SUBDIV. } \\
\text { (east) }\end{array}$} & \multicolumn{2}{|c|}{$\begin{array}{l}\text { JOURNEAUX et al. } \\
\qquad 1996\end{array}$} \\
\hline 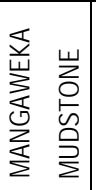 & Mangamahu Horizon & & $\begin{array}{l}\text { Mangaweka Concretionary } \\
\text { Mudstone }\end{array}$ & 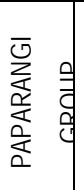 & $\begin{array}{l}\text { Mangaweka } \\
\text { Mudstone }\end{array}$ & 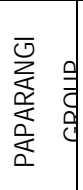 & $\begin{array}{l}\text { Mangaweka } \\
\text { Mudstone }\end{array}$ \\
\hline 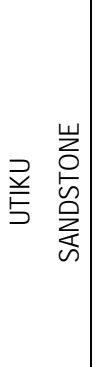 & $\begin{array}{l}\text { Conglomeritic Limestone } \\
\text { Upper Concretionary } \\
\text { Sand } \\
\text { Silty Mudstone } \\
\text { Lower Concretionary } \\
\text { Sand }\end{array}$ & 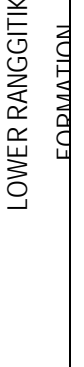 & $\begin{array}{l}\text { Hautapu Shell Limestone } \\
\text { Concretionary Mudstone }\end{array}$ & 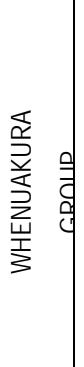 & & 站學 & $\begin{array}{l}\text { Manui Formation } \\
\text { Kawhatau } \\
\text { Formation } \\
\text { Tarere Formation }\end{array}$ \\
\hline
\end{tabular}

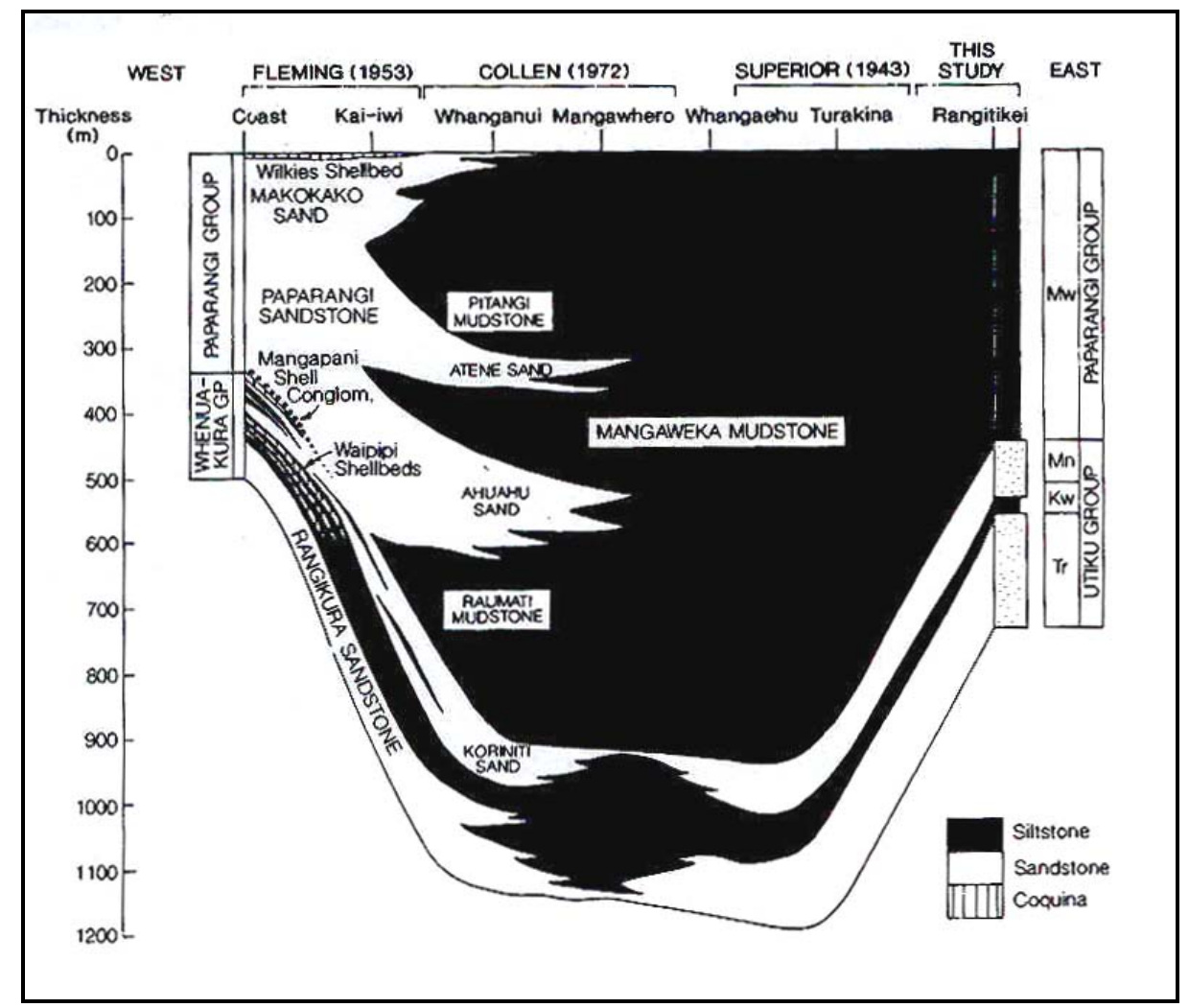

Figure 5-5 (a) The historical study and identification of Wanganui Basin sediments, adapted from Journeaux et al. 1996, and (b) areas of study in the Wanganui Basin shown by west-east cross-section from Journeaux et al. 1996 


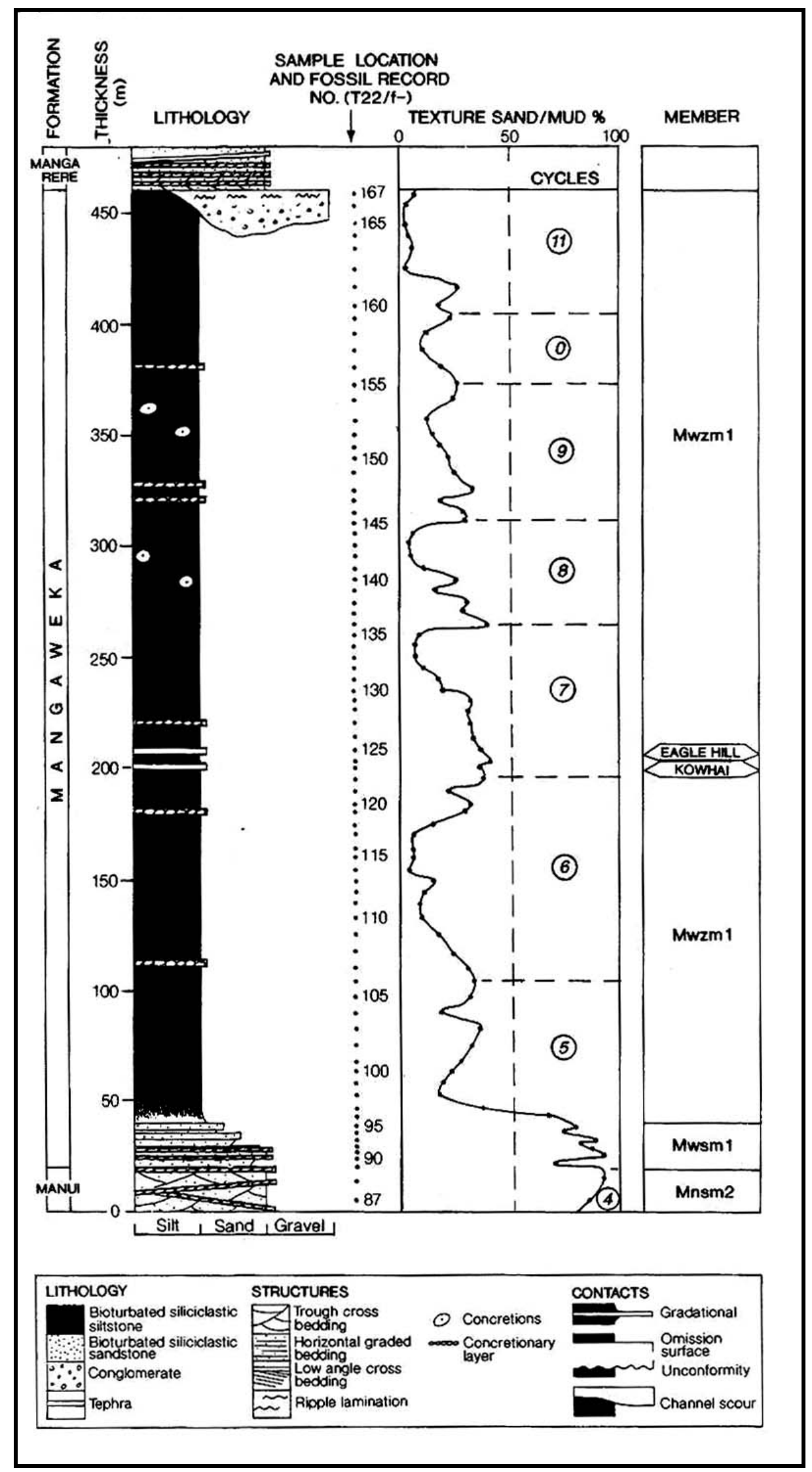

Figure 5-6 Stratigraphic column showing youngest seven cycles of Mangaweka mudstone formation, from Journeaux et al. 1996 


\subsection{Geomorphic History}

Several major (Wellington, West Wairarapa) and some minor (Waverly, Nukumaru, Upukurongo, and Galpin) faults are located near to the Wanganui Basin. Diastrophic movement (tilting and faulting) in the area was at its maximum rate after the laying down of Basin sediments. After the Wanganui Series formation the soft rocks of the hill country area rapidly peneplained. Rivers flowed freely over the region creating a delta plain with an alluvial veneer in the south and west of the Basin. As the peneplain warped and uplifted, rivers entrenched deeply. In the north-eastern section of the Wanganui Basin the hill country is highly dissected due to uplift processes. Rock strata are tilted gently towards the south, dipping at an angle between $2^{\circ}$ and $8^{\circ}$ (Neall 1982). Dendritic (branching irregularly) and torturous river courses flow through the dissected hill country in the soft Upper Tertiary sediments (Suggate 1982). Rivers are deeply incised due to rapid uplift processes, creating narrow, over-steepened valleys. In the highest hills in areas of most persistent rock, some sub mature marine terraces exist but most ridges are steep and narrow (Figure 5-7).

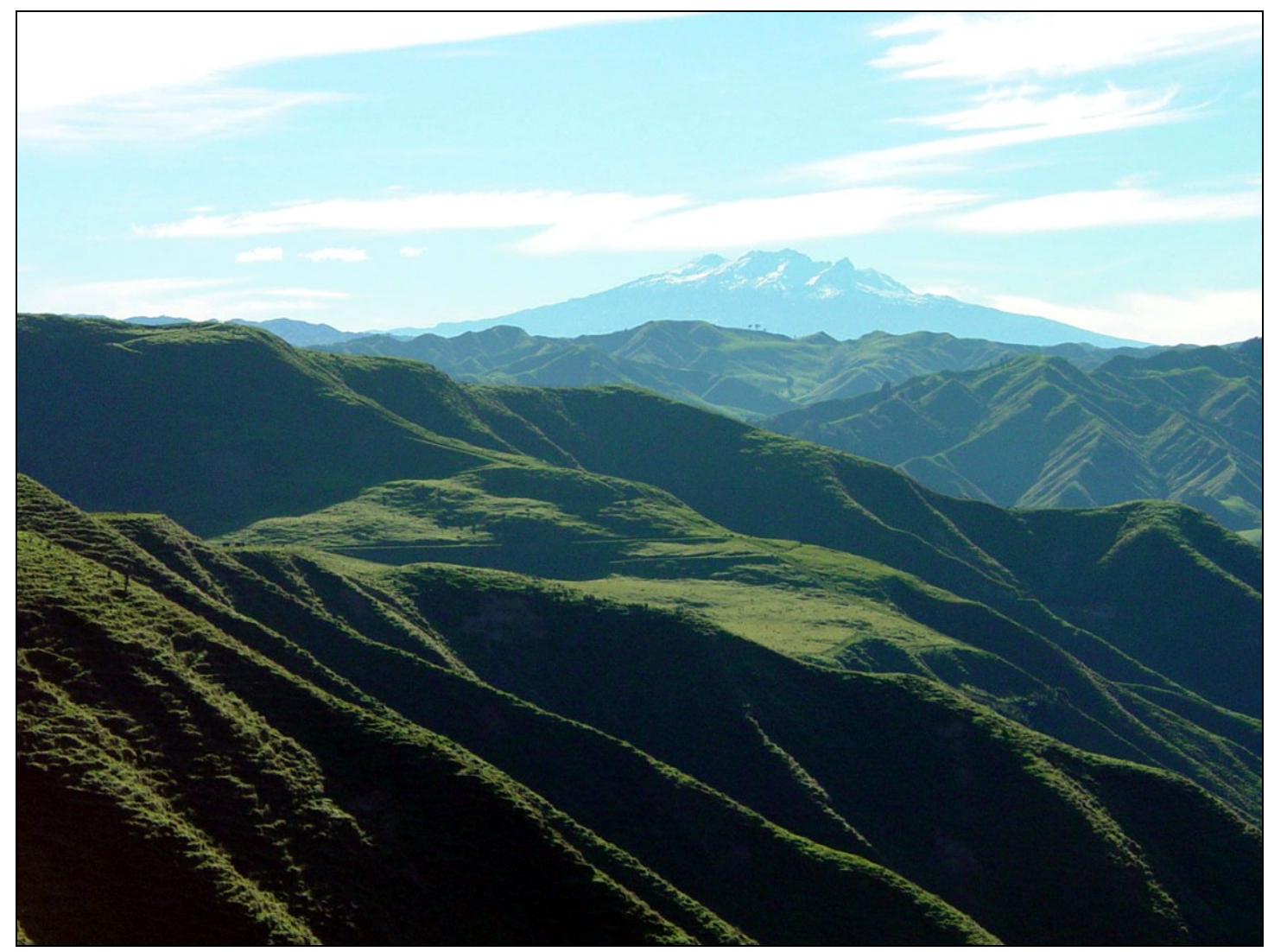

Figure 5-7 Looking north towards Mt Ruapehu across typical Tertiary Rock hill country (foreground, right and background) with a preserved terrace in image centre, photograph Crozier 2004 
In the south, active shallow mass movements result from the predominance of pumiceous sediments. As the sediments get older towards the north there is no presence of pumice, but the rocks are weakly compacted and cemented, with interbedding of calcareous strata. These surfaces show prominent dip slopes, or bluffed escarpments. The northern and north-easternmost surfaces are predominately Mangaweka Mudstone. This type of material also exhibits many large-scale massmovements on hillslopes, in particular in the hill country between the Rangitikei and Wanganui Rivers (Neall, 1982).

The hill country of the northeast Wanganui region is comprised of Mangaweka Mudstone capped with Paparangi Sandstone. The Paparangi Group sandstone is a fine, muddy rock and is cream coloured on its weathered surfaces. Mangaweka Mudstone is massive, unbedded rock, blue-grey when unweathered and lighter grey when exposed for some time. The main Mudstone unit of the hill country produces hills that are steep and highly susceptible to failure (Suggate 1982).

Landsliding in the region has been observed and recorded since European settlement and massive pre-historic paleoslides can be identified from aerial photographs and ground observations throughout the hill country. Pre-historic landslides and slumps are of much greater dimensions than historical rainfall or earthquake triggered slides (Figure 5-8). The 1855 earthquake on the West Wairarapa fault resulted in widespread slope failure but nothing approaching the magnitude of existing paleoslides was reported (Fleming 1953). From their positions in the dissected hill country it can be inferred that the period when these large paleoslides formed is later than the dissection of the landscape and down-cutting river valleys. In some areas landslidedammed lakes were formed and still exist. From radiocarbon dating of deep-seated paleoslides in the adjacent Taranaki region, Crozier et al. (1995) established three main age groups for the failures; the oldest at 31,500 $\pm 850 \mathrm{yr} \mathrm{BP}$, and the youngest group at $1470 \pm 250 \mathrm{yr}$ BP. As the topography, fault proximity, and lithology of the Wanganui region paleoslides are alike, it is reasonable to assume that there would be similar age ranges and groupings for the Wanganui landslides. The distinct groupings suggest large seismic events as triggering factors for these massive landslides (Crozier et al. 1995). 


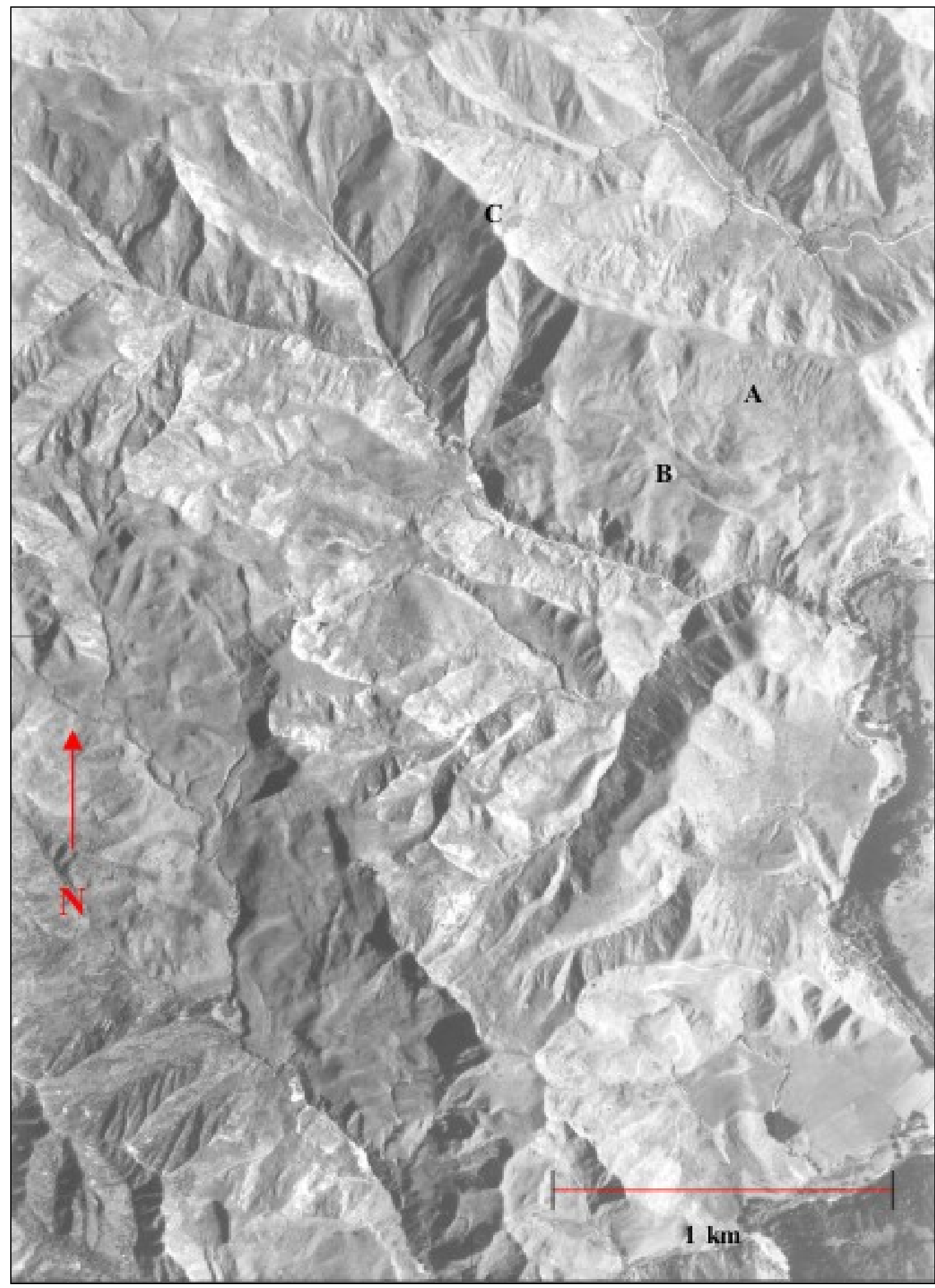

Figure 5-8 Area on the west of the Mangawhero River showing paleoslide slope modification; the landslide source area is slope $A$, while the runout (deposit) area is at $B$. Ridge $C$ tops an unmodified hill slope with much steeper faces. The Mangawhero study catchment is the amphitheatre shaped feature directly above the scale bar photograph Dept. of Lands and Survey 1943 


\subsection{Soils of the Wanganui District}

Soil formation is a function of parent material, time, climate and organic activity. In the Wanganui region the climate is mild and moist with gradual climatic gradients. The parent material is weak to moderately consolidated Tertiary and Pleistocene rocks, which are relatively easily weathered. The landscape is described as early mature (by steepness of slopes and rounding of ridges), and hillslopes are steep with hill country highly dissected by deeply entrenched dendritic river channels (Campbell 1977).

\subsubsection{Climate and soils}

The Wanganui Region experiences a humid zone from about $35 \mathrm{~km}$ inland. The coastal region west of the $35 \mathrm{~km}$ zone is drier and warmer. For the inland region, the average summer temperature is $12.8^{\circ} \mathrm{C}$, and the average winter temperature is $5^{\circ} \mathrm{C}$. The average annual temperature for the inland region is $9.5^{\circ} \mathrm{C}$. The region experiences between 1200 and $1400 \mathrm{~mm}$ of rainfall on average, per year (Campbell 1977). Summer rainfall is usually the result of convective turbulence with warm air masses rising quickly to produce intense but short-lived storms. Winter rainfall is typically the result of warm and cold front interactions over the North Island and orographic rainfall produced by moist air masses becoming trapped against the ranges as they travel eastwards with prevailing winds. In the inland Wanganui Region there is a moisture surplus for most of the year (Figure 5-9). These moist soil conditions produce soils referred to as Fulvic soils (Campbell 1977).

Under conditions of high rainfall and low evapotranspiration, there is surplus soil moisture for most of the year. At the end of summer in the inland region there is a short period of soil moisture utilisation; that is, the soil dries as moisture is taken up by plants and the soil moisture is below saturation. In these conditions the soil will absorb incoming precipitation until saturation occurs, after which surface flow will occur. Rainfall conditions for January and February of 2004 were normal for the hill country; that is, soil moisture was being utilised by plants, as little recharge had occurred from precipitation and evapotranspiration levels are highest for these two months. 


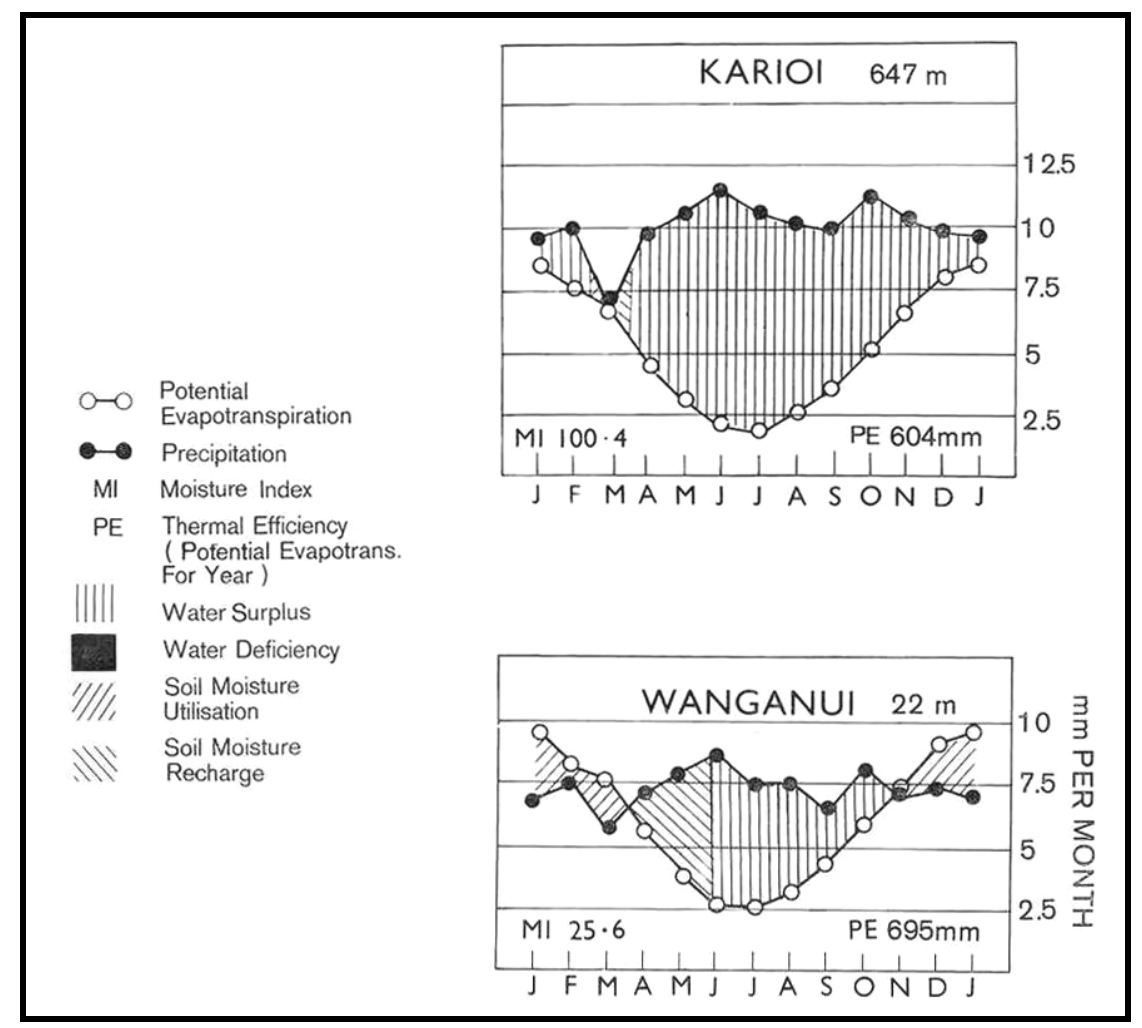

Figure 5-9 Moisture records for Karioi (hill country) and Wanganui (coastal). Note there is surplus (horizontal bands) for nearly all months in the inland region, fromCampbell, 1977

\subsubsection{Soil parent material and geomorphology}

The soils in the inland region are forming predominately from weathering of mudstones and sandstones. Production of different soils in this area is related more to the degree of weathering of parent material, rock texture, or consolidation of the parent rock than lithology of parent rock. The inland soils are classified as steepland soils, with a range of soil types formed throughout the region and nomenclature based on location of typical profiles and the topography in which they form. The solum (combined horizons of in situ soil) is usually $60-100 \mathrm{~cm}$ deep; overlying unweathered or weakly weathered parent material. Each soil type also exhibits different depths of individual horizons and rate of development depending on where on the slope (top of ridge, intermediate slope, eroded slope, or accumulation slope) it is forming (Campbell 1977).

More than $68 \%$ of the Wanganui County is steeply sloping, highly dissected land, divided by deep narrow valleys. Uplift within the Pleistocene period coupled with the weak consolidation of some sedimentary rocks in the area has resulted in the 
continual down-cutting of streams. The landscape is in the early mature stage of development; valleys are narrow and steeply sloping, valley floors have begun widening but flood plains are narrow, ridges are narrow and sharp, and streams and rivers can be deeply incised. The steepland shows distinct relief variations that can be related to underlying lithology (Neall 1982, and Campbell 1977). The weakly consolidated (weakly compacted) rocks of the Okehu and Maxwell Groups are prone to the development of deep-seated slumps and exhibit hummocky topography. The unconsolidated to weakly consolidated Nukumaru Group sediments produce straight $\mathrm{V}$-shaped valleys with rounded ridges. The firmer sandstones and siltstones of the Okiwa and Paparangi Groups (the soils present in the area of this study) form shallower "V"-shaped valleys, sharp narrow ridges, and erosion detritus may produce slightly concave lower slopes. Sandstone capped ridges may have a fluted appearance. Where Mangaweka Mudstone is present, the landscape has a more mature appearance; valley slopes are more concave with considerable deposits of eroded material on lower slopes, and small patches of gently sloping, moderately steep land and ponding may be found (Campbell 1977). Soils formed in the steepland environment are produced almost entirely within a degradational environment; the only aeolian deposits found are a few scattered areas of volcanic ash.

\subsubsection{Vegetation and Soil}

The original vegetation cover of the inland Wanganui region was predominantly forest, the exception being some valley floors. Species present included podocarps such as Rimu, Kahikatea, Totara, Matai and Miro, as well as Tree Ferns, and Beech varieties. The steep and fairly inaccessible inland region was not significantly developed by Maori and the vegetation cover of the area was not significantly altered until settlement in the region by Europeans (see Section 5.5). The large scale removal of forest cover by burning led mainly to changes in topsoil development as sheet wash processes increased with reduce interception rates and the organic litter layer was removed. Soils in areas previously forested that are now under pasture are less stable than forest soils. Soil moisture storage is lower, sheet wash erosion is more frequent, and the structural strength of tree roots within the soil has been lost (Campbell 1977). 


\subsubsection{Soil of the Mangawhero River Hill Country}

The soil in this study area and the surrounding hill country is Turakina Steepland Soil. This soil type dominates north, west and east of the study area with considerably more variety in soil types south of the study area. The soil is Clini-Fulvic (a steepland soil related to yellow-brown earths). The soils are considered to be moderately stable and slipping is generally infrequent, however intense or prolonged rainfall may produce locally extensive erosion, including large deep-seated slips and earthflows. When soil or parent material is just below saturation slips initiate. Because of the high moisture content of the parent material the erosion debris may travel rapidly as earthflows (Campbell 1977). Where massive bedrock faces are exposed recovery of the soil and revegetation is a slow process, but where shattered, rubbly parent rock is exposed, revegetation may occur relatively quickly.

\subsection{Land use: Present, Historical, Pre-historical}

Although the Wanganui region supported a considerable Maori population prior to the arrival of Europeans, the hill country north and east of Wanganui was not heavily populated or utilised before this time. Major transport routes for Maori followed the coast and the Wanganui River; minor tracks ran along the Waitotara, Mangawhero, Whangaehu and Turakina River Valleys (Fleming 1953). A location map of the Wanganui County and surrounding counties with major settlements and rivers is shown in Figure 5-10.

European settlement and subsequent road building and bush clearing opened up the area. The steep topography and thick bush cover made travel through this terrain difficult. Maori settlements before the 1840s were situated primarily in coastal areas and along the Wanganui River banks. Prior to European settlement the Mangawhero River Valley was sparsely inhabited. There was sparse European settlement of the Valley by 1866 and the Valley began to be settled more extensively by European farmers in the 1870's. The Parapara Hill country began to be cleared for sheep and beef farming in 1897 (Voelkerling and Stewart 1986), but rough terrain and difficult access restricted clearing rates. Establishment of farming land from bush country continued into the $20^{\text {th }}$ century (Figure 5-11). The process of conversion of bush to pasture was: cutting down of bush in the winter; burning off the stumps and remaining 
scrub in late summer; then spreading of grass seed on the ashes. Farmers often hired transient single men to do the clearing. These bushmen, or bushwhackers, travelled between farms and clearing progressed as long as farmers had the ability to pay. Even in the earliest period of hill country clearance for pasture production, it was observed that the steep Sandstone on Mudstone hills were susceptible to erosion.

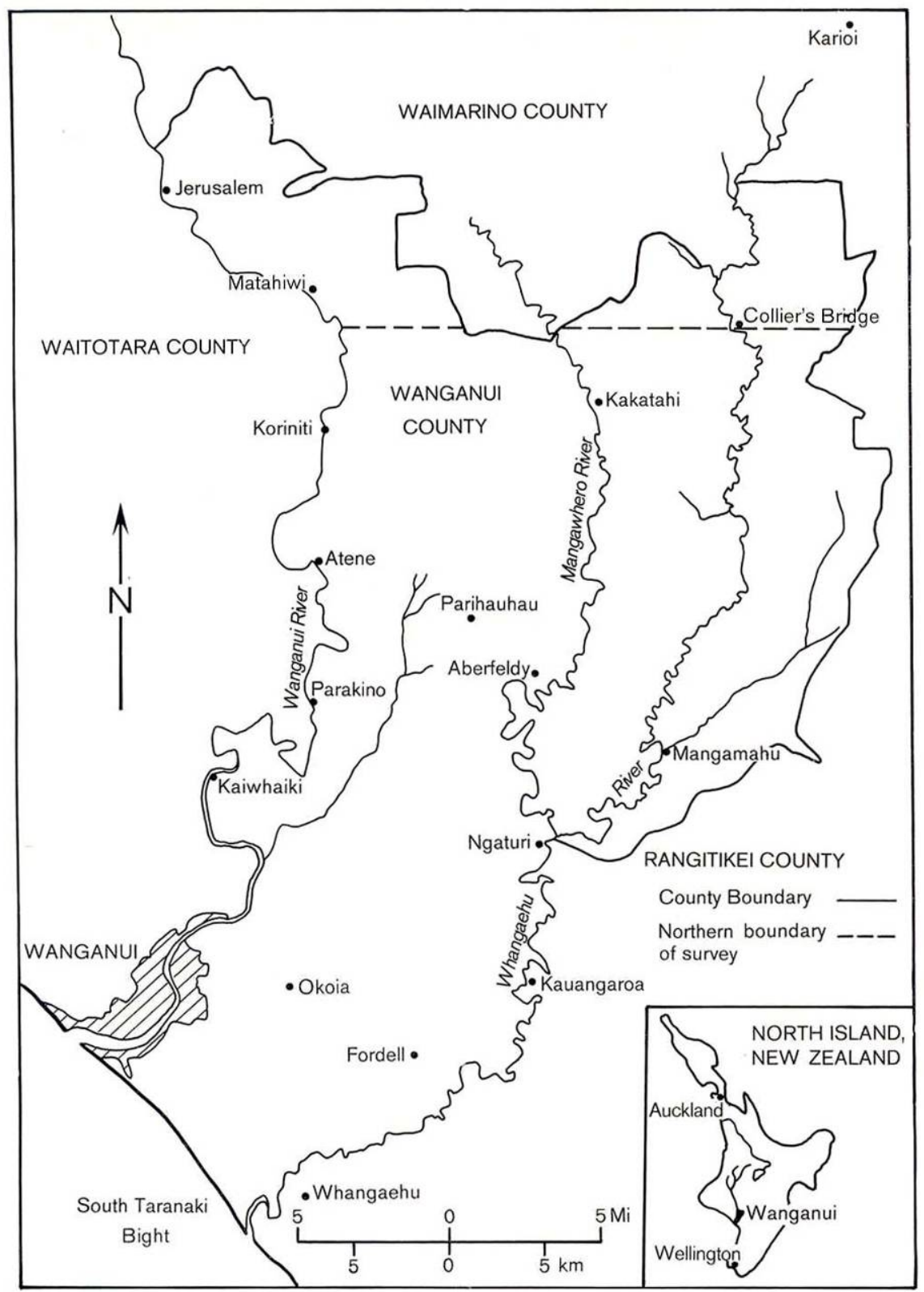

Figure 5-10 Wanganui and surrounding counties, major rivers and settlements, from Campbell 1977 


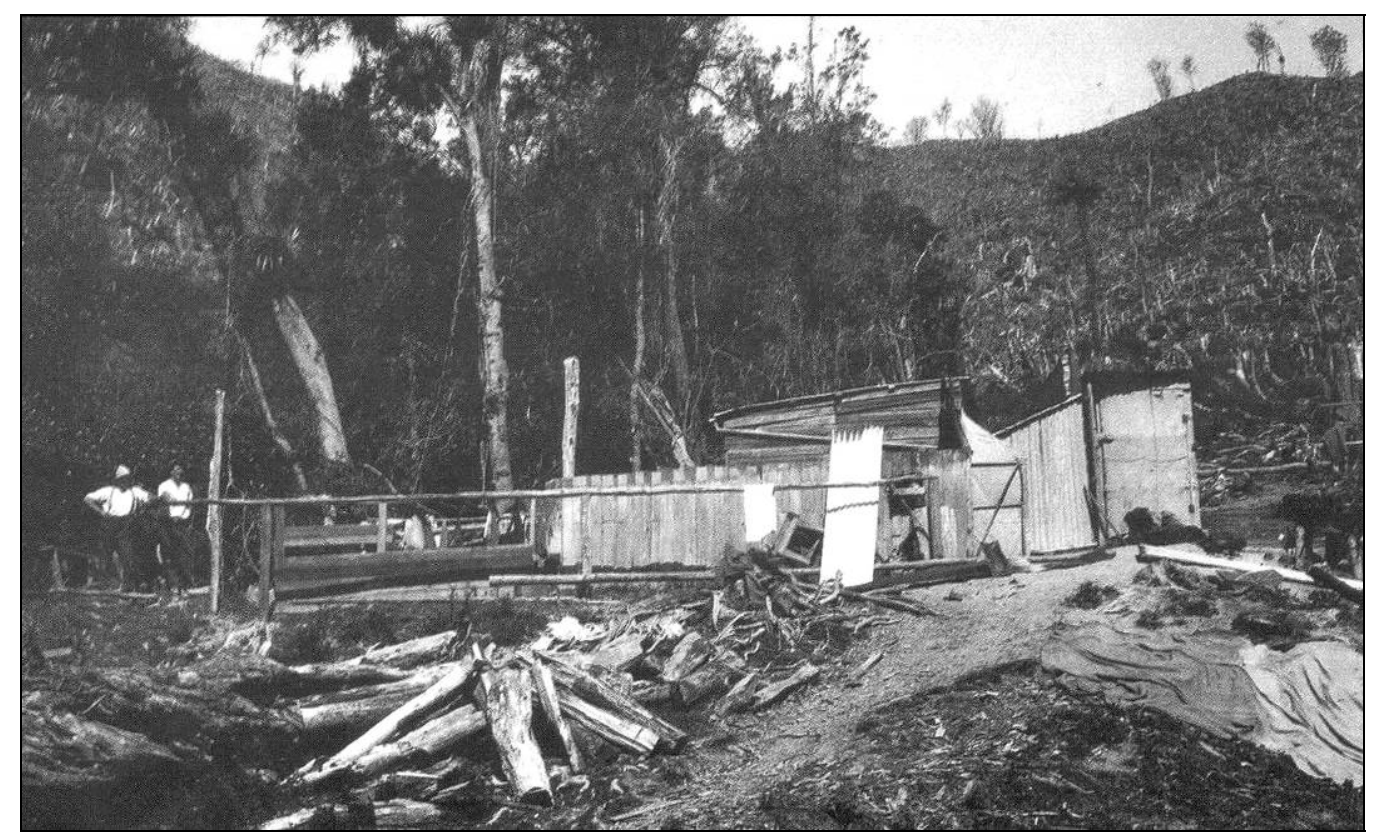

Figure 5-11 Clearing of hill country in Kakatahi (Mangawhero River Valley) for farming, 1926, from Davies 1994

\subsubsection{Mangawhero; Road Building and Valley Life}

The region was initially opened up to European settlement by the New Zealand Company in a series of spurious and illegal land sales to purchasers in England. Blocks of land around Wanganui were offered for sale without proper title being available. Due to increased unrest among Maori and dissatisfaction among English land purchasers the Wanganui region was declared part of the Wellington Province in the 1952 Constitution Act, which also reserved the right of land sales to the Crown only. Under this Act provinces gained their own legislative powers. The New Provinces Act (1958) undermined the existing provincial system and legislation, and the Provincial system crumbled in 1876. Local boroughs and counties were introduced at this time (Voelkerling and Stewart 1986). In 1908 the Mangawhero Road Board was established, to oversee the construction of the Parapara Road (now State Highway 4 connecting Wanganui and Taupo). The road board was absorbed into the Wanganui County in 1918.

The construction and location of the Parapara Road was first proposed by surveyor Henry Field in 1869. After several proposals following different routes (e.g. Whangaehu River Valley, Mangawhero River Valley) were evaluated, Field's Mangawhero route was selected as the most viable option by the local council and 
construction of the road began in 1880 (Voelkerling and Stewart 1986). Construction was difficult in the unstable hill country; roadmen were reported to be leaving the area in 1896 due to the difficulty of working in slip-prone areas. By 1906 the road had extended six km north of Aberfeldy, a distance of about $36 \mathrm{~km}$ from Wanganui. The extent of the developed road was also the limit of European settlement at the time (Voelkerling and Stewart 1986). A large population of single men and unemployed family men in the area during the 1920s and 1930s provided unskilled road gang labour for road construction in the area (Figure 5-12). Living in mobile camps and working for minimal wages, the forced work was inefficient and of a poor standard. Many sections of road constructed by the gangs had to be rebuilt due to poor drainage and stability problems.

Life was difficult for the early European settlers; in 1878 there were only 45 women to every 100 men. Further up the Mangawhero Valley there was a scattering of Maori communities but no large settlements. Farming in the eroding hill country became less productive as topsoil was lost and nutrients levels declined. The blue "Papa" (Mangaweka Mudstone) continually slipped at road faces. As late as the 1950's and 1960's the Parapara Rd continued to be closed by slips for several days on several occasions. The Parapara Rd was finally tar-sealed along its entire length in the late 1950's, early 1960's. The loss of soil fertility and viability of farming in the area was such that in 1925 subsidies were provided by the government to assist with topdressing and fencing costs. Marginal hill country farmland continued to be utilised and made prone to erosion and landslides. New hillslope stability methods such as tree planting were introduced after 1945, and some stabilisation of hill country was achieved from these improved techniques (Voelkerling and Stewart, 1986).

In a 1970's survey, farmers were identified as being pessimistic about the future of farming in the region. Issues affecting viability were isolation, low prices for produce, and bad road infrastructure. All farm subsidies were phased from 1984, however, farming in the region continues with greater diversity of stock types and large areas of forest plantations in less accessible hill country (Figure 5-13). 


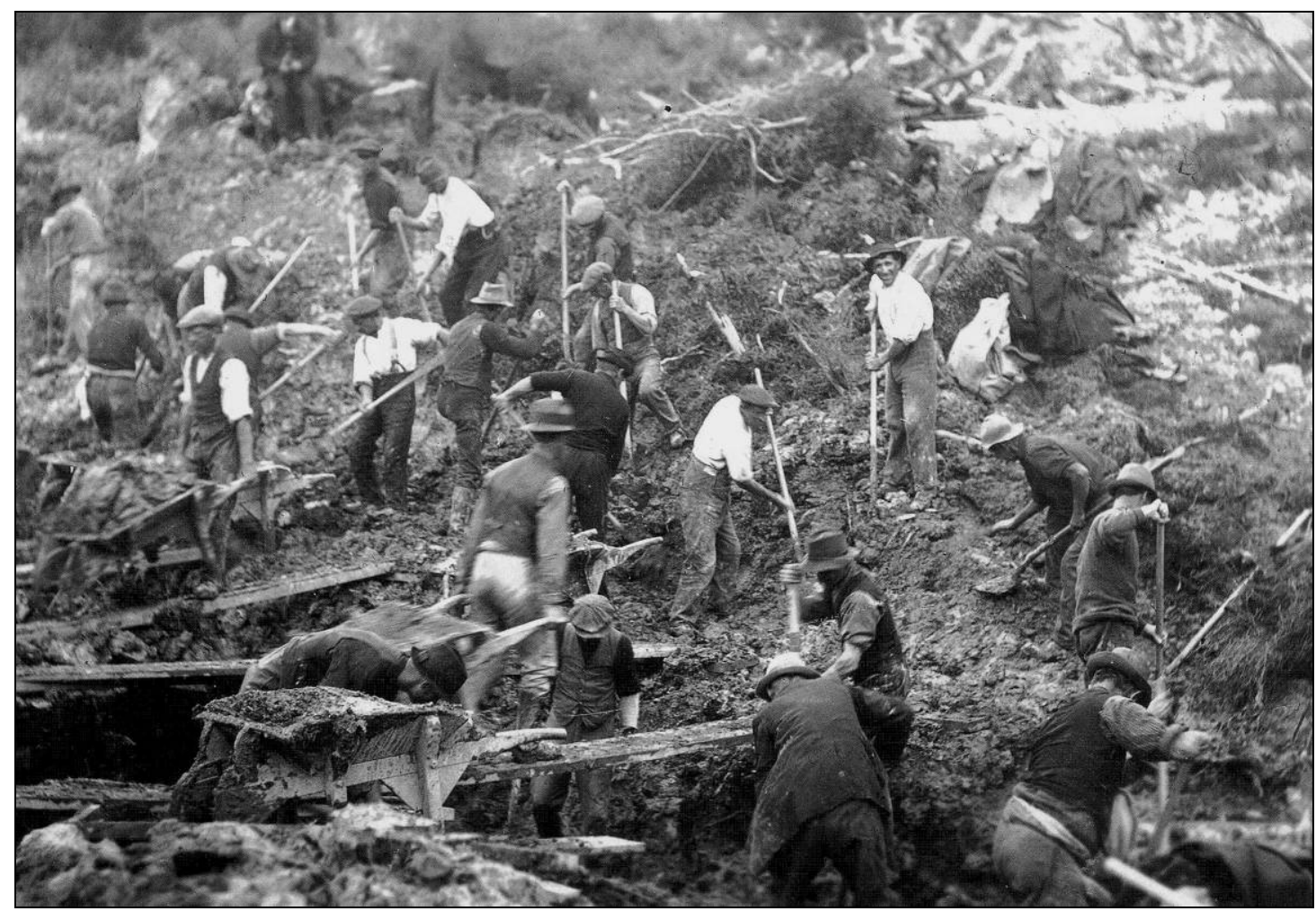

Figure 5-12 Unskilled, poorly paid road gangs were used to build the Parapara Rd, from Davies 1994

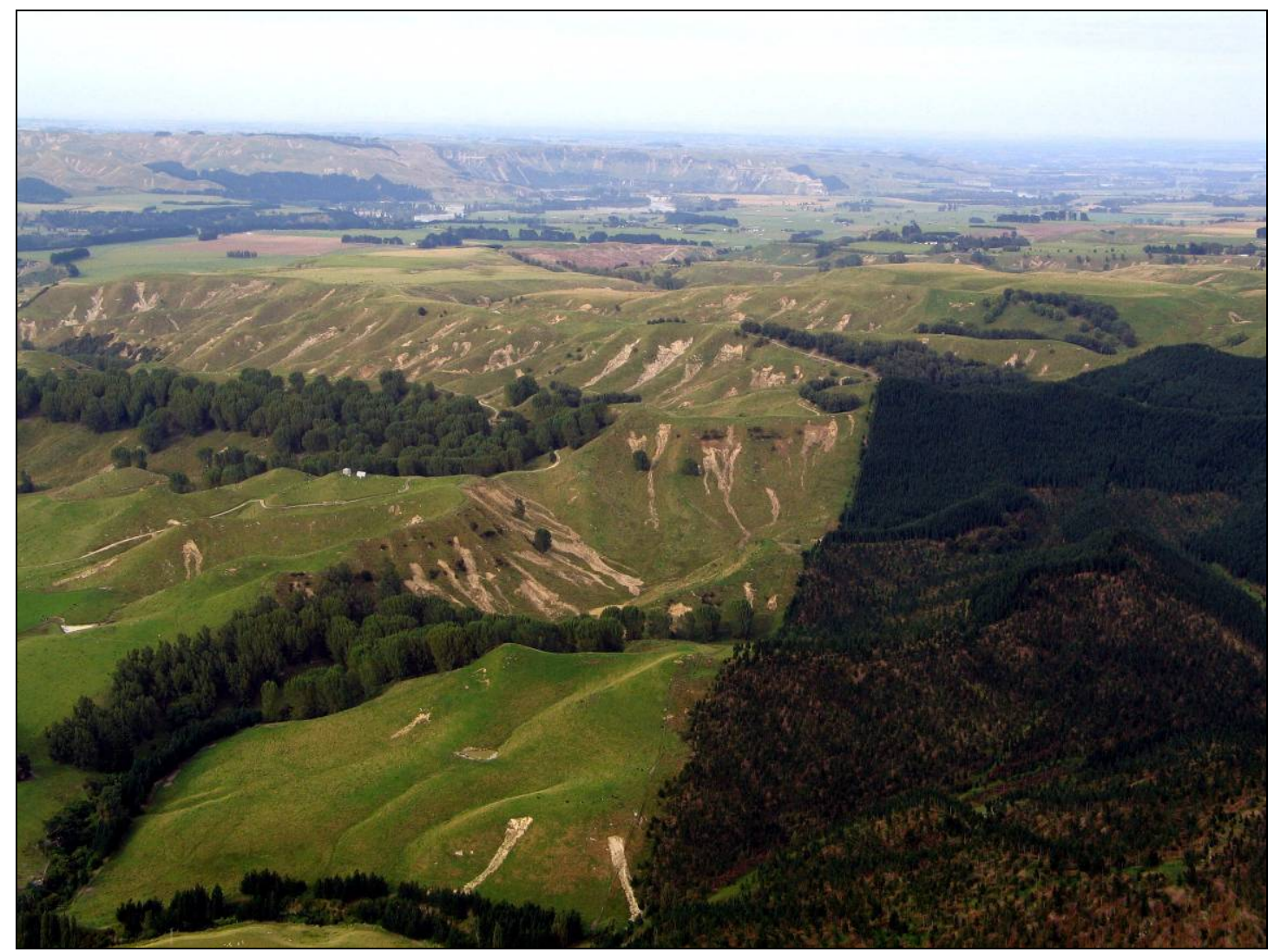

Figure 5-13 Slope protection and farm diversification measures; pine plantations, juvenile in foreground and mature in centre (right), and drainage line deciduous planting, Rangitikei River area. Notice that slips are not present in forested areas, photograph Hancox, 2004 


\subsubsection{Natural Hazards of Early Wanganui}

During the main period of European settlement, throughout the latter half of the $19^{\text {th }}$ century and the start of the $20^{\text {th }}$ century, several flood and earthquake events were recorded in the region. A landslide-triggering earthquakes impacted the region in 1838 and 1843, and during the 1855 West Wairarapa Fault earthquake, some large landslides were reported. Flooding was recorded in 1857, 1861, 1898, 1904, and 1906. During the 1857 event the Whangaehu Bridge was swept away, and the Mangawhero Bridge suffered a similar fate during the 1898 flood (Voelkerling and Stewart, 1986).

Natural hazards present in the Wanganui Region as defined by Horizons Regional Council (2004) are shown in Table 5-1. There is no record of the region being affected by tsunami or volcanic hazard during the European settlement period.

Table 5-1 Identified Natural Hazards of the Manawatu-Wanganui region, Horizons Regional Council 2003

\begin{tabular}{|l|l|}
\hline Hazard (Natural) & \multicolumn{2}{c|}{ Remarks } \\
\hline Volcanic action & $\bullet \quad$ Includes storm information \\
\hline Flooding & \\
\hline Earthquake & \\
\hline Tsunami & \\
\hline Land subsidence & \\
\hline
\end{tabular}

Tsunami hazard is not present in the inland Wanganui region; however, the hill country is at risk from the other four hazards listed above. The most frequently experienced hazards in the region in the region are flooding and land subsidence. The damage resulting from volcanic eruption, lahar flow, or earthquake is potentially far greater, but the frequency of these events is considerably lower. When a storm event of sufficient magnitude occurs, it is likely to induce landslides in saturated hill country, and a multiple-hazard situation results. Likewise, an earthquake of sufficient magnitude will induce landsliding in structurally weak or saturated hillslope materials. The combination of multiple hazards during one event increases the potential damage considerably as positive feedback systems may be created. For example, a heavy storm may cause river levels to rise. River banks may be eroded and the bank material input to the fluvial system. As sediment enters the river any non- 
soluble material (gravels and larger sediment) will raise the bed level or increase the volume of transported material, decreasing the volume available for water flow and therefore raising the river level further. As the level rises then more of the bank will be vulnerable to erosion. If hillslopes become saturated and landslides occur on fluvially coupled hillslopes, then this landslide debris material will also increase river levels through sediment input, as well as contributing large organic debris such as branches or entire trees. With increased bank erosion and undercutting of the base of slopes due to higher river levels, hillslopes in turn become more vulnerable. The base of a slope is the most important part of the hill for structural stability, when material is removed from the base the entire hillslope is weakened as a result.

\subsection{Summary}

The Wanganui hill country consists of massive Pliocene sedimentary deposits uplifted during the Pleistocene period. Mangaweka Mudstone and Paparangi Sandstone dominate, and the overlying soil is Turakina Steepland soil. The hills are susceptible to deep-seated landslides with sufficient triggering magnitudes, although no landslides of the volume exhibited by pre-historic slides have been witnessed even in the largest storm events in historic times. These paleoslides are most likely to be earthquaketriggered. The area is subject to flooding and rainfall-triggered, multiple-landslide events, exacerbated by the clearance of land from forest cover to pasture, with the resulting loss of soil stability. 


\section{Field Study Catchment}

\subsection{Catchment Selection}

The scale of the landslide damage from the February 2004 storm creates difficulty when trying to quantify the event in terms of geomorphic work done and frequencymagnitude. By selecting a manageable-sized study catchment representative of the event a more detailed field analysis of the event may be undertaken. Due to time and travel constraints selection of a study catchment was based on the following:

- That the catchment be of a measurable area when creating the DEM using hand-held GPS instruments, and;

- The catchment needed to be accessible, i.e. nearby a major access road.

For research validity the following criteria also had to apply to the selected catchment:

- That a number of landslide types be present within the catchment (e.g. deepseated, shallow, at different positions on the slope etc);

- That the lithology, topography, slope height and angle be representative of the majority of damaged slopes within the region, and;

- That the catchment contain fluvially-coupled slopes, and non-fluviallycoupled landslides.

\subsection{Location}

From aerial reconnaissance undertaken in the fortnight after the storm event (see also Chapter 4), several catchments in various locations stood out as being suitable for more detailed investigation. Four areas stood out as exhibiting the most dense landslide damage for the event; Mangawhero, Whangaehu and Turakina all within the hill country northeast of Wanganui, and Pohangina, in the Manawatu hill country. Although damage was severe in the Pohangina (Manawatu) region (Figure 6-1) and suitable-sized catchments relatively accessible, the limited range of landslide styles (nearly all slips were shallow, multiple-headed translational slides, following the drainage channels) and differing lithology and topography from the majority of the impacted area excluded it from consideration. The Pohangina slope parent material is 
weak Sandstone with pumice layers and some greywacke gravels and the Pohangina hill country has a history of shallow landsliding.

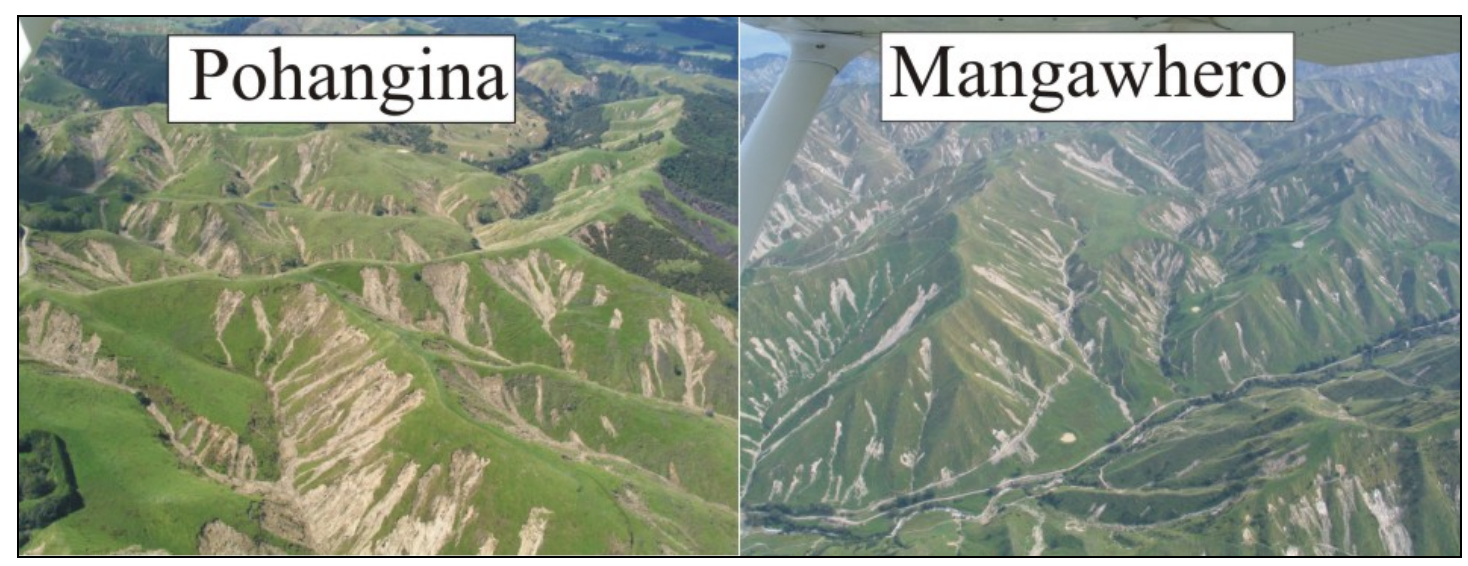

Figure 6-1 The structurally weak sandstone country of the Pohangina hill country, and the weak, yet massive Mudstone hill country of Mangawhero (shown), Whangaehu and Turakina hill country, photographs Hancox 2004

The hill country of the Mangawhero (Figure 6-1), Whangaehu, and Turakina Rivers have similar lithological and topographic characteristics (see Chapter 5). The massive Mangaweka Mudstone unit is the regolith parent material and in places this unit is overlain by a cap of Paparangi Sandstone. Both units are prone to landsliding with the mudstone somewhat more resistant but prone to deeper slides and flows. The Sandstone unit produces shallower slides in general but these are slower to heal than those formed in mudstone. Selection of a catchment from these lithologically similar areas was therefore based on other factors.

The Mangawhero River Valley hill country is bisected by State Highway 4, (also known as the Parapara Road) making it relatively accessible. Damage was most severe in the Mangawhero region (see Chapter 4), and the decision was made to focus on the catchment containing the largest landslide form the event. This catchment was selected, even though it may be considered 'atypical', because values derived form measurements of the largest landslide in the event would be useful for determining the frequency-magnitude status of the event, in particular using the magnitude scale produced by Malamud et al. (2004) (see Chapter 9). The catchment, which is approximately $0.7 \mathrm{~km}^{2}$ in area, is approximately $50 \mathrm{~km}$ north east of Wanganui adjacent to, and west of, State Highway 4 (Figure 6-2). The catchment was informally 
dubbed "the Octopus Catchment" due to the shape of the largest landslide within the catchment (Figure 6-3).

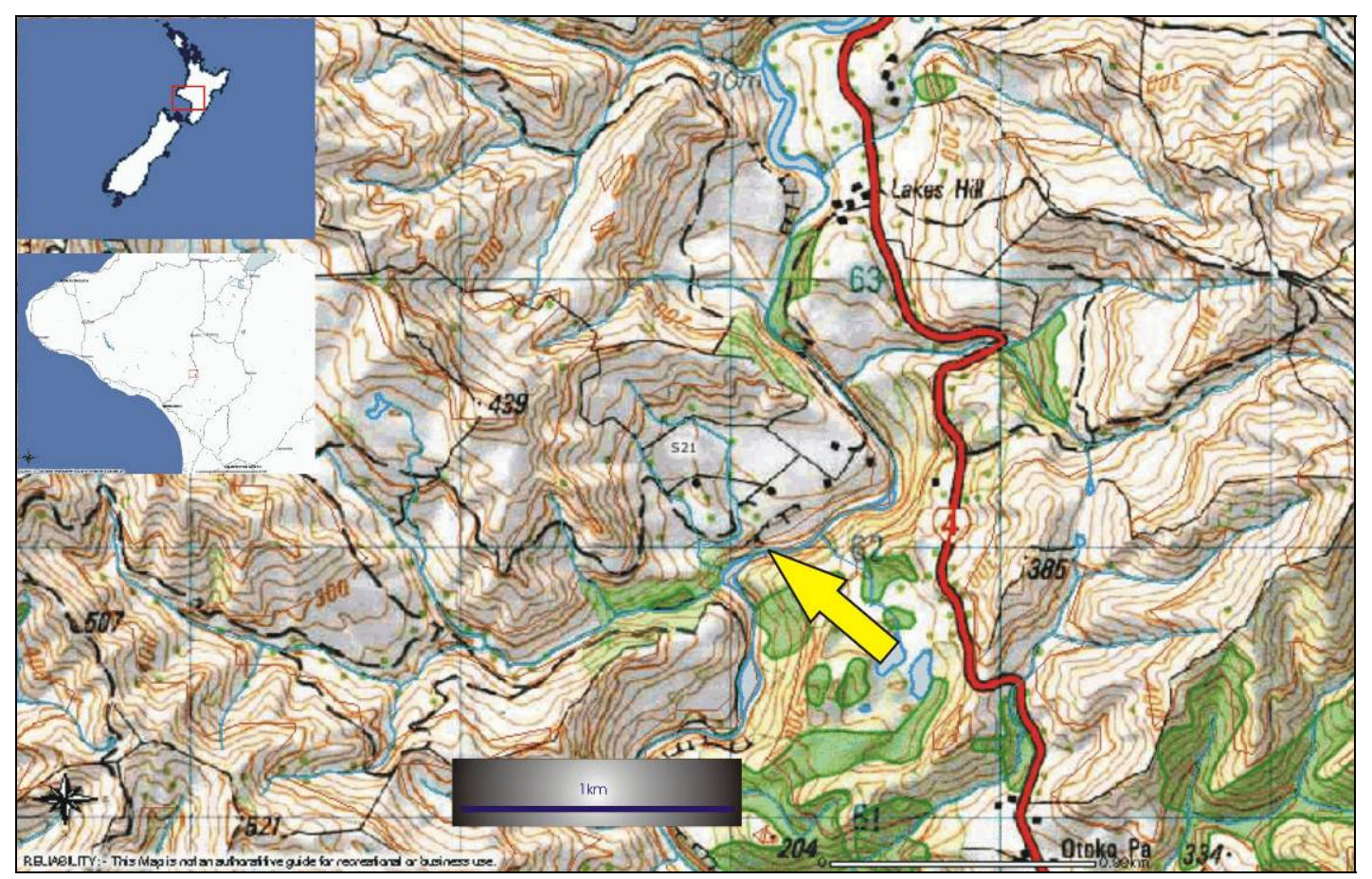

Figure 6-2 Location map of the Octopus catchment; State Highway 4 runs north-south, the catchment is the amphitheatre-shaped basin indicated by the yellow arrow; the catchment location in national and regional context is shown top left adapted from DOC 2004 


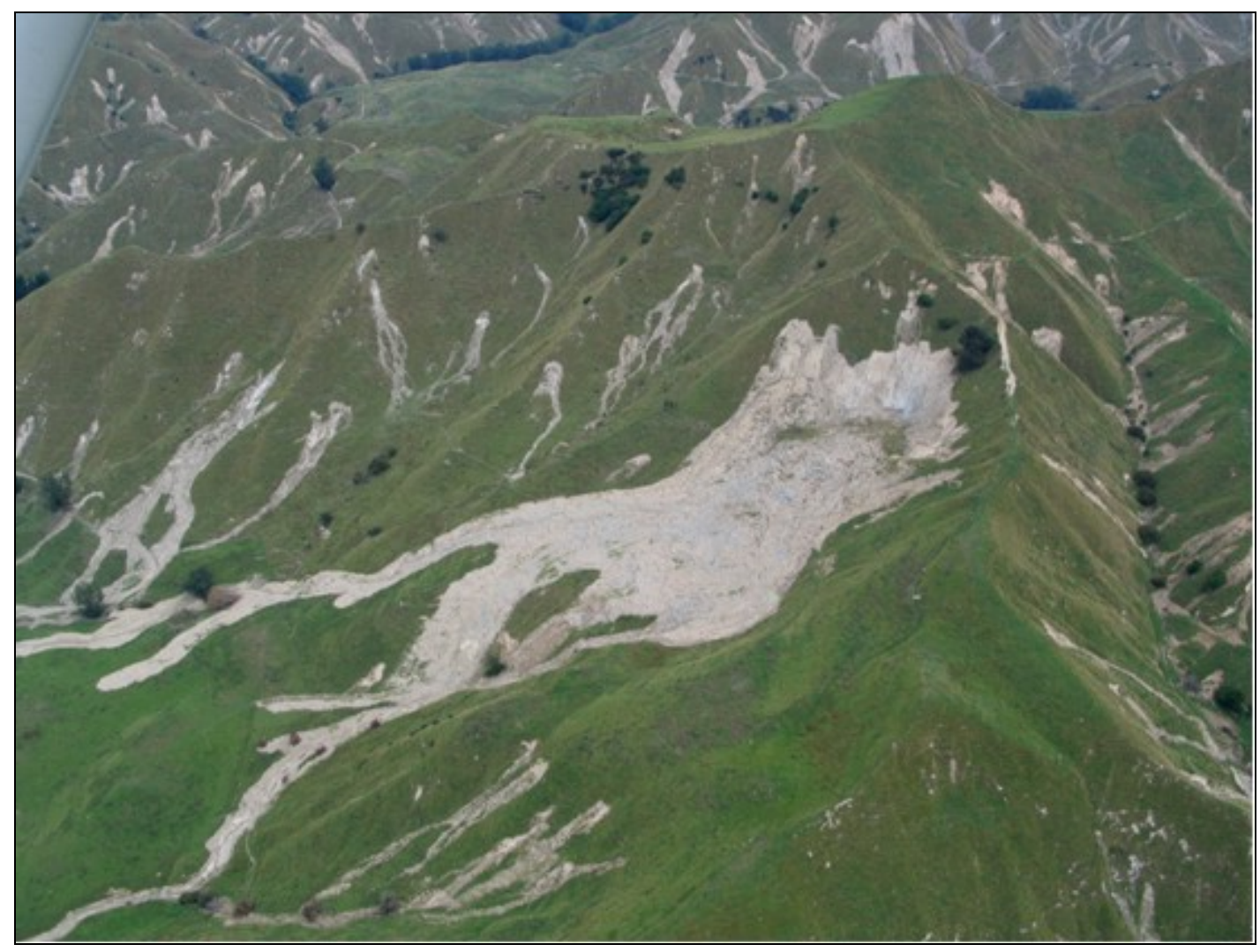

Figure 6-3 Looking south over the upper slopes of the east-facing 'Octopus Catchment"; landslides are in various positions on the slopes, and are a range of sizes, photograph Hancox 2004

\subsection{Lithology, Topography and Geomorphology}

The catchment bedrock is predominantly the massive Mangaweka Mudstone unit, with a thin cap of Paparangi Sandstone on the upper ridges. The mudstone shows no evidence of bedding or shell fragments, and the exposed bedrock surface in landslide scars has a "platy" appearance.

The maximum elevation of the catchment above sea level is $390 \mathrm{~m}$, and the lower terrace is at $120 \mathrm{~m}$ elevation. Natural hillslopes vary between $23^{\circ}$ and $38^{\circ}$ on the upper slopes, while the lower part of the catchment exhibits terraces and a more rolling topography. All landslides occurred on slopes greater than $23^{\circ}$. Some terracing is evident at higher elevations on the north side of the catchment (slopes are facing southwards); the slopes facing east are the steepest and most rectilinear in the catchment (Figure 6-4). 


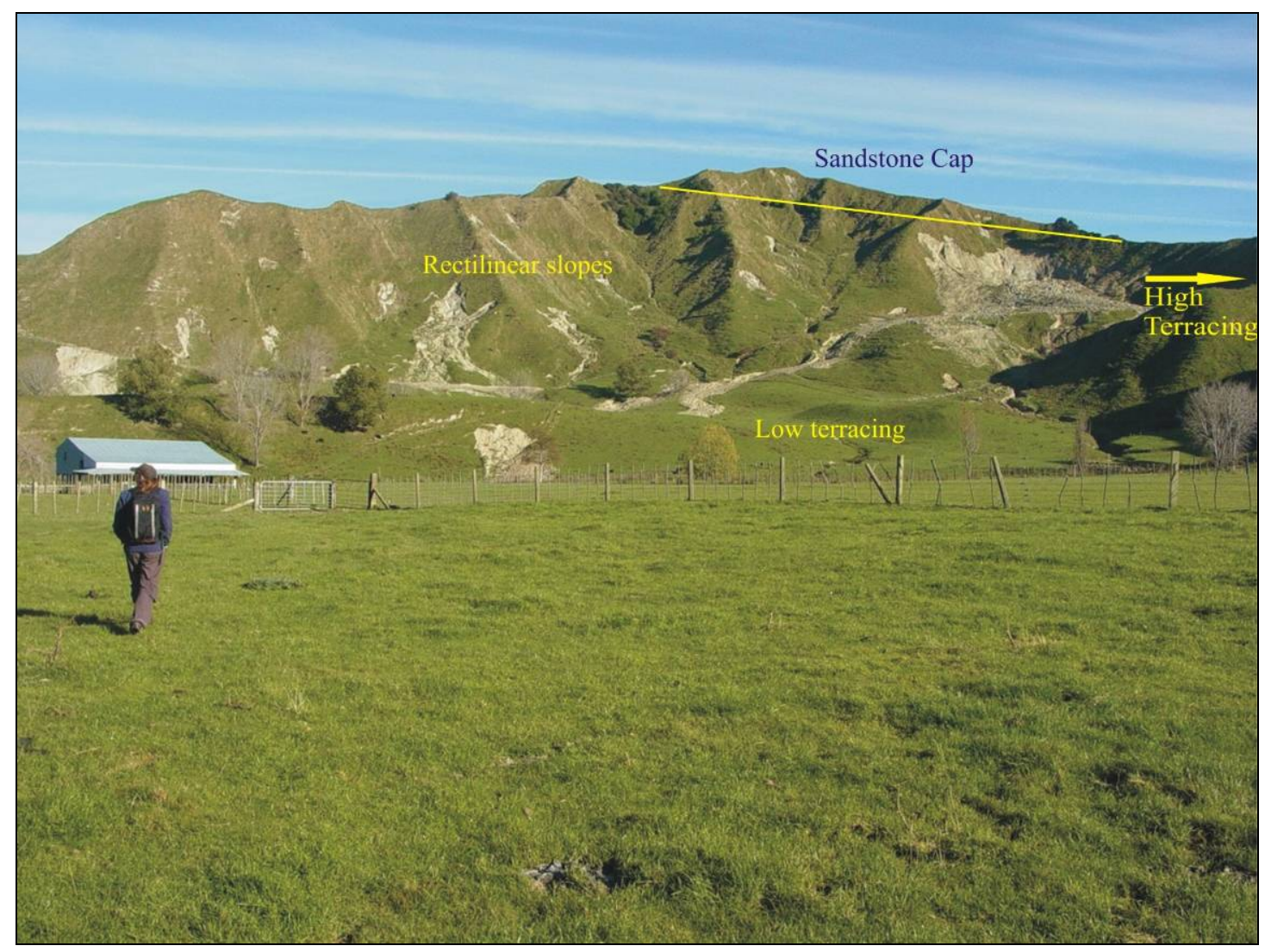

Figure 6-4 Looking north-west into the head of the Octopus catchment, the Mangawhero River is to the south-east, photograph Crozier 2004.

The lowest terrace (Figure 6-4) has a slope angle less than $5^{\circ}$ and is comprised of colluvium and fluvial gravels. All buildings within the catchment are situated on the lower terrace; however fencing and farm tracks extend to the highest slopes of the catchment. Almost all fences and farm tracks on the slopes were destroyed or damaged by the landslide event.

\subsection{Aerial Photographs}

The study catchment has not undergone significant land use changes over the last 40 years. Vertical aerial photographs from 1963 (Department of Lands and Survey, New Zealand 1963) show only slight changes in vegetation cover have occurred. In both photographs (Figure 6-5 and Figure 6-6) sometime in the last 40 years the small stand of pine trees in the centre of catchment has been removed. Also a few small patches of native trees have become established on some of the highest slopes. Some plantings of poplars and willows have been undertaken, most probably in an attempt to reduce erosion. No new buildings have been constructed, but the woolshed (centre of lower terrace) has been modified. The 2004 photograph shows that adjacent to the northern ridge of the catchment, and along the Mangawhero River to the south of the 
catchment, pines have been planted. From the 1963 photograph it can be seen that these areas have very steep slopes and while the pines seen in the later photograph have been only partially successful in reducing riverbank erosion, it appears they have successfully reduced damage to the northern hillslope.

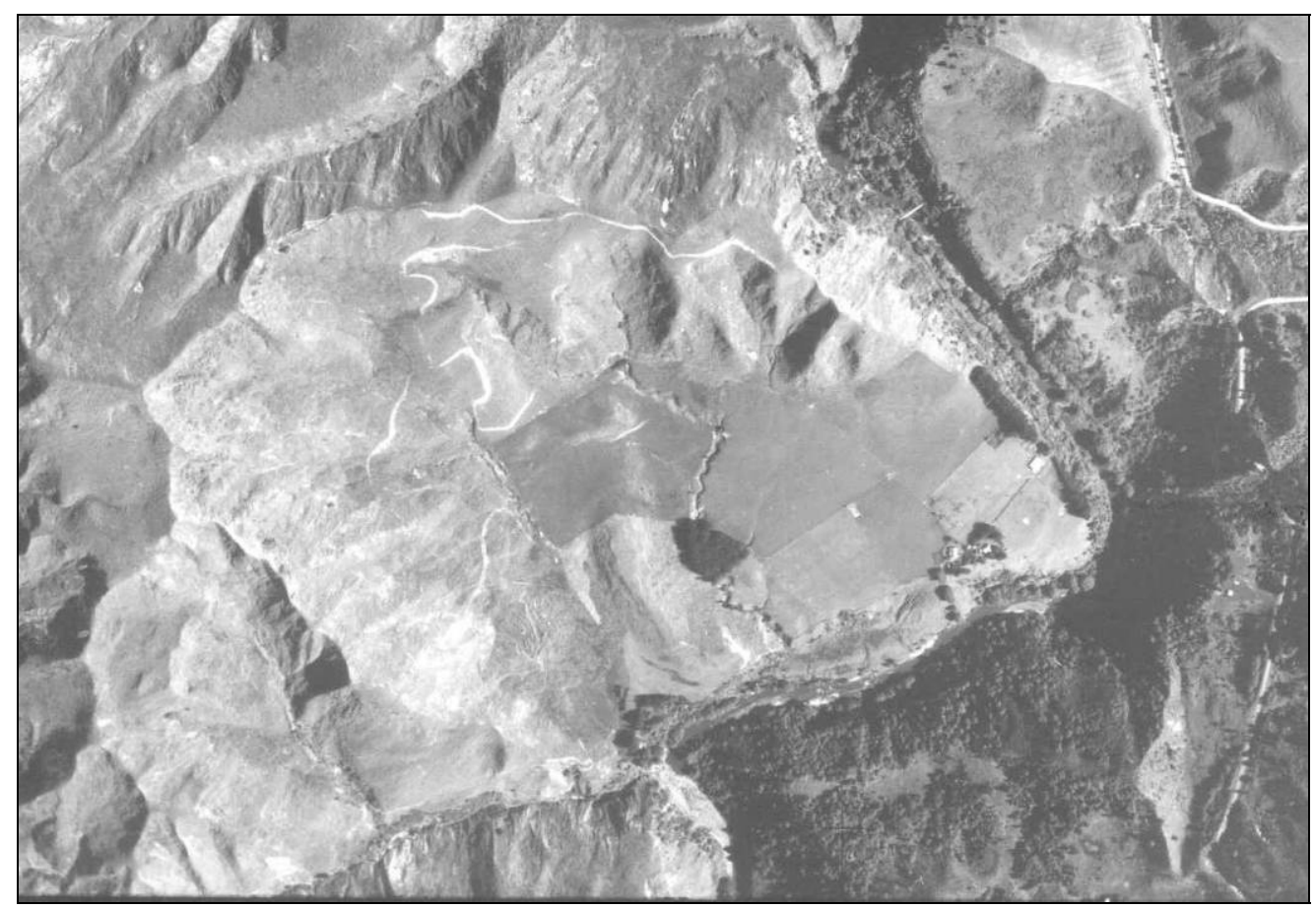

Figure 6-5 The Mangawhero study catchment photographed in 1963, source Dept. of Lands and Survey 1963 


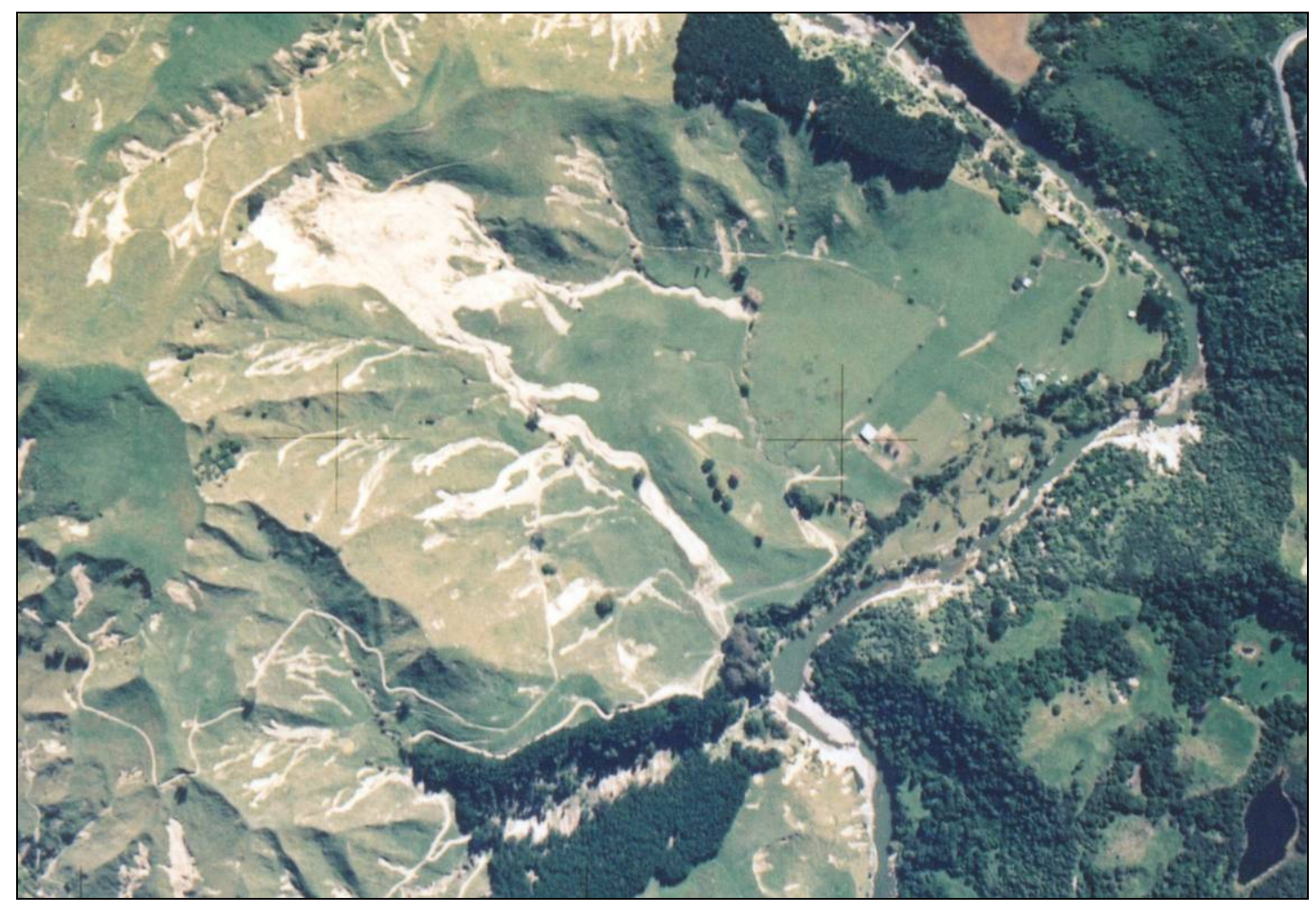

Figure 6-6 Vertical aerial photograph taken within 3 months of the February 2004 event, source L. Cairns 2004

\subsection{Catchment Mapping}

For sediment budget creation and estimation of damage ratios (proportion of slopes affected or proportion of total area affected) within the catchment an accurate map of the catchment as well as each landslide was required. The process by which these maps were created was to measure the area (and calculate volume with measured depth) of individual landslides within the catchment using GPS technology. For the overall catchment map, a DEM was created using GPS measurements of the catchment, providing greater accuracy than existing $20 \mathrm{~m}$ contour data (see Chapter 7).

\subsection{Landslide types within the catchment}

The catchment contains landslides on the upper, middle, and lower parts of the slopes. Landslides from the event were found on both concave and convex slopes within the catchment. Disturbed material ranged from bedrock to regolith to colluvium, and sometimes a combination of materials. Types of landsliding include multiple-headed slides, earth flows, deep-seated rotational bedrock slides, and shallow translational slides. Volumes of individual landslides ranged from less than $50 \mathrm{~m}^{3}$ to greater than 
$200000 \mathrm{~m}^{3}$. A closer look at some of the landslides and material types can be seen in Figure 6-7 A-H.

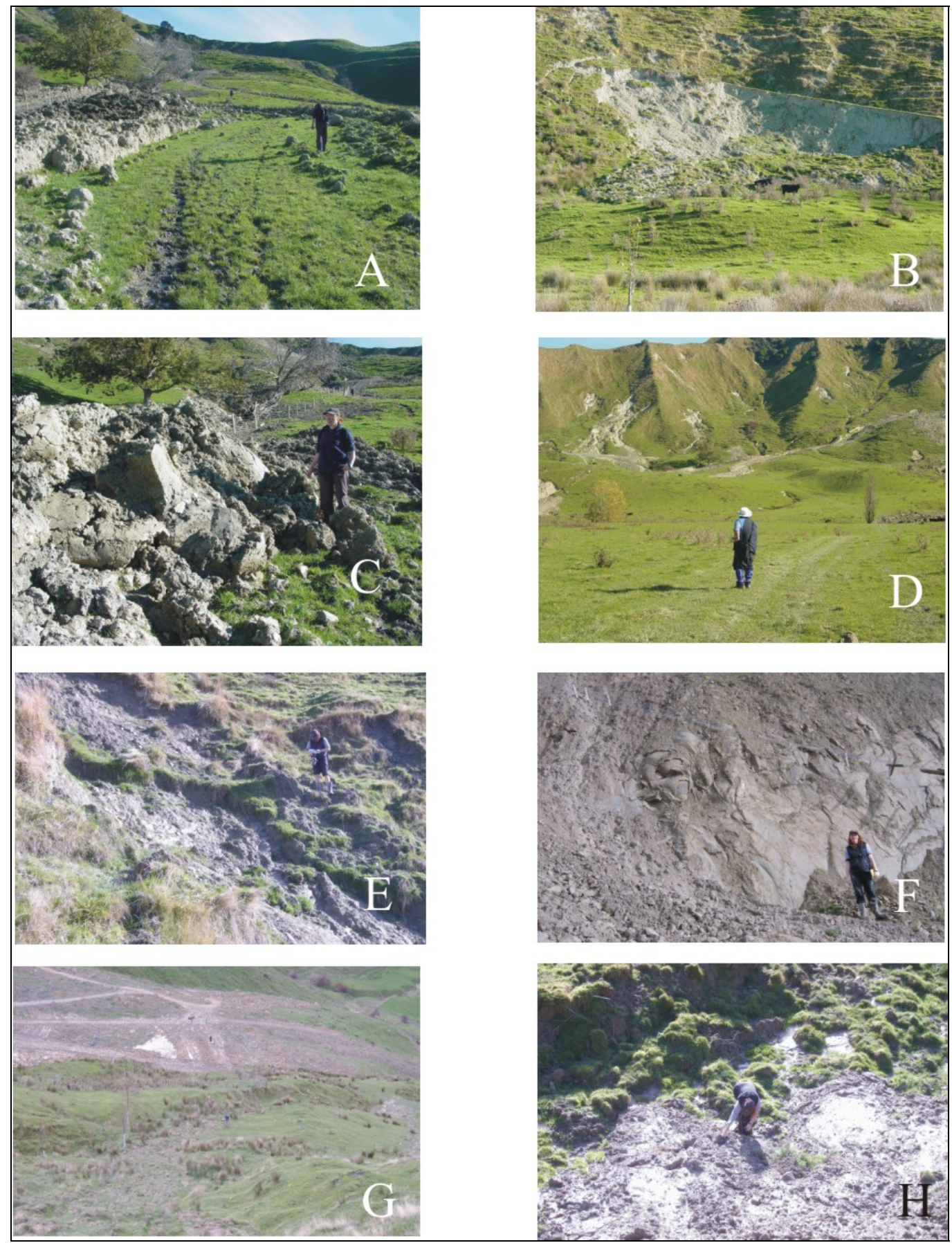

Figure 6-7 A - a new track for farm vehicles has been formed as debris material has covered existing tracks. B - a translational slide with a road cut as the upper face of the scar. C - debris flow material from the largest slide, person is $1.6 \mathrm{~m}$ tall. $\mathrm{D}$ - looking into the western side of the catchment, showing landslides on different parts of the slope. $E$ - the scars of a multiple-headed translational landslide that becomes a debris flow further downslope. $F$ - exposed Mudstone bedrock in the scar of the Octopus landslide. $G$ - looking downslope into the debris flow material of the Octopus landslide, with newly established farm vehicle tracks, $\mathbf{H}$ - quicksand-like flow material still saturated several months after the event, photographs Hancox 2004 and Crozier 2004 
Approximately half of the landslides exhibited fluvial coupling in either scar or runout area, and in one case both. The earliest photos were taken in May and the majority of the field photos in August and September. During the August field work period (six months after the event) debris material and slopes were still saturated, with some drying of slopes and hardening of debris by the final field work dates in October. Fencing repair work was ongoing right through the field study period and was not completed by October 2004, eight months after the landslide event.

\subsection{Summary}

The Octopus Catchment was selected based on its lithology, topography, accessibility, and the variety of landslide types and occurring on differing slope positions. The catchment is approximately $50 \mathrm{~km}$ northeast of Wanganui adjacent to State Highway 4, also known as the Parapara Rd. The current land use of the catchment is pasture production for sheep and beef farming. The largest landslide in the catchment is a deep-seated bedrock slide; however other slides have formed in regolith and colluvium. Some slides have developed into earth flows with extensive runout of flow material. The hillslopes remained saturated for months after the February event, as did earth flow material. 


\section{Catchment-based Study; Methodology and Results}

\subsection{Introduction}

The February 2004 landslide event affected an area of over $16,000 \mathrm{~km}^{2}$ within the lower North Island; the areal extent of damage for the Wanganui-Manawatu region is calculated to be $8,000 \mathrm{~km}^{2}$ (Hancox and Wright 2005a). For an event of this magnitude methods of measurement and analysis must be used which provide comparable and useful data. Two overall methodologies involving data collection and data analysis were used; field methods and non-field methods. The study catchment in the Mangawhero hill country was examined using a combination of field and nonfield methods; while the regional analysis was undertaken using mostly non-field methodologies, and five days of aerial surveillance (see Chapter 8). The aerial surveillance provided the impetus for the undertaking of this study (and others; e.g. Hancox et al. 2004, Hancox and Wright 2005b), and provided some initial indication of the extent, variety, and effects of damage from visual observations.

Following the decision to create this study of the February 2004 landslide event, a study catchment was selected (see Chapter 6), and methodologies developed for investigating the geomorphic significance of the event. Measurements and observations undertaken in the field were:

- $\quad$ Landslide scar and runout area;

- $\quad$ Landslide scar and runout depths;

- $\quad$ Changes in slope angle between original hill slope angle, and scar and runout slopes angles;

- $\quad$ Fluvial connectivity of landslides;

- $\quad$ Evacuation percentage of runout debris from scar area;

- $\quad$ Landslide material types (bedrock, regolith, colluvium);

- $\quad$ Landslide types (e.g. translational slide, debris flow);

- $\quad$ Position on slope of landslide scar area (upper, middle, lower), and;

- $\quad$ Creation of a Digital Elevation Model (DEM) of the catchment. 


\subsection{Field Methods}

\subsubsection{Mapping the Catchment Topography}

The construction of a DEM from GPS data was undertaken. A base station was erected to provide calibration data for the location and elevation points collected with hand-held Trimble ${ }^{\circledR}$ GPS units. Traversing the catchment on foot while holding the GPS units at a constant height above the ground provided 15,000 data points from which to construct the DEM. Some parts of the catchment, particularly close to the upper ridges, did not receive a continuous signal from the required number of satellites (at least five) and precision mapping of these areas was difficult. However, the areas affected by satellite signal loss were not large and also were almost entirely unaffected by landsliding. To complement the catchment DEM, a digital $20 \mathrm{~m}$ contour map of New Zealand was available to use as a backdrop to the GPS data where areas of low signal had provided insufficient data. The DEM was created only to provide a layer on which to calculate the area of landslide scars and runouts. The resolution of the DEM created from GPS points and contour data, while being greater than that of DEM derived from existing $20 \mathrm{~m}$ contours, is still not sufficient to produce high resolution maps Figure 7-1. However the DEM layer produced was of sufficient accuracy for the measurements required in this study. For comparison a bestresolution map produced with Tumonz software is provided in Figure 7-2.

\subsubsection{Mapping Scar Areas and Runout Areas}

Using the hand-held GPS unit 26 landslide scar and runout areas were traced by walking around the perimeter of each of these features. For nearly all landslides in the study catchment some part of the runout material remained in the scar area, however in one instance (landslide ID 24) there had been complete evacuation of runout material into a stream channel. Scar and runout boundaries were in general easily traced; however difficulties arose where several scar areas fed material into one combined landslide runout area. In two instances, this was the case (landslide ID $13 / 14$, originally mapped as two landslides on a low-visibility day; and landslide ID 23 a triple-headed landslide). Figure 7-3 is a 2D map showing position of the landslides. Figure 7-4 shows landslides with scar areas unobscured (i.e. runout material not fully evacuated is removed from map). 
With scar and runout boundaries mapped by GPS as polygon areas, it was possible to overlay these polygons onto the catchment DEM, which in turn made possible calculation of areas in square metres for each of the scar and runout polygons. Scar areas ranged between $30 \mathrm{~m}^{2}$ (ID number 6) and $14265 \mathrm{~m}^{2}$ (ID number 18), runout areas ranged from $0 \mathrm{~m}^{2}$ (ID number 24) to $53718 \mathrm{~m}^{2}$ (ID number 18). Detailed descriptions of individual landslides' measurements and characteristics are provided in Appendix 1. 


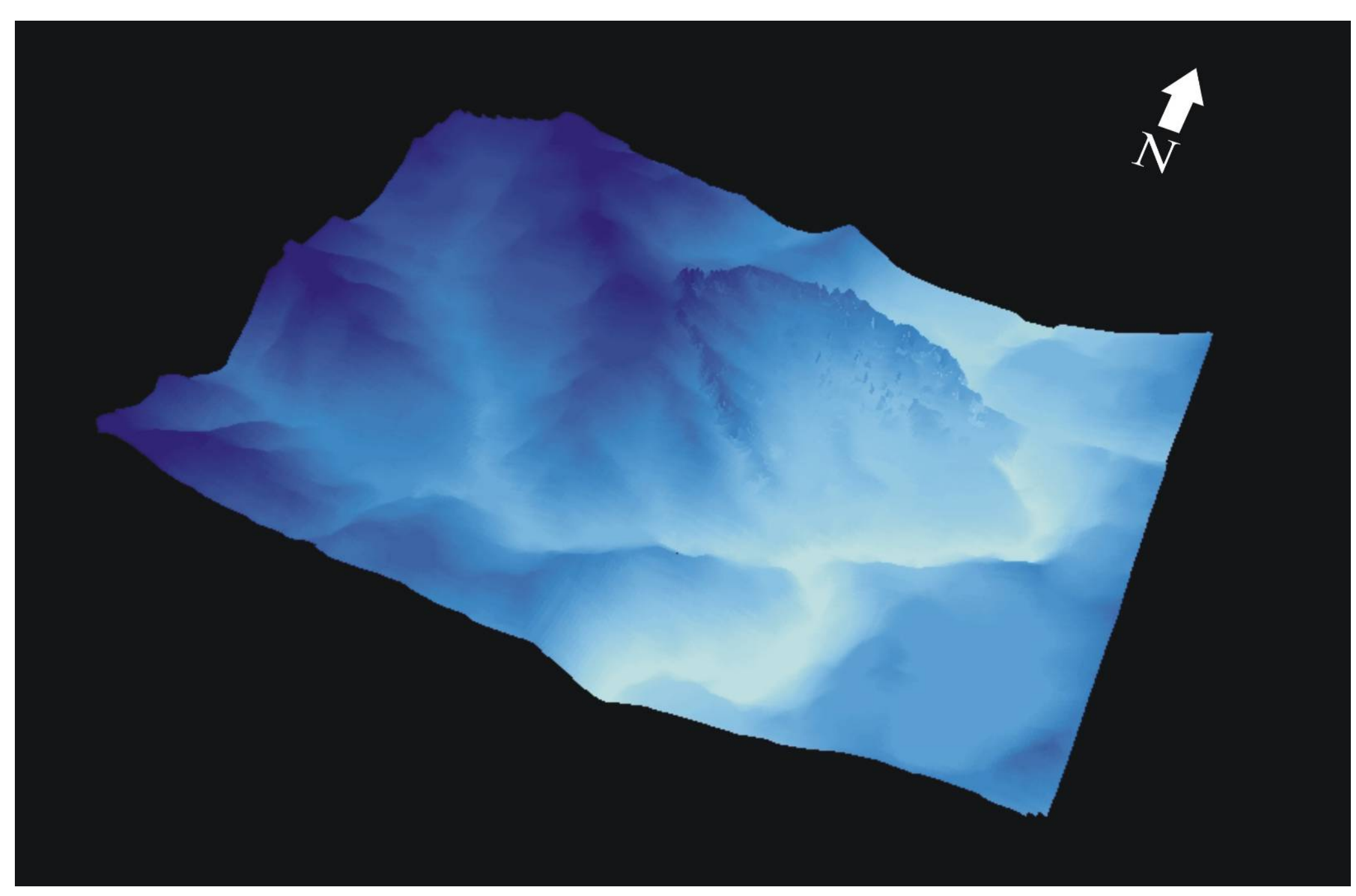

Figure 7-1 Combined $20 \mathrm{~m}$ contour data and GPS data, the catchment has a jagged appearance due to vertical exaggeration factors used in the $3 \mathrm{~d}$ projection, the Mangawhero River is seen as a white valley, little detail is able to be seen in the 3-d projection but this is irrelevant when calculating areas 


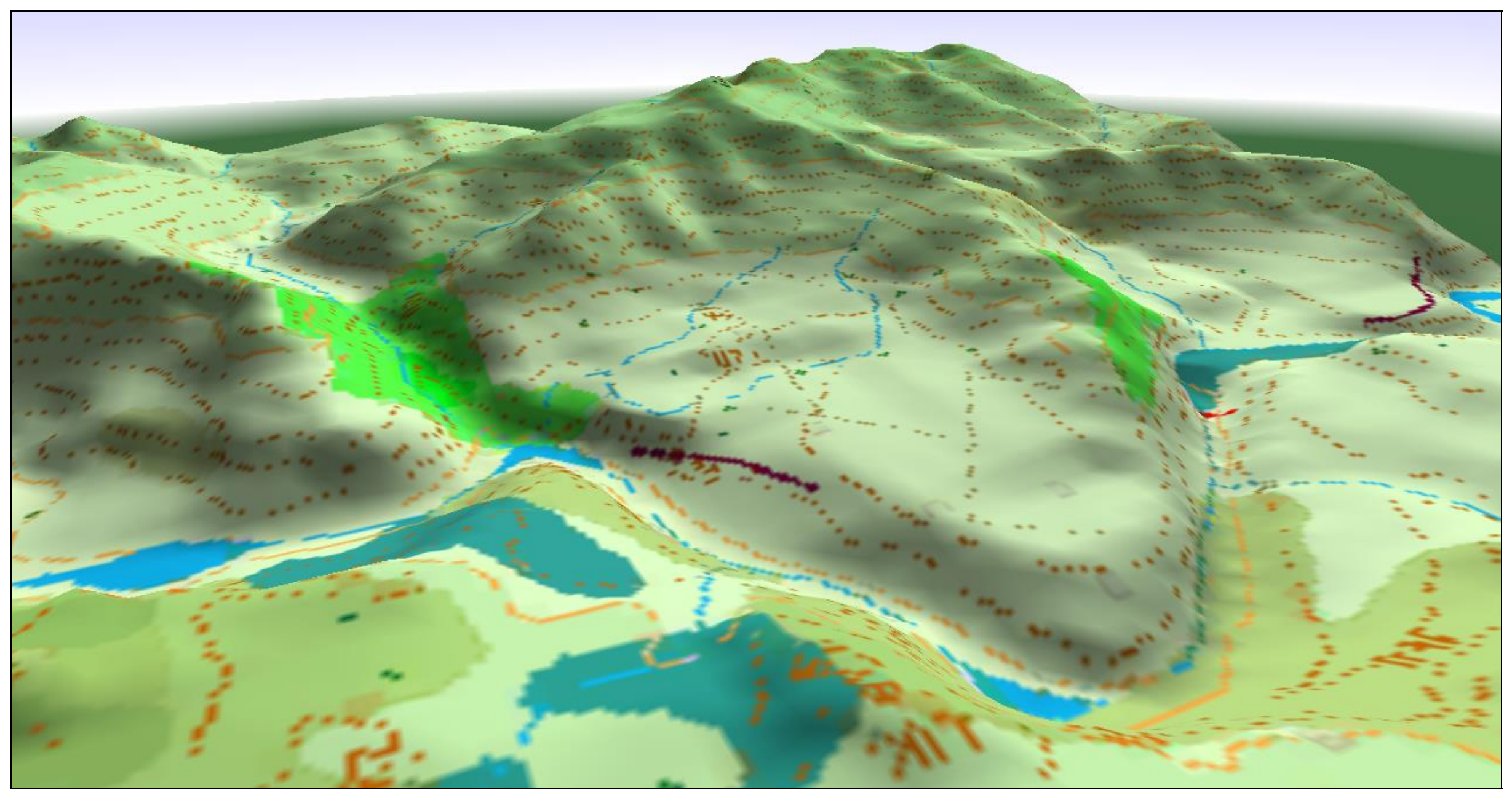

Figure 7-2 Tumonz projection of the Octopus catchment, produced from 20m contour data and looking into the catchment from the north-east 


\section{Mangawhero Valley Landslides}

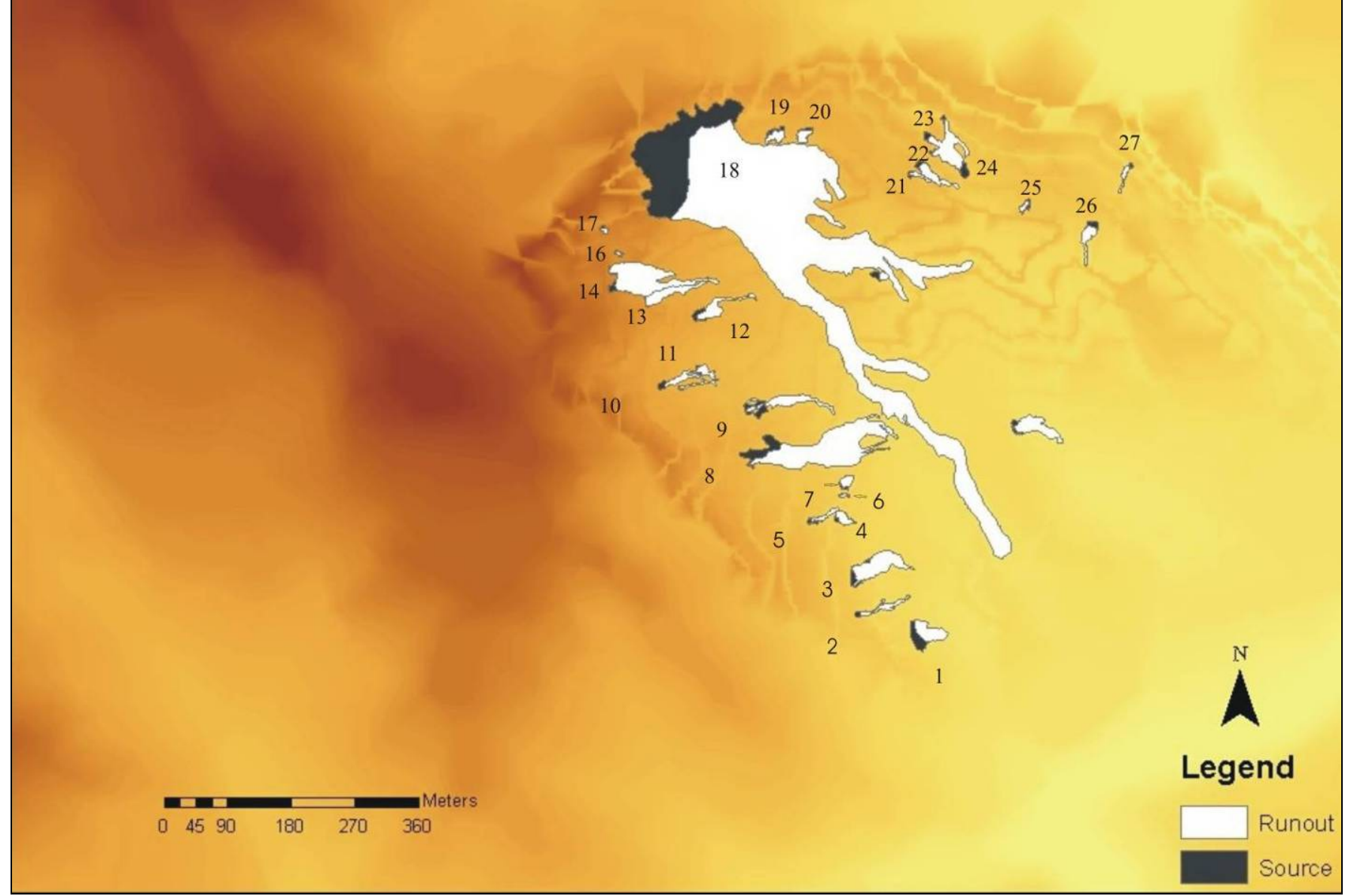

Figure 7-3 Location and number ID of landslides in the Octopus Catchment. Note the discrepancy between the 20m contours and the GPS data is visible as faint lines. 


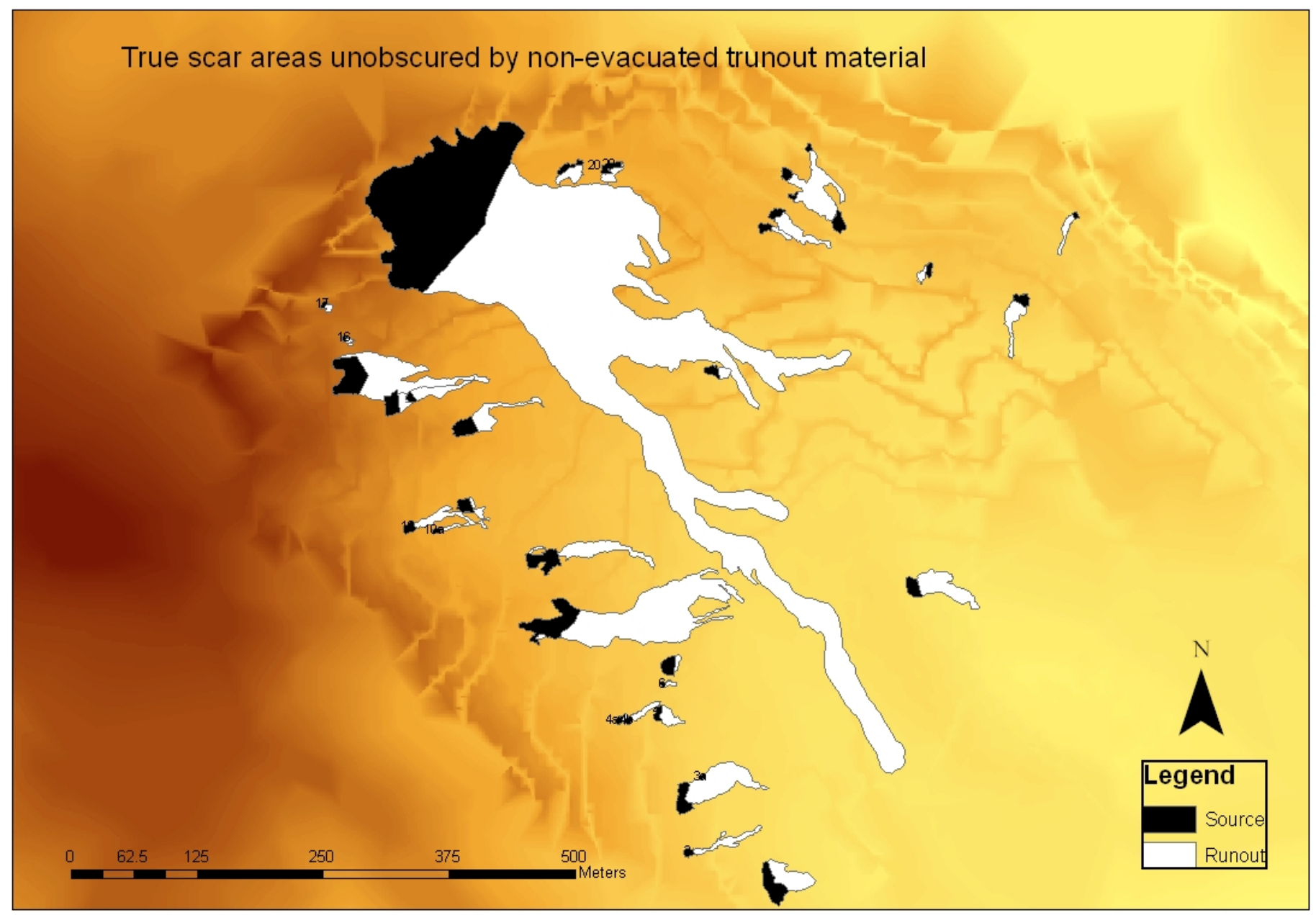

Figure 7-4 When un-evacuated runout material is removed from the map true scar (source) areas are visible. Compare this map with Figure 7-3 to see differences 


\subsubsection{Estimating Scar and Runout Depths}

Using a handheld soil probe runout depth (Figure 7-5) was measured at several positions across the runout material and an average runout depth estimated for each landslide. Scar depth was measured using the height of visible scar face and the difference in angles between original slope angle and scar slope angle. The method of scar and runout depth calculation is shown in Figure 7-6. Scar depths and runout depths are presented with scar and runout areas and volumes in (Section 7.2.5).

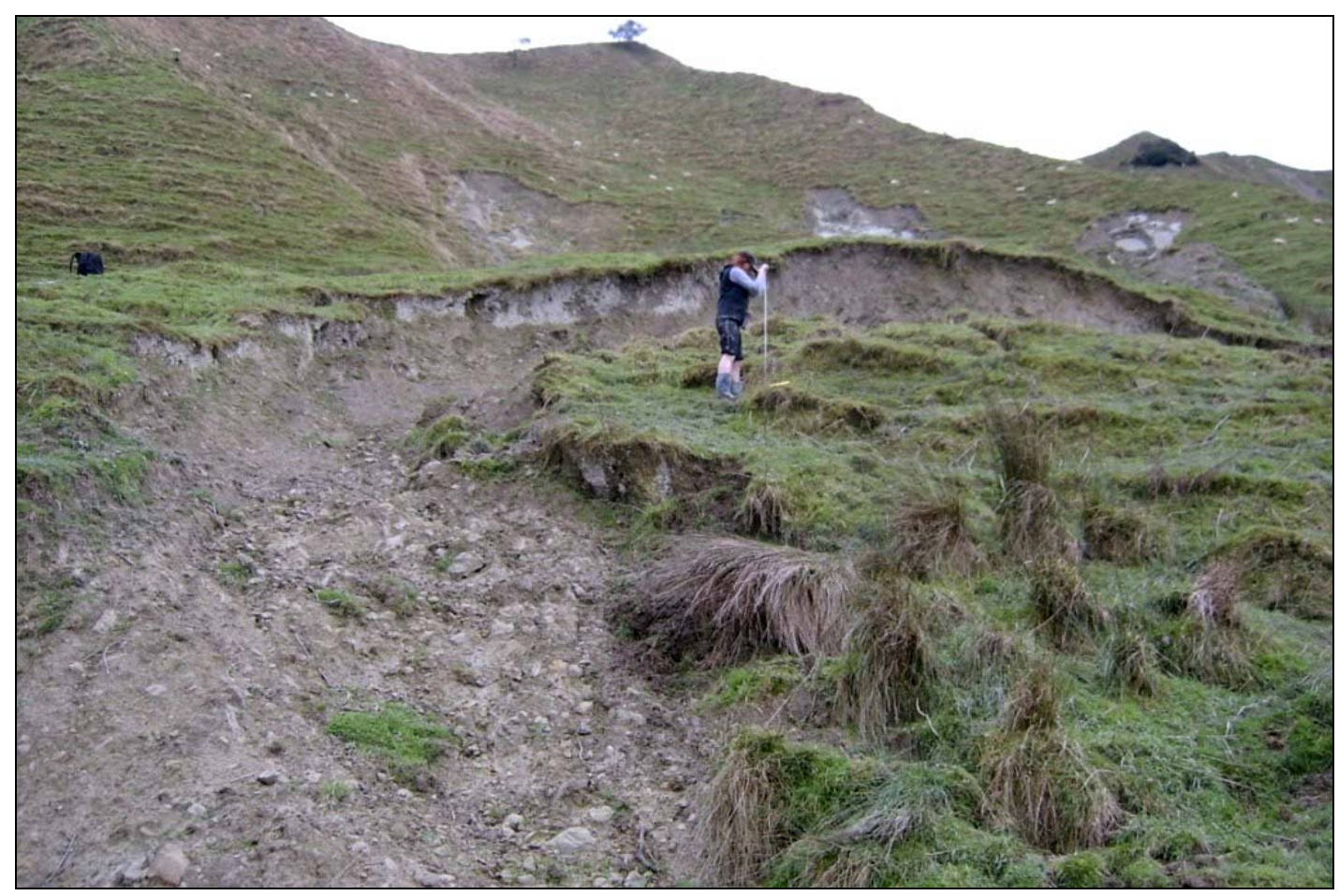

Figure 7-5 Using the soil probe to gauge runout/deposit depth, as the probe is inserted vertically and not perpendicular to the slope a basic calculation is used to convert vertical depth to slopeperpendicular depth (see Figure 7-6) 


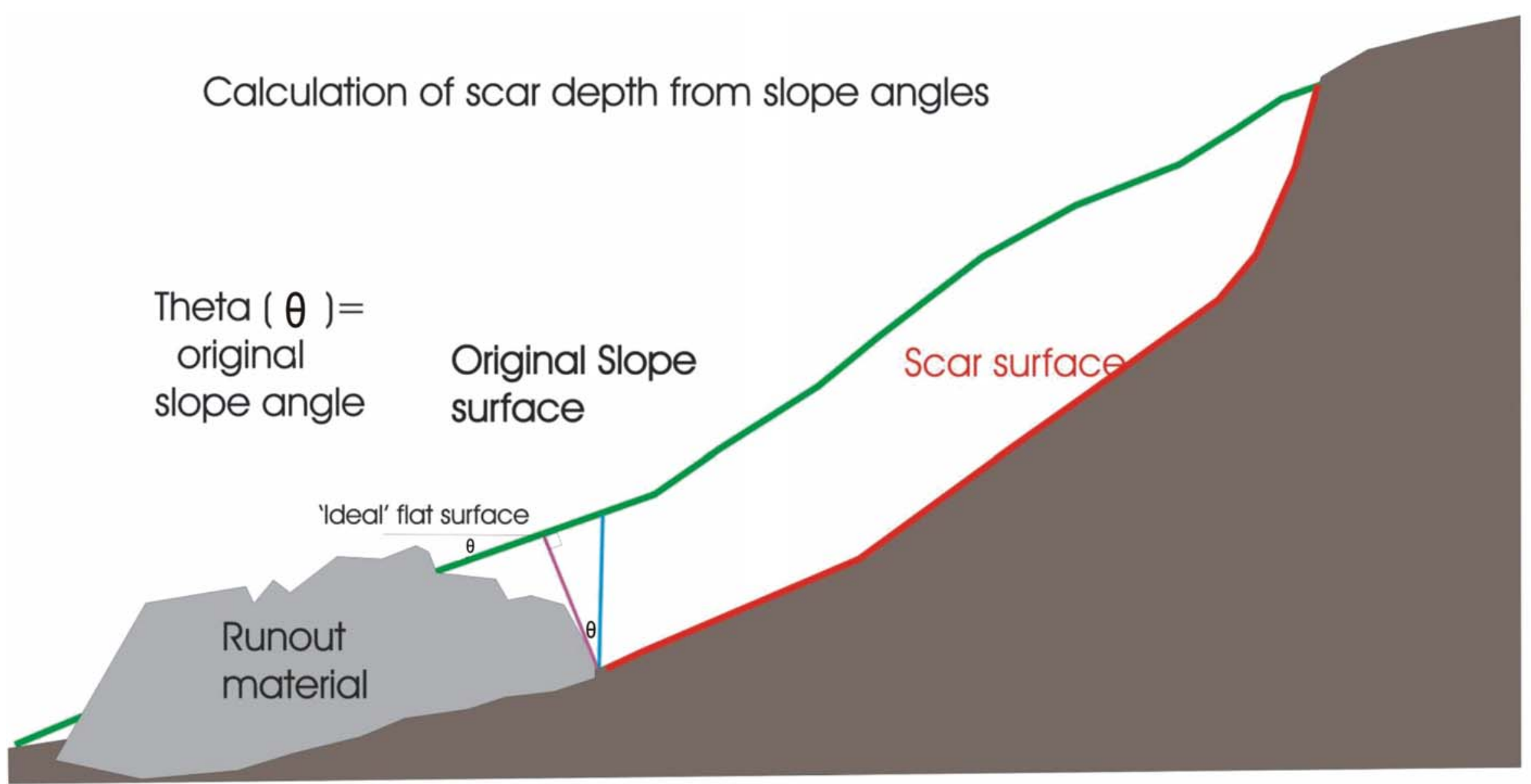

Actual depth of scar (pink line) is cos field-measured vertical depth of scar

$\mathrm{x}$ hypoteneuse (blue line) of right triangle, hypoteneuse is

Figure 7-6 Method for estimating scar depth (pink line) from field measurements of vertical scar depth (blue line) and slope angles (scar angle and original hillslope angle); scar depth is measured at right angles from new surface 


\subsubsection{Slope Angle Measurements}

For estimation of scar depths and evaluation of landform change in the study catchment, original slope, scar slope and runout slope angles were measured. This was done using a hand-held Abney level whereby a person of known height was used as a reference point for the operator of the level. Where both people (operator and reference person) are the same height the level is focussed on the reference person's eye; where there is height discrepancy the level is aimed at whatever point on the reference person is the same height as the operators eye when standing on level ground (Figure 7-7). Measurements may be made either upslope or downslope.

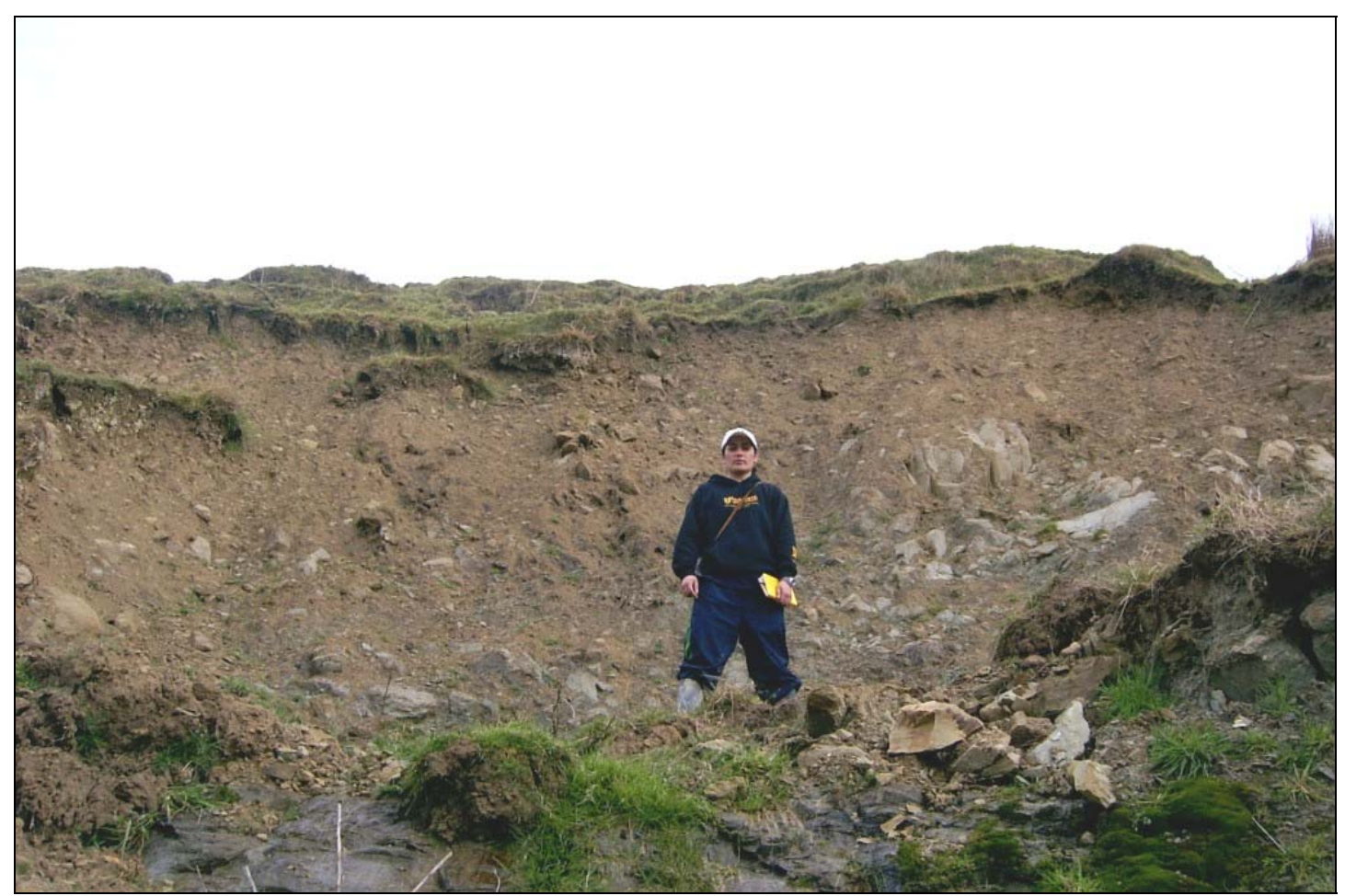

Figure 7-7 The person in the photo is the same height as the Abney level operator, therefore the level is aligned with the reference person's eye; reference person stands at the upper limit of runout material for calculation of runout slope angle

Original slope angles were measured on both flanks of each landslide and an average original slope angle produced. Scar angle was measured from the base of the visible scar to the upper scar edge. Runout angle was measured along the main flow lobe to the upper edge of runout material in the case of earthflow, and for more blocky deposits from the upper edge of deposit along a profile covering the main deposit area. 


\subsubsection{Calculation of scar and runout volumes}

Volumes of scar and runout material for each landslide were calculated by the simple calculation of area $\mathrm{x}$ average depth. Each scar and runout volume was calculated separately; however for multiple-headed landslides (e.g. landslide IDs 13 and 14) it was necessary to sum all contributing scar volumes and associated runout volumes (Table 7-1). The reason for this is that while mapping individual scar areas on a multiple-headed landslide is relatively straightforward; defining the boundaries of runout areas was not as straightforward. It was impossible in some cases to determine how much material had originated from each scar; therefore to avoid error, arbitrary non-overlapping runout boundaries were defined for each multiple-headed landslide based on best guess estimates of where the runout material from one scar ended and the next began. From volume calculations it can be seen that the best guess estimate for landslides ID numbers 13 and 14 are not very accurate (it can be seen that landslide ID 13 appears to have a $75 \%$ greater runout volume than scar volume), however when the scar volumes and runout volumes are combined the scar and runout volume ratios are realistic based on other landslides within the catchment. Note in Table 7-1, there are no calculations for landslide ID 15; this landslide was in a slope position too dangerous to map with GPS (Figure 7-8).

Figure 7-8 Landslide 15 on a very steep slope in the uppermost part of the catchment was unable to be mapped by GPS as the wet and slippery slope presented too much of a risk to the mapper; interesting to note is the high liquidity of the earthflow material, and the scouring of the channel produced by high velocity flow.

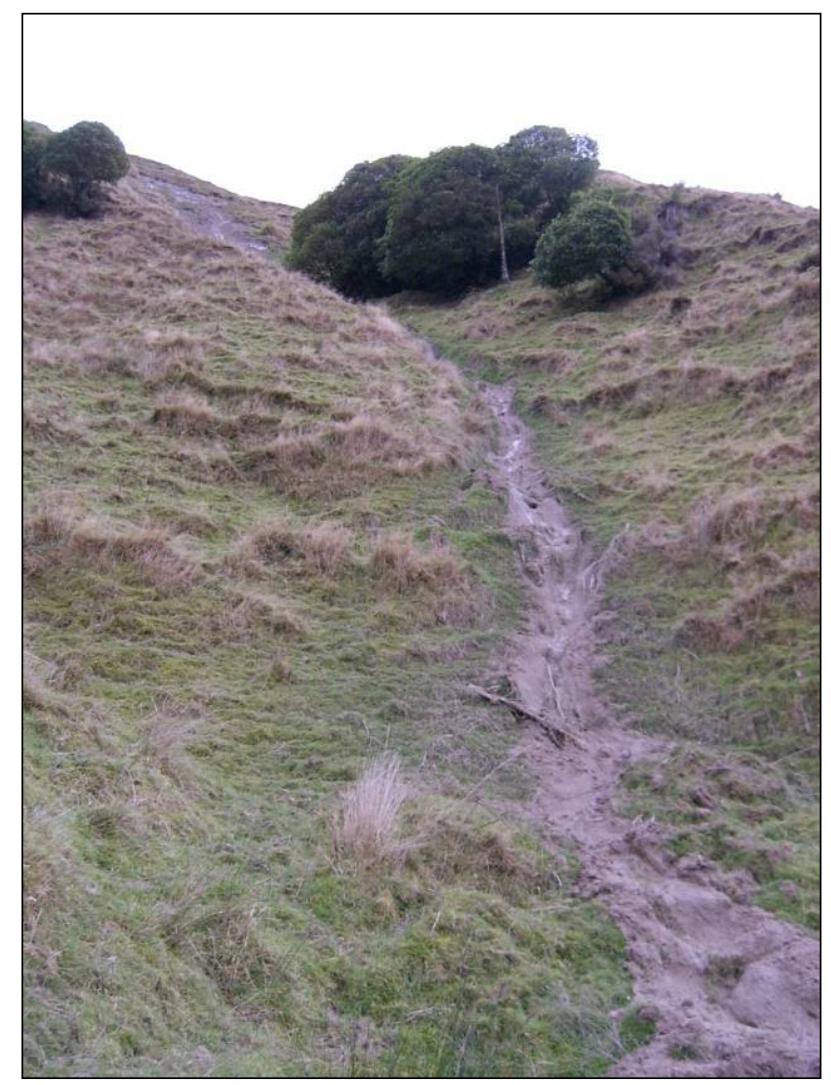


Table 7-1 Volume calculations, including total and percentage material lost from hillslope system to fluvial system.

\begin{tabular}{|c|c|c|c|c|c|c|c|c|c|c|c|c|}
\hline L/s ID & Scar Area & Scar Depth & $\cos \theta$ & depth $x \cos \theta$ & Scar Volume & Runout Area & Runout Depth & $\cos \theta$ & depth $x \cos \theta$ & Runout Volume & Material Loss & \%Loss \\
\hline & $\mathrm{m} 2$ & $\mathrm{~m}$ & & $\mathrm{~m}$ & $\mathrm{~m} 3$ & $\mathrm{~m} 2$ & $\mathrm{~m}$ & & & m3 & $\mathrm{m} 3$ & \\
\hline 1 & 537.1 & 0.69 & 0.83 & 0.60 & 322.2 & 858.3 & 0.43 & 0.83 & 0.35 & 300.4 & 21.82 & 6.8 \\
\hline 2 & 69.2 & 0.66 & 0.84 & 0.55 & 38.3 & 418.0 & 0.10 & 0.84 & 0.08 & 33.4 & 4.90 & 12.8 \\
\hline 3 & 358.6 & 3.80 & 0.87 & 3.31 & 1185.5 & 1737.7 & 0.55 & 0.87 & 0.48 & 831.5 & 354.00 & 29.9 \\
\hline 4 & 91.9 & 0.75 & 0.81 & 0.61 & 55.8 & 214.6 & 0.20 & 0.81 & 0.16 & 34.8 & 21.05 & 37.7 \\
\hline 5 & 90.6 & 0.82 & 0.90 & 0.74 & 66.9 & 309.6 & 0.20 & 0.90 & 0.18 & 55.7 & 11.16 & 16.7 \\
\hline 6 & 29.7 & 1.50 & 0.91 & 1.37 & 40.6 & 55.4 & 0.40 & 0.91 & 0.36 & 20.2 & 20.41 & 50.3 \\
\hline 7 & 212.7 & 1.48 & 0.94 & 1.39 & 295.9 & 221.5 & 1.30 & 0.94 & 1.22 & 270.6 & 25.28 & 8.5 \\
\hline 8 & 1112.8 & 2.70 & 0.91 & 2.46 & 2734.0 & 6553.7 & 0.42 & 0.91 & 0.38 & 2504.8 & 229.20 & 8.4 \\
\hline 9 & 499.4 & 0.80 & 0.91 & 0.73 & 363.5 & 1071.1 & 0.30 & 0.91 & 0.27 & 292.4 & 71.13 & 19.6 \\
\hline 10 & 149.9 & 0.67 & 0.89 & 0.59 & 89.0 & 595.1 & 0.15 & 0.89 & 0.13 & 79.4 & 9.55 & 10.7 \\
\hline 11 & 179.3 & 0.48 & 0.92 & 0.44 & 79.2 & 252.2 & 0.30 & 0.92 & 0.276 & 69.60 & 9.56 & 12.1 \\
\hline 12 & 343.4 & 1.10 & 0.86 & 0.95 & 324.9 & 764.2 & 0.40 & 0.86 & 0.35 & 267.5 & 57.43 & 17.7 \\
\hline $13 / 14$ & 1329.9 & 1.79 & 0.91 & 1.63 & 2166.3 & 4417.4 & 0.40 & 0.91 & 0.36 & 1607.9 & 558.34 & 25.8 \\
\hline 16 & 23.8 & 0.45 & 0.91 & 0.41 & 9.7 & 52.4 & 0.20 & 0.91 & 0.18 & 9.5 & 0.21 & 2.2 \\
\hline 17 & 35.1 & 0.60 & 0.83 & 0.50 & 17.5 & 57.8 & 0.30 & 0.83 & 0.25 & 14.4 & 3.09 & 17.7 \\
\hline 18 & 14264.8 & 17.00 & 0.83 & 14.11 & 201276.9 & 53717.6 & 3.04 & 0.83 & 2.52 & 135549.3 & 65727.64 & 32.7 \\
\hline 19 & 35.1 & 0.55 & 0.89 & 0.49 & 17.2 & 57.8 & 0.25 & 0.89 & 0.22 & 12.9 & 4.32 & 25.1 \\
\hline 20 & 249.0 & 0.50 & 0.81 & 0.41 & 100.8 & 324.0 & 0.25 & 0.81 & 0.20 & 65.6 & 35.24 & 34.9 \\
\hline 21 & 121.8 & 0.90 & 0.91 & 0.82 & 99.8 & 122.6 & 0.60 & 0.91 & 0.55 & 66.9 & 32.84 & 32.9 \\
\hline 22 & 218.1 & 1.90 & 0.84 & 1.60 & 348.0 & 796.7 & 0.40 & 0.84 & 0.34 & 267.7 & 80.32 & 23.1 \\
\hline 23 & 191.7 & 2.26 & 0.91 & 2.06 & 394.2 & 1560.8 & 0.20 & 0.91 & 0.18 & 284.1 & 110.13 & 27.9 \\
\hline 24 & 191.5 & 1.81 & 0.93 & 1.68 & 322.4 & 0.0 & 0.00 & 0.93 & 0.00 & 0.0 & 322.40 & 100.0 \\
\hline 25 & 74.4 & 0.75 & 0.82 & 0.62 & 45.8 & 122.5 & 0.40 & 0.82 & 0.33 & 40.2 & 5.61 & 12.2 \\
\hline 26 & 145.1 & 0.80 & 0.82 & 0.66 & 95.2 & 472.2 & 0.20 & 0.82 & 0.16 & 77.4 & 17.72 & 18.6 \\
\hline 27 & 31.7 & 0.50 & 0.82 & 0.41 & 13.0 & 188.7 & 0.08 & 0.82 & 0.07 & 12.4 & 0.61 & 4.7 \\
\hline Total & & & & & 210502.5 & & & & & 142768.5 & 67733.96 & \\
\hline
\end{tabular}


Total material removed from the catchment hillslope system (combined scar volumes minus combined runout volumes) is over $67,000 \mathrm{~m}^{3}$. This material has left the catchment via fluvial drainage systems either through direct fluvial coupling or via sheetwash into active drainage channels. Over $94 \%$ of the total material input to fluvial systems has been input by landslide ID 18 "The Octopus", which is fluvially coupled on several earthflow lobes and also in the upper deposit area of thick, blocky material (Figure 7-9 and Figure 7-10).
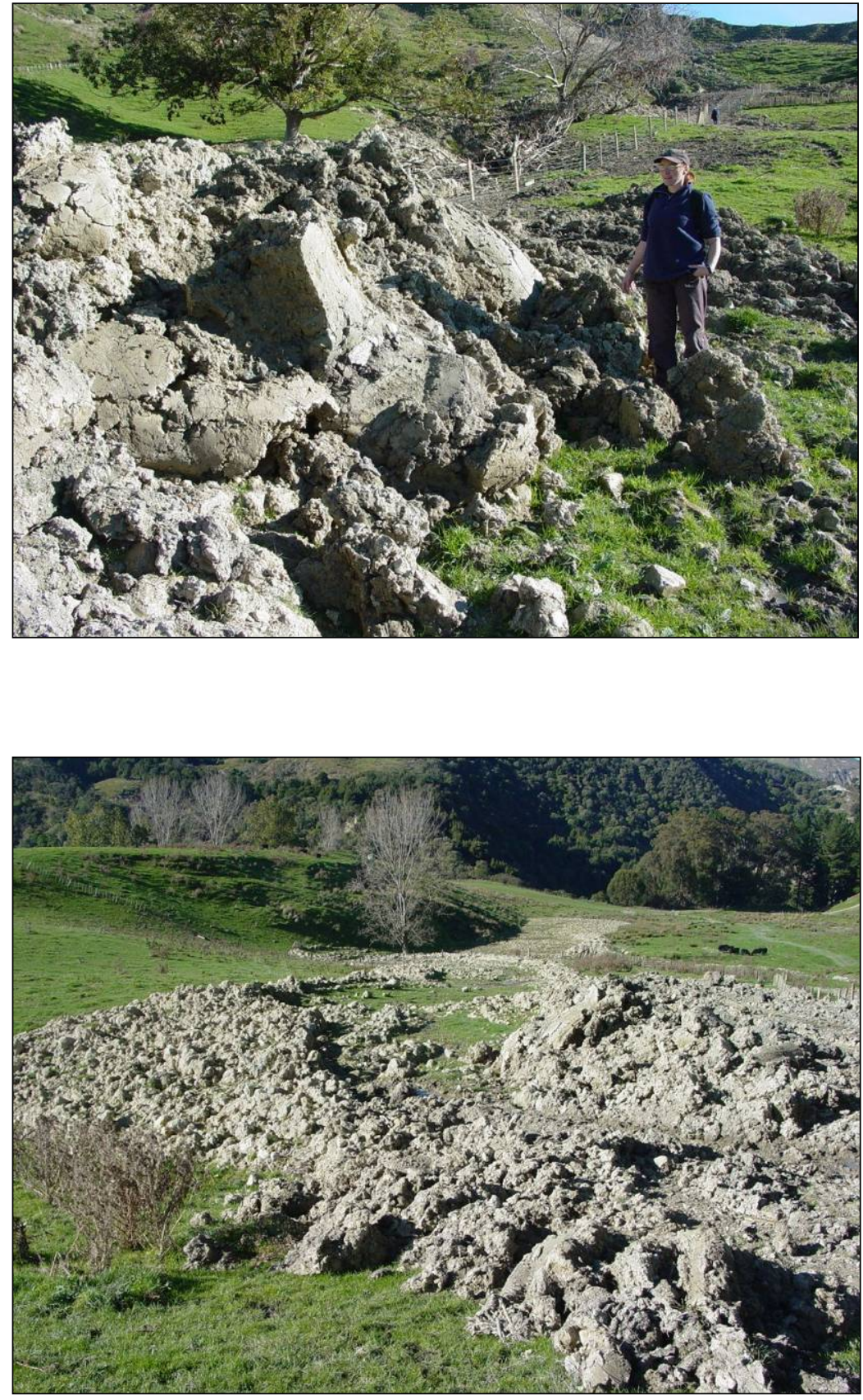

Figure 7-9 Blocky flow material from landslide 18, material is running alongside and into an active stream, stream course lies between tree and flow material path
Figure 7-10 Looking down an earthflow lobe of landslide 18, the flow material feeds into a swamp (beyond cattle), and eventually into the Mangawhero River 
From Table 7-1 it can be seen that the percentage volume of material loss (the difference between scar and runout volume expressed as a percentage rather than an absolute volume) varies from between $2.17 \%$ (landslide ID 16) to $100 \%$ (landslide ID 24). What is not shown is whether individual landslides are fluvially coupled; where there is landslide fluvial coupling the percentage loss of material is generally greater. Average percentage loss for fluvially coupled landslides is $33 \%$ and for noncoupled landslides the average is $14 \%$ loss. Figure $7-11$ provides a basic overview of the percentage of scar volume present as runout volume for all landslides measured.

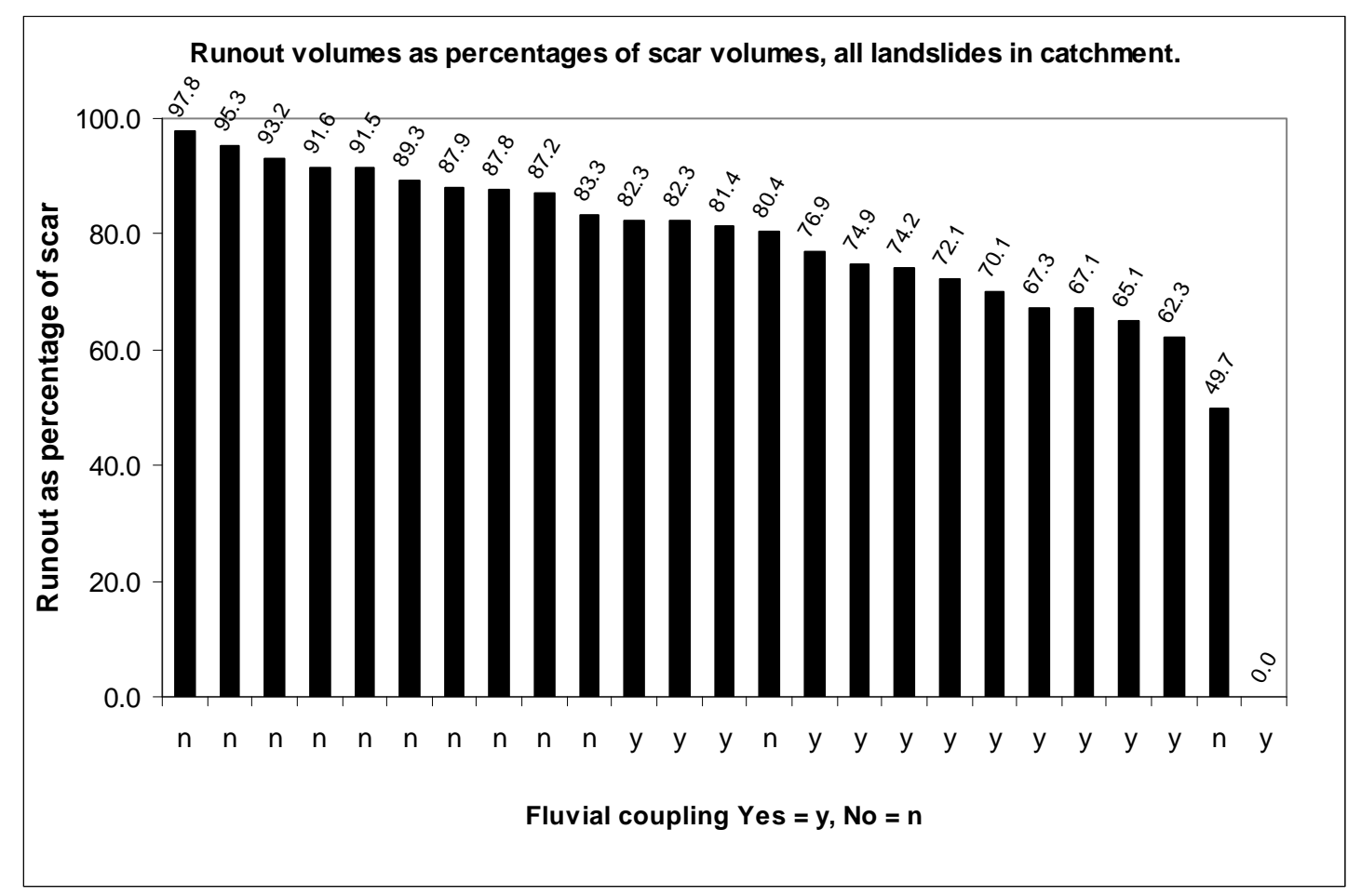

Figure 7-11 Basic comparison of runout volume as \% of scar volumes for all landslides in catchment

Comparisons of material loss (the volume of scar material not present in runout volume) for fluvially coupled and non-coupled landslides are shown in Figure 7-12 and Figure 7-13. Material "lost" from runout volume is mostly through landslide material entering active drainage channels, and therefore being removed from the hillslope system via fluvial transport, and subsequently lost from the catchment. Another, less significant source of material loss, is surface wash, whereby small particles of material are transported by saturated overland flow processes. This form of material transport is ineffective in uplifting and transporting thick earthflow 
material or blocky deposits, however some fraction of fine material will always be washed off the landslide surface and be available for sheet wash transport.

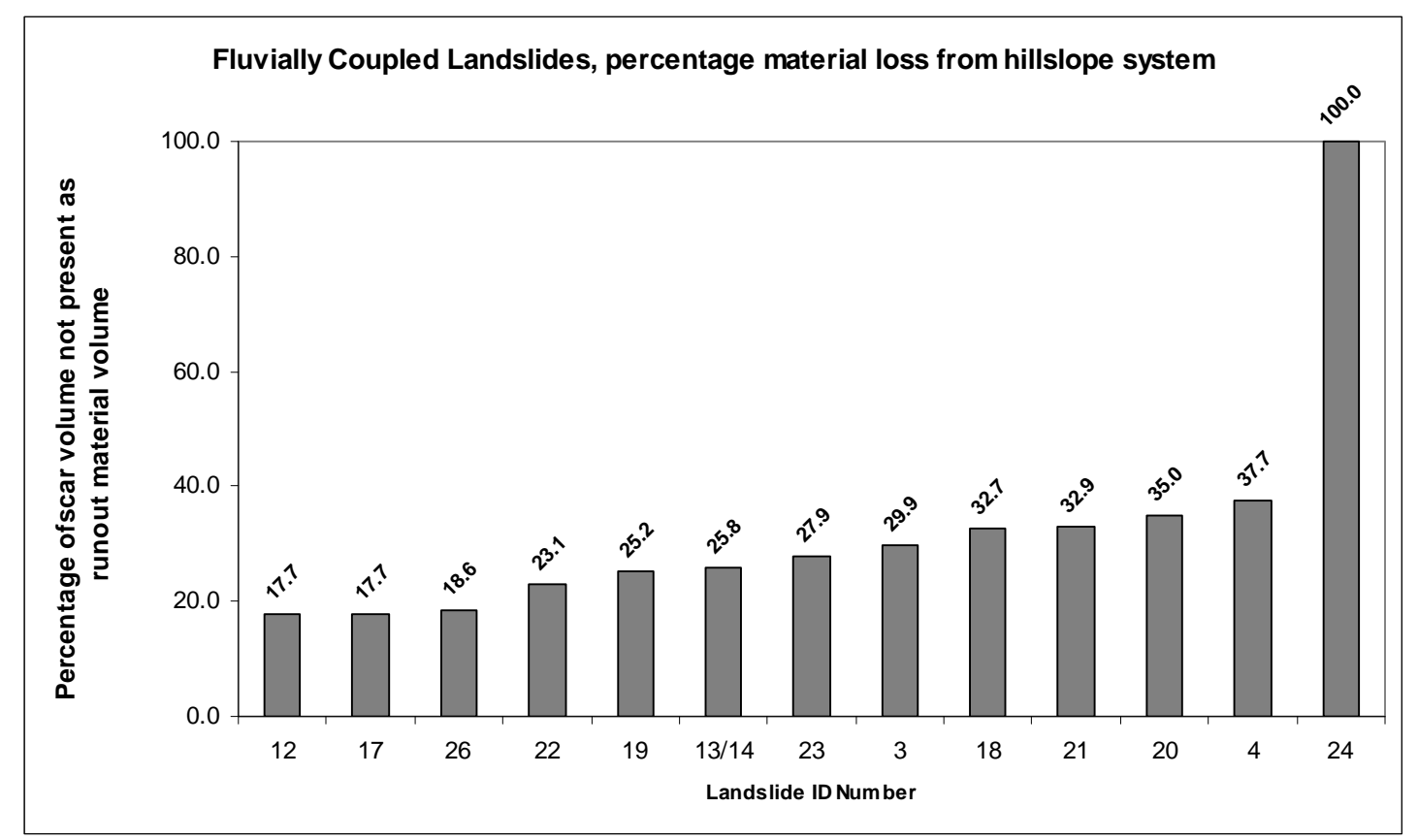

Figure 7-12 The percentage of scar material volume not present in runout volume for fluvially coupled landslides; the average loss of material to fluvial systems is $33 \%$

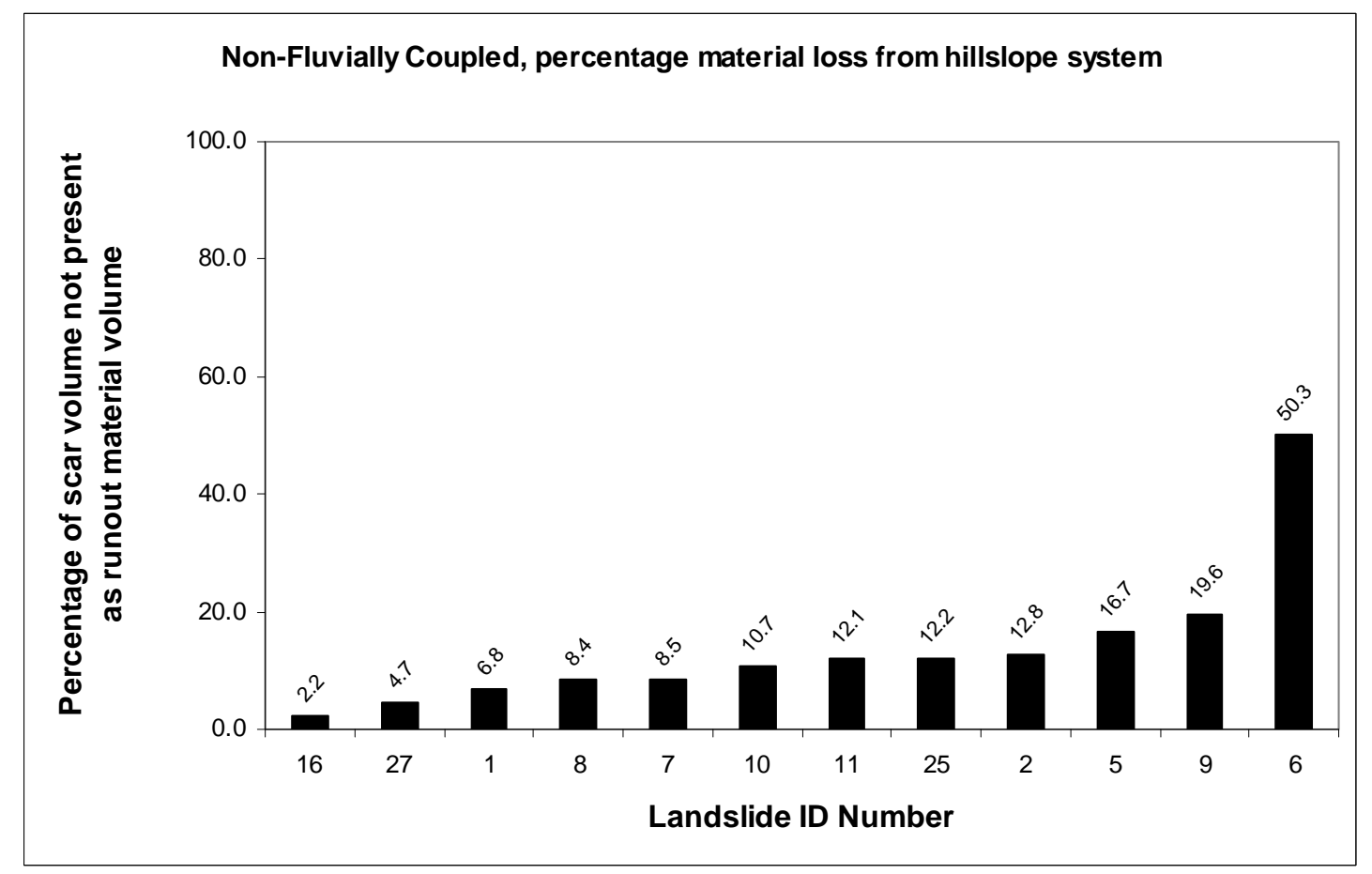

Figure 7-13 The percentage of scar material volume not present in runout material volume for non-coupled landslides, the average loss of material to fluvial systems is $14 \%$ 
From Figure 7-12 and Figure 7-13 it can be seen that some percentage losses for noncoupled landslides are greater than for coupled landslides, for example landslide ID 6 has lost a significant percentage of material whilst it is not fluvially coupled. In the case of landslide ID 6, road cutting has removed a significant portion of runout material due to the landslide deposit area covering an existing farm track, which was re-established before field measurements were undertaken. More detailed descriptions of factors affecting landslide scar and runout volumes (and other landslide characteristics) are provided in Appendix 1.

\subsubsection{Changes to slope angle and slope form, due to landsliding}

Landslide activity on slopes has been observed to alter original slope angles; in particular it has been noted that the scar angle of a landslide is often steeper than the original slope angle (Young 1972). Increases in the natural angle of repose of slope material (Figure 7-14 and Figure 7-15) may contribute to further instability. The oversteepening of slopes by landslide activity or undercutting of the slope basal area by a river provides a pre-conditioning factor for landslide susceptibility. The runout or deposit material of a landslide may create a new slope form also. Typically the runout slope is gentler than the original slope because to initiate landsliding - slope material has lost internal shear strength and therefore cannot maintain the maximum natural angle of repose. Where material is saturated and acts as a liquid in the form of an earthflow it is also likely to form a (relatively) gentle slope as the earthflow material has very low internal strength (Figure 7-16).

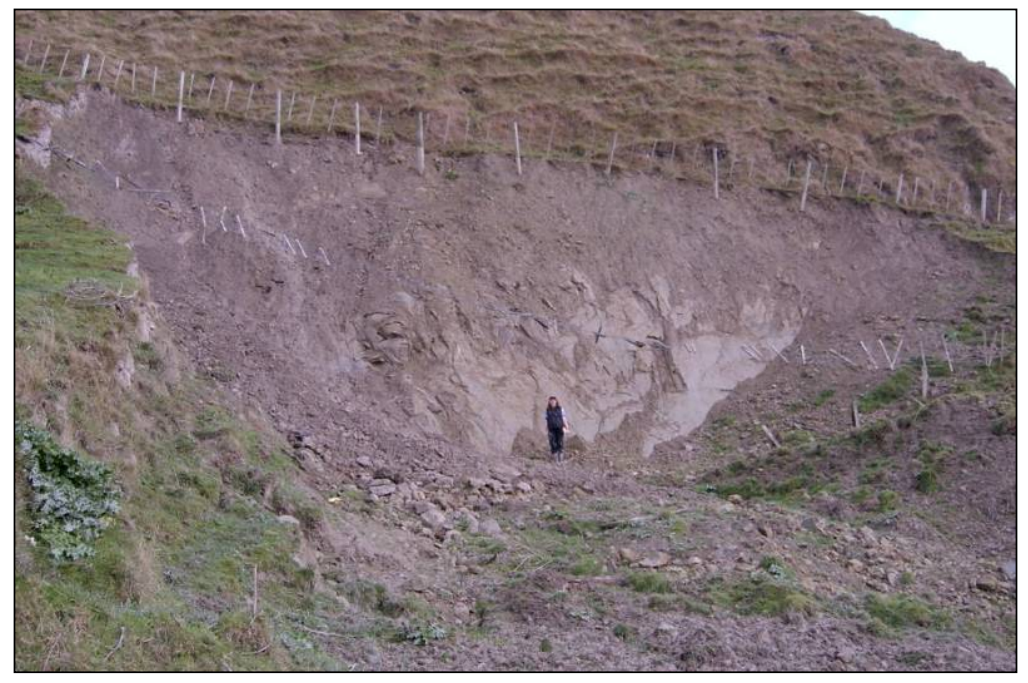

Figure 7-14 Very steep scar face and shallower runout slope on landslide 3 . This landslide formed of bedrock and regolith material failed at the farm track edge. Note the damage to fencing in the right of the photo 

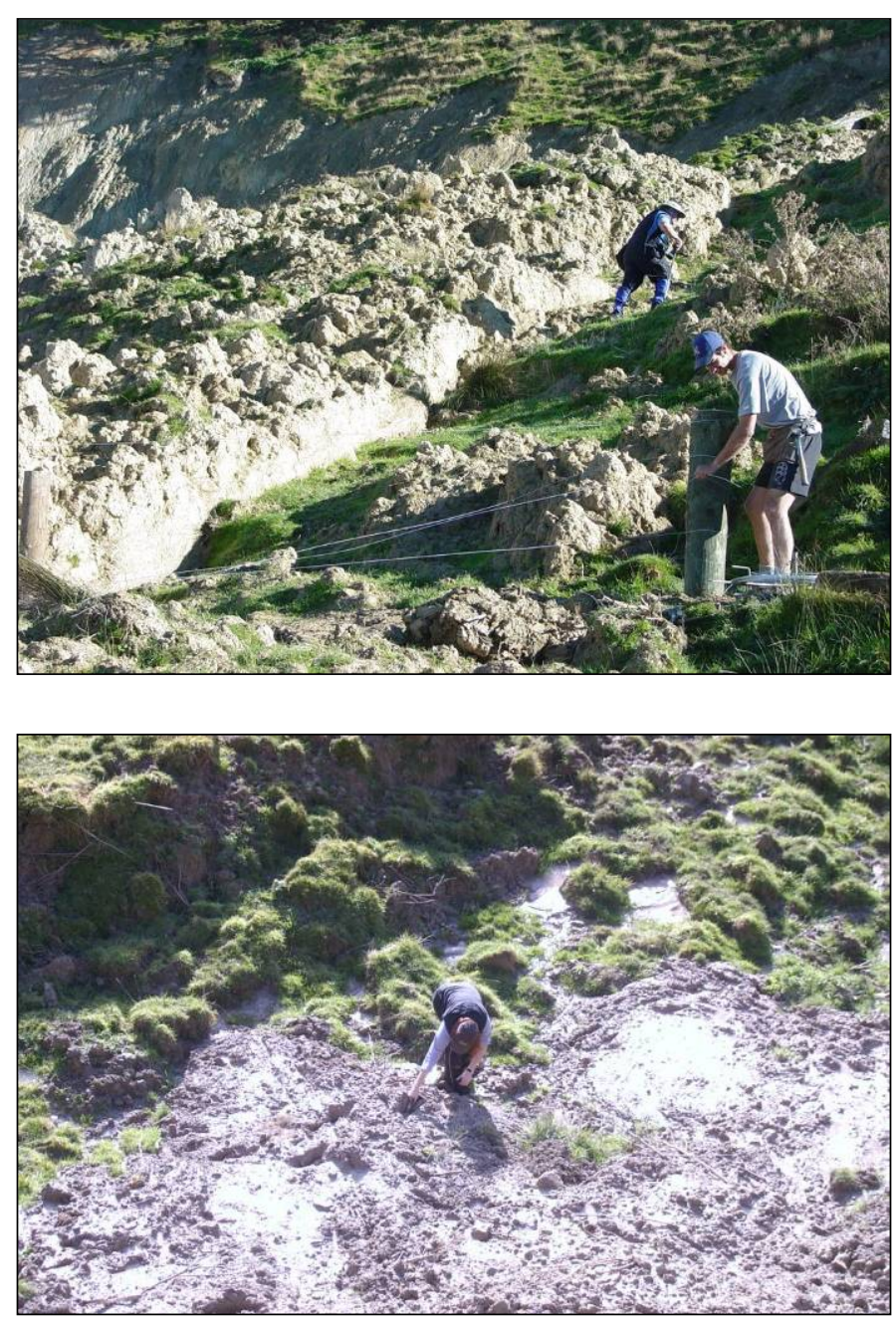

Figure 7-15 Scar and runout material of landslide 18 (The Octopus), several months after the event repairs to fencing and farm tracks were still ongoing

Figure 7-16 Highly liquid runout material at the base of landslide 1 , the saturated material has quicksand-like properties but luckily is only deep enough to claim a gumboot. Material saturated to this degree flows to form very shallow angles (in this instance $11^{\circ}$ )

Differences between pre-event and post-event slope angles were found to be greater between scar angles and original slope angles than runout angles and original slope angles. The average change in slope angle between scar and original slope was $16.2^{\circ}$, with a range of slope steepening values of $4^{\circ}$ to $31^{\circ}$. There is a trend for the change in scar slope angle to increase as original slope angle decreases (Figure 7-17), however as the fitted trend line has an $\mathrm{R}^{2}$ value of only 0.3576 it is not a strong trend. Runout slope angles were generally shallower than original slope angles (Figure 7-18), however in three cases (ID numbers 23, 26 and 27) material had remained blocky and upright and also predominantly in the scar area. For the other 23 landslides measured runout material had created a shallower slope than the original pre-event slope. The average change in slope between original and runout values was $4.7^{\circ}$. 


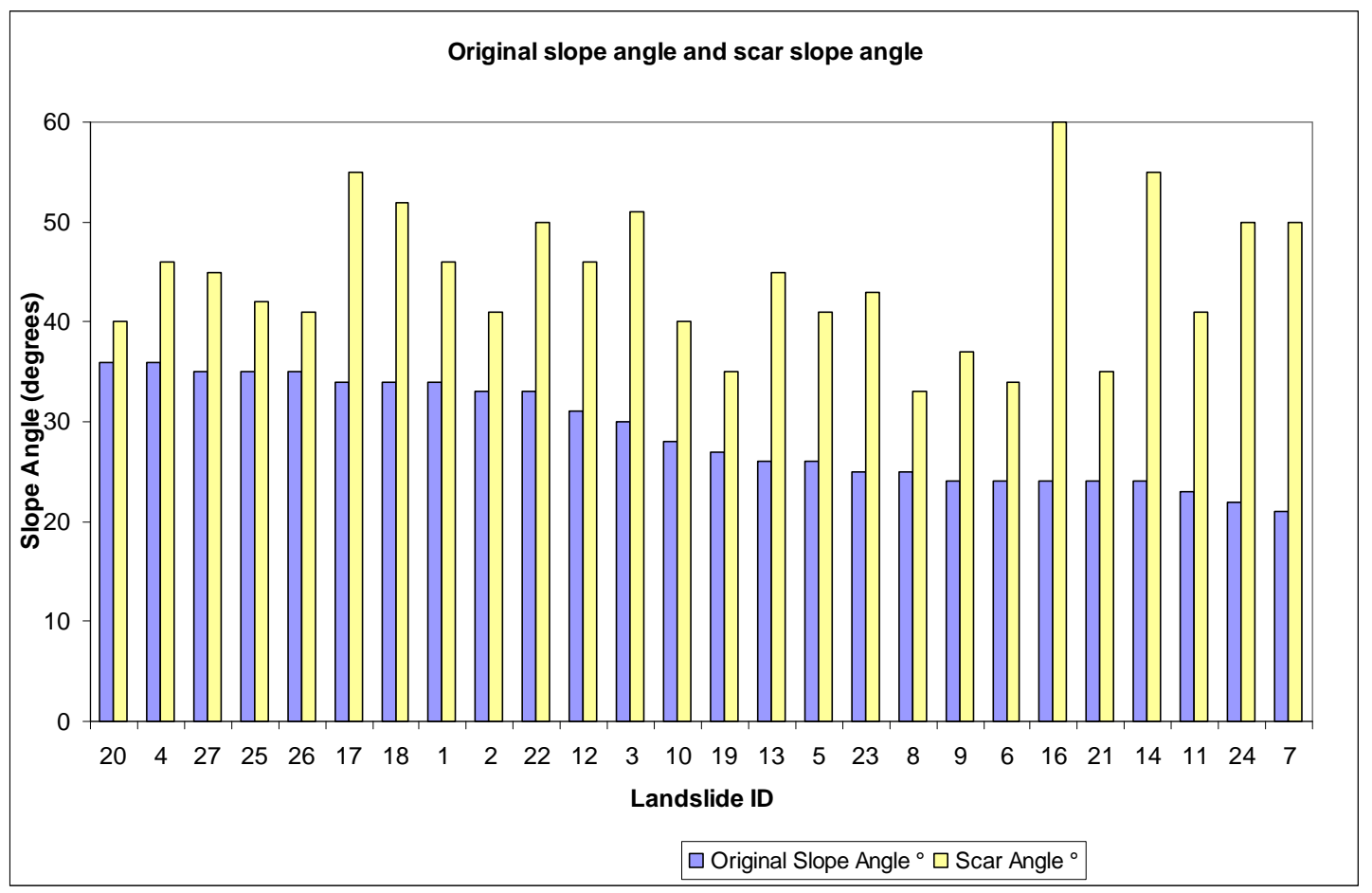

Figure 7-17 Ranked by original slope angle, changes in slope angle appear to correlate weakly with scar slope angle (when change in slope is plotted as a line an $\mathbf{r}^{2}$ value of 0.61 is derived, however data is discrete not continuous so this trend is not statistically robust). Average change in slope is $16.2^{\circ}$

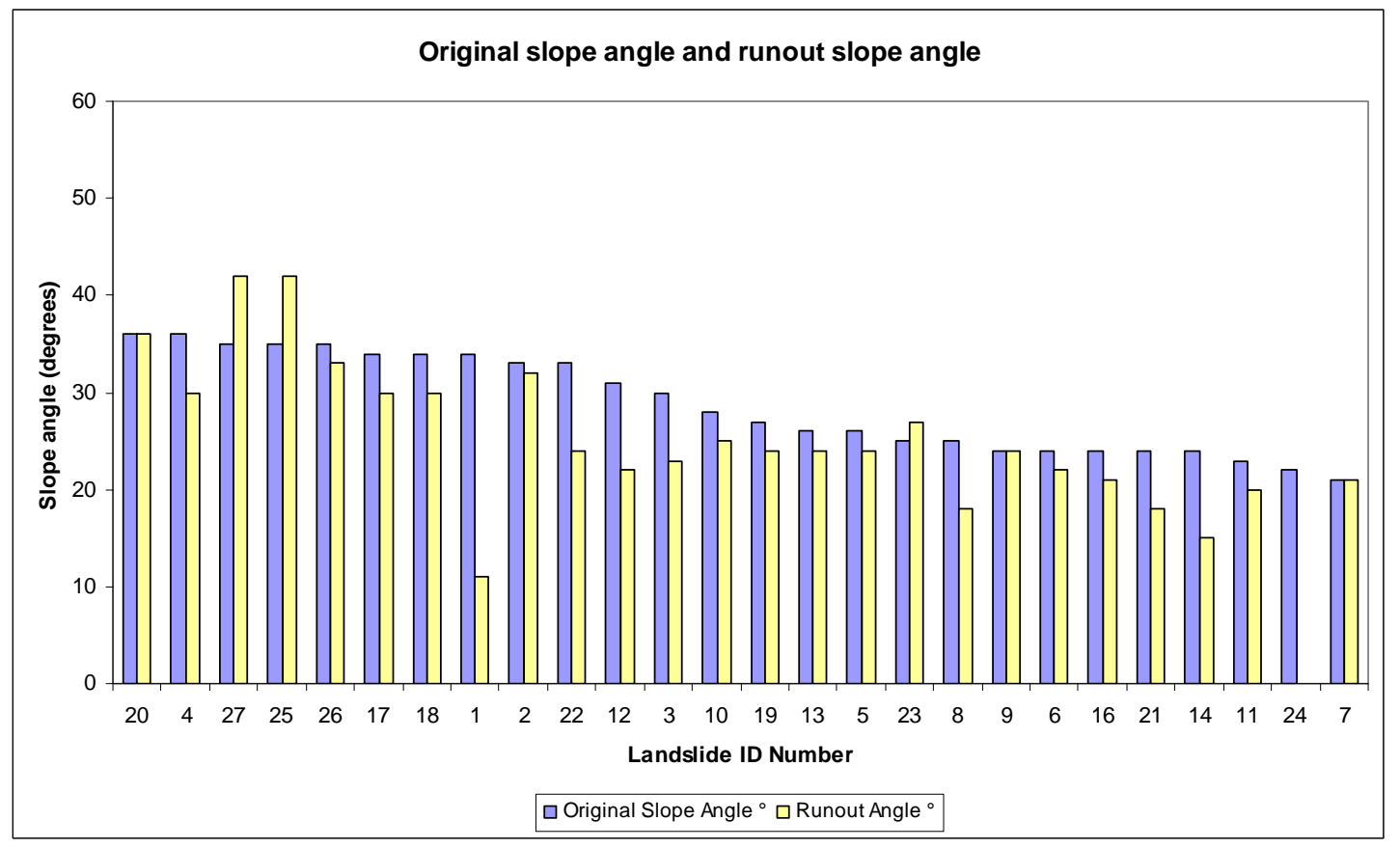

Figure 7-18 Ranked by original slope angle, this figure shows runout angles and original slope angles. There is a weak $\left(r^{2}=\mathbf{- 0 . 4}\right)$ negative correlation between runout slope angle and change in slope when change in slope data are plotted as a line. Average change in slope between runout and original slope angles is $5.7^{\circ}$ 


\subsubsection{Slope form and position on slope of landslides}

Landslides were found on upper, middle and lower parts of slopes within the catchment. Lower parts of slopes have relatively higher moisture contents during rainfall events due to groundwater rising and the concentration of throughflow and surface flow on the lower parts of the slopes. Theoretically, these higher moisture levels makes lower slopes more susceptible to landsliding, however they are often areas of deposition, and therefore slope angles may be less, making them more stable than upper parts of the slope (Selby 1982). Where landslides occur on lower slopes earthflows are more likely to develop due to the material being closer to, or at, saturation. Theoretically, landslide initiation during intense or prolonged rain events is more likely on concave slopes as they concentrate moisture flow into the centre of the slope. Two distinct patterns of landsliding commonly found in New Zealand of slope form and related slope position are presented in Figure 7-19. Landslides were formed on concave, convex and rectilinear slopes within the study catchment. Slope form and position of landslides for the study catchment are presented in Table 7-2.
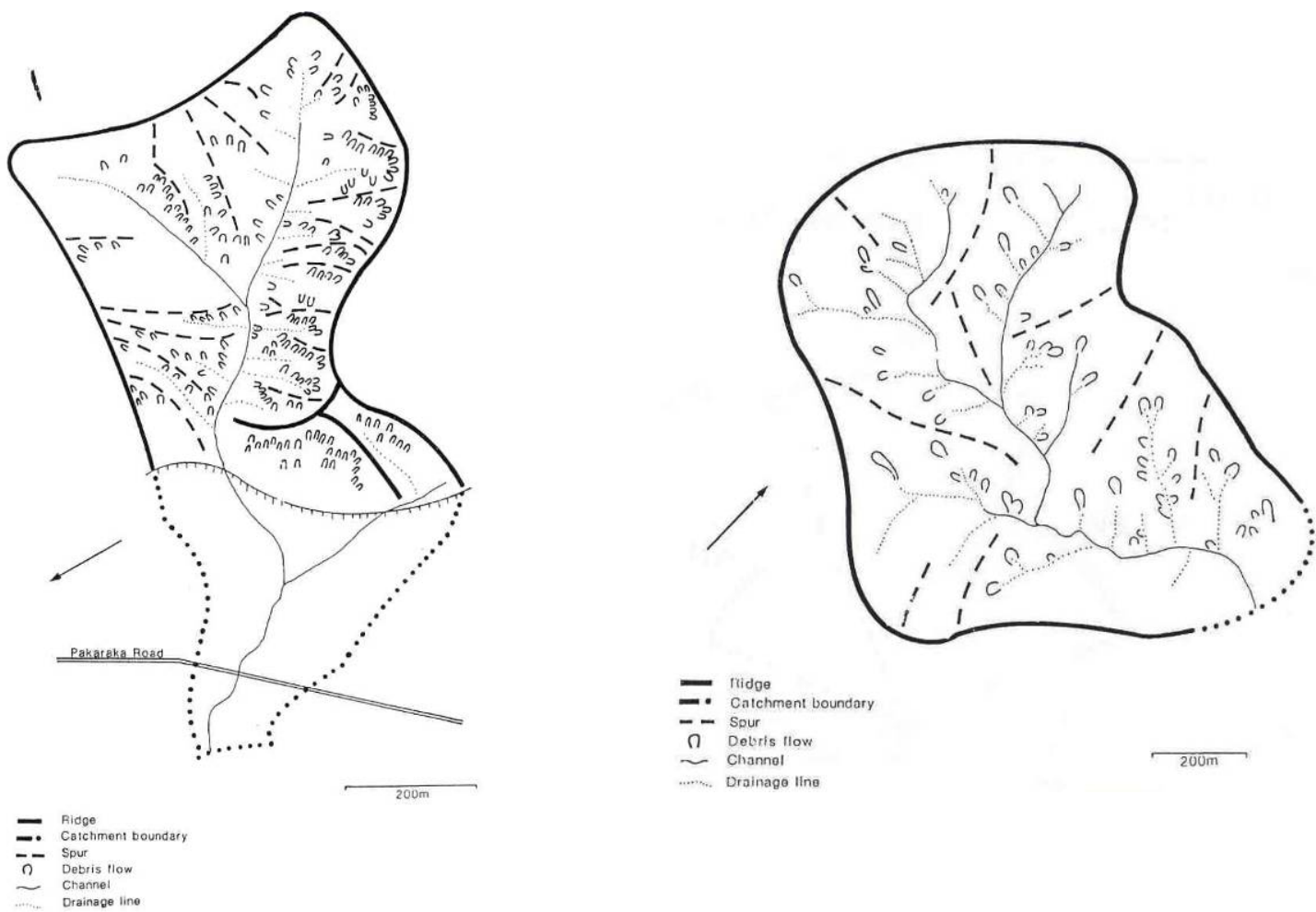

Figure 7-19 Landslide formation on upper slopes and ridges mapped from the Wairarapa 1977 event (left), and landslide formation on lower and middle slopes in concave drainage channels during the Belmont (Wellington) storm of 1976 (right) from Crozier 1991. The February 2004 event tends to resemble the Wairarapa pattern over the region, however the study catchment does not match this pattern. 
Table 7-2 Slope form, part of slope, and also included are earthflow and fluvial coupling data for the field study catchment

\begin{tabular}{|c|c|c|c|c|}
\hline Landslide ID Number & Slope Form & Part of Slope & Fluvial coupling & Flow formed? \\
\hline 1 & concave & middle & no & yes \\
\hline 2 & concave & upper & no & yes \\
\hline 3 & concave & middle & yes & no \\
\hline 4 & concave & upper & yes & yes \\
\hline 5 & concave & middle & no & yes \\
\hline 6 & rectilinear & middle & no & no \\
\hline 7 & convex & middle & no & yes \\
\hline 8 & convex & upper & no & yes \\
\hline 9 & rectilinear & upper & no & yes \\
\hline 10 & concave & upper & no & yes \\
\hline 11 & concave & middle & no & yes \\
\hline 12 & convex & lower & yes & yes \\
\hline 13 & concave & upper & yes & yes \\
\hline 14 & convex & middle & yes & yes \\
\hline 16 & convex & middle & no & yes \\
\hline 17 & concave & upper & yes & yes \\
\hline 18 & concave & upper & yes & yes \\
\hline 19 & convex & middle & yes & no \\
\hline 20 & concave & middle & yes & yes \\
\hline 21 & convex & lower & yes & no \\
\hline 22 & concave & upper & yes & yes \\
\hline 23 & concave & upper & yes & no \\
\hline 24 & concave & middle & yes & no \\
\hline 25 & concave & upper & no & no \\
\hline 26 & convex & upper & yes & yes \\
\hline 27 & concave & middle & no & yes \\
\hline
\end{tabular}

Of the 26 landslides which were able to be measured (of 27 total) in the study catchment, $61.5 \%$ were located on concave slopes, $30.8 \%$ were on convex slopes, and $7.7 \%$ on rectilinear slopes. Landslides were not found to have formed along ridge profiles, however one had formed from the ridge line downslope (landslide ID 26), and some from farm road cuts (landslide ID numbers 1 and 3). The parts of slope on which landslides formed were distributed as follows: upper slopes $-46.15 \%$ of landslides; middle slope $-46.15 \%$ of landslides; and lower slopes $7.7 \%$ of landslides.

Earthflows formed from $77 \%$ of measured landslides in the catchment. In relation to slope form, earthflows formed from $75 \%$ of concave and convex slope landslides, and on $50 \%$ of landslides on rectilinear slopes. In relation to parts of slope, landslides formed in the upper part of the slope formed flows in $83 \%$ of cases, for the landslides on the middle part of the slope $67 \%$ formed flows, and $100 \%$ of landsides on the lower part of the slope formed earthflows. The formation of earthflows for such a high percentage of landslides is more likely to be linked to the amount of incident rainfall, combined with slope material type (bedrock and soil). As the catchment 
received $193 \mathrm{~mm}$ of rainfall in three days (pers comm. Medlicott 2004) during the storm event and the underlying bedrock is relatively impermeable mudstone it is reasonable to assume that all slopes reached saturation.

\subsubsection{Landslide types}

Several types of landslides were found in the study catchment: one rotational slide, and many translational slides and earthflows (Table 7-3). Some landslides were a combination of types. Scar areas were mostly translational slides with many of these forming earthflows. The largest landslide of the catchment (ID number 18) had a rotational scar area and part blocky, part earthflow, runout area. Landslides had formed in areas of previous deposition (colluvium) in $19.2 \%$ of cases. An equal number had scars that had formed in bedrock (and regolith). The remaining 61.6\% (16 landslides) formed from regolith material (Table 7-3) except landslide ID 3, which formed from a cut road scar in the middle of a slope. Examples of types of landslides and the various materials are shown in Figure 7-20 to Figure 7-23.

Table 7-3 Landslide types and materials

\begin{tabular}{|c|c|c|}
\hline ID Number & Landslide Type & Material \\
\hline 1 & Translational slide and earthflow & regolith \\
\hline 2 & Translational slide and rapid earthflow & colluvium and regolith \\
\hline 3 & Translational slide and earthflow & bedrock and regolith \\
\hline 4 & Translational slide and earthflow & colluvium and regolith \\
\hline 5 & Translational slide and rapid earthflow & colluvium and regolith \\
\hline 6 & Translational slide & regolith \\
\hline 7 & Translational slide and earthflow & regolith \\
\hline 8 & Translational slide and rapid earthflow & bedrock and regolith \\
\hline 9 & Translational slide and rapid earthflow & colluvium and regolith \\
\hline 10 & Translational slide and rapid earthflow & bedrock and regolith \\
\hline 11 & Translational slide and earthflow & colluvium and regolith \\
\hline 12 & Translational slide and earthflow & regolith \\
\hline 13 & Translational slide and earthflow & regolith \\
\hline 14 & Translational slide and earthflow & regolith \\
\hline 16 & Translational slide and earthflow & regolith \\
\hline 17 & Translational slide and earthflow & regolith \\
\hline 18 & Rotational slide and earthflow & bedrock and regolith \\
\hline 19 & Translational slide & regolith \\
\hline 20 & Translational slide and earthflow & regolith \\
\hline 21 & Translational slide & regolith \\
\hline 22 & Translational slide and earthflow & bedrock and regolith \\
\hline 23 & Translational slide & regolith \\
\hline 24 & Translational slide & regolith \\
\hline 25 & Translational slide & regolith \\
\hline 26 & Translational slide and earthflow & regolith \\
\hline 27 & Translational slide and earthflow & regolith \\
\hline
\end{tabular}



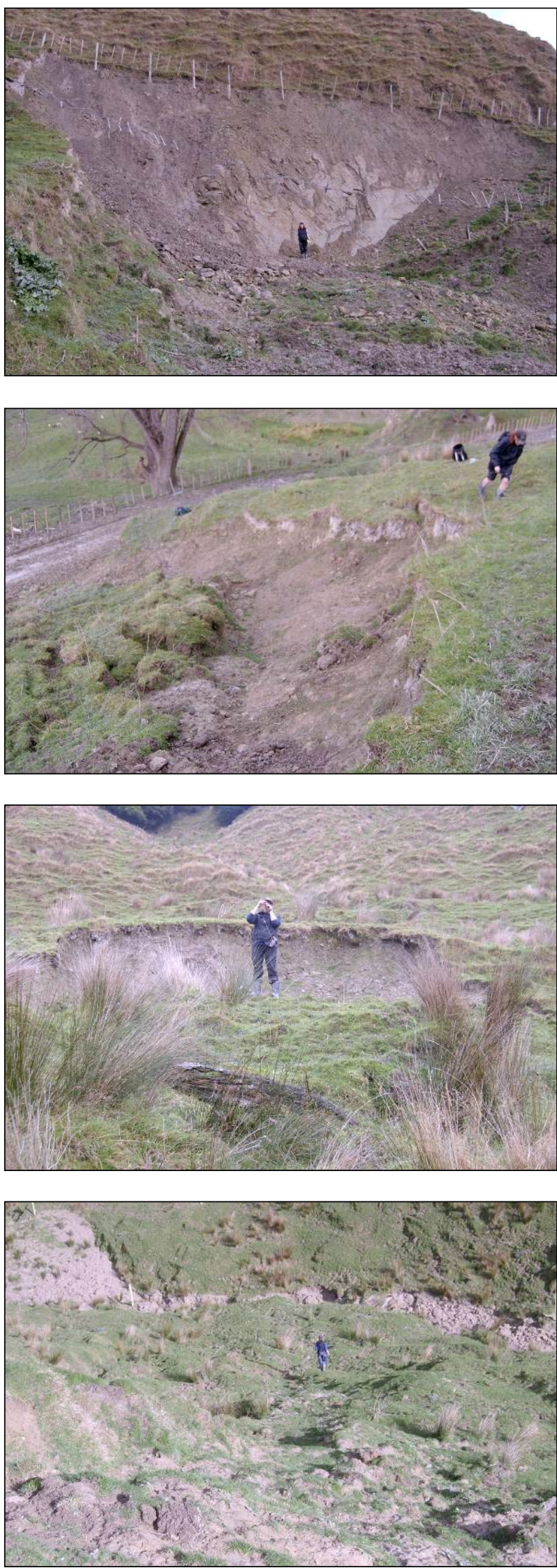

Figure 7-20 Landslide ID number 3 , translational slide and earthflow formed in bedrock and regolith from a roadcut

Figure 7-21 Translational slide formed in regolith, much of the material remains in the scar area

Figure 7-22 Translational slide scar formed in colluvium. Notice the gravels which are not visible in the scar of Figure 7-21

Figure 7-23 The runout material of landslide ID number 25, this material did not flow readily. At top left earthflow material of landslide ID number 26 is visible. 

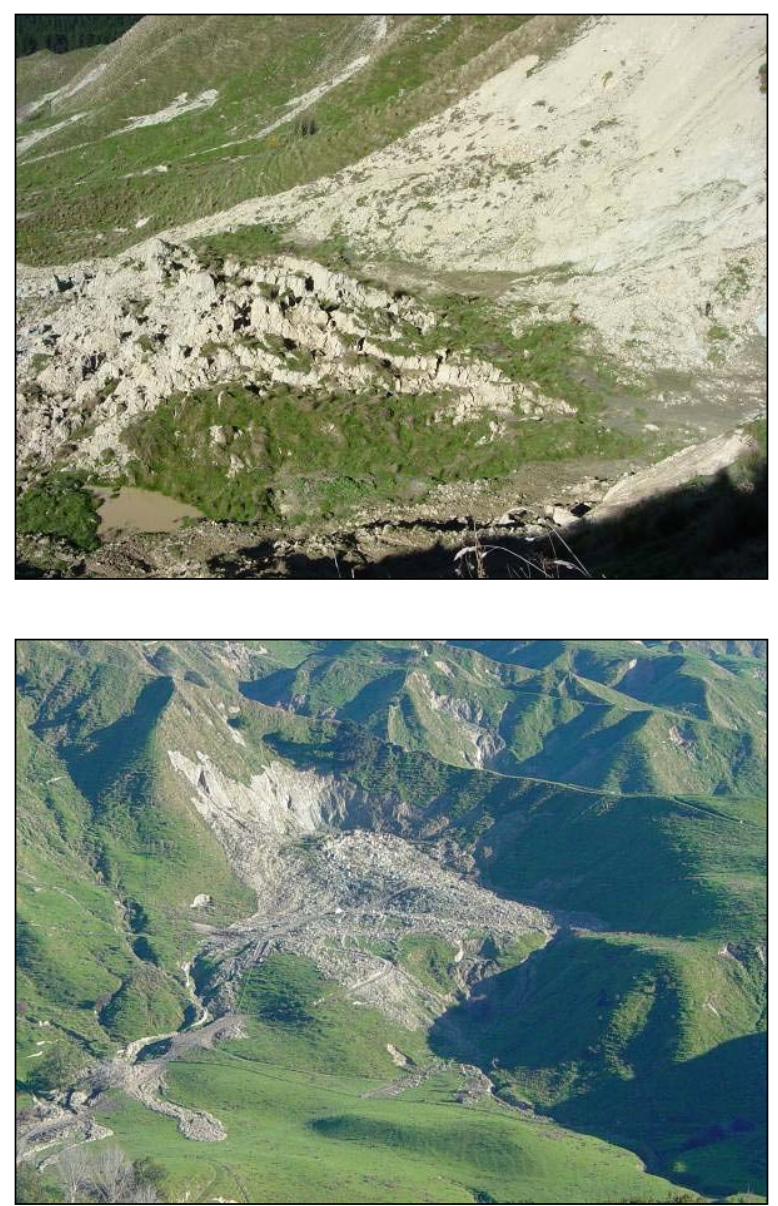

\subsection{Summary of Field Catchment Results}

Of the 26 landslides measured within the Octopus study catchment $54 \%$ were coupled with the fluvial system. Total input from landslides to the fluvial system is estimated at $46006.52 \mathrm{~m}^{3}$, nearly all $(94.6 \%)$ of this material is derived from landslide ID number 18. Most landslides (25 out of 26) had translational scar faces; the remaining landslide had a rotational scar face. The rotational slide and 19 of the translational slides (a total of $77 \%$ of landslides) formed earthflows from their runout material. Landslides formed on all parts of the slope and on concave, convex and rectilinear slopes, however most $(61.5 \%)$ formed on the concave slopes. Five landslides formed in bedrock material, five in colluvial material and the remaining landslides formed in hillslope regolith. Changes to slope angles were greater between original slopes and scar slopes than original slopes and runout slopes. 


\section{Regional landslide and terrain analysis methods and results}

\subsection{Background}

Previous publications have documented the extent of, and main areas affected by landsliding, and described the nature and effects of the landslides on the landscape and damage to roads and infrastructure in affected areas (Hancox 2004; Dymond et al. 2004; Hancox and Wright 2005a, Hancox and Wright 2005b). This section of the study presents the results of a combined analysis of terrain characteristics and landsliding caused by the 15-17 February 2004 storm in selected areas of the Wanganui and Manawatu hill country. It includes examination of the characteristics of the landslides formed (e.g. landslide density, debris runout to scar length ratio, terrain damage, and fluvial coupling), and relates the findings to the physical terrain characteristics (e.g. lithology, soil, slope angles, slope aspect, vegetation) of the affected terrain and the storm event responsible for the landsliding.

Aerial reconnaissance was part of an immediate response to the February 2004 storm event undertaken by staff members of the Institute of Geological and Nuclear Sciences (IGNS). G. Hancox of IGNS and K. Wright (student under summer contract to IGNS) undertook the aerial reconnaissance of landslide damage after word of mouth reports filtered through various sources indicating severe and widespread landslide damage in the Waitotara, Turakina, Whangaehu, Taihape, and Manawatu regions. Initial flight paths were planned to cover Waitotara (north-west of Wanganui), Turakina-Whangaehu, and Taihape (north-east of Wanganui), Manawatu Gorge, Pohangina, and Wellington including Hutt Valley. From the five days of aerial reconnaissance in late February and early March 2004, G. Hancox created an oblique photographic record of damage comprising hundreds of high quality digital images, which have been cross-referenced to flight paths and locations. The first flight over the Turakina-Whangaehu area was also expanded to cover the Mangawhero hill country, as from the air it was apparent this area was also severely damaged. Particularly large and deep-seated slides were prominent in the Mangawhero, Whangaehu, and Turakina hill country as well as high-density damage from shallow landslides (see also Chapter 4). Based on these five days of aerial reconnaissance it was decided that the event, as well as being spectacular and highly damaging, was 
potentially geomorphically significant, and therefore required further, more detailed investigation.

Non-field methods include analysis of vertical aerial photographs (original print scale 1:18,000) of four areas severe landslide damage; Mangawhero, Whangaehu, Turakina and Pohangina. Information on the geology, soils, slope angles, slope forms, slope heights, and slope aspects prevalent in each of the four areas was examined, as well as landslide density, scar volumes, runout length to scar length ratios, effect of vegetation type on landslide numbers and densities, and damage ratios (percentages high, moderate, and zero to slight damage for given area).

From examination of oblique and vertical aerial photographs of landslide damage resulting from the February 2004 storm event (Hancox and Wright 2005b), four areas of interest were identified (Figure 8-1); Mangawhero, Whangaehu, Turakina, and Pohangina (regions are named for the main river channel that runs through them). These four hill country areas experienced the most sever damage to hill slopes during the storm event and detailed examination of the nature of these regions (lithology, soil, slope angles, slope aspect), and the nature of landsliding (runout length as proportion of scar length, landslide density, and damage ratio) was undertaken.

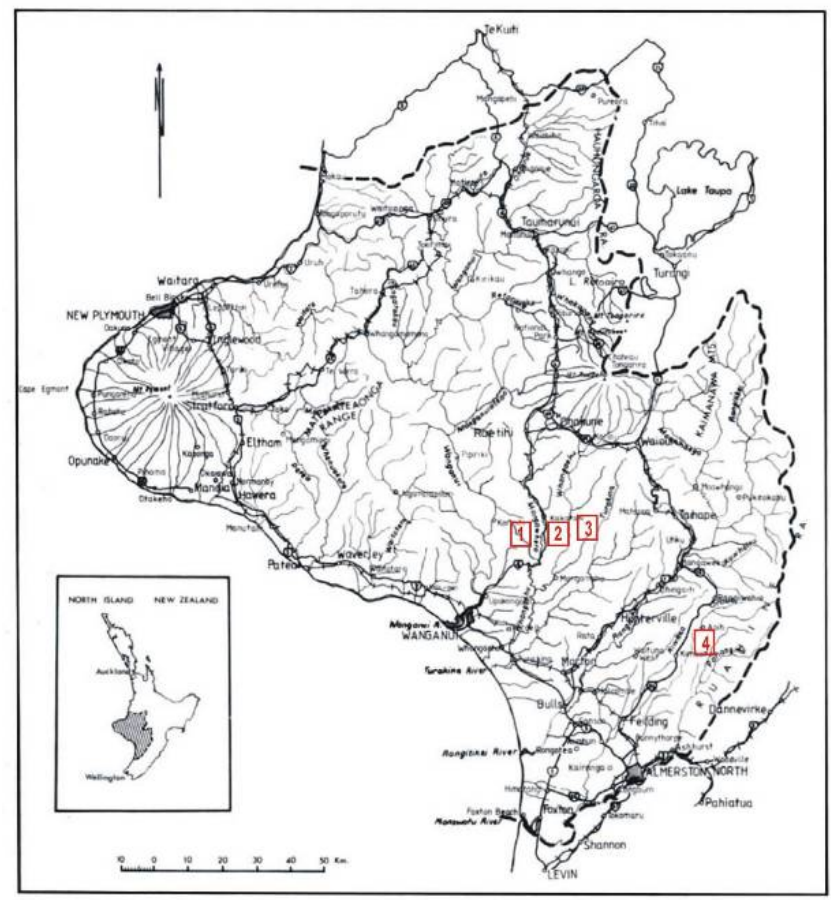

Figure 8-1 Location map of the four study areas described in this thesis; 1 Mangawhero, 2 - Whangaehu, 3 Turakina, and 4 - Pohangina. Map adapted from Fletcher, 1987 


\subsubsection{Relevance of the regional study}

In New Zealand most past (pre-1990) studies of rainfall-triggered, multiple landslide events investigated damage from landsliding as scar area only. This is because earlier studies (e.g. Bell 1976, Painter 1981, and Hicks 1991) were concerned with pasture productivity loss, and scar damage has a much slower recovery time than runout damage. More recent studies have examined triggering thresholds and antecedent conditions (Crozier 1999, Brooks et al. 2002, Crozier et al. 1995, Crozier and Preston 1999), frequency-magnitude estimations (Crozier and Glade 1999), the geomorphic impact of landsliding (Page et al. 1994, Kasai et al. 2001), modelling of landslide behaviour (Terlien et al. 1996, Morgan 1996), and landslide hazard and risk (Luckman et al. 1999). This part of the study is concerned mostly with the relationship between terrain types and characteristics, and the landslide response to a large storm event in terms of: landslide density, scar volumes, fluvial coupling, damage ratios, and scar length to runout length ratios. Most of these characteristics are useful for frequency-magnitude assessment as they assist with the description of the landslide event magnitude. Any slope aspect preference in the distribution of landsliding damage can often be linked to triggering thresholds (sufficient rainfall, or sufficient hillslope material), slope characteristics, differences in vegetation, and possibly directional aspects of the triggering agency, in this case intense and prolonged rainfall. Fluvial coupling ratios can assist with the assessment of increase in fluvial hazards and permanent loss of hillslope material from a system. This part of the study can also be linked to landslide hazard studies, as runout damage provides a high proportion of the hazard associated with landsliding; debris runout commonly blocks roads, destroys fencing, increases sediment loads in rivers, and less commonly destroy buildings, causes stock losses or loss of human life. For these reasons both scar and runout affected terrain are included in damage ratios, and an examination was undertaken of runout length: scar length ratios. These issues are examined in relation to the four study areas.

\subsection{Terrain Characteristics}

The magnitude of a landsliding event (landslide volumes, density, and areal extent) is determined not only by the magnitude of the triggering force, but also by the nature of the terrain in which the event occurs. Terrain characteristics that are known to affect the geomorphic landslide response such as earthquakes (Keefer 1984; Hancox et al. 
2002) and rainstorms (Bell 1976, Page and Reid 1998, Crozier 1999) to the triggering force include:

- $\quad$ Hill slope geology/lithology;

- $\quad$ Regolith (weathered soil parent material) and soil type and thickness;

- $\quad$ Slope angle;

- $\quad$ Slope hydrology - determined by soil, bedrock, slope angle, slope aspect, topography and climate;

- $\quad$ Topography; elevation, slope type (concave/convex), changes in slope form;

- Which part of the slope fails - upper, middle or lower slope;

- What processes acting on and within the slope - weathering, mass wasting, soil creep, overland flow erosion, subsurface piping

- Vegetation cover, and;

- Whether the slope is a denudation slope (losing material), accumulation slope (gaining material), or transportation slope (material losses equal gains).

Other factors affecting the hill slope response include:

- $\quad$ The magnitude of the triggering force (rainfall, earthquake);

- $\quad$ Previous slope failure removing transportable material, and;

- $\quad$ Antecedent water status of hill slopes; saturated slopes are more likely to fail due to reduction of shear strength and increase of increase in shear stress.

(Young 1972, Carson and Kirkby 1972, Selby 1982, and Crozier et al. 1982).

This regional study mainly involved analysis of vertical aerial photographs, and reviewing of existing literature, with some "on the ground" field observations but few systematic field measurements, therefore some slope characteristics were unable to be included. The slope characteristics examined were those considered to be most important in landslide initiation on hills slopes (Crozier 1982); hillslope geology/lithology; regolith and soil characteristics; slope angle; slope aspect, slope height, slope form and vegetation cover. Landslides were mapped and assessed on several magnified vertical aerial photos (original print scale $\sim 1: 18,000$ ) as was vegetation cover, while slope angle, height, form and aspect were determined from 
the 1:50,000 topographic maps (NZMS 260-S22, T22, T21), and geology/lithology and soil information was obtained from published geological studies (Fleming 1978, Fletcher 1987, Stevens 1990) and soil maps (N.Z. Soil Bureau 1954, Campbell 1977, Rijkse 1977). All examined factors contribute to hill slope hydrological processes; how these processes operate determines the likelihood of hill slope saturation under intense or prolonged rainfall. Saturation of slopes is a major source of landslide initiation in the New Zealand hill country (Crozier et al. 1982).

The following sections provide detailed descriptions of terrain characteristics examined in this report with respect to the four study areas, and the relationship between these characteristics and potential slope instability. Description of the four study areas and their susceptibility to hillslope failure as well as actual degree of failure is related to:

- Underlying geology;

- Regolith and soils;

- Slope angle;

- Slope aspect;

- Slope form;

- Slope height, and;

- Vegetation Cover.

\subsubsection{Regional Geology/Lithology}

The Mangawhero, Whangaehu and Turakina study areas are situated within the hill country northeast of Wanganui. The Pohangina study area is in the northeast of the Manawatu Region. The Wanganui and Manawatu regions have undergone similar processes of sediment deposition and tectonic uplift however differences in types and ages of sediment exist. Regional geological descriptions are given in Sections 7.4.5 to 7.4.8. A geological map (scale 1:2,000,000) shows the major geological units of the lower North Island (Figure 8-2); also labelled are the four regional study areas; Mangawhero, Whangaehu, Turakina and Pohangina. Although background geology has been presented in Chapter 5, some of the information is presented again in a different form to provide a basis for geological comparison between the three Wanganui study areas and the Manawatu study areas. 


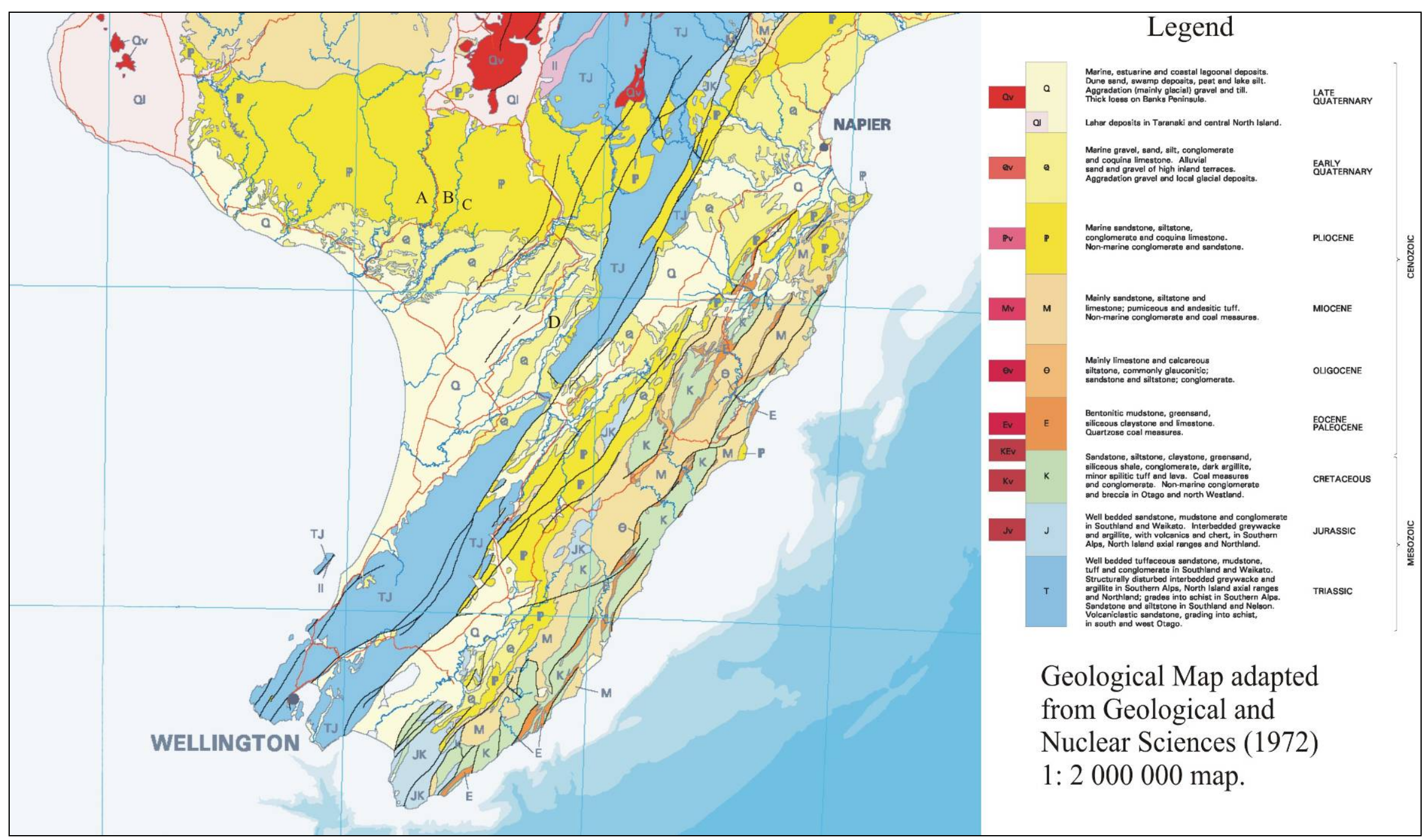

Figure 8-2 Geological units of the lower North Island, source Institute of Geological and Nuclear Sciences 1972 


\subsubsection{Wanganui}

The Wanganui region is dominated by Tertiary sediments laid down during Pliocene and Pleistocene marine transgression. A gravity anomaly situated near the lower west coast of the North Island has produced local crustal downwarping, creating the Wanganui Basin and allowing marine transgression and sediment deposition onto basement rocks. During the Quaternary uplift of anticlinal structures in older Mesozoic rock formed the Ruahine and Tararua Ranges which formed the eastern and southern boundaries of the Wanganui Basin; the Taranaki, Ruapehu, Ngauruhoe, and Tongariro volcanoes are situated along the northern boundary of the Basin. The soft Tertiary sediments within the Basin were also affected by tectonic uplift during the Quaternary; the sediments became raised and folded, forming steep sharp hillslopes which became highly dissected by downcutting streams (Fleming 1978).

The north-eastern Wanganui hill country, which includes the Mangawhero, Whangaehu and Turakina study areas, is comprised of very steep $\left(25-40^{\circ}\right)$, rectilinear slopes formed in weak Tertiary age sandstone and mudstone strata which dip gently (between $2^{\circ}$ and $8^{\circ}$ ) to the southwest (Neall 1982). Slope ridges are narrow and sharp and appear fluted where sandstone caps the dominant mudstone (Neall 1982). Dendritic drainage patterns produce highly dissected topography in the soft Tertiary sediments (Figure 8-3) typical of (geomorphically) young terrain. River channels are typically deeply incised with little or no flood plain development, creating narrow, over-steepened valleys. In the highest hills of most persistent rocks some sub-mature marine terraces remain (Figure 8-4) but the majority of ridges are sharp and narrow.

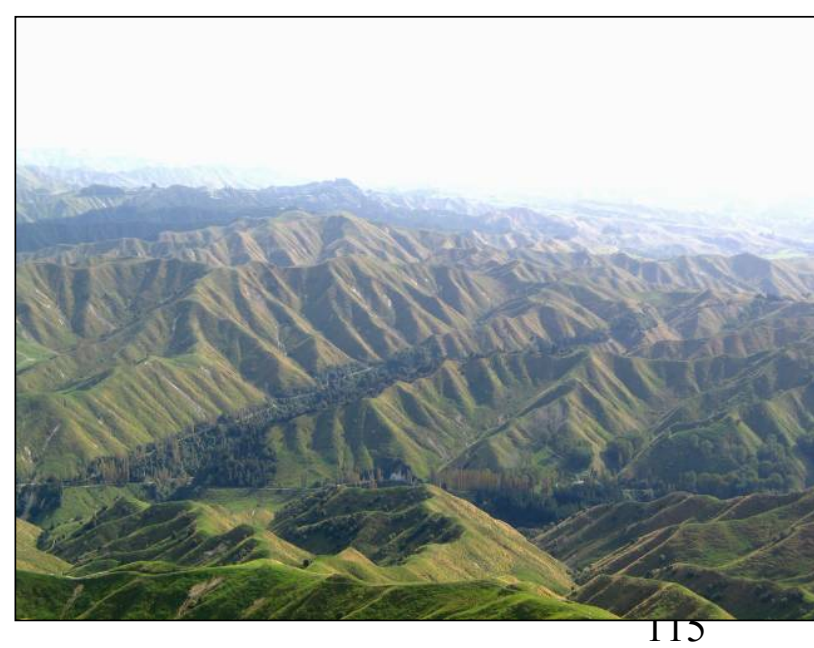

Figure 8-3 Typical Tertiary hill country of north-east Wanganui region, photograph Hancox 2004. 


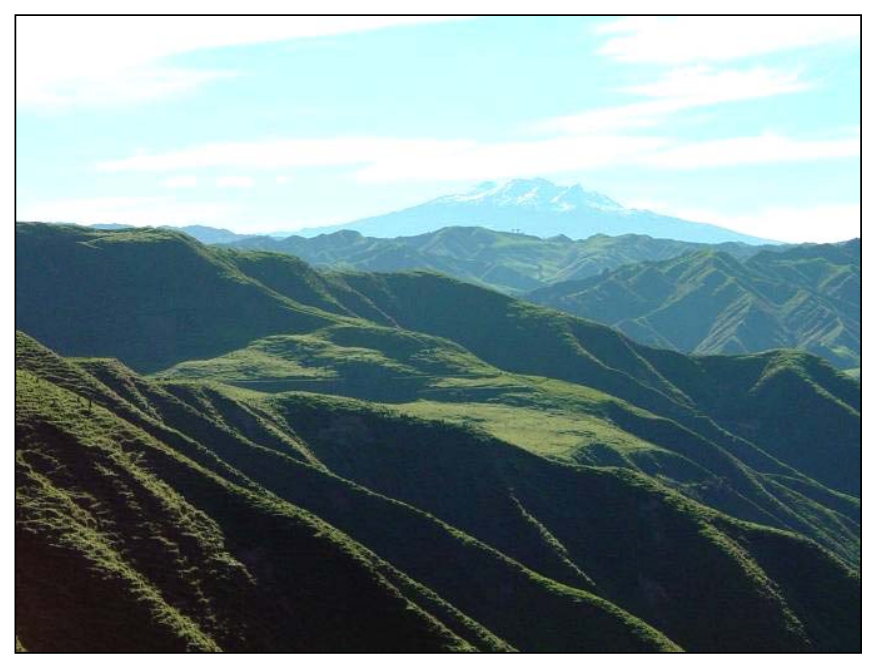

Figure 8-4 Preserved marine terrace in Mangawhero hill country, Mt Ruapehu in the background, photograph Crozier 2004.

\subsubsection{Manawatu}

In the Manawatu hill country, processes of uplift and deposition also determined the form of hill slopes; however source materials differ from those further north. The Manawatu region was entirely under water until 50 000 yrs BP; underlying basement rocks consist of planed off areas of argillite and greywacke sandstone of the Tararua and Ruahine ranges. This basement material was broken up into a series of blocks by tectonic activity, however blanketing of marine sediments resulted in the blocks never forming an exposed unit at the land surface. As tectonic activity forced these underlying blocks upwards the overlying deformable sediments behaved like plasticine, gently buckling upwards to form domes (Figure 8-5 and Figure 8-6); blocks that were forced down formed sediment filled depressions. These domes prevent the Manawatu river from flowing in a direct route to the coast, instead an extra $40 \mathrm{~km}$ is added to its course as it flows southwest around them (Stevens 1974).

The Manawatu, and therefore the Pohangina hill country, is less steep and dendritically dissected than that of the Wanganui Region. Hillslopes exhibit a gentler, more rounded form with lower elevation than that of the study areas to the north. The Pohangina hill country does not exhibit the characteristic rectilinear slopes meeting in deeply incised valleys of the Wanganui hill country and when viewed in terms of topography and slope form appears less susceptible to hillslope erosion. 


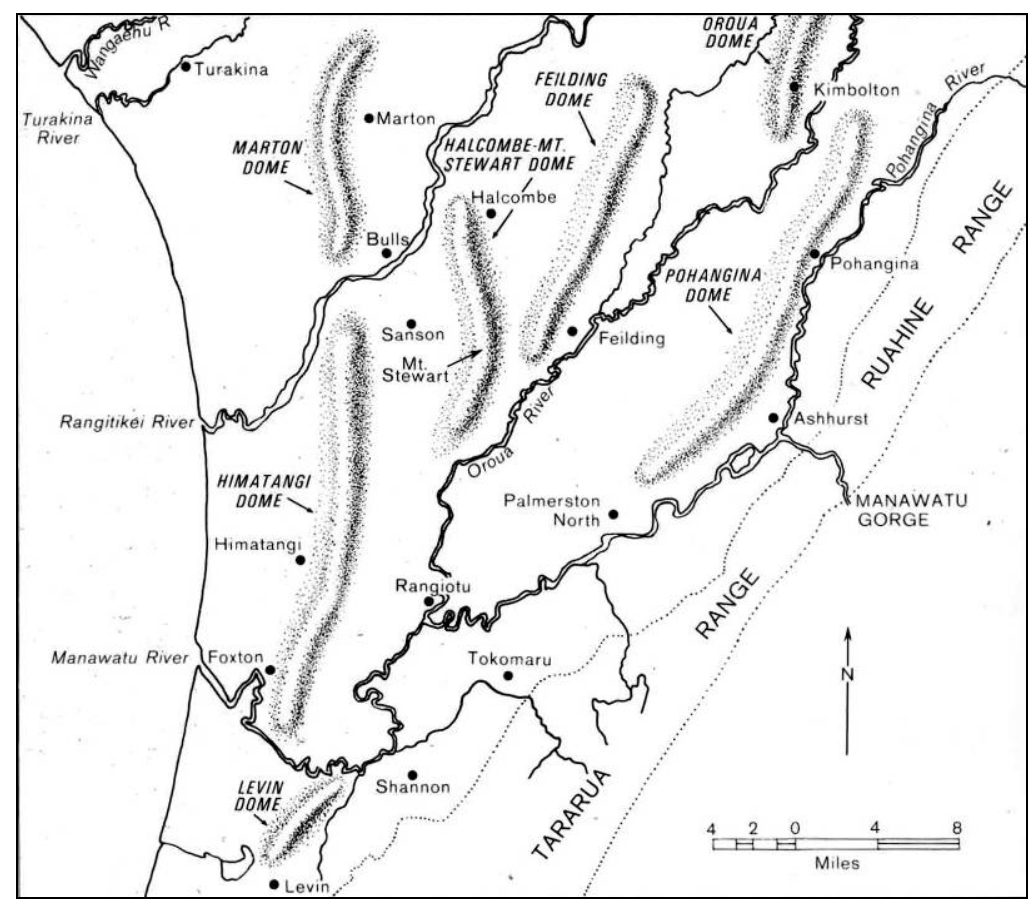

Figure 8-5 Dome formations of the Manawatu and lower Wanganui regions. Note the course of the Manawatu River, instead of flowing directly due west to the coast, is diverted between the Pohangina Dome and the Ruahine Ranges, from Stevens 1974

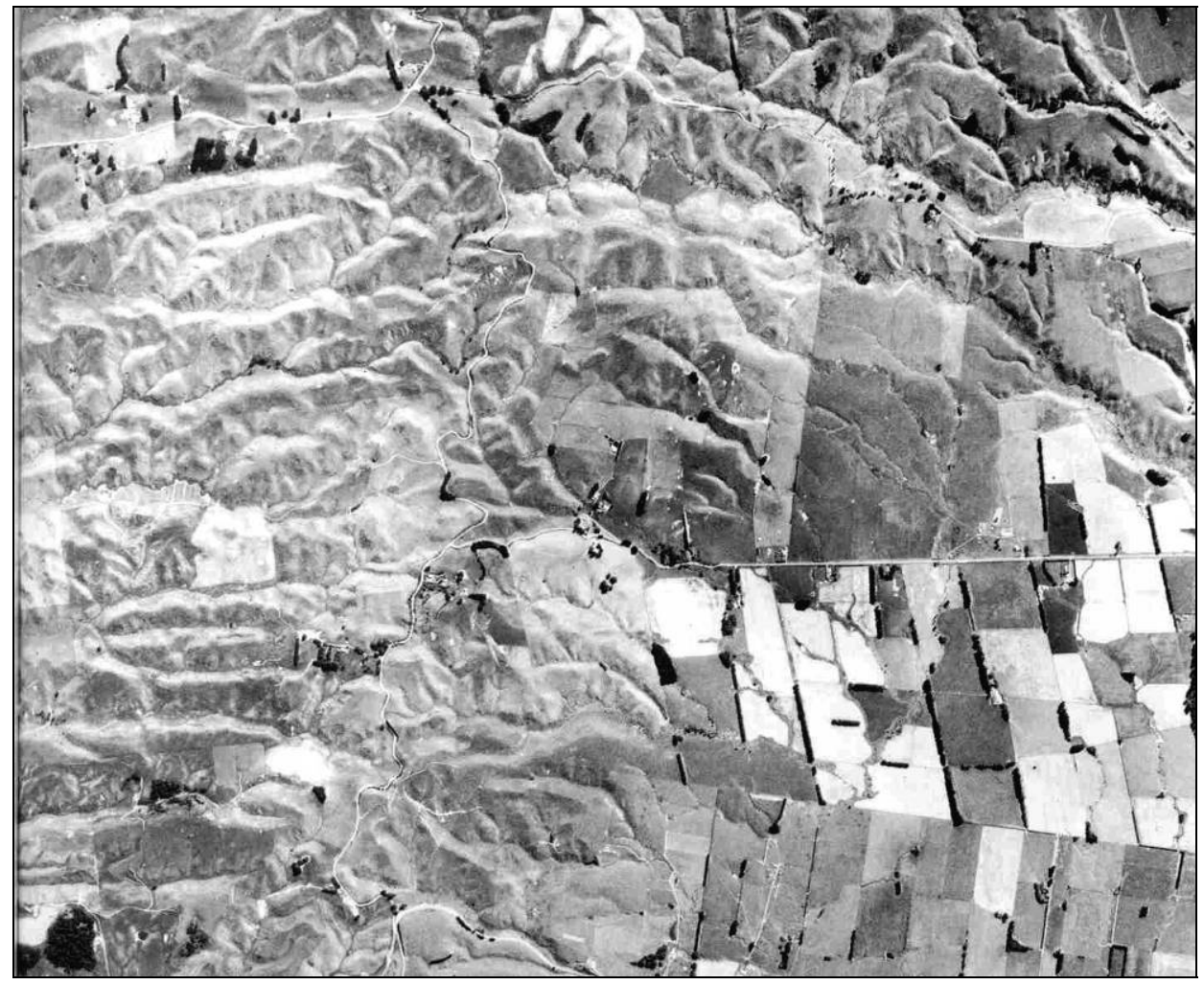

Figure 8-6 The crest of the Pohangina Dome, north is at the top of the photograph, from Stevens 1974 


\subsubsection{Major geological units}

In general, all four study areas are dominated by sedimentary rocks with some variance between the four locations in rock type and age; the Wanganui hill country consists of Pliocene Tertiary sediments, whereas the Pohangina hill country consists of Pleistocene early Quaternary sediments. Nomenclature used is that of the New Zealand Land Resource Inventory (NZLRI) rock classification system (Fletcher 1987) with the exception that the words compaction or strength are substituted for "consolidation" (used by NZLRI), as this term is more widely recognised as a term for soil rather than rock description.

The Mangawhero, Whangaehu and Turakina regions are dominated by the massive Mangaweka Mudstone unit $(\mathrm{Mm})$, a clayey siltstone. The Mangawhero and Whangaehu regions also contain a relatively compact and strong massive sandstone unit (Sm). The Whangaehu hill country also contains a less compacted, weaker form of the Sm unit (termed moderately consolidated in NZLRI nomenclature). The Mm and Sm units are Pliocene in age. The Pohangina hill country is formed from younger Quaternary rocks of Pleistocene age. Layers of weaker (less compacted) Sandstone (Us), gravel, and minor beds of silts and clays comprise the hills Pohangina study area

\subsubsection{Geological characteristics and erosion susceptibility}

The study area units are all relatively susceptible to erosion. The Mm unit is described as weak to very weak and typically massive (little or no bedding). Soil/regolith slips are common, and shallow earthflows are likely to develop on colluvial footslopes. Deep-seated rotational slides may also occur in the Mudstone unit. In drier areas colluvial footslopes may be subject to tunnel gullying (this has been observed in the field in Mangawhero study area).

The Sm unit is weak to very weak also (strength is dependent on the degree of material compaction), and is typically massive; however some bedding may be present. Erosion in the Sm unit may take the form of soil/regolith slip, sheet erosion or tunnel gullying. In the moderately compacted Sm rock of the Upper Whangaehu area slumping and earthflow are also possible. 
The weakest of the units is the Us unit, which consists of thickly to very thinly bedded sands and clays, varying from loose to very compact sediments. Gravel bands and pumice layers may also be present. The Us unit is subject to gullying, often severe, and also slip erosion and wind erosion (Lynn and Crippen 1991). Examples of slip types in the various hill slope material are shown below (Figure $8-7)$.

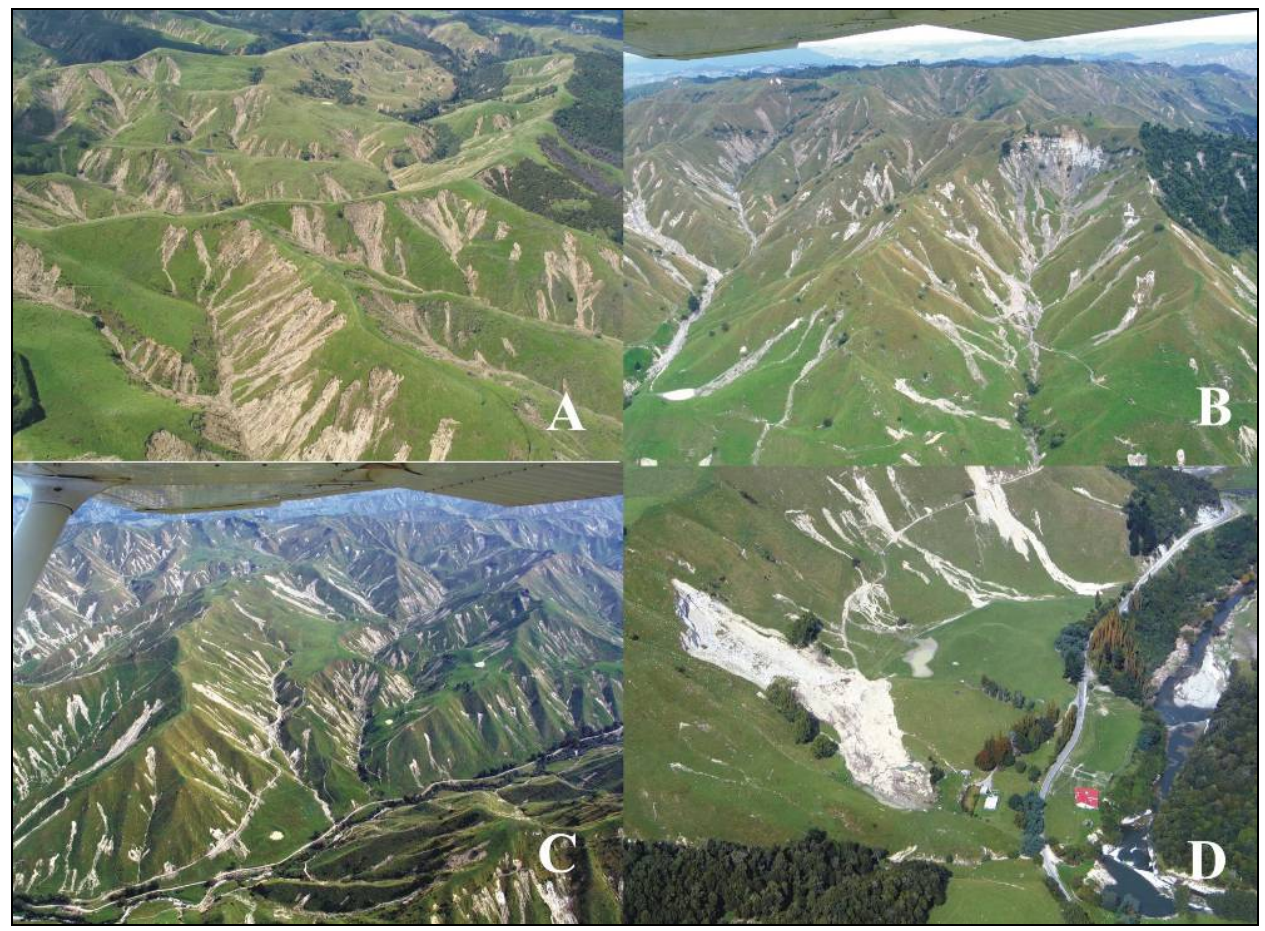

Figure 8-7 A - Shallow slipping in the weak sandstone (Us) unit in the Pohangina hill country; B- Mudstone (Mm) underlying relatively strong (compacted) sandstone (Sm) Whangaehu hill country. Note the shallow slipping on the upper ridges in the sandstone cap and flows in the lower mudstone slopes; $\mathrm{C}$ - Shallow and some deeper slipping and flows in Mudstone (Mm) hill country of the Mangawhero; $D$ - a deep seated rotational slide in mudstone in the Mangawhero River valley, photographs Hancox 2004

Recovery times (development of soil and revegetation) for bedrock, regolith, or soil slipping varies between the units. A summary of recovery times for different damage types and materials follows.

Slip exposes soft rock, vegetation establishes quickly:

- $\quad$ Mudstone (Mm)

- $\quad$ Sandstone $(\mathrm{Sm})$

- $\quad$ crumbly mudstone (Mj)

Slip exposes hard rock, vegetation establishes slowly:

- $\quad$ sandy mudstone (Mm) 
- $\quad$ sandstone $(\mathrm{Sm})$

Slip exposes rock, erosion of bedrock follows:

- shattered greywacke $(G w)$

- $\quad$ soft sandstone (Us) (Fletcher 1987)

From the summary it can be seen that the Pohangina Us unit is particularly susceptible to further damage once slipping occurs, also slipping often triggers gullying. The Sm unit is slow to recover, and the Mm unit recovers most rapidly, unless a deep-seated slide occurs during which the massive bedrock is exposed.

Of the Tertiary rocks of New Zealand, Mudstone is at the same time the most fertile soil parent material with pasture producing the highest stock-carrying capacities, while also exhibiting the most severe and potential erosion hazards (Ministry of Works 1969). This makes this unit both desirable and undesirable for pasture grazing, and the sustainability of farming on this unit in the long term must be examined. Recovery rates must keep pace with soil erosion rates; the recovery rate for landslide disturbed hillslopes is estimated to be $3.5 \mathrm{~mm} / \mathrm{yr}$ for the first 50 years of recovery (if undisturbed by further slipping) and $1.2 \mathrm{~mm} / \mathrm{yr}$ for the following 50 years (Pillans and Trustrum 1991).

\subsubsection{Regolith and Soils of the Four Study Regions}

Soil characteristics affect the likelihood of landsliding. The ability of a soil to drain freely, or hold large amounts of moisture, will influence underlying hillslope hydrology. The strength of a soil is a function of its parent material, and is determined by porosity, cohesiveness, compaction, and Atterburg limits (e.g. the liquid limit; the likelihood of a soil behaving as a liquid when saturated). Variations in soils among the four study areas are closely linked to the underlying geology and parent materials of each of the four regions.

\subsubsection{Regolith/Parent material}

Regolith, or soil parent material, is the unconsolidated material in which the soil develops, and differs from parent rock in that parent rock is the rock from which the parent material is derived by weathering. Depending on weathering agents and rates, it is possible that more than one kind of regolith can be formed from one parent rock (Ministry of Works 1969). The soil-forming regolith of the four study areas is 
controlled by the underlying parent rock with little air-blown material such as loess or volcanic ash present, Tertiary and Quaternary parent rocks dominate regolith formation (Figure 8-8).

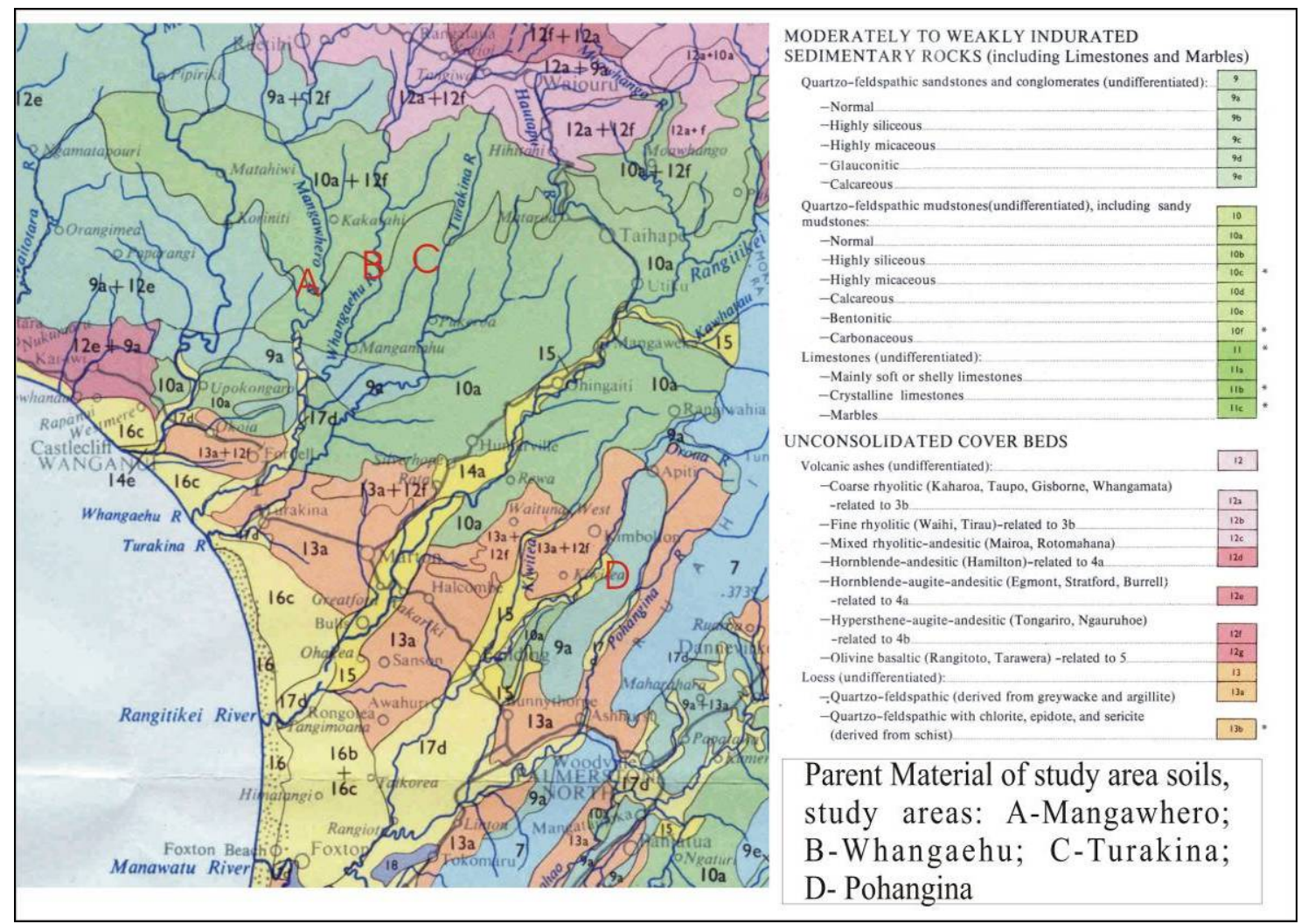

Figure 8-8 Soil parent material for study locations adapted from N. Z. Soil Bureau 1973

The soils formed in the four study areas are controlled for the most part by the underlying parent rock, however soil thickness and horizon development is also a function of slope position. The soils that form in these parent materials are all classed as steepland or hill soils. Steepland and hill soils of the North Island are relatively unstable, and periodically rejuvenated by erosion (N. Z. Soil Bureau 1954). These soils are mostly shallow, and under native vegetation are relatively fertile; fertility varies with variation in underlying rock. Mudstone soils are typically thicker and more fertile than sandstone-derived soils. The steepland soils are more strongly dominated by the parent materials from which they are derived than by variations in climate and vegetation than older soils on gentler slopes. 


\subsubsection{Soils of the Four Study Areas}

The three study areas of north-east Wanganui; Mangawhero, Whangaehu, and Turakina are all dominated by steepland soil varieties although pockets of hill soils can be found. These steepland units vary according to underlying parent material; with variation in soil type, susceptibility to slipping and the types of slipping that are likely to occur also varies (Campbell 1977). The degree of development and thickness of these steepland and hill soils are determined in part by the position on the slope where they form. Campbell (1977) identifies four geomorphic controls on soil development, and has identified variants of soils formed on ridges, intermediate steep slopes, eroded slopes and accumulation slopes from the same parent material.

The ridge variants typically show maximum soil profile development and occur on moderately steep slopes on ridges and spurs. Intermediate steep slope soils form on uneroded steep valley sides in areas where there is neither significant accumulation nor depletion of soil material. Intermediate steep slope soils have shallower profiles than ridge soils and less distinct horizon development; fragments of parent rock may also be present. The eroded slope variants develop on eroded surfaces, and are typically characterised by weak, shallow profile development. There is wide variation among the eroded slope variants depending on the degree of erosion and extent of soil re-development. Lastly, the accumulation slope variants develop on lower surface of valley sides where slope debris has accumulated. These types of soils are generally deep but poorly draining (Campbell 1977). Although these four variants of steepland soils have been identified and characteristics described, general mapping and classification is based on the intermediate steep slope variant as this has been identified as the principle component the four.

Individual units for the Wanganui hill country study areas are all associated with yellow-brown earths; locations and descriptions are as follows:

- Turakina Steepland Soil (TkS) dominates the Mangawhero and Turakina study areas. TkS is a silt loam which ranges in depth (total of A and B horizons where horizons $\mathrm{A}, \mathrm{AB} \mathrm{B}_{2}, \mathrm{~B}_{3}$ are present) from $1.09 \mathrm{~m}$ to $1.9 \mathrm{~m}$. It is often found with Upukonui Steepland soil, and Mangatea Hill soil. Parent material of TkS is sandy mudstone. This soil is moderately stable with slipping generally infrequent. Prolonged or high-intensity rainfall, however, may cause locally extensive erosion, 
including deep-seated slides and flows. Hillslope failure occurs when soils are at close to saturation; this high moisture content encourages the development of flows within landslide material. Where shattered rock is exposed, revegetation can occur quickly; where massive parent rock is exposed revegetation occurs more slowly.

- Mangatea Hill Soil (MtH) is formed under similar elevation, climate and vegetation conditions as $\mathrm{TkS}$, and from similar parent material, however the slopes it forms on are less steep and therefore soils show greater development $\mathrm{MtH}$ is a silt loam with depth ranges comparable to but slightly greater than TkS soils. Profile development is similar to $\mathrm{TkS}$ however $\mathrm{B}$ and $\mathrm{C}$ horizons are deeper. $\mathrm{MtH}$ is found on undulating and rounded hill country, and is relatively common on this terrain in the Whangaehu study area, with some developing in pockets in the Turakina study area. Erosion in this soil type is mainly in the form of slumps or earthflows.

- Upukonui Steepland Soil (UpS) occurs in the Mangawhero study area and in small pockets in the Whangaehu study area. UpS is a sandy loam which ranges in depth from $0.94 \mathrm{~m}$ to $1.66 \mathrm{~m}$ where all possible A and B horizons (as for TkS) are represented. UpS is formed from moderately strong (compacted) silty sandstone in higher rainfall areas (1250-1525 mm) where there is a facies change in parent material from sandy to silty textured formations. The soil profile changes with the degree of compaction of the underlying sandstone unit. This soil unit is moderately susceptible to slip erosion; however slips stabilise and revegetate relatively quickly as the parent rock weathers relatively rapidly to form regolith.

- Mangamahu Steepland Soil (MhS) occur on very step slopes in deep valleys, up to an altitude of about $525 \mathrm{~m}$ above sea level. MhS is a silt loam to fine sandy loam with a depth range between $1.21 \mathrm{~m}$ and $2.28 \mathrm{~m}$ when all possible horizons (A, $\mathrm{AB}, \mathrm{B}_{21}$ and $\mathrm{B}_{22}$ ) are present. MhS soils occur mostly on long valley slopes that are only slightly concave. Parent material is predominantly compacted sandy siltsone; however MhS can form on sandstones and siltstones of varying hardness. Where MhS forms on sharp ridges of sandstone the ridges take on a fluted appearance. MhS soils are found only in the lower reaches of the Whangaehu study area. These soils are prone to slipping and very slow to heal due to resistance to weathering of the parent rock (Campbell 1977). 
The Pohangina soils are formed in weaker parent material, and all are prone to erosion (Rijkse 1977). The soil types are as follows:

- Pohangina Steepland Soils (PhS) form on loosely banded sandstone with greywacke gravels and pumice bands. $\mathrm{PhS}$ is comprised of horizons of sandy loam and loamy sand, and varies in depth between $0.05 \mathrm{~m}$ and $0.25 \mathrm{~m}$; horizons may include $\mathrm{O}_{1}, \mathrm{~A}_{1}$, and $\mathrm{Bg}$. These soils dominate the Pohangina hill country west of the Pohangina River. The parent material renders these soils susceptible to severe slip erosion and gullying on slip scars. Slip scars in PhS heal very slowly as erosion can readily accelerate into gullying. On slopes over $40^{\circ}$ a very steep phase (PhvS) of this soil forms which is highly unstable.

- Opawa Steepland Soils (OaS) are common in the north west of the Pohangina Valley hill country. AS with PhS, these soils include horizons of sandy loam and loamy sand, with depth ranges of $0.18 \mathrm{~m}$ to $0.58 \mathrm{~m}$ (horizons $\mathrm{A}_{1}$, and $\mathrm{B}$ ). Formed form the same parent material as $\mathrm{PhS}$, these soils are also subject to moderate to sever slip erosion, but slips do not progress to gullies and scars heal rapidly in the easily weathered parent rock (Rijkse 1977).

All soil units in the four study areas are susceptible to some form of slip erosion; the main differences between units lie in the type of slipping that will occur and the recovery time of the hillslope as scars heal and re-vegetate. The key differences between soil types that appear to play a controlling factor in landslide characteristics are:

- Soil depth - the Pohangina soils are generally much thinner than those of the Wanganui regions;

- Soil parent material - the Pohangina soils are derived from weakly banded layers of sandstone, pumice and gravels whereas the Wanganui soils are mostly derived from mudstones, and;

- Slope position on which soils fare formed - this factor is important for the development and thickness of the Wanganui soils, depositional slope soils tend to be thicker and more well developed (therefore capable of absorbing more moisture), whereas erosional slope soils are thinner and less developed (Campbell 1977). 


\subsubsection{Slope Angle}

Slope angle is a controlling factor in how far landslide runout material will travel. It also plays a key role in slope hydrology, controlling overland runoff rates and groundwater levels within the slope to some degree. Other factors such as soil type, rainfall intensity and slope form (concavity/convexity) will also control hillslope drainage (Kirkby 1978). In this study slope angle classes and descriptions for hill country terrain are those defined in the Land Use Capability Survey Handbook (Ministry of Works 1969) as follows:

- $\quad 0^{\circ}-3^{\circ} \quad$ flat to gently undulating

- $\quad 4^{\circ}-7^{\circ} \quad$ undulating

- $8^{\mathrm{o}}-15^{\mathrm{o}}$ rolling

- $\quad 16^{\circ}-20^{\circ} \quad$ strongly rolling

- $\quad 21^{\circ}-25^{\circ} \quad$ moderately steep

- $\quad 26^{\circ}-35^{\circ} \quad$ steep

- $\quad>35^{\circ} \quad$ very steep

Average slope angles of landslide affected slopes in the four study areas were calculated from the $20 \mathrm{~m}$ contours shown on the 1: 50000 NZMS260 maps Surface areas and slope angles of approximately 700 landslides were measured in each study area to provide the damage ratios, landslide densities, and scar length: runout length ratios. Because landslide density (number of slides per $\mathrm{km}^{2}$ ) varied between each of the four areas, a different number of slopes were measured for each of the four regions.

Each of the four areas exhibited a range of slope angles with average slope angles within $3^{\circ}$ from highest to lowest. The values for average slope angles and range of slope angles for the four units are shown in Table 8-1.

Table 8-1 Slope angles for the four study areas

\begin{tabular}{|c|c|c|c|c|}
\hline & Mangawhero & Whangaehu & Turakina & Pohangina \\
\hline $\begin{array}{c}\text { Average } \\
\text { slope angle }\end{array}$ & $25^{\circ}$ & $24^{\circ}$ & $24^{\circ}$ & $23^{\circ}$ \\
\hline $\begin{array}{c}\text { Range of } \\
\text { slope angles }\end{array}$ & $15^{\circ}-40^{\circ}$ & $15^{\circ}-30^{\circ}$ & $16^{\circ}-34^{\circ}$ & $18^{\circ}-32^{\circ}$ \\
\hline
\end{tabular}




\subsubsection{Slope Aspect}

Slope aspect affects hillslope hydrology in that southern facing slopes are generally wetter, with lower evapotranspiration rates than north facing slopes. Aspect may also be a strong controller on hillslope hydrology during localised storm events which are impacting from a given direction directly onto hillslopes (orographic rainfall). The February 2004 storm centre was located off the east coast of the North Island with rainfall peaking between 9am February $15^{\text {th }}$ and 9am February $16^{\text {th }}$. During the storm event the main airflow and rainfall over the lower North Island originated from a southerly direction, with the flow orienting from the west in the final day of the event (February $16^{\text {th }}$ to February $17^{\text {th }}$ ).

Eight classes of slope aspect (West, Northwest, North, Northeast, East, Southeast, South, and Southwest) were used, and each of the landslide affected slopes measured for slope angle was placed in one of the eight classes. Aspect of all slopes within each of the four defined study areas was identified to eliminate bias caused by local topography. Summaries of this data are provided in graph format in (Appendix 2). Figure 8-9 shows "aspect roses" of aspect preference for all slopes, in the study areas, while the aspect preferences for landslide-affected slopes are shown in Figure 8-10. A summary of landslide aspect preference data is presented in Figure 8-11, which shows the aspect of landslide-affected slopes as a percentage of all slopes of that aspect. For example, if for one study area the percentage of eastfacing slopes (in relation to over all slopes) is $12.5 \%$, and the percentage of eastfacing slopes affected by landslides is $25 \%$, the percentage of landslide affected east-facing slopes in relation to of all east-facing slopes within the study area would be $200 \%$. 


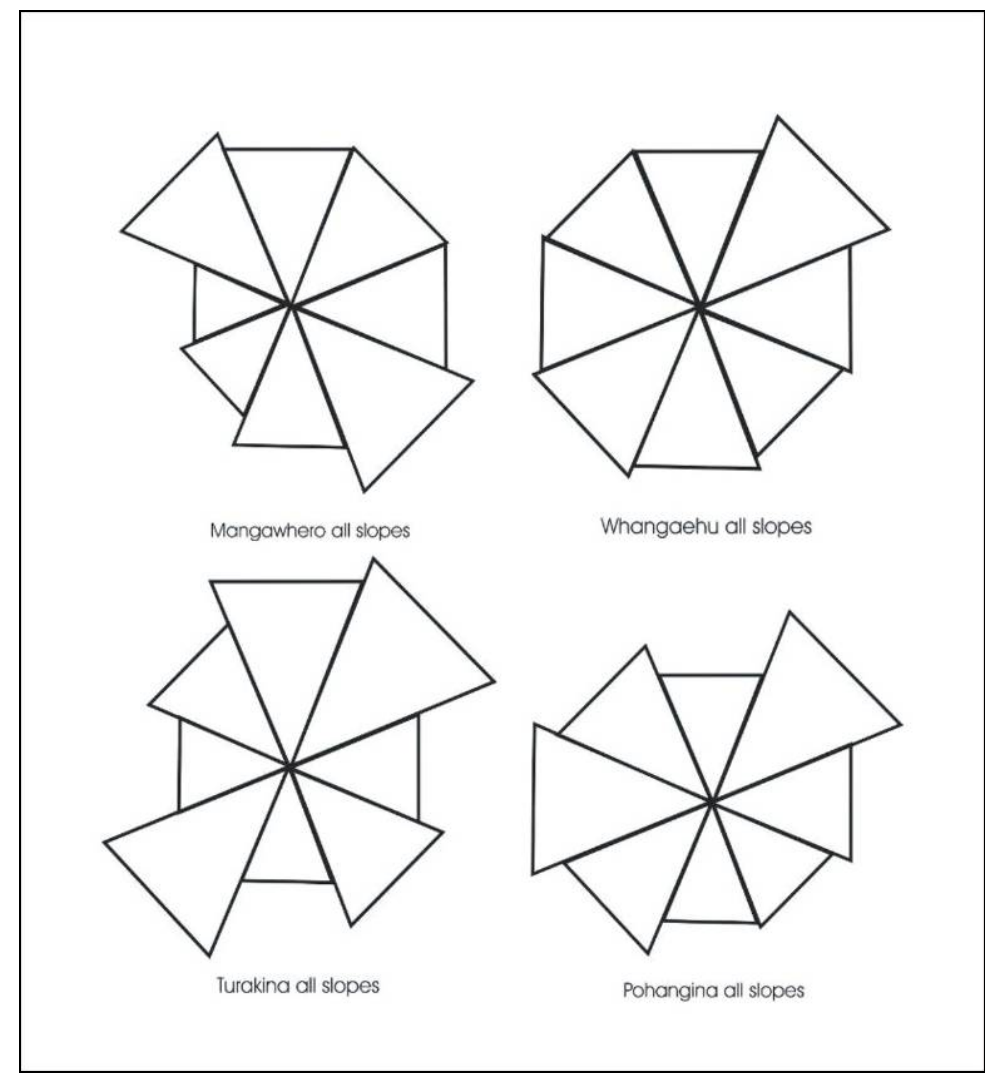

Figure 8-9 Aspect roses for all slopes within the study areas, while there is some variation between aspects from the ideal of $\mathbf{1 2 . 5 \%}$ for each aspect within a catchment variation is not extreme

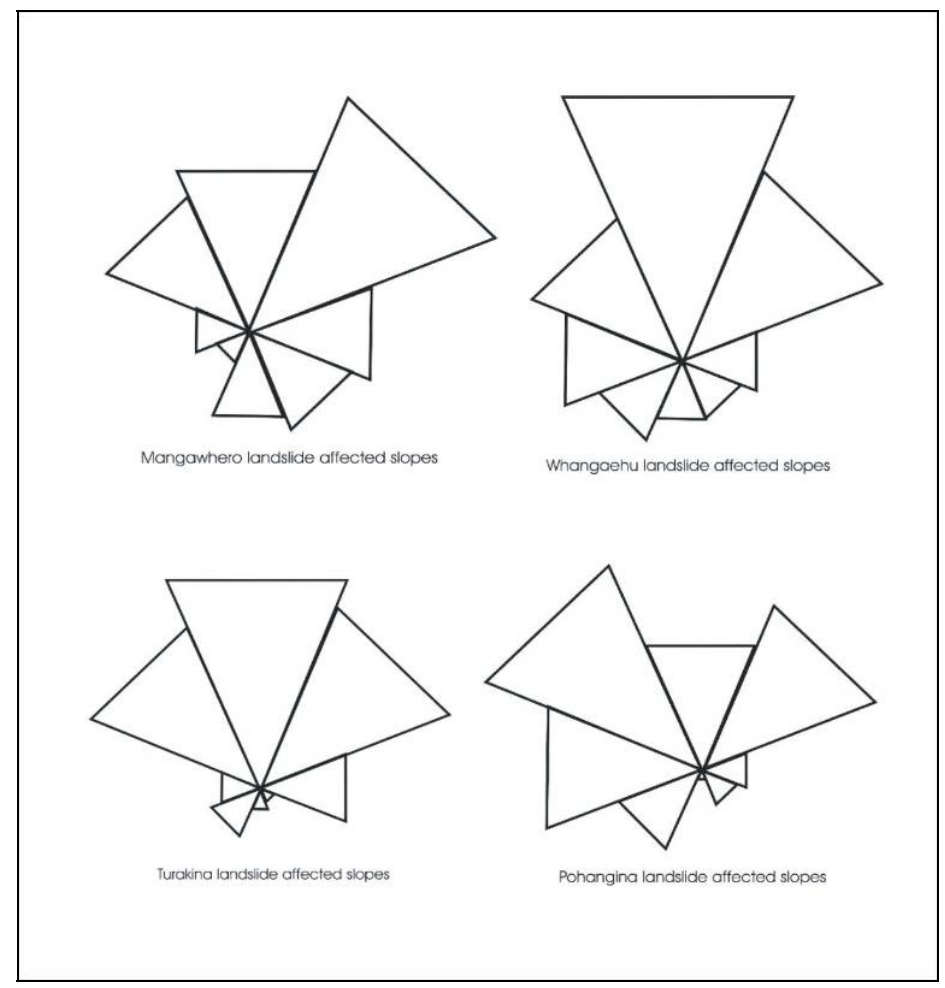

Figure 8-10 Aspect roses for landslide affected slope preference; theoretically for an "ideal" landslide event landsliding preference would match all slope aspect preference 


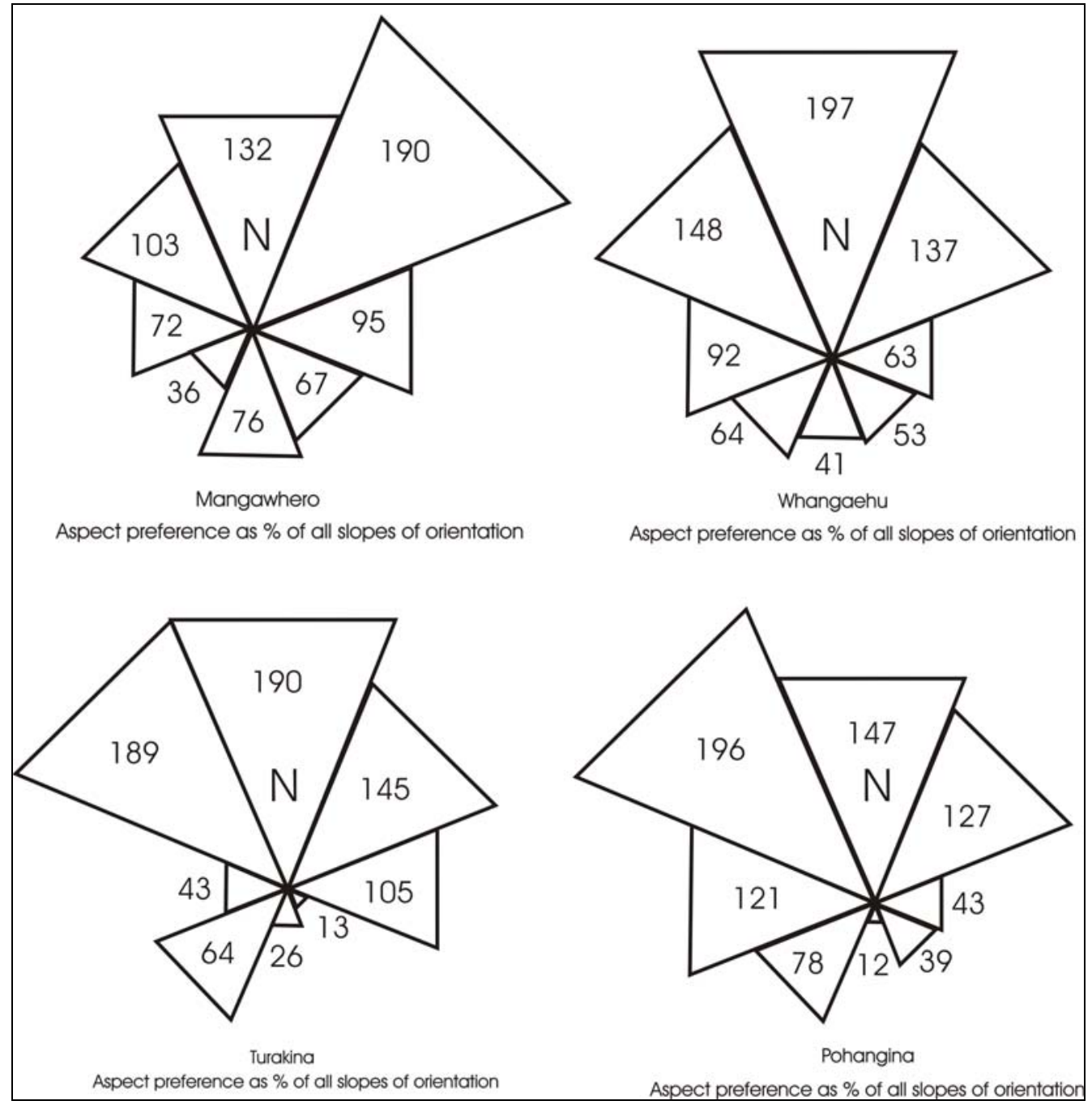

Figure 8-11 Landslide affected slope aspect ratios as percentage of all slopes aspect ratios, with percentages shown for each aspect class; there is some variation in preference although a sunny slope preference ( $N W, N, N E)$ is clear for all study areas. The numbers in each of the aspect classes represent the percentage of actual aspect preference once the number of slopes of each aspect is taken into consideration (e.g. for the Mangawhero study area $13.4 \%$ of all slopes faced north, and $17.6 \%$ of landsliding occurred on north-facing slopes, this gives an actual aspect preference of $131.8 \%$.

From Figure 8-9 and Figure 8-10 it can be seen that landsliding aspect ratios do not correlate with the aspect ratios for all slopes. It is also apparent that traditionally wetter southward (SW, S, SE) facing slopes appear least affected for all study areas. Antecedent rainfall conditions prior to the event suggest slopes were not apparently close to saturation (pers. comm., John Medlicott 2004); for these areas January and February are the driest months of the year with maximum evapotranspiration. The storm impacted from a southerly direction for most of its duration; this would perhaps be expected to provide greater saturation on southern facing slopes. The ratio of landslide affected slopes as percentages of all slopes suggest that there is 
another control on preferential landsliding in the affected area. A study of a similar rainfall-induced, multiple landslide event in the Wairarapa hill country (Crozier et al. 1980) found similar aspect preference of landsliding on north (NW, N, NE) facing slopes. Similarly for that earlier study aspect preference could not be attributed to the directional impact of rainfall, and it was concluded that previous landsliding on the wetter south facing hillslopes had rendered them less susceptible to landsliding during the 1977 Wairarapa storm. Crozier et al. (1980) theorised that the removal of regolith and soil from south facing slopes in previous storms had left less material able to be saturated and mobilised during the 1977 event.

As all of the study areas have lithologies and soil properties which render them vulnerable to landsliding and there are many scars from previous landslide events visible on the hills in the affected areas at the present time, it seems possible that aspect preference for the February 2004 event may be attributed to previous failure on south facing slopes. However, other factors such as greater thermal expansion and weathering effects on north-facing slopes, and possibly differences in soil thickness, particularly of aeolian soils (tephra and loess) are also likely to have contributed to the preference for landsliding on north-facing slopes seen in the study areas. Further studies of soil thickness and previous landsliding on slopes with southerly aspect need to be carried out to clarify these unresolved issues of landsliding in relation to slope aspect.

\subsubsection{Slope form}

Slopes that had been affected by landsliding within the four study areas are separated into four classes: concave, convex, rectilinear, and mixed. Slope form is linked to hillslope hydrology in that concave slopes concentrate drainage paths within them, while convex slopes disperse surface water to other parts of the slope. Rectilinear slopes provide direct paths downhill for surface water, neither concentrating nor dispersing surface flow. Mixed slopes include both concave and convex elements and are often 'lumpy' in appearance; many mixed slopes have the appearance of being modified by previous landslide events. The proportion of slopes falling within each form class for each study area is shown in Figure 8-12. The data is displayed principally by slope form rather than study area in Figure 8-13. Appendix 3 provides a summary table of slope form data. 


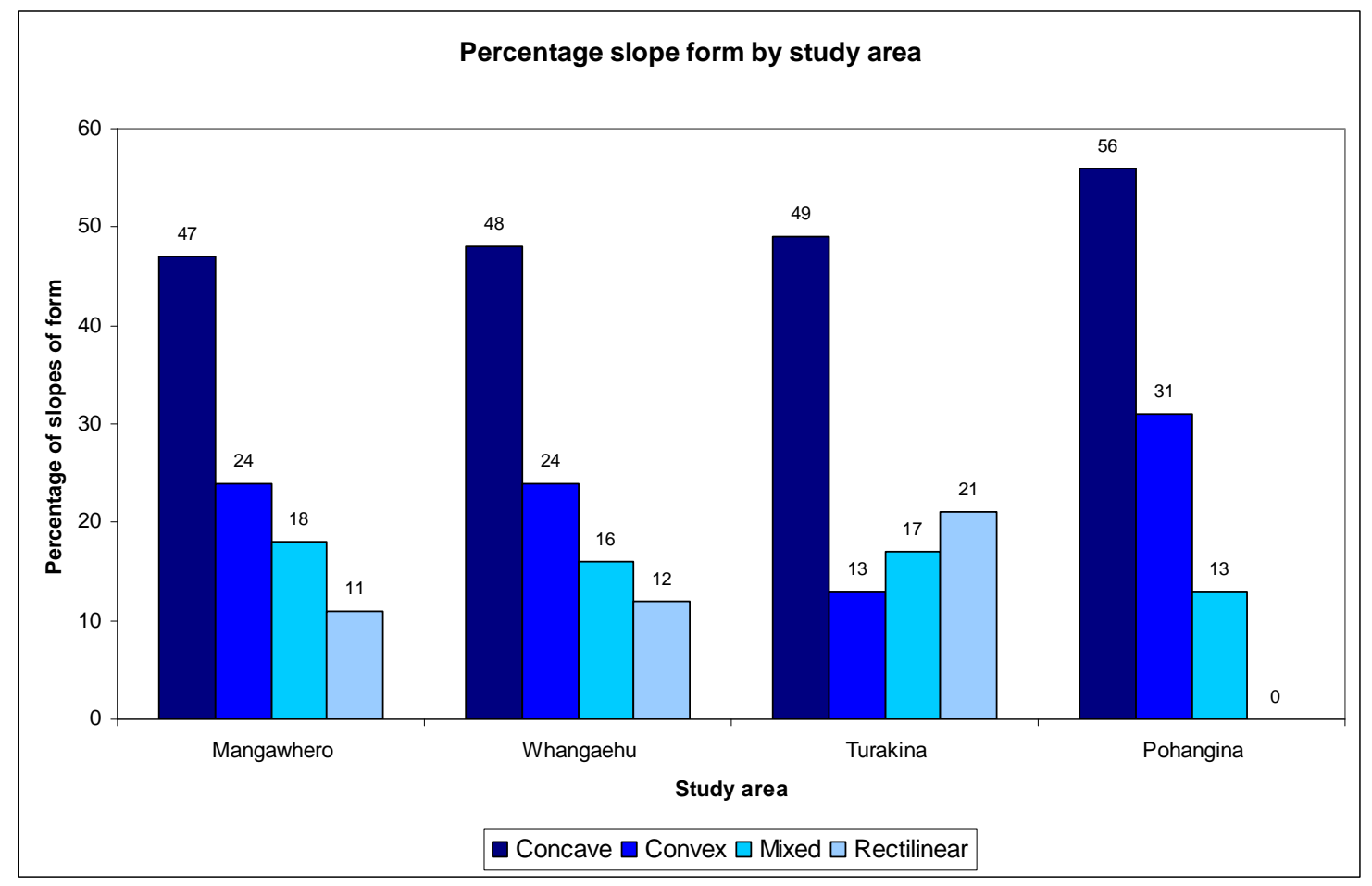

Figure 8-12 Percentage of landslide affected slopes within each form class for the four study areas

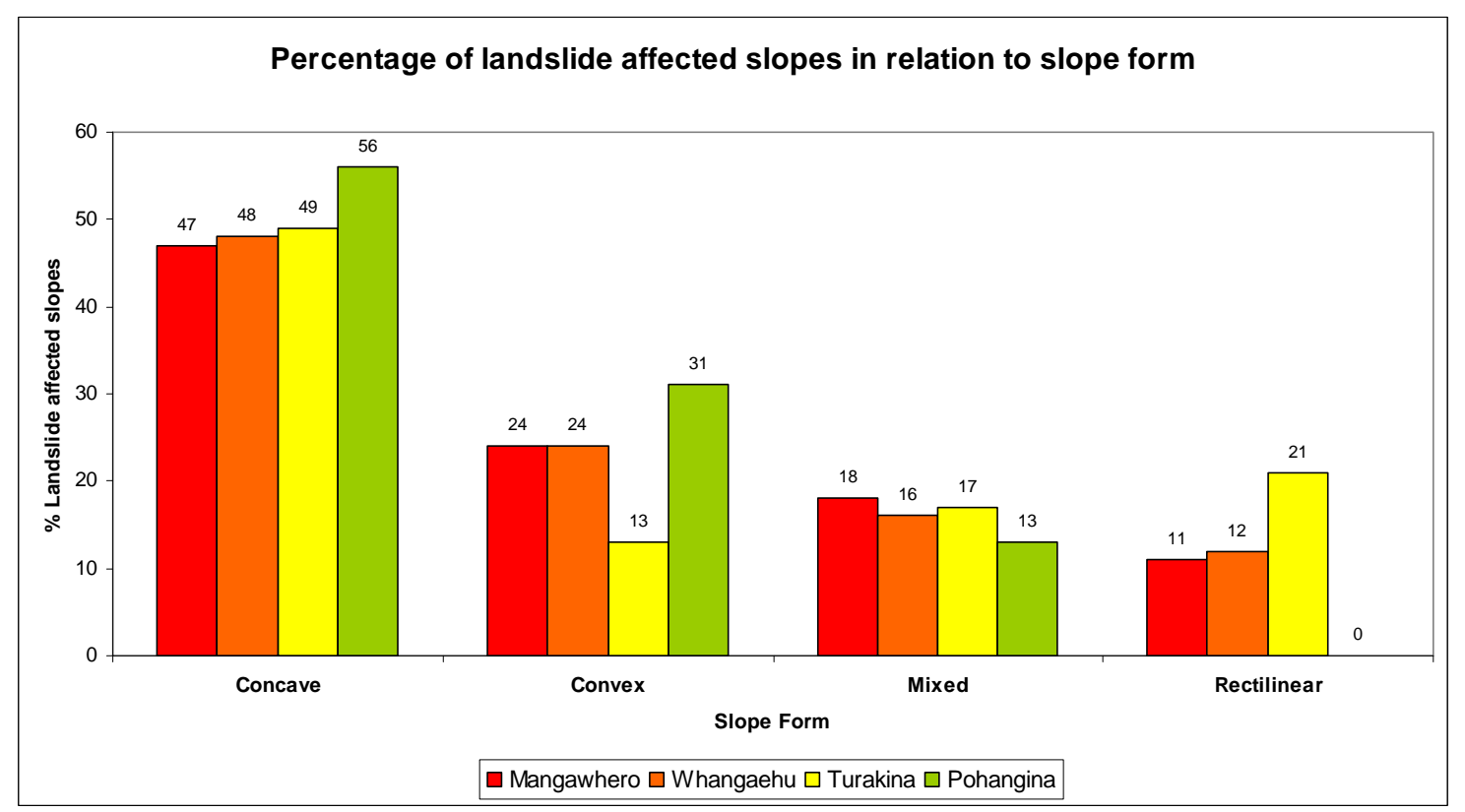

Figure 8-13 Proportion of landslide affected slopes divided by slope form

A similar ratio of slope forms is shown for Mangawhero and Whangaehu. Turakina is similar to the other Wanganui study areas in terms of proportion of concave slopes; however, unlike Mangawhero and Whangaehu it has a slightly higher proportion of rectilinear and mixed slopes than convex slopes. Pohangina has no rectilinear slopes and shows similarity to Mangawhero and Whangaehu in 
distribution shape of slope forms for concave, convex and mixed slopes. The data shows that concave slopes produced approximately half of the landslides in all four study areas.

\subsubsection{Slope Height}

Slope height controls terrain coupling and therefore fluvial (or event) coupling. In general, the shorter the slope the likelier it is that a landslide forming upon the slope will reach the drainage channel at the slope bottom. The height of a slope also controls the maximum angle of repose for unconsolidated or weak hillslope materials. Average slope heights for landslide affected slopes in the four study areas were derived from topographic map analysis, the results are shown in Table 8-5.

Table 8-2 Average slope heights for the four study areas

\begin{tabular}{|l|c|c|c|c|}
\hline & Mangawhero & Whangaehu & Turakina & Pohangina \\
\hline $\begin{array}{l}\text { Average slope } \\
\text { height }\end{array}$ & $144 \mathrm{~m}$ & $148 \mathrm{~m}$ & $138 \mathrm{~m}$ & $64 \mathrm{~m}$ \\
\hline
\end{tabular}

The Pohangina terrain shows clearly lower average slope heights, whereas the three Wanganui study areas show similar values. A comparison of slope height in relation to slope form was also made; this is shown in Figure 8-14. It can be seen that there is no apparent trend across study areas in terms of the highest slopes being related to particular slope forms, however, mixed slopes are higher for Mangawhero, Whangaehu and Pohangina study areas. Turakina which has the greatest proportion of rectilinear slopes also has these slope forms as it's highest on average. Pohangina shows very little variation in slope height between slope forms, implying the terrain is far more regular in form. This regularity of slope form can be seen in the photograph (Figure 8-17) in a later section (Section 7.4.17) on landslide density. 


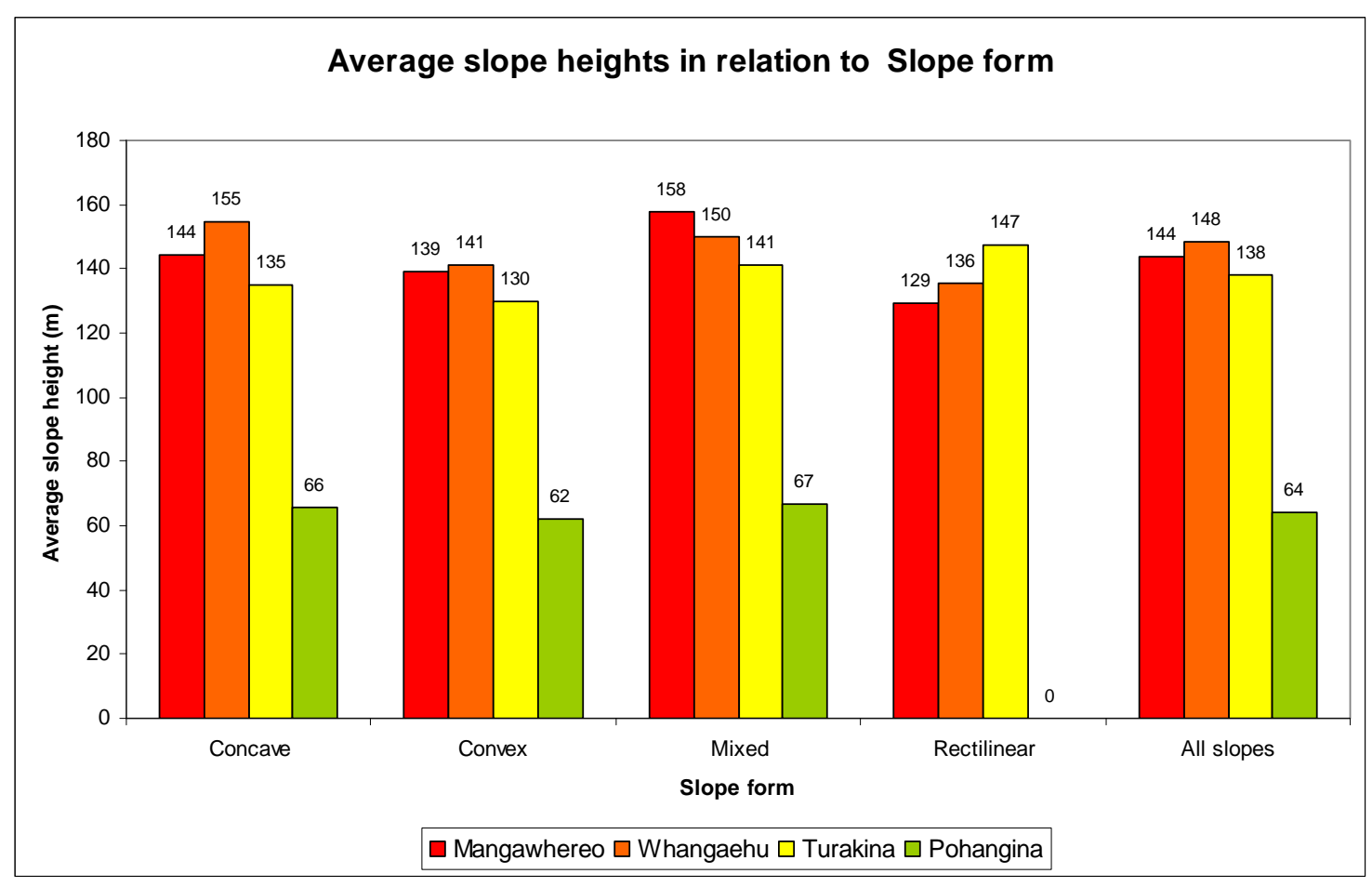

Figure 8-14 Slope height and slope form comparison, shown for each study area and all slopes

\subsubsection{Vegetation type and landsliding}

Using the same vertical photo runs (but not the same photographs) as for other sections of this regional analysis, photographs were selected for analysis of vegetation cover effects on landsliding. Four photographs from each study area, each with a variety of vegetation types was chosen. Photos that had been used for slope aspect and height analysis, as well as landslide density, scar volumes and runout length to scar length ratios were not suitable as these photos were selected as representing maximum damage and were almost entirely of one vegetation type pasture. Therefore photos that had at least $50 \%$ of other vegetation cover in the same photo run were used. Vegetation type was assigned four classes: pasture; bush/scrub, pine, and poplar/willow. For each of the photographs kilometre $(\mathrm{km})$ grid squares were overlaid, referenced form NZMS260 sheets. These grids were then divided into 100 smaller grids, each one hectare in area. For each $\mathrm{km}$ grid square the number of hectare grids of each vegetation class was counted, as well as the number of grids of each vegetation class that contained some degree of landsliding damage. These figures were then converted to percentages, to determine the proportion of landslides present in each vegetation class for each study area (Figure 8-15 and Figure 8-16). 


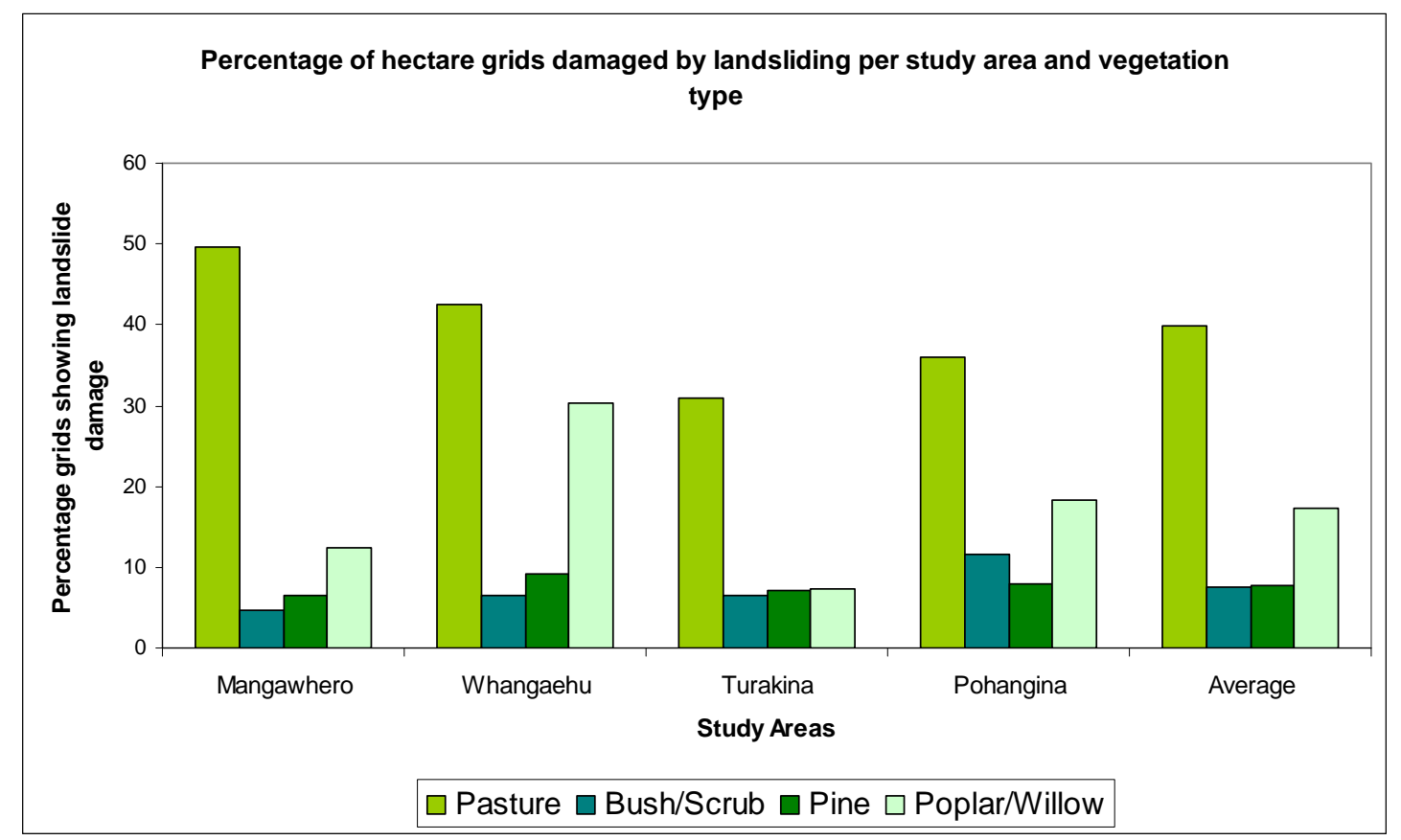

Figure 8-15 Landsliding displayed as percentage of landslides in each vegetation class for each of the four study areas

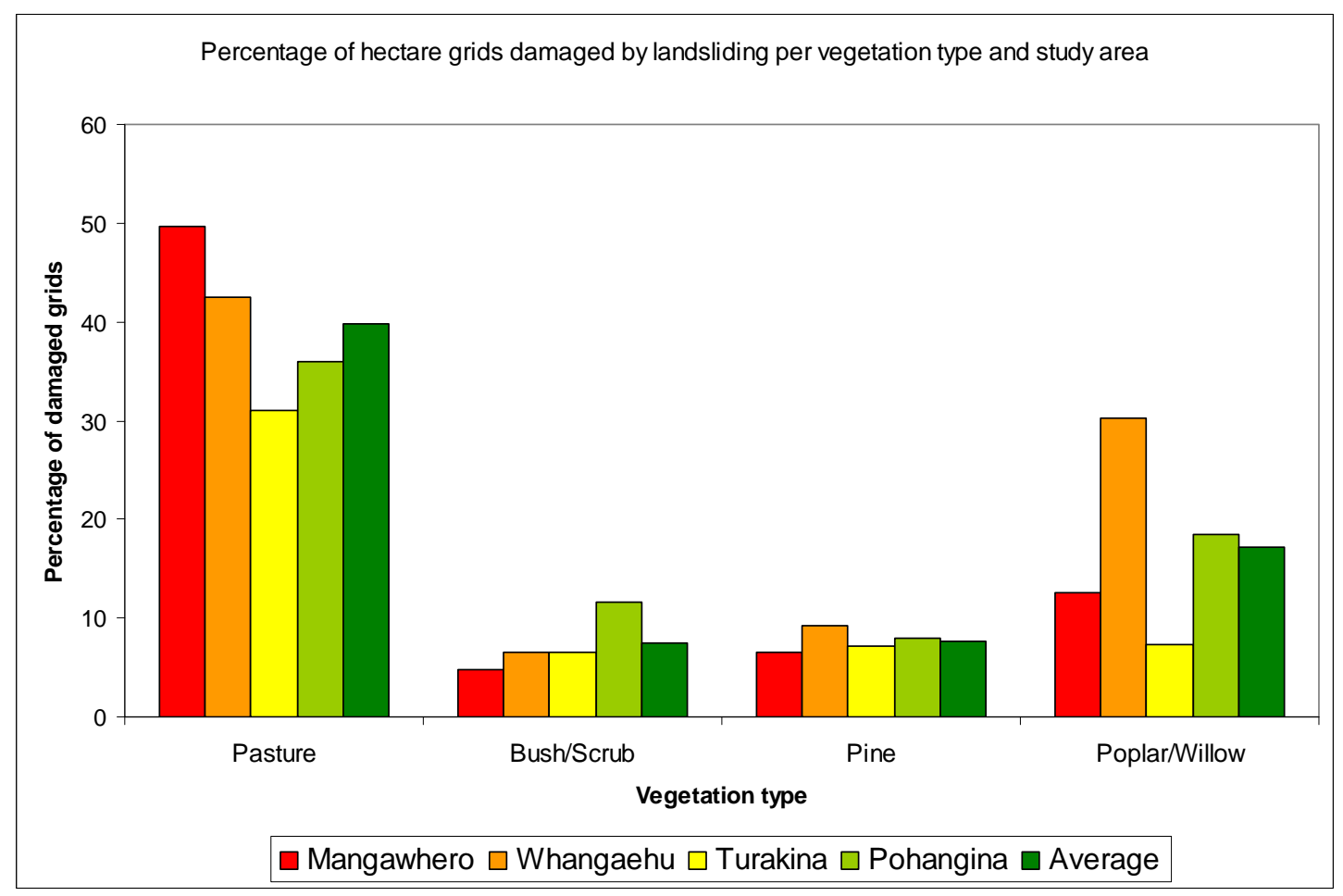

Figure 8-16 The vegetation type-landsliding relationship, with data grouped by vegetation type rather than study area

A summary of the data is provided in Appendix 5. Of the four vegetation types pasture produced the most landslides in all four study areas with a range of values between $31 \%$ and $49.6 \%$. The average proportion of landsliding damage on pasture 
was $39.8 \%$. Bush/scrub and pine produced similar average percentages of landsliding ( $7.5 \%$ and $7.7 \%$ respectively); however in Pohangina the percentage of landsliding in bush was greater than other study areas as there was considerable landsliding on steep riverbank bush margins. These bush-covered riverbank collapses would most certainly have contributed to the water-borne debris that destroyed the Ashurst Bridge further downstream (Figure 3-12 A). Poplar and willow plantings appear to have some influence on landsliding as percentage values are lower than for bare pasture, however as these have been planted often in drainage channels and on vulnerable slopes the percentages are still higher than for pines or bush/scrub. Pine plantations and bush/scrub covered areas have dense vegetation with far greater capacity for interception of incoming rain than sparsely planted poplars and willows and appear to provide far greater resistance to landsliding. Of the individual $\mathrm{km}$ grids that showed far higher than average percentages of damage, it was observed that this damage was occurring in areas where the trees were young as the plantation rows were more visible and ground was visible beneath. The canopy layer was not complete as with mature pines or the bush/scrub areas.

\subsubsection{Landslide Density}

For each of the four study areas a selected sample area of most severe damage was examined. Some of the vertical aerial photographs used are shown in (Figure 8-17). Grids within photographs containing forest or no landsliding were not included in the sample.

The area examined was dependent on the number of landslides within it as a sample of approximately 700 landslides was examined for each of the sample areas (Appendix 4). Depending on landslide density the areas studied ranged from 16.61 $\mathrm{km}^{2}$ (Mangawhero) to $22.73 \mathrm{~km}^{2}$ (Turakina). Kilometre square grids were laid over vertical aerial photographs; these were then divided further into grids containing 100 hectares sized grids. Kilometre grid squares were aligned to match those on the NZMS260 map sheets. The grid square overlays of vertical aerial photographs were also used when measuring damage ratios (percentage of landslide-affected terrain including scar and runout damage), and provided spatial referencing to avoid double 
measuring of individual landslides when measuring scar length to debris runout length ratios.

Landslide density is the number of landslides (Ls) per $\mathrm{km}^{2}$, and gives no indication of the volume of landslide debris involved. Damage ratios provide an indication of the proportion of terrain within a given area affected by landsliding. Landslide densities (Table 8-3) ranged from $43.4 \mathrm{Ls} / \mathrm{km}^{2}$ (Mangawhero) to $32.1 \mathrm{Ls} / \mathrm{km}^{2}$ (Turakina).

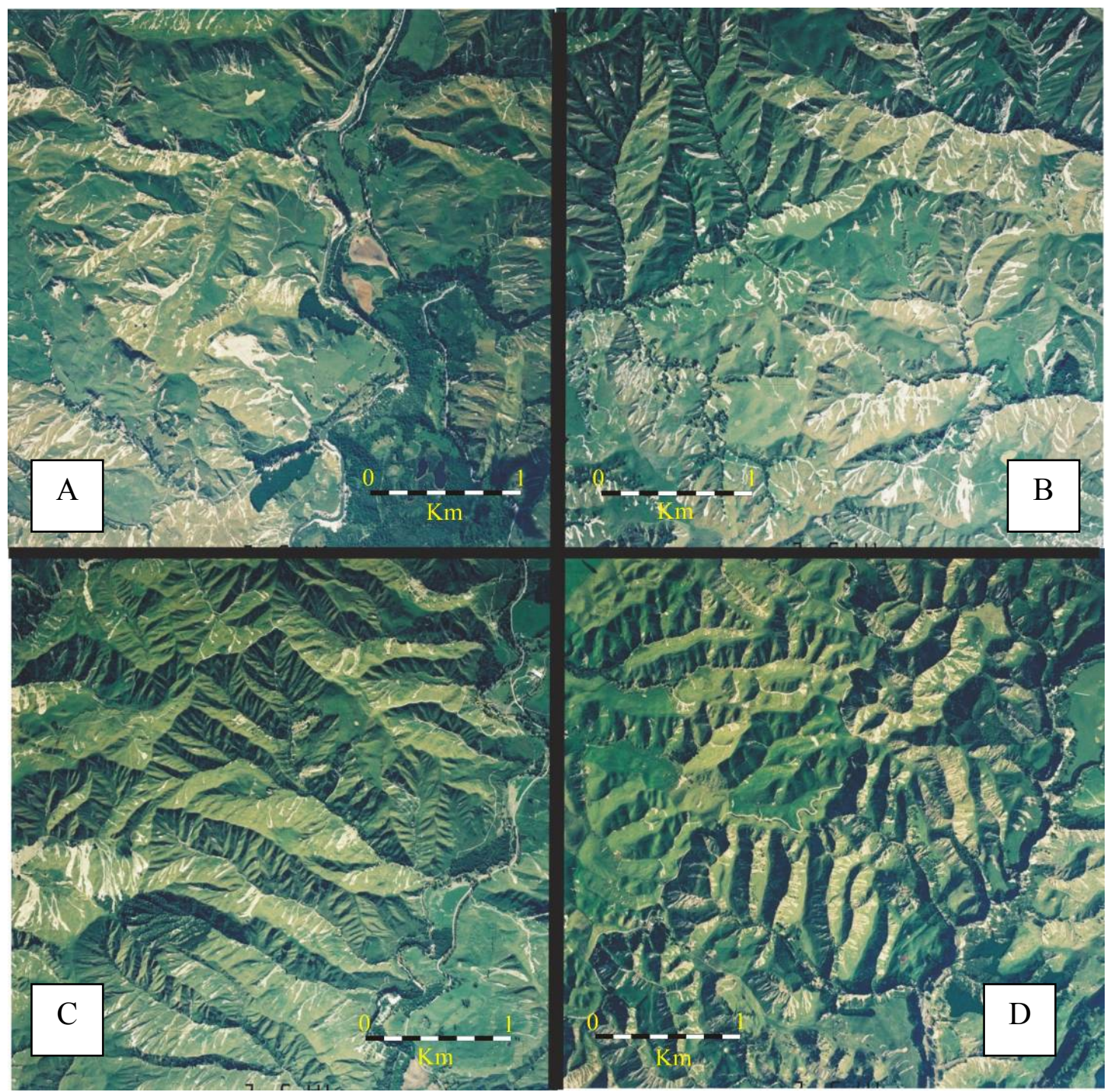

Figure 8-17 Some of the vertical aerial photographs used for this study A - Mangwhero, B Whangaehu, C - Turakina, and D - Pohangina, original print scale was 1: 18000 
Table 8-3 Landslide densities for samples of approximately 700 landslides for each study area

\begin{tabular}{|l|c|c|c|c|}
\hline & Mangawhero & Whangaehu & Turakina & Pohangina \\
\hline Total slips (Ls) & 721 & 723 & 730 & 748 \\
\hline Total area $\left(\mathrm{km}^{2}\right)$ & 16.6 & 20.2 & 22.7 & 19.9 \\
\hline Density $\left(\mathrm{Ls} / \mathrm{km}^{2}\right)$ & 43.4 & 35.8 & 32.1 & 37.7 \\
\hline
\end{tabular}

This data is also displayed as a graph in Appendix 5. It clearly shows that landslides were more numerous for a given area in the severely affected hill country of the Mangawhero Valley than other areas studied. The Pohangina study area was found to have the second highest density of landsliding; this difference can possibly be attributed to the nature of the terrain - lower hills, with many coalescing slips, which leads to higher landslide densities than the larger more spread out ridges of Whangaehu and Turakina Valleys (Figure 8-17). Topography as well as lithology and soil can be seen to exert some control over landslide densities for the four sample areas.

\subsubsection{Damage Ratios}

For each of the sampled areas within each study area, values for heavy, moderate, and zero to slight landslide damage were estimated (Table 8-4). This was done by visually estimating the proportion of each hectare grid square that had either scar or runout landslide damage. Grids squares were then assigned to the following classes:
- Heavy
$>20 \%$ damage
- Moderate $5-20 \%$ damage
- Zero to slight $0-5 \%$ damage

Table 8-4 Damage ratios for sample study areas

\begin{tabular}{|c|c|c|c|c|}
\hline Landslide Damage & Mangawhero & Whangaehu & Turakina & Pohangina \\
\hline Heavy >20\% & $12.9 \%$ & $7.1 \%$ & $4.1 \%$ & $7.8 \%$ \\
\hline $\begin{array}{c}\text { Moderate } \\
5-20 \%\end{array}$ & $23.7 \%$ & $23.6 \%$ & $19.1 \%$ & $20.9 \%$ \\
\hline $\begin{array}{c}\text { Zero - Slight } \\
0-5 \%\end{array}$ & $63.5 \%$ & $69.3 \%$ & $76.8 \%$ & $71.3 \%$ \\
\hline
\end{tabular}

From Table 8-4 it can be seen that the highest total damage from landsliding was found in the Mangawhero sample area, followed by Whangaehu and Pohangina. Turakina had the lowest overall damage as well as the lowest landslide density. 
Larger landslides such as those seen in Figure 8-17 clearly have a strong influence on overall damage ratios. No large deep seated slides were present in the Pohangina sample area; however high-density shallow landsliding in the area gives damage ratios similar to the Whangaehu sample area. Although there were some large deepseated slides in the Turakina study area they were not of sufficient quantity to produce heavy damage values comparable to either Whangaehu or Pohangina.

Because grid squares are based on the NZMS260 series kilometre map grid squares, not all of the sampled area is terrain of a type that is susceptible to landsliding, however the majority of grid squares selected cover hill country areas. The use of areal grid squares to provide densities of landslides per kilometre squared does not provide information on the proportion of hillslopes affected for a given area. The number of hillslopes affected ranges between 119 (Whangaehu) and 173 (Pohangina) for sample areas, and this value is dependent on the areal extent of individual hillslopes and the density of landsliding. Areal measurements of each slope were not undertaken for this study. Also, because the sample is focussed upon the most heavily damaged hillslopes within each of the four study areas, a value for proportion of hillslopes damaged would not be valid from this sample.

\subsubsection{Runout length: Scar length ratios}

The distance of landslide debris runout can have a major influence on the overall damage caused by an individual landslide. Greater runout distances (usually in the form of soil flows) increase the possibility of landslide-fluvial coupling (during rainstorms (landslide debris entering streams and rivers and contributing to overall sediment transportation during floods). Landslide debris that enters river channels increases sedimentation loads, raises river levels, contributes to bridge damage (through build up of sediment on bridge supports, and increased force of rising, sediment laden waters upon supports), and lowers water quality. When the debris also includes trees and other woody material the chances of damage to bridges increases further as the amount of force exerted on a bridge support is proportional to the area of the material that is being forced against it. Runout length: scar length ratios also give an indication of the nature of landsliding, especially the type of movement, a higher ratio would suggest material that easily forms or is incorporated 
into flows, a lower ratio material that stays intact and fails in a blocky form or as a slump. When the propensity for hillslope material to travel as runout flow is identified, it assists with the design of mitigations measures and future hazard and risk planning, particularly where buildings or other infrastructure may be at risk.

The landslides measured (approximately, and not less than, 700) for each of the sample areas were measured on enlarged copies of vertical aerial photographs overlain with hectare grid squares visually georeferenced to the NZMS260 map grid to prevent double counting of landslides that appear on adjacent photographs. Scar areas appear brighter and "cleaner" on the photographs and were reasonably simple to identify on enlarged photographs; runout material often had a more textured appearance as well as a "murkier" colour assisting with identification of the two landslide components. The maximum scar length and maximum runout length was then manually measured for each landslide and a ratio of runout length to scar length calculated. For multiple-headed (more than one scar contributing to runout tail) slides a combined scar length was used as all scars were contributing to the runout material.

Average runout length: scar length ratios are shown in Table 8-5. Figure 8-18 shows the spread of the data which is also listed as a table in Appendix 7.

Table 8-5 Average of all runout length: scar length ratios for each sample area

\begin{tabular}{|c|c|c|c|c|}
\hline & Mangawhero & Whangaehu & Turakina & Pohangina \\
\hline $\begin{array}{c}\text { 1. Average } \\
\text { runout length: scar } \\
\text { length ratio }\end{array}$ & $3.48: 1$ & $2.62: 1$ & $2.71: 1$ & $2.69: 1$ \\
\hline
\end{tabular}

The average values shown are considerable higher than those calculated by Dymond et al. (2004), whose study found average values of runout area: scar area of between 1: 1 and 2:1. The Dymond et al. (2004) study focussed on area rather than length which would account for some difference, however from the vertical aerial photographs it can be seen that the majority of slips have a relatively regular, linear form, meaning that length is in proportion to area. The sampling and measuring methods were also different as Dymond et al.'s (2004) study used digitised aerial 
photographs and manual digitisation of scar and landslide areas of a total of 440 landslides.

The sampling method also differed for this study, which is concerned with sample areas of greatest damage, while the Dymond et al. (2004) study chose a more random sampling method, although still within similar areas of landslide damage. Due to the increased sample size used in this study and field observations of many individual landslides it appears that the results of this study are valid for the sample areas, with some component of error from the use of non-rectified photographs.

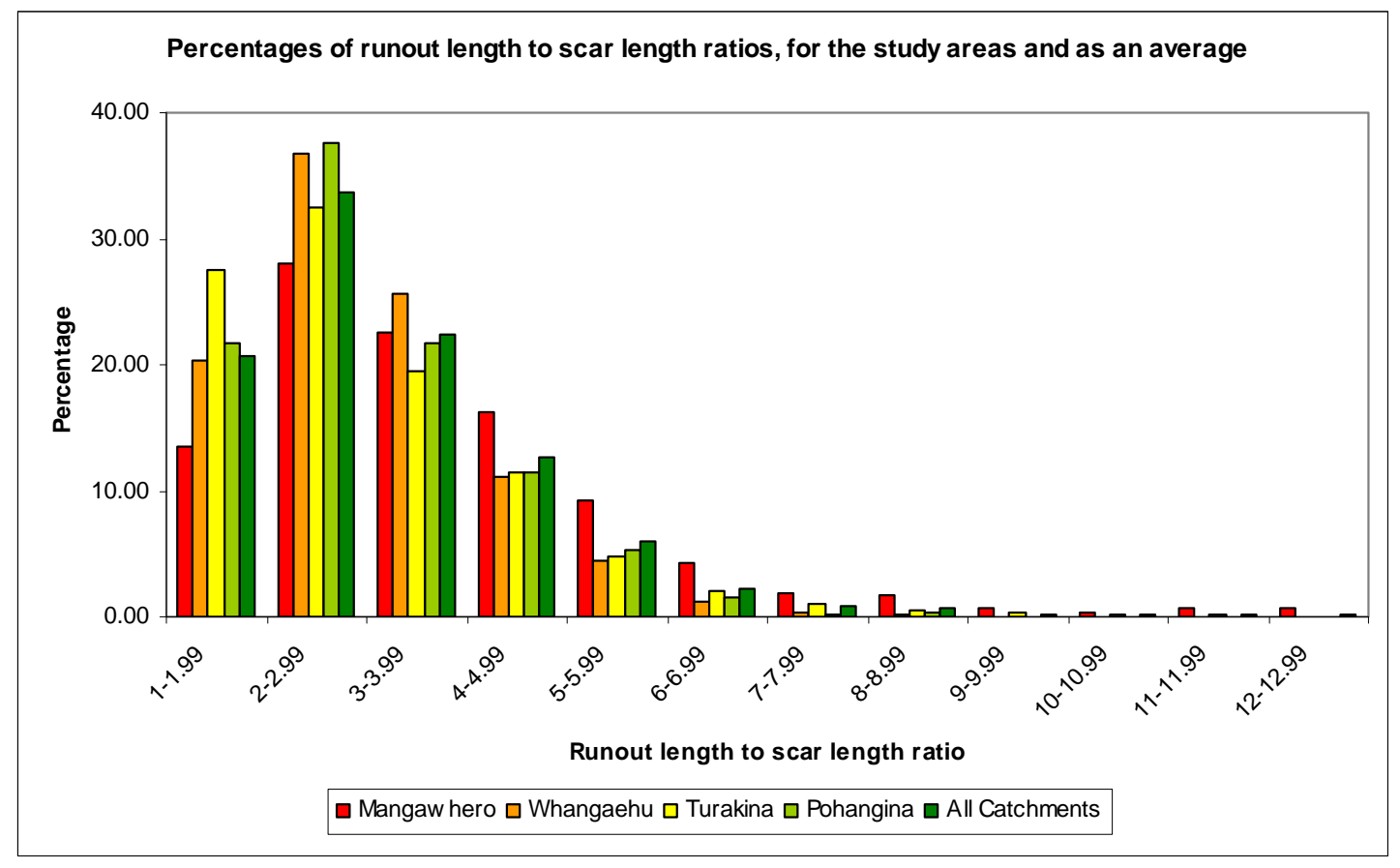

Figure 8-18 The spread of data from the four sample areas; note Mangawhero sample area has some very high ratios ( $>10: 1)$ of runout length to scar length, and fewer low ratios $(<2: 1)$. In general the same spread of data appears for each of the four areas

\subsubsection{Scar Volume Comparisons}

Geomorphic frequency magnitude theory in relation to landsliding is that the most work (a given volume moved a given distance in a given time) is done by large infrequent events rather than small frequent events (Selby 1982, Crozier and Glade 1999). This theory when applied to a landslide event containing thousands of individual landslides should theoretically apply at a lower scale i.e. that larger less common individual landslides are producing more hillslope erosion than many small scale landslides. Using the same aerial photographs from the four study areas as were 
used for the density and scar length to runout length ration analyses, this theory was tested. Using highly magnified digital copies of the aerial photographs a $10 \times 10 \mathrm{~m}$ ruler was used to measure at least 500 landslide scars in each study area. By default a value of $0.5 \mathrm{~m}$ depth was given to all landslides unless it was obvious that the landslide was deep-seated; in this case a depth value of $1.5 \mathrm{~m}$ was assigned. These values should err on the conservative side of volume estimation and therefore weigh any test of the theory towards an increased importance of smaller landslides. Once volumes were calculated landslides were assigned to one of three classes: large (greater than $\left.1000 \mathrm{~m}^{3}\right)$; medium $\left(100-1000 \mathrm{~m}^{3}\right)$; and small (less than $100 \mathrm{~m}^{3}$ ). The percentage of landslides in each size class (Figure 8-19), as well as the percentage of total scar volume represented by each size class (Figure 8-20) were than determined for each study area

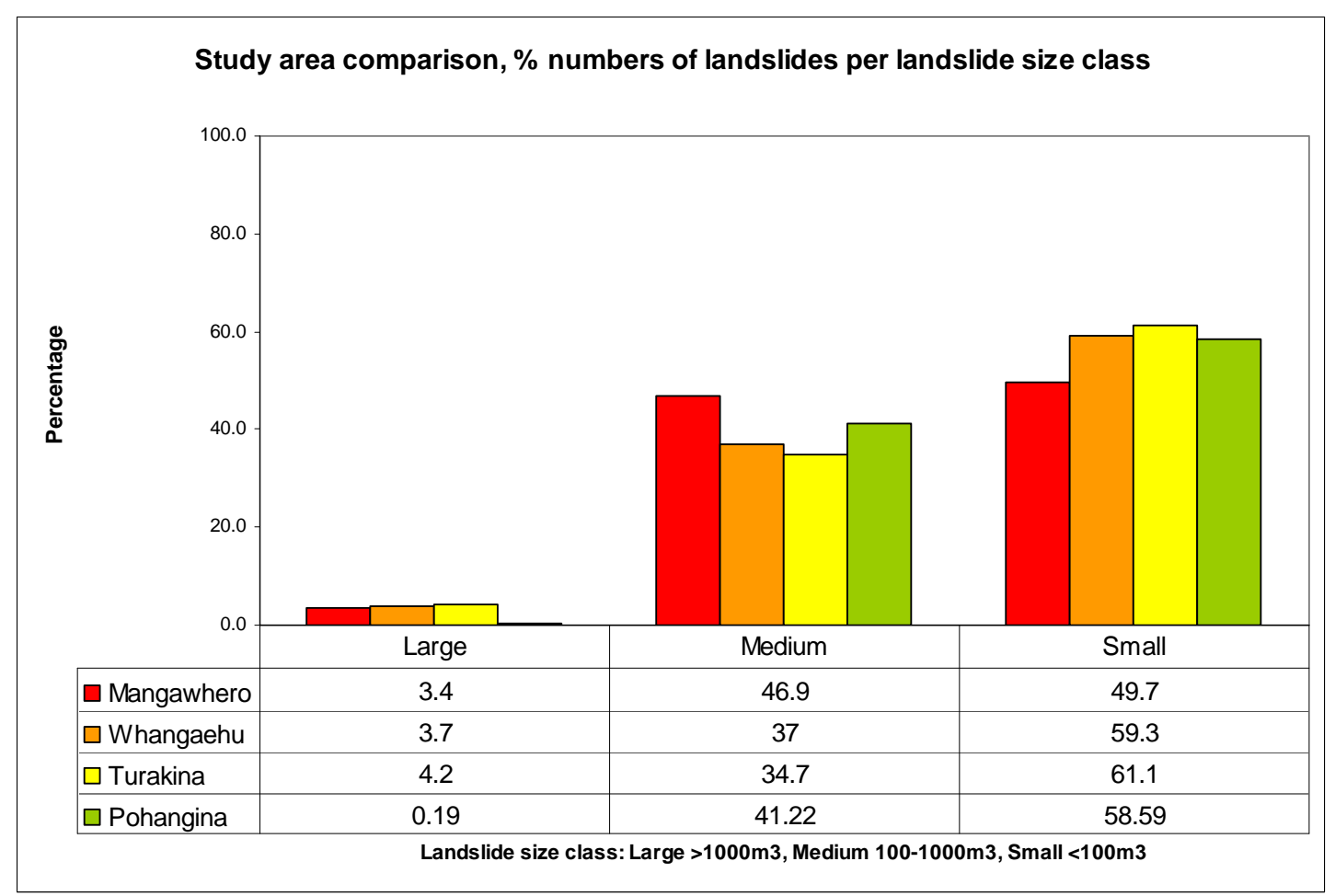

Figure 8-19 The percentage of landslides that fall within each size class for each of the study areas 


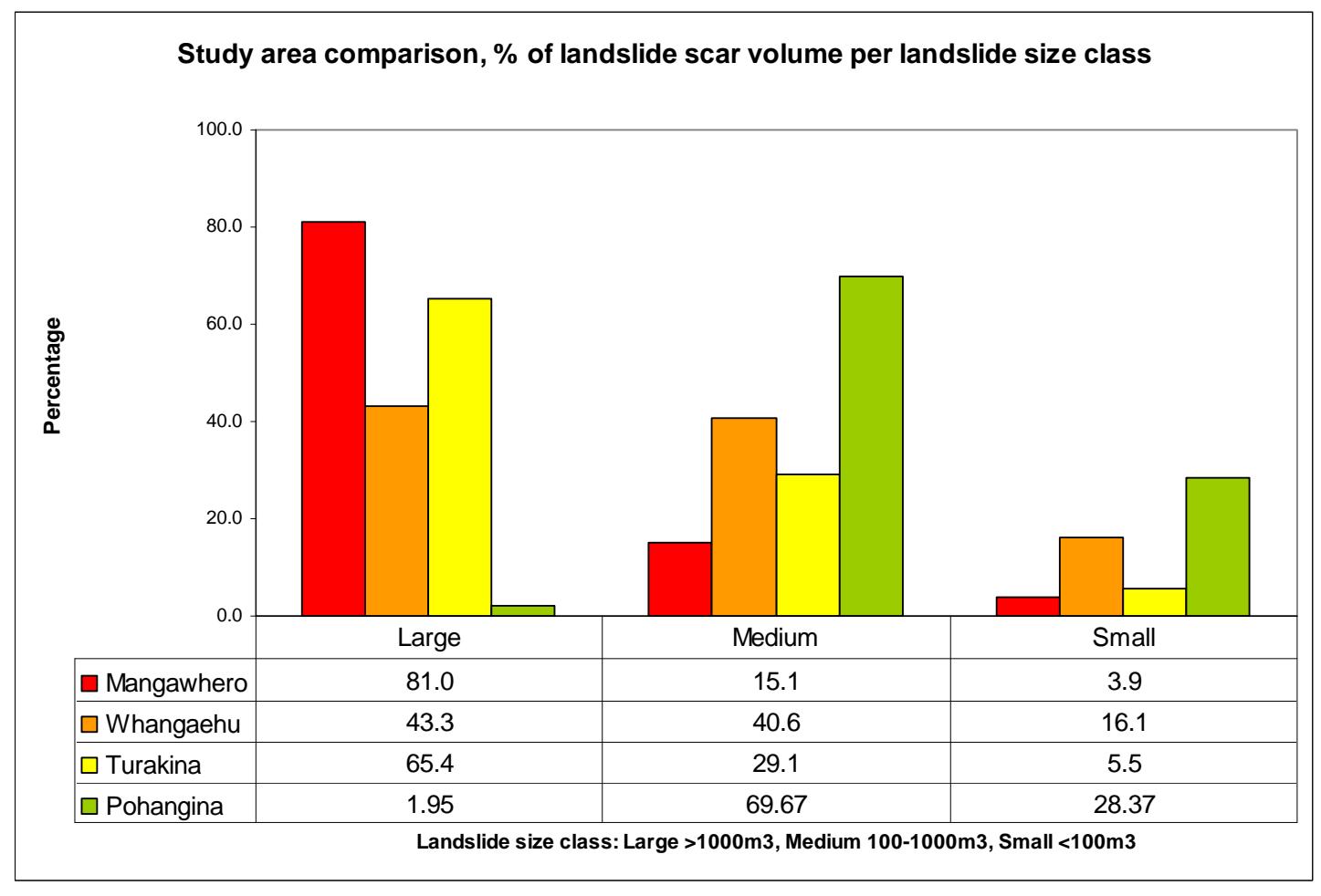

Figure 8-20 The percentage of scar volume that is represented by each size class for each of the four study areas. When compared with Figure 8-19 it can be seen that very few landslides in number (the large landslides) produce the majority of scar volume except for in the Pohangina study area (e.g. for Mangawhero the percentage of landslides falling within the large size class is only $3.4 \%$, yet the scar volume percentage represented by the large size class in Mangawhero is $81 \%$, that is only $3.4 \%$ of landslides have produced $81 \%$ of the erosion in this area). Comparisons by area for this data are shown in Appendix 8.

Graphs of individual study area comparisons between percentage of landslides per size class and the percentage of scar volume contained in each size class are shown in Appendix 8. What is immediately apparent from Figure 8-19 is that very few landslides fall into the large size class, with the majority of landslides in the small size class for all study areas. The percentage of scar volume present in each size class however is not in proportion to the percentage of landslides in that size class (Figure 8-20). For the three Wanganui study areas the greatest contribution to hillslope erosion is provided by the large size class, followed by the medium size class. The Pohangina terrain is such that only one large landslide was identified within the study area; one landslide out of 524 is not sufficient to produce a scar volume great enough to contribute more than the combined volumes of medium or small landslides for this area. Generally however the data support frequency magnitude theory of geomorphic work done by landsliding in that an average of 48 $\%$ of material was eroded by large landslides (average of all study areas), when the 
average percentage of occurrence of large landslides for the four study areas was just under $3 \%$.

\subsubsection{Error calculation of non-rectified photographs}

Non-rectified vertical photographs have an increasing degree of distortion from the centre of the photograph towards the edges. The magnitude of this error was calculated by examining adjacent (and therefore overlapping) photographs, and then measuring the dimensions of landslides appearing in the centre (non-distorted) of one photograph and comparing with the dimensions of that landslide as it appeared on the edge of the adjacent photograph. Distortion between adjacent east-west photographs was examined as well as adjacent north-south photographs. Measurements of total lengths (scar and runout) were compared (Appendix 9) and the average east-west error was found to be $4.13 \%$. For adjacent north south photographs (as they are taken in each image run, either flying north to south, or south to north) the error was found to be $2.37 \%$. The average error values seem low, however errors of up to $25 \%$ were found for a few individual landslides. It must also be noted however that while the error measured is for the entire length of the landslide, it is expected that both scar and runout contain the same degree of error, as they are in the same position on the photograph, and as this study uses ratio comparisons the slight error due to the use of non-rectified photos does not significantly effect the overall results.

\subsection{Summary of the regional terrain and landslide characteristics analysis}

A summarised table of terrain attributes of each of the four study/sample areas, as well as landslide characteristics examined, is presented in Table 8-6 at the end of this Chapter. From the terrain and landslide analysis of the four study areas it is clear that some terrain characteristics are more important than others in determining the magnitude (i.e. volumes, densities, damage ratios) of landsliding in the study areas. The most obvious controlling terrain factors on landsliding magnitude for this analysis were:

- underlying geology; which controls soil development and the potential for large rotational slides to develop. Deep-seated slides were universally formed in mudstone hill country; 
- vegetation cover; controls the density and to a degree the volume of landslides formed, pasture lands were far more affected by landsliding than bush/scrub or pine plantations; willows and poplars were partially effective in reducing erosion;

- slope height; controls the maximum angle at which a hillslope will be stable, it also, along with topographic form, controls the area of hillslopes, and therefore the maximum scar size, and;

- slope aspect; sunnier facing slopes experienced more severe (denser) landslide activity than shady slopes. This phenomenon has been observed during other multiple landslide events, in particular during the Wairarapa 1977 event studied by Crozier et al. (1980).

Aspect preference for landsliding on north facing slopes was found in all study areas. This preference cannot be attributed to the direction of the prevailing winds and therefore incident rainfall. It is suggested that a likely explanation for this preference is low antecedent rainfall conditions, and high evapotranspiration so all slopes are at a similar degree of saturation prior to the event, and that many of the south facing slopes have lost susceptible hillslope material in previous events rendering them less likely to fail in February 2004.

Vegetation type has a clear effect on landsliding occurrence (Figure 8-21 to Figure 8-25). Pasture is the most susceptible to landslide damage followed by poplar and willow plantings. It must be noted that poplars and willows are generally planted on the steeper pasture slopes or in coincidence with drainage channels and therefore are situated mostly on slopes that are more susceptible to failure. However, these plantings appear to provide some protection as the proportion of hectare grids of poplar/willow that exhibited landsliding damage was on average $17.2 \%$, while for pasture land the average percentage of affected grids was $39.8 \%$. Pine and bush/scrub covered land both had low damage percentages $(7.7 \%$ and $7.5 \%$ respectively). Percentage damage under young pines was generally higher than for mature pines, and for bush/scrub land undercut river bank slopes showed considerably more damage than non-riverbank slopes. 

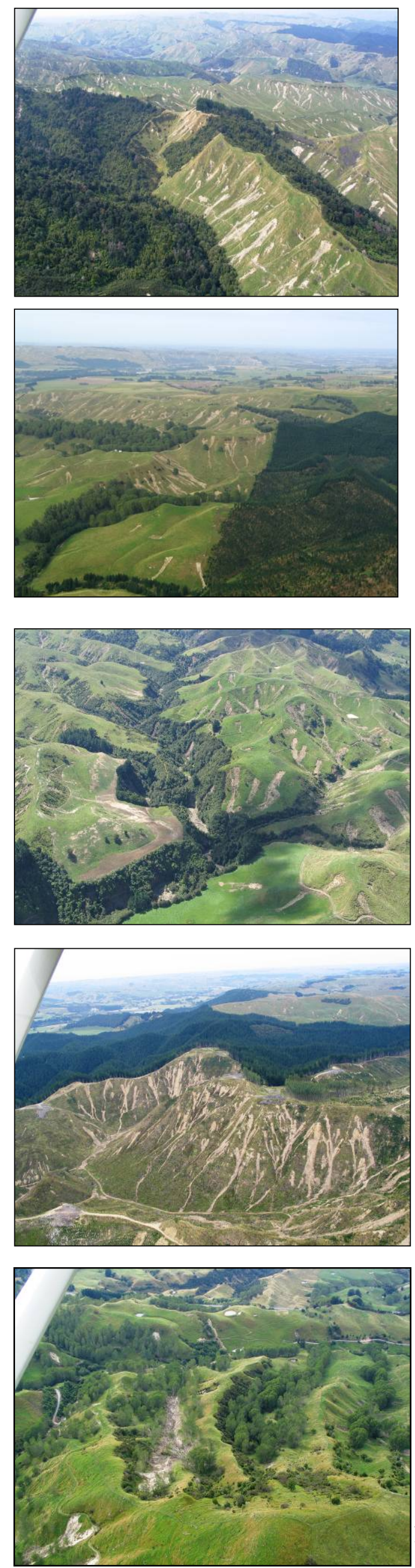

Figure 8-21 Bush covered slopes in comparison with pasture slopes, photograph Hancox 2004

Figure 8-22 Mature pine forest, poplar plantings, and pasture comparison. Poplars provide greatest cover where plantings are dense photograph Hancox 2004

Figure 8-23 A narrow bush/scrub valley with several landslides on the steep undercut slopes, photograph Hancox 2004

Figure 8-24 Mature pine forest (background) and young pines (foreground); the young pines have offered no erosion protection to the affected hillslopes, photograph Hancox 2004

Figure 8-25 Poplars and willows planted in drainage channels to reduce soil saturation, in the valley on the left planting has been unsuccessful in preventing landsliding, photograph Hancox 2004 
The four study areas differ in the intensity (damage ratio and density) of landslide damage. Lithological and soil properties control the style of landsliding and recovery times of affected hillslopes. Mangawhero study area shows the greatest damage ratio, the highest density of landsliding and the highest runout length: scar length ratios. Slope angle, lithology and soils are similar for this area to those of Whangaehu and Turakina yet significant differences exist for the magnitude of the landslide event between these three areas. The presence of the Upukonui Steepland Soil (UpS) may be linked to increased damage for Mangawhero however this soil type is also found to a lesser degree in Whangaehu and is described by Campbell (1977) as only "moderately susceptible to slipping". Turakina has suffered the least damage of all four study areas, while sharing terrain attributes with both Mangawhero and Whangaehu. Pohangina has differences in both lithology and soil characteristics from the Wanganui study areas, yet its weaker, erosion-prone terrain shows similar damage ratios to Whangaehu, and to some degree to Turakina.

Scar volumes appear to coincide with slope height. Pohangina has an average slope height of $64 \mathrm{~m}$, while the three Wanganui study areas have average slope heights of between $138 \mathrm{~m}$ and $148 \mathrm{~m}$. Only one large (scar volume $>1000 \mathrm{~m}^{3}$ ) landslide was found in the Pohangina study area. Slopes are short in profile and terrain coupling with the fluvial system is high in this area; in general hillslopes are not of sufficient area to produce the larger scar volumes. Contribution to overall hillslope erosion from the large landslide scars far outweighed their frequency of occurrence. On average the frequency of large landslides across the four study areas was $2.9 \%$ however, the total scar volume percentage produced by these few large landslides was $47.9 \%$ on average. For the three Wanganui catchments large landslides are clearly doing the majority of geomorphic work.

Differences between the magnitudes of landslide damage for the four study areas cannot be attributed to terrain attributes alone, therefore localised pockets of intense rainfall may have contributed to higher damage in some areas. Rainfall data available is not sufficiently detailed to test this theory. There may also be a link between previous failure and the magnitude of damage for the four study areas. All study areas are known to have experienced rainfall-triggered landslide events prior to February 
2004, the timing and magnitude of these past events (especially highly localised events) will affect future hillslope response to storm events.

The runout length: scar length calculations provide average values of between 2.5: 1 and 3:1. These values are important for assessing future hazard in the four areas, as some prediction of how likely flow is to occur, and over what distance, is possible for a given magnitude of storm event. The implication for the construction of buildings and infrastructure at the base of, or upon, landslide susceptible hillslopes is that planning should be based not only on whether the land on which construction occurs is vulnerable, but whether hillslopes above are likely to fail. The February 2004 event was extreme in the extent and degree of damage; that no lives were lost to landsliding is mostly due to the most severe damage occurring in sparsely populated farm land.

Manual measurement and comparison of over 2800 landslides is time-consuming and contains a degree of human error. Digitisation and rectification of vertical aerial photographs would provide the capacity to undertake a similar study to much greater levels of detail in less time and is recommended for future studies of this nature. Digitisation does not remove all error however, as identifying landslide scar and runout material based on pixel shade only (Dymond et al. 2004) removes the capacity for human experience of actual landslides to assist with identification. It is suggested that a combination of both digital and manual methods be used to provide increased validity.

The February 2004 landslide event created most damage in the Mangawhero hill country. Other badly affected areas included the hill country of Whangaehu, Pohangina and Turakina. The nature of landsliding in the four areas can be attributed to some degree to terrain characteristics; however other factors appear to have influenced the location, slope aspect, and magnitude of damage.

Studies comparing different terrain types (lithology, topography, soils etc) provide some insight into the nature of landsliding, however pre-conditions which enhance susceptibility to landsliding, and the nature of the triggering event also require examination to determine whether varying landslide response is a function of terrain variance, pre-conditioning variance or event variance within a region. 
Table 8-6 Summary of regional landslide and terrain analysis

\begin{tabular}{|c|c|c|c|c|}
\hline Attribute & Mangawhero & Whangaehu & Turakina & Pohangina \\
\hline Bedrock & $\begin{array}{l}\text { Mudstone; weak and massive, Sandstone } \\
\text { Consolidated (strong) } \\
\text { (Pliocene) }\end{array}$ & $\begin{array}{l}\text { Mudstone; weak and massive, Sandstone } \\
\text { Consolidated (strong) and moderately consolidated } \\
\text { (mod. strong) } \\
\text { (Pliocene) }\end{array}$ & $\begin{array}{l}\text { Mudstone; weak and massive } \\
\text { (Pliocene) }\end{array}$ & $\begin{array}{l}\text { Sandstone; } \\
\text { unconsolidated } \\
\text { (weak), containing thinly bedded clays and limestones, some } \\
\text { gravel and pumice layers } \\
\text { (Pleistocene) }\end{array}$ \\
\hline $\begin{array}{c}\text { Soil Parent } \\
\text { Material }\end{array}$ & $\begin{array}{llll}\begin{array}{l}\text { Quartzo-feldspathic } \\
\text { mudstones }\end{array} & \text { Mudstones, including } & \text { sandy } \\
\end{array}$ & $\begin{array}{l}\text { Quartzo-feldspathic Mudstones, including sandy } \\
\text { mudstones }\end{array}$ & $\begin{array}{lll}\begin{array}{l}\text { Quartzo-feldspathic } \\
\text { mudstones }\end{array} & \text { Mudstones, including sandy } \\
\end{array}$ & Quartzo-feldspathic Sandstone and conglomerates \\
\hline Soil characteristics & $\begin{array}{l}\text { Turakina steepland soil (TKS) dominant, Upokoni steepland } \\
\text { (UpS) soil at mudstone-sandstone boundary. TKS generally } \\
\text { stable, but can develop deep seated slides and earthflows, } \\
\text { heals slowly on bedrock rapidly on regolith. UpS } \\
\text { moderately susceptible to slipping, heals reasonably } \\
\text { rapidly. }\end{array}$ & $\begin{array}{l}\text { TkS in north with areas of Mangatea hill soils (MtH). } \\
\text { Mth on shallower slopes prone to slumps and } \\
\text { earthllows. Mangamahu steepland soils (MhS) in the } \\
\text { south. MhS prone to slipping and heals slowly. Some } \\
\text { UpS present. }\end{array}$ & $\begin{array}{l}\text { TkS dominates, } \\
\text { Small regions of Mth where slopes are less steep. }\end{array}$ & $\begin{array}{l}\text { Pohangina steepland soils (PhS), Opawa steepland soils } \\
\text { (OhS), both prone to slip erosion, Phs slow to heal, OhS more } \\
\text { rapid }\end{array}$ \\
\hline $\begin{array}{l}\text { Average Slope } \\
\text { Angle and class }\end{array}$ & $\begin{array}{l}24.85^{\circ} \text { - Moderately steep. } \\
\text { Range of affected slopes: } 15^{\circ}-40^{\circ}\end{array}$ & $\begin{array}{l}23.60^{\circ} \text { - Moderately steep. } \\
\text { Range of affected slopes: } 15^{\circ}-30^{\circ}\end{array}$ & $\begin{array}{l}24.00^{\circ} \text { - Moderately steep. } \\
\text { Range of affected slopes: } 16^{\circ}-34^{\circ}\end{array}$ & $\begin{array}{l}22.54^{\circ} \text { - Moderately steep. } \\
\text { Range of affected slopes: } 18^{\circ}-32^{\circ}\end{array}$ \\
\hline Slope form and height & $\begin{array}{l}\text { Mostly concave average height } 144 \mathrm{~m} \\
\text { Height range } 80 \mathrm{~m}-220 \mathrm{~m}\end{array}$ & $\begin{array}{l}\text { Mostly concave average height } 148 \mathrm{~m} \\
\text { Height range } 60 \mathrm{~m}-280 \mathrm{~m}\end{array}$ & $\begin{array}{l}\text { Mostly concave average height } 138 \mathrm{~m} \\
\text { Height range } 80 \mathrm{~m}-240 \mathrm{~m}\end{array}$ & $\begin{array}{l}\text { Mostly concave average height } 64 \mathrm{~m} \\
\text { Height range } 20 \mathrm{~m}-140 \mathrm{~m}\end{array}$ \\
\hline Vegetation and landsliding & $\begin{array}{l}\text { Landsliding occurs on } 49.6 \% \text { of pasture, } 4.7 \% \text { of } \\
\text { bush/scrub, } 6.5 \% \text { of pine and } 12.5 \% \text { of poplar/willow }\end{array}$ & $\begin{array}{l}\text { Landsliding occurs on } 49.6 \% \text { of pasture, } 4.7 \% \text { of } \\
\text { bush/scrub, } 6.5 \% \text { of pine and } 12.5 \% \text { of poplar/willow }\end{array}$ & $\begin{array}{l}\text { Landsliding occurs on } 49.6 \% \text { of pasture, } 4.7 \% \text { of } \\
\text { bush/scrub, } 6.5 \% \text { of pine and } 12.5 \% \text { of poplar/willow }\end{array}$ & $\begin{array}{l}\text { Landsliding occurs on } 49.6 \% \text { of pasture, } 4.7 \% \text { of bush/scrub, } \\
6.5 \% \text { of pine and } 12.5 \% \text { of poplar/willow }\end{array}$ \\
\hline $\begin{array}{l}\text { Landslide }(\mathbf{I s}) \\
\text { Density }\left(\mathbf{I} / \mathbf{k m}^{2}\right)\end{array}$ & 43.31 & 35.81 & 32.12 & 37.66 \\
\hline$\underset{\%}{\text { Damage Ratio }}$ & $\begin{array}{ll}\text { Heavy } & 12.9 \\
\text { Moderate } & 23.7 \\
\text { 0-slight } & 63.5\end{array}$ & $\begin{array}{lr}\text { Heavy } & 7.1 \\
\text { Moderate } & 23.6 \\
\text { 0-slight } & 69.3\end{array}$ & $\begin{array}{lr}\text { Heavy } & 4.1 \\
\text { Moderate } & 19.1 \\
\text { 0-slight } & 76.8\end{array}$ & $\begin{array}{lc}\text { Heavy } & 7.8 \\
\text { Moderate } & 20.9 \\
\text { 0-slight } & 71.3\end{array}$ \\
\hline $\begin{array}{c}\text { All slopes } \\
\text { aspect preference* }\end{array}$ & $\begin{array}{l}\text { Range } 7.9 \% \text { - } 15.8 \% \\
\text { Ideal topography: all slopes } 12.5 \%\end{array}$ & $\begin{array}{l}\text { Range } 12.0 \%-14.7 \% \\
\text { Ideal topography all slopes } 12.5 \%\end{array}$ & $\begin{array}{l}\text { Range } 9.2 \%-16.6 \% \\
\text { Ideal topography all slopes } 12.5 \%\end{array}$ & $\begin{array}{l}\text { Range } 10.0 \% \text { - } 15.9 \% \\
\text { Ideal topography all slopes } 12.5 \%\end{array}$ \\
\hline $\begin{array}{l}\text { Landslide (Is)-affected } \\
\text { slope aspect } \\
\text { preference* }\end{array}$ & $\begin{array}{l}\text { Range } 3.5 \% \text { (SW) - 26.1 \% (NE) } \\
\text { Preference: Northeast } \\
\text { I/s affected slopes as \% of NE slopes: 190.2\% }\end{array}$ & $\begin{array}{l}\text { Range } 5.0 \%(\mathrm{~S})-23.5 \%(\mathrm{~N}) \\
\text { Preference: North } \\
\text { I/s affected slopes as \% of N slopes: 196.9\% }\end{array}$ & $\begin{array}{l}\text { Range } 1.6 \% \text { (SE) - } 28.8 \% \text { (N) } \\
\text { Preference: North } \\
\text { l/s affected slopes as \% of N slopes: } 190.4 \%\end{array}$ & $\begin{array}{l}\text { Range } 1.2 \%(\mathrm{~S}) \text { - } 25.4 \%(\mathrm{NW}) \\
\text { Preference: Northwest } \\
\text { |ls affected slopes as \% of NW slopes: 196.0\% }\end{array}$ \\
\hline $\begin{array}{l}\text { Scar volume percentages } \\
\text { Large }>1000 \mathrm{~m}^{3} \\
\text { Medium } 100-1000 \mathrm{~m}^{3} \\
\text { Small }<100 \mathrm{~m}^{3}\end{array}$ & $\begin{array}{cc}\text { \% of total landslides } & \text { \% total scar volume } \\
3.4 & 81.0 \\
46.9 & 15.1 \\
49.7 & 3.9\end{array}$ & $\begin{array}{cc}\text { \% of total landslides } & \text { \% total scar volume } \\
3.7 & 43.3 \\
37.0 & 40.6 \\
59.3 & 16.1\end{array}$ & $\begin{array}{cc}\text { \% of total landslides } & \text { \% total scar volume } \\
4.2 & 65.4 \\
34.7 & 29.1 \\
61.1 & 5.5\end{array}$ & $\begin{array}{l}\% \text { of total landslides } \\
0.2 \\
41.2 \\
58.6\end{array}$ \\
\hline
\end{tabular}




\section{Comparison of rainfall-triggered, multiple landslide events}

\subsection{Frequency Magnitude Parameters}

The parameters required for determining frequency-magnitude status for multiplelandslide events differ from those used for frequency-magnitude assessment of other geomorphic processes such as the fluvial process, in which data are often in continuous forms such as river stage height, or flow discharge. Because each multiple-landslide event is comprised of many discrete and non-continuous landslides, data are examined with respect to combined event values, and determination of the frequency magnitude status is based on study of the affected area. The affected area is defined as "the land surface area within an envelope enclosing the cluster of landslides that occurred during the event" (Crozier and Glade 1999). Within the affected area, the magnitude of a multiple landslide event is described by the percentage of the affected area subject to erosion and/or transport and deposition of hillslope material, the density of landslides (number per unit area), and the volume displaced per unit area. The areal extent of the affected area may also be considered as describing the magnitude of the landslide event. Comparisons between the February 2004 event and other New Zealand rainfall triggered, multiple landslide events are therefore based on the assessment of these parameters if sufficient data are available.

\subsection{Comparison of frequency and areal extent of landsliding}

Eyles and Eyles (1982) produced a map of New Zealand showing the location and areal extent of landslide episodes producing damage between 1973 and 1981. This map has been updated by Hancox (Hancox and Wright 2005a) to include the Cyclone Bola Hawkes Bay event (1988), and the February 2004 lower North Island event (Figure 9-1). From Eyles and Eyles (1982) original mapping (black areas) it can be seen that on average at least one damaging landslide event occurred each year during the period mapped. Figure 9-1 clearly shows that the areal extent of damage from the February 2004 event is greater than all other mapped events. The number of landslides which occurred during this event is estimated to be over 70000 (Hancox and Wright 2005a). This estimation was done using SPOT satellite technology whereby landslide scar-containing pixels are able to be counted. Unfortunately 
comparison of the number of landslides across other events is not possible using this technique as this type of event analysis is not common. Most existing analyses have been carried out using air photographs and/or field sampling to produce parameters such as landslide density (landslides/ $\mathrm{km}^{2}$ ) or damage ratios (percentage of hillslope area affected or eroded).

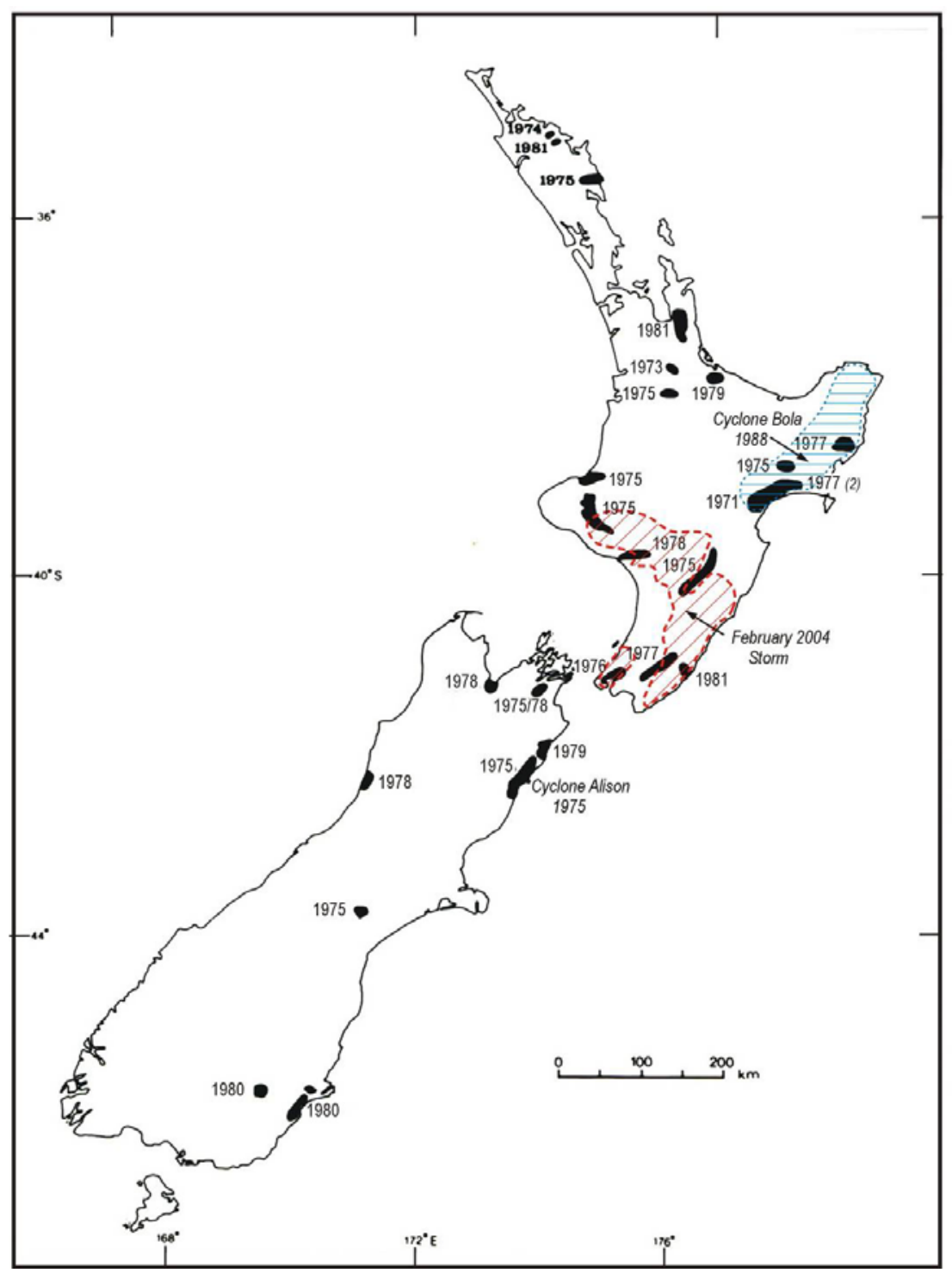

Figure 9-1 The Eyles and Eyles (1982) map adapted by Hancox (Hancox and Wright 2005a); the areal extent of Cyclone Bola (1988) landslides and February 2004 landslides surpasses by far other post 1970 events

A lengthier period was examined by Crozier et al. 1982 for the eastern Wairarapa hill country. Historical records and aerial photographs were used to determine the chronology of landslide episodes for this area (Figure 9-2). Their findings were that over an 100 year period (1880 to 1980) damaging landslide events occurred 
approximately every five years, with an increase in frequency suggested from the mid-1930s onwards. This increase may be partially due to increase in reporting and the availability of aerial photographs for study; however it is clear that the Tertiary hill country of North Island experiences frequent damaging events. Figures for the frequency of landsliding in the Wanganui hill country are unavailable however from Figure 9-1, it can be seen that the area experienced damaging events in 1975 and 1978, and also experienced these events in 1990 ands 1992 (Crozier 1996), while Wairarapa experienced events in 1977 and 1981 (Figure 9-1 Figure 9-2). As both areas are subject to southerly storms, the frequency of damaging landslide events could be expected to be similar in both these areas, depending on the epicentre of rainfall events.

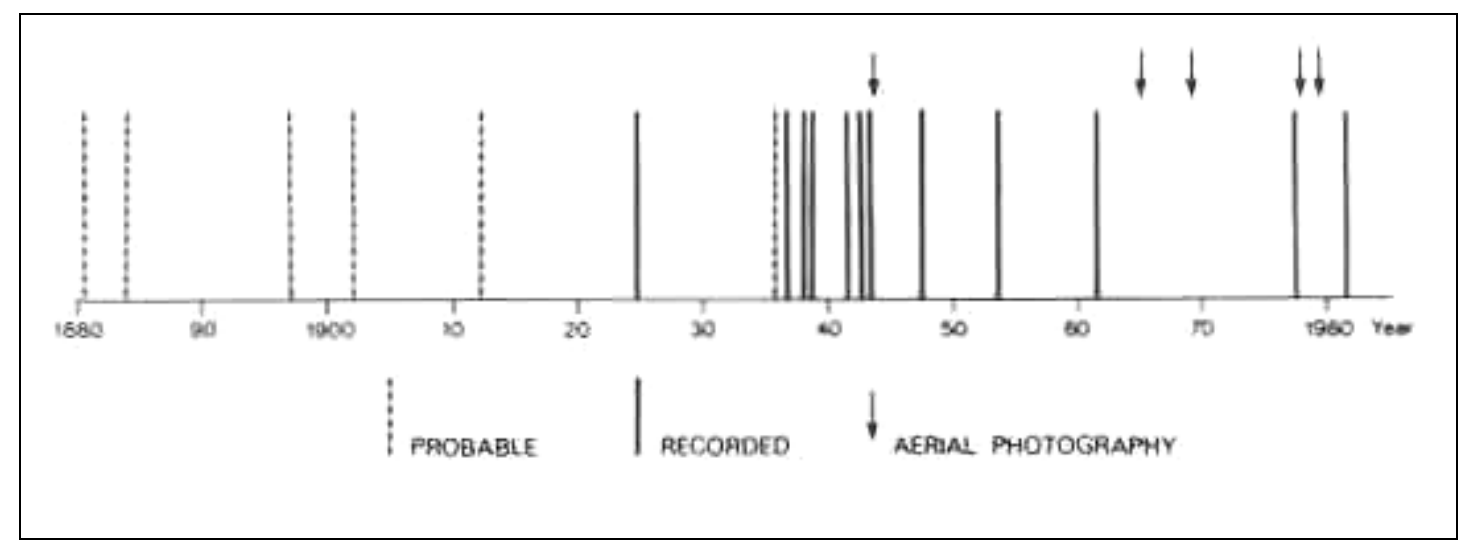

Figure 9-2 The chronology of landslide episodes for the period 1880 to 1980 , for the eastern Wairarapa hill country, from Crozier et al. 1982

\subsection{Comparison of landslide densities}

For the February 2004 event landslide density has been determined on a catchment level, and at the four regional study area levels (Table 9-1). Densities are given in number of landslides per $\mathrm{km}^{2}$.

Table 9-1 Landslide densities for the study catchment and regional study areas

\begin{tabular}{|l|c|}
\hline \multicolumn{1}{|c|}{ Area } & Landslides per $\mathrm{km}^{2}$ \\
\hline Mangawhero Study Catchment & 38.6 \\
\hline Mangawhero Study Area & 43.4 \\
\hline Whangaehu Study Area & 35.8 \\
\hline Turakina Study Area & 32.2 \\
\hline Pohangina Study Area & 37.6 \\
\hline
\end{tabular}


Potentially the greater the area examined the lower the landslide density, as there are always areas with localised high-density landsliding. Depending on the landslide triggering force, maximum density is either within the zone of highest rainfall or nearest to the earthquake epicentre. Using the estimate from Hancox and Wright (2005a) of at least 70,000 landslides being produced during the February 2004 event, over an areal range of $16,000 \mathrm{~km}^{2}$, the density of landsliding for the entire event is rather low; only 4.4 landslides per $\mathrm{km}^{2}$. For the February 2004 event catchmentbased study, the catchment was chosen not for the density of landsliding but for the volumes and variety of landslide types, however the catchment density is still relatively high compared with similar landslide events. The four study areas however were chosen as areas of maximum density by visual analysis of aerial photographs and therefore can be compared with values from other New Zealand (and one Fijian) events. The event density, catchment density and study area densities are compared with these previously studied events in Table 9-2.

Table 9-2 Landslide density comparisons of New Zealand (and Fijian) rainfall triggered events

\begin{tabular}{|c|c|c|c|}
\hline \multicolumn{2}{|c|}{ Density Is/km² } & \multicolumn{2}{|c|}{ Density ls/km² } \\
\hline Parakaka, Wairarapa, $1977_{1}$ & 478 & Tangoio, Hawkes Bay, 19719 & 31 \\
\hline Wairarapa, 1977 regional mean 2 & 90 & Puriri, Hauraki,1981 10 & 31 \\
\hline Mangawhero, 20043 & 43 & West Coast, SI Sandstone 1973-7511 & 19 \\
\hline Mangawhero study catchment 4 & 39 & Wellington City, 197412 & 19 \\
\hline Pohangina, 20045 & 38 & Wellington City, 197613 & 16 \\
\hline Whangaehu $2004_{6}$ & 36 & West Coast, SI Waimaungan gravels 1973-7514 & 11 \\
\hline Wainitubatolu, $1980_{7}$ & 34 & West Coast, SI Old Man gravels 1973-7515 & 10 \\
\hline Turakina, $2004_{8}$ & 32 & Lower NI, February 2004 Storm event 16 & 4.4 \\
\hline
\end{tabular}

Note: All data are from New Zealand localities, except for (6) which is from Viti Levu, Fiji.

Sources: 1, and 2, Crozier et al. (1982)

3, 5, 6 and 8, Wright and Hancox 2005b, and this study (2005).

4, this study (2005)

7, Crozier et al. (1981)

9, Eyles (1971)

10, Eyles and Eyles (1982)

11, 14, and 15 O'Laughlin and Pearce (1976)

12, and 13, Eyles et al. (1978)

16, Hancox and Wright (2005a)

Table adapted from Crozier (1986) 


\subsection{Denudation rate comparison}

Denudation rates, or the average lowering of the ground surface by erosion, can be used to compare events of a similar nature. The total volume of scar material generated for an affected area, or area studied, is divided by that area to produce and average lowering of the ground surface. Page et al. (1994) calculated denudation rates for the Lake Tutira catchment in Hawkes Bay, which was experienced severe landsliding during the Cyclone Bola storm of 1988. For the Tutira catchment the denudation rate was calculated at $42 \mathrm{~mm}$ of ground surface lowering, with the worst affected part of the catchment giving a denudation rate of $83 \mathrm{~mm}$. Similar calculations (volume divided by area studied) were used to give denudation rates for the February 2004 event (Table 9-3). For the Mangawhero study catchment which had a total scar volume of $210191 \mathrm{~m}^{3}$ and an area of $700,000 \mathrm{~m}^{2}$, an average lowering of $300 \mathrm{~mm}$ was calculated. The large volume landslide 18 and small catchment size have combined to produce a denudation rate that is over $350 \%$ of the worst affected part of the Tutira catchment. Values for the four study areas (calculated using scar volumes and areas shown in Section 7.4.20) were appreciably lower, as is expected with increased study area. Also these volumes were calculated using measured areas and arbitrary depths of $0.5 \mathrm{~m}$ so may be somewhat conservative. An average denudation rate for the event was calculated using the number of landslides and average depth of landslides form the regional study.

Table 9-3 Denudation rates for the February 2004 landslide event

\begin{tabular}{|l|r|r|r|}
\hline Locality & Total scar volume $\left(\mathrm{m}^{3}\right)$ & Study area $\left(\mathrm{m}^{2}\right)$ & Denudation rate $(\mathrm{mm})$ \\
\hline Mangawhero catchment & 210,191 & 700,000 & 300 \\
\hline Mangawhero study area & 323,433 & $6,900,000$ & 47 \\
\hline Whangaehu study area & 71,872 & $5,500,000$ & 13 \\
\hline Turakina study area & 62,333 & $5,700,000$ & 12 \\
\hline Pohangina study area & 57,856 & $5,600,000$ & 10 \\
\hline February 2004 event & $21,560,000$ & $16,000,000,000$ & 1.4 \\
\hline
\end{tabular}

The Mangawhero study area (as opposed to the Mangawhero study catchment) provides a similar value to that of Tutira catchment, suggesting that the most severely affected areas of the February 2004 event are likely to have experienced as great an impact on hillslope soil and pasture productivity as occurred in Tutira during the Cyclone Bola event. Pillans and Trustrum (1991) have estimated new soil production rates on landslide affected mudstone disturbed hillslopes as initially rapid (3.5 mm/yr) 
over the first 50 years if slopes remain undisturbed, and the rate declines to $1.2 \mathrm{~mm}$ year over the following 50 years. From this estimation it can be seen that the Mangawhero study catchment will require approximately 154 years $(3.5 \mathrm{~mm}$ x 50 years and $1.2 \mathrm{~mm} \times 104$ years) for soil to be at pre-event thicknesses if no landslides occur during that period. Denudation rates are somewhat misleading however as not all of the catchment has lost soil. Obviously deep-seated landslides where the surface is steep and comprised of exposed bedrock (such as landslide ID 18) will take many years to heal, whereas shallow regolith slides of $0.5 \mathrm{~m}$ deep will recover much more quickly. From the denudation and recovery rates it can be expected, however, that landslide scars will be visible form this event for decades, particularly if there is no fresh landsliding during the recovery period while new regolith and soil is forming.

\subsection{Sediment delivery to fluvial systems}

The ratio of sediment delivery to fluvial systems via event (or fluvial) coupling and lesser contributors such as sheet wash, will differ with landslide material type (how easily a flow is formed), the magnitude of the triggering force (in this case the amount and intensity of rainfall) and pre-existing terrain coupling (the proximity to drainage channels of all parts of the hillslope) of the landforms affected. Preston (2002) examined 250, mostly shallow, landslides formed during the Gisborne 2002 rainstorm. Similar to the February 2004 event, the terrain was Tertiary dissected hill country; the rainfall amounts were somewhat different, however. Gisborne received $300 \mathrm{~mm}$ during the 2002 event (Preston 2002) whereas the Mangawhero study catchment received 193mm during the 2004 event (Medlicott, 2004). Sediment delivery ratios however, are similar. Preston (2002) found that an average of $30 \%$ of material was delivered to the fluvial systems; he also noted that material was readily forming into flows. For the Mangawhero catchment $33 \%$ of material from event (fluvially) coupled landslides reached fluvial systems, while $14 \%$ of material from non-coupled landslides reached fluvial systems. While rainfall was lower for the February 2004 event it appears that event coupling increases the likelihood of sediment delivery from hillslope to fluvial systems by over $200 \%$.

\subsection{The Landslide Event Magnitude Scale}

Malamud et al. (2004) have produced a method of assessing frequency-magnitude status for multiple landslide events. Their method is designed to be used for a variety 
of landslide triggering mechanisms, and was tested using data from earthquaketriggered, rainfall-triggered and snowmelt-triggered multiple landslide events from around the world. Malamud et al.'s (2004) methodology involves a complex series of equations for which many known parameters are required. The February 2004 event may be fit into one of Malamud et al. (2004) frequency-magnitude tests, however there is not sufficient data to use all 44 equations and produce values for comparisons cross all tests (i.e. some tests require the combined total area of all landslides from the event to be known, as well as combined total volumes). However, because the number of landslides which occurred during the February 2004 event is known to be at least 70,000 , event magnitude evaluation of the February 2004 event is possible using this parameter and one of the Malamud et al. (2004) tests, cross-referenced with some of the equations used to produce a landslide event magnitude scale. The scale is logarithmic, similar to the Modified Mercalli Scale for earthquake intensity, and has a range of zero to six. Because some parameter values are unavailable to fit into the full methodology used by Malamud et al. (2004) the method used here is one which was used by them to produce a landslide event magnitude value derived from earthquakeinduced landslide data. However from previous comparisons in the Malamud et al. (2004) study it is shown that the three landslide triggering forces provided very similar landslide data distributions. The value for the landslide event magnitude is derived from Equation 9-1, where $m_{L}$ is the landside event magnitude and NLT the total number of landslides $(70,000)$.

\section{Equation 9-1 Calculation of landslide event magnitude}

$$
m_{L}=\log N_{L T}
$$

Equation 9-1 gives a landslide event magnitude of 4.85. This puts the February 2004 event at the higher end of the magnitude scale. The event magnitude values derived for the three landslide event in the study using the complete methodology compared with the value for this study are as follows (Table 9-4):

Table 9-4 Landslide event magnitudes from Malamud et al. (2004) and this study

\begin{tabular}{|l|c|c|c|c|}
\hline & $\begin{array}{c}\text { Northridge earthquake } \\
\text { (USA) }\end{array}$ & $\begin{array}{c}\text { Umbria snowmelt } \\
\text { (Italy) }\end{array}$ & $\begin{array}{c}\text { Guatemala rainfall } \\
\text { (Guatemala) }\end{array}$ & $\begin{array}{c}\text { February 2004 } \\
\text { rainstorm } \\
\text { New Zealand }\end{array}$ \\
\hline $\begin{array}{l}\text { Landslide event } \\
\text { magnitude } m_{L}\end{array}$ & 3.89 & 3.61 & 3.98 & 4.85 \\
\hline $\begin{array}{l}\text { Number of event } \\
\text { landslides }\end{array}$ & 11,111 & 4,233 & 9,454 & 70,000 \\
\hline
\end{tabular}


To verify whether this earthquake trigger derived method is valid for use with the February 2004 data the value is fitted to the graph shown in Figure 9-3.

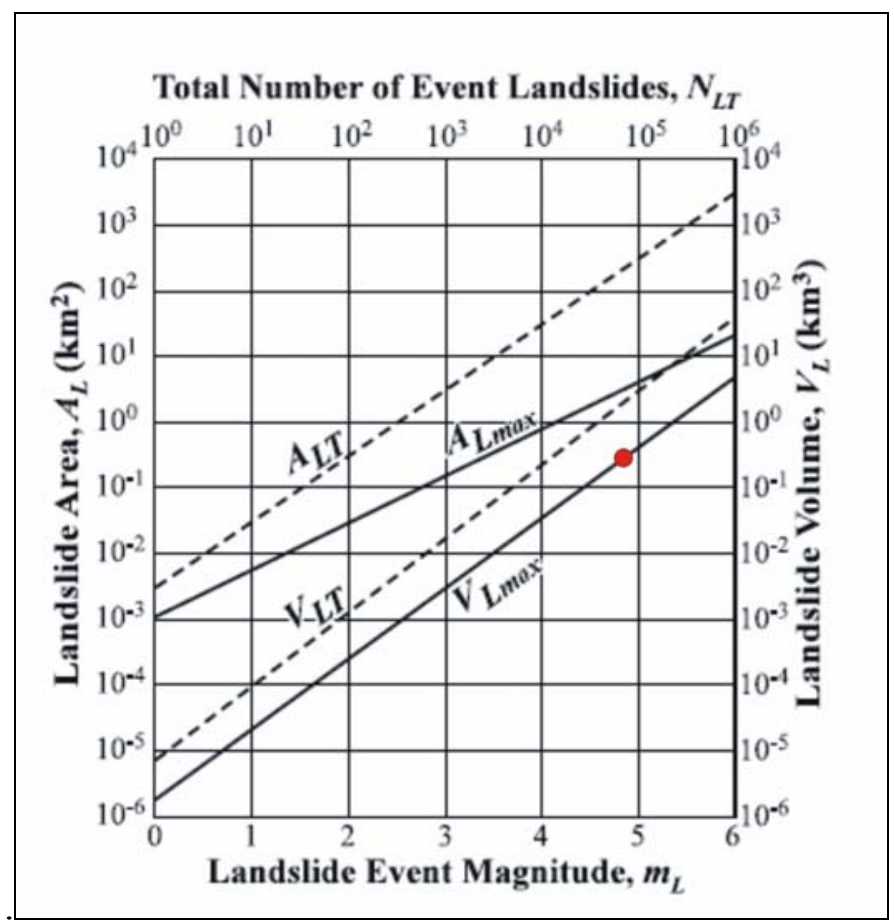

Figure 9-3 The landslide event magnitude in comparison with total landslide areas, volumes, and number of landslides; predicted total landslide area is shown by a dashed line, as is predicted total volume, maximum single landslide area and volume are shown by solid lines. The red dot shows the maximum volume of landslide expected in a magnitude 4.85 event

The number of event landslides is not the only control on landslide event magnitude; if it were then the event magnitude for Northridge would be greater than for Guatemala. Therefore the February 2004 data was fitted into Equation 9-2 to test whether the reduced methodology provides an acceptable comparison. When the maximum landslide volume of the February 2004 event is fitted into this equation the data fits the model well.

Equation 9-2 Calculation of VLmax

$$
V_{L M A X}=1.82 \times 10^{-6} N_{L T}^{1.071}
$$

Where $V_{\text {Lmax }}$ is the volume of the single largest landslide of the population of landslides from the event.

For Equation 9-2 the calculated value of $V_{L \max }$ gives a value of $0.28 \mathrm{~km}^{2}$. The scar volume of landslide ID 18, (in all probability the largest from the event, based on 
examination of aerial photographs covering all the landslide-affected area except the Wairarapa hill country) is $0.20 \mathrm{~km}^{2}$, while slightly lower than the value the Malamud et al. (2004) provides it is in the same order of magnitude and justifies the use of equation Equation 9-1 in deriving landslide event magnitude using this method. The February 2004 event data, while not suitable for transference into all the Malamud et al. (2004) tests, produces a landslide event magnitude value which places it near the higher end of the event magnitude scale.

\subsection{Summary of the landslide event comparisons}

The February 2004 event covered a greater area in terms of that areal extent of landsliding than any other rainfall-triggered, multiple-landslide event studied in New Zealand over the last 35 years. The rainstorm that triggered the February 2004 event was labelled a "one in 100 year storm event". The length of the landslide data record is not sufficient to determine whether the landslide event is a "one in 100 year landsliding event". The Cyclone Bola event of 1988 also covered a very large area and produced thousands of landslides. The return period for the Cyclone Bola event was estimated at well in excess of the modelled rainfall for the 100 year return period event. Perhaps both of these events were one in 100 year landslide events, but to determine this will require an increased dataset over a longer period. When this dataset is available landslide event return periods may then be able to be modelled. However, due to triggering thresholds to changing with time (i.e. exhaustion phase after material removal, or increased terrain resistance as bedrock is exposed or slope angles reduced) landslide modelling and prediction will constantly require updating of the input parameters. The February 2004 event was of sufficient magnitude to produce localised extremely high denudation rates, and landslide density rates second only to those produced by the Wairarapa 1977 storm. Compared with the international study by Malamud et al. (2004), the February 2004 landslide event has an event magnitude at the high end of the scale derived by them, and can therefore be said to be of geomorphic significance in terms of frequency-magnitude status. 


\section{Discussion and Conclusions}

\subsection{Geomorphic significance evaluation}

Evaluating the geomorphic significance of a landslide event requires determination of changes to landforms and geomorphic work done. For an event of this scale the creation of a full sediment budget for the event is not possible, as it requires field measurements of the area and depth of 70,000 landslides over an affected area of $16,000 \mathrm{~km}^{2}$. On a catchment level, sediment budgets may be produced to assist with the understanding of landslide geomorphic work and geomorphic change as well as induced hazards for the event, such as runout areas and volumes, and sediment loading of fluvial systems. The volumes of material eroded and/or transported and/or input to fluvial systems are most easily determined by field measurements. However, geomorphic significance for this event is more easily described on an event or regional scale for some frequency-magnitude parameters such as landslide density, and damage ratios. These types of event characteristics, determined at larger scales, are useful for comparisons with other rainfall-triggered, multiple-landslide events. Some of the event characteristics derived from catchment-scale studies are useful for comparisons of parameters such as denudation rates, because localised rates of extreme denudation may be lost in the overall average value. Therefore, for this study many parameters used to describe landsliding frequency and magnitude are presented, and related to influencing terrain characteristics where appropriate.

\subsection{Methodologies}

When determining the geomorphic significance of an event such as the February 2004 landslide event the methodologies used must take into account that not all landslides can be studied (e.g. measured or counted). Methodologies should include both field and non-field methods, and include as mach data as possible to reduce possible errors. By studying the February 2004 landslide event on a catchment-based level, as well as across four study areas on a regional level it is possible to construct a more complete analysis of the nature of the landsliding event. The catchment-scale study produced a sediment budget, changes to slope angle values, a catchment denudation rate, landslide density rate, fluvial coupling rate, and information on the largest landslide produced by the February 2004 event. The regional study provided comparisons 
between different terrain types and locations and produced values for landslide densities, damage ratios, scar volume frequency-magnitude analysis, and the effects of vegetation cover, slope angle, slope height, slope aspect and slope form on landsliding. The methods used for the regional study were based mostly on the analysis of non-rectified vertical aerial photographs; a small degree of error is therefore expected in these results. However, because the regional study is comparison based, the error should have little effect.

\subsection{Field study catchment}

The field study catchment was selected based on accessibility, the nature of the catchment terrain and setting, variety of landsliding types and characteristics, and because it included the "Octopus" landslide, the largest landslide triggered by the storm. While in many ways this catchment was typical of the area, it also included the largest landslide from the February 2004 event, making it useful for frequencymagnitude comparison, particularly in relation to the Malamud et al. (2004) event magnitude scale. However the choice of this catchment may limit the transferability of conclusions based on the catchment-scaled study to regional or event scales. For this reason, the regional study based on four study areas provides more transferable and scalable results. From this study it is clear that large landslides produced the greatest proportion of geomorphic work during this event and therefore should be investigated at a field level as well as through photographic analysis.

\subsection{Conclusions}

1. The February 2004 landslide event caused changes to affected hillslopes that will remain in the landscape for decades, and in some areas hundreds of years, if the effects are not concealed by future geomorphic events during the period of landslide scar healing and the regeneration of regolith and soil.

2. This event produced damage over a larger area than any other rainfall-triggered, multiple-landslide event of the last 35 years. As records of the areal extent of landsliding events of this nature only extend back 35 years it is not possible to extrapolate the magnitude of landsliding over a longer period. Whether this event is the largest rainfall-triggered multiple-landslide event of the last 100 years or even of the last 50 years it is not possible to determine. 
3. The Mangawhero field study catchment contributed almost $68,000 \mathrm{~m}^{3}$ of hillslope material to fluvial systems; $98 \%$ of this material was lost from landslide ID 18, the "Octopus" landslide. In the study catchment, the average material loss from hillslopes to fluvial systems from fluvially-coupled (event coupled) landslides was twice as great as the average material loss from non-coupled landslides.

4. The February 2004 event produced at least 70,000 landslides. The average estimated volume of landslide scars over the four study areas was $308 \mathrm{~m}^{3}$. If this average value is multiplied by the number of landslides a value of 21.6 million $\mathrm{m}^{3}$ of landslide scarring was produced by this event. However, as the volume of landslides was calculated from an assumed depth, this is only an estimation, (probably conservative).

5. Denudation rates from the event were as high as $300 \mathrm{~mm}$ for the Mangawhero study catchment and between $10 \mathrm{~mm}$ and $47 \mathrm{~mm}$ for the four study areas. The event denudation rate is estimated to be $1.4 \mathrm{~mm}$. These values are given as a uniform lowering of the total land surface within the selected study areas. In reality denudation rates are only relevant to landslide scar areas, and do not refer to values for accumulation rates in areas of landslide deposition. Denudation rates are useful for localised comparisons but lose value when the area examined is extremely large. In other words, because it is not known how much material is lost from hillslopes, the denudation rate is strictly a "displacement rate".

6. The February 2004 event produced some vulnerable over-steepened slopes, particularly above large rotational scars. However, where bedrock is exposed slopes would be expected to have greater resistance to landsliding than regolith slopes. While landslide runout deposit areas often showed reduction in slope angles from original slope angles, this was not always the case.

7. Landslide density rates for the study catchment, four regional study areas, and the event were compared with other rainfall-triggered, multiple-landslide events. Landslide densities of between 32 and $43 \mathrm{Ls} / \mathrm{km}^{2}$ for the four study areas and the study catchment were among some of the highest recorded in New Zealand since 1970. The landslide density for the event is among the top 16 recorded values at $4.4 \mathrm{Ls} / \mathrm{km}^{2}$. In general, the larger the study area, the lower the density value, as localised areas of high rainfall can produce localised areas of high density landsliding. Whereas wide-ranging storm activity such as in February 2004 will 
produce pockets of intense rainfall together with areas of lower intensity rainfall which will be averaged to produce an overall lower landslide density.

8. The nature of the terrain in which landslides occur clearly controls the nature of the landsliding. The main controls on landsliding magnitude (e.g. density, damage ratios, scar volumes) for this event are: vegetation cover, slope aspect, slope height, underlying geology, and regolith and soil thickness.

9. The February 2004 landslide event is not unique in New Zealand history yet it is geomorphically significant. This event caused the loss of tens of thousands of cubic metres of productive hillslope pasture to fluvial systems; over-steepening of some hillslopes; an increase in resistance on bedrock-exposed slopes; and, destruction of infrastructure such as bridges, fences, roads, and farm tracks. Where erosion rates are greatest the effects will be felt for generations in terms of economic loss and increased hazard. 


\section{Acknowledgements}

This thesis has been the overwhelming focus of my life for the last 14 months and at although it is definitely a labour of love, at times I know I wouldn't have made it without the friendship, advice and support of my friends, colleagues, the university staff, and my family.

Firstly I would like to thank my Supervisor Prof. Mike Crozier for his energy, enthusiasm, expertise and support. He never said outright "that's a dumb idea" or "you've got it all wrong"- in a gentle yet persistent way he let me know when I was heading down the wrong track, and encouraged me to think laterally, critically and thoroughly about my research. To the other Vic staff who have encouraged me, employed me, and shared their lunchtimes and coffee breaks with me, I'm really going to miss being a part of the Geography "family".

Graham Hancox has been my mentor throughout this thesis, his passion for rigorous data testing, confidence in my abilities and methods, and support of my work has been invaluable. Thanks Graham, without your input this research would not be as robust, or as encompassing, and working with you at GNS has been an honour and a pleasure. I'd also like to thank Grant Dellow and Nick Perrin of GNS for their support.

My fellow students at Vic have been there too. Thanks Julie for the proof-reading, I'm glad you found something to laugh at in there. While we were all at different stages, it was great to see others finish before me and know it can be done, cheers Julie and Kylie for the inspiration you provided. Also it was great to feel that as I got closer to completing I was showing to others that yes it is possible to actually stop writing and say, "yes, I'm done". Waverly, I know soon you will be where I'm at and I can tell you it feels pretty good. To the other inmates of the Postgrad computer lab, there've been times of hilarity, times of despair, and my love-hate relationship with Pali the colour printer.

I had help from various people in the field; all were gracious and hardworking despite being more often than not ankle-deep in mud, and having to struggle up steep very hills in the rain. Cheers to Waitangi, Anke, Nick, and Faust.

I have received support and encouragement from friends outside the university. You guys made me feel like I had made the right choices, that I was doing something worthwhile, and you never lost faith in my ability to get the job done. Thanks a lot Peter and Rochelle.

Lastly I would like to thank my family; Mum and Brian, Dad and Bev, my sister Sandi and her husband Roger (all in Canterbury), and especially my sister Nicola who lives here in Wellington. Nic, since I've been in Wellington you have been a great friend, and when we were house-sharing, a great flatmate. You graciously undertook the final proof-read and it's lucky for me you did, thanks a lot. I wish I could've got down to Christchurch to see the rest of the family more often but with study and work it wasn't possible. Nevertheless I knew you were thinking of me and wishing me well. All of you have encouraged me in my decision to start a whole new life and career, from the move to Wellington to the completion of this thesis. I know that my Mum and my Dad are both proud of my achievements and it feels good to have earned this. Mum and Dad you always encouraged us to use our minds to the best of our abilities, it happened a little later for me, but I got there in the end. Cheers everyone 


\section{References}

Anderson, M and Brooks, S. 1996. Advances in hillslope processes. Wiley and Sons.

Bell, D. 1976. High intensity rainstorms and geological hazards: Cyclone Alison, March 1975, Kaikoura, New Zealand. Bulletin of the International Association of Engineering Geology 14, 189-200.

Betts, H. 1998. Digital terrain modelling of gully systems in the Waipoa catchment. Catchment Connections Issue 3, 1998, p 3.

Brooks, S., Crozier, M.J., Preston, N, Anderson, M. 2002. Regolith stripping and the control of shallow translational hillslope failure: application of a two-dimensional coupled soil hydrology-slope stability model, Hawke's Bay, New Zealand. Geomorphology 45, 165-179.

Brunsden, D. and Chandler, J. 1996. Development of an episodic landform change model based upon the Black Ven Mudslide 1946-1995, in Advances in Hillslope Processes p869-870. Anderson, M. and Brooks, S. (eds) Wiley and Sons.

Campbell, I.B. 1977 Soils of part Wanganui County, North Island, New Zealand. Wellington: DSIR. Soil Bureau bulletin 40.99 p. N.Z. Department of Scientific and Industrial Research.

Carson, M. and Kirkby, M. 1972. Hillslope form and process. Cambridge University Press.

Collen, J. D. 1972. Studies in Wanganui Series Pliocene: Foraminifera from Wanganui Basin. Unpublished PhD Thesis, Victoria University of Wellington.

Crozier, M.J. 1986. Landslides. Causes, consequences and environment 251 p. Croom Helm Dover, New Hampshire.

Crozier, M.J. 1991. Scale effects on locational controls of regolith landslides. Bulletin of Geomorphology 19, 47-58.

Crozier, M.J. 1996. Runout behaviour of shallow, rapid earthflows. Zeitschrift fur Geomorphologie 105, 35-48.

Crozier, M. J. 1999. Prediction of rainfall-triggered landslides: a test of the antecedent water status model. Earth Surface Processes and Landforms 24, p825-833. Wiley and Sons.

Crozier, M.J., Eyles, R., Marx, S., McConchie, J., and Owen, R. 1980. Distribution of landslips in the Wairarapa hill country. New Zealand Journal of Geology and Geophysics, 23, 575-586. 
Crozier, M.J., McConchie, Owen, R. J., and Eyles, R., 1982. Mass Movement Erosion Wairarapa 151 p. Department of Geography, Victoria University of Wellington.

Crozier, M.J. and Pillans, B. 1991. Geomorphic events and landform response in south eastern Taranaki, New Zealand. Catena 18 (5), 471-488.

Crozier, M. J., Deimel, M. S., and Simon, J. S. 1995. Investigation of earthquake triggering for deep-seated landslides, Taranaki, New Zealand. Quaternary International, Vol. 25 pp65-73. INQUA/Elsevier Science Ltd.

Crozier, M. J., Gage, M., Pettinga, J., Selby, M., Wasson, R 1982. The stability of hillslopes. In Landforms of New Zealand p45-66. Soons, J.M. and Selby, M.J. (eds). Longman Paul Ltd.

Crozier and Glade, 1999. Frequency and magnitude of landsliding: fundamental research issues. Zeitschrift fur Geomorphologie, 115, 114-155.

Crozier, M. J., and Preston, N. 1999. Modelling changes in terrain resistance as a component of landform evolution in unstable hill country in Process Modelling and Landform Evolution, Hergarten, S. and Neugebauer, H., (eds). Springer.

Cruden D., and Varnes D. 1996. Landslide types and processes. In Landslides, Investigation and Mitigation, Turner A., and Schuster R. (eds). Special Report 247. Transportation Research Board: Washington DC; 36-75.

Davies, V. 1994. The Way We Were, pictorial memories of early New ZealandTaranaki/Wanganui. Moa Beckett Publishers Ltd.

Dikau R, Rasemann S and Schmidt J 2004. Hillslope Form in The Encyclopaedia of Geomorphology. Goudie, A. S. (ed) Routledge.

Dymond, J. R., Gaelle-Ausseil, J., and Shepherd, J.D. 2004. Validation of a region-wide model of landslide risk in the Manawatu/Wanganui region of New Zealand submitted to Geomorphology for publication (in prep).

Evans, S., Hungr, O., and Clague, J. 2001. Dynamics of the 1984 rock avalanche and associated distal debris flow on Mount Cayley, British Columbia, Canada: implications for landslide hazard assessment on volcanoes. Engineering Geology 61, 29-51.

Eyles, R.J. and Eyles, G.O. 1982. Recognition of storm damage events. Proceedings of eleventh New Zealand Geography Conference, Wellington 1981: 118-23.

Fleming, C. A. 1953. The Geology of Wanganui Subdivision. Waverly and Wanganui sheet district (N137 and N138). New Zealand Geological Survey Bulletin n.s. 52. New Zealand Department of Scientific and Industrial Research.

Fleming, C .A. 1978. Tertiary: Wanganui-Manawatu in The Geology of New Zealand Vol. 2 p460-465.. Suggate, R.P., Stevens, G.R. and Te Punga, M.T. (eds). New Zealand Geological Survey 
Fletcher, J.R. 1987 Land use capability classification of the Taranaki-Manawatu Region: a bulletin to accompany the New Zealand land resource inventory worksheets. Wellington: Water and Soil Directorate, Ministry of Works and Development. Water and Soil miscellaneous publication 110. 227 p.

Fleming, C.A. 1978 Tertiary: Stratigraphy: Subsurface geology of Taranaki Wanganui - Manawatu. p. 465-469 In The Geology of New Zealand Suggate, R.P.; Stevens, G.R.; Te Punga, M.T. (eds). Wellington: Government Printer.

Hancox, G.T. and Wright, K., 2005a. Landslides caused by the February 2004 rainstorms and floods in southern North Island, New Zealand. Institute of Geological \& Nuclear Sciences science report 2005/10.

Hancox, G.T. and Wright, K., 2005b. Analysis of landsliding caused by the 15-17 February 2004 rainstorm in the Wanganui-Manawatu hill country, southern North Island, New Zealand. Institute of Geological \& Nuclear Sciences science report 2005/11.

Hicks, D.1991. Erosion under pasture, pine plantations, scrub and indigenous forest: a comparison from Cyclone Bola. New Zealand Forestry, November, 1991, 21-22.

Horizons Regional Council 2003. Manawatu-Wanganui Civil Defence Emergency Management Plan. Palmerston North: Horizons Regional Council.

Horizons Regional Council 2004. Storm, Civil emergency - storm and flood report February 2004. Horizons Regional Council Report number: 2004/Ext/591.

Journeaux, T.D., Kemp, P.J.J. and Naish, T. 1996. Middle Pliocene Cyclotherms, Mangaweka region, Wanganui Basin, New Zealand; a lithostratigraphic framework. New Zealand Journal of Geology and Geophysics, 1996, Vol. 39: 135-149. The Royal Society of New Zealand.

Kasai, M., Marutani, T., Reid, L, and Trustrum, N. 2001. Estimation of temporally averaged sediment delivery ratios using aggradational terraces in headwater catchments of the Waipoa River, North Island, New Zealand. Earth Surface Processes and Landforms 26, 1-16.

Kirkby, M. 1978. Hillslope hydrology. Wiley and Sons.

Luckman, P.G., Gibson, R.D. and DeRose, R.C. 1999. Landslide erosion risk to New Zealand pastoral steeplands productivity. Land Degradation and Development $10,49-65$.

Lynn I.H.; Crippen T.F. 1991 Rock type classification for the New Zealand Land Resource Inventory. Lower Hutt: DSIR Land Resources. DSIR Land Resources scientific report $10.123 \mathrm{p}$.

Malamud B., Turcotte D., Guzetti F., and Reichenbach P. 2004. Landslide inventories and their statistical properties. Earth Surface Processes and Landforms, $29,687-711$. 
Medlicott J. 2004. Rainfall records of the Cashmore farm for January and February 2004.

Morgan, R.P.C. 1996. Verification of the European soil erosion model (EUROSEM) for varying slope and vegetation conditions, in Advances in Hillslope Processes. Anderson, M. and Brooks, S. (eds). Wiley and Sons, p658

Neall, V.E. 1982. Landforms of Taranaki and the Wanganui Lowlands, in Landforms of New Zealand p193-211. Soons, J.M. and Selby, M.J. (eds).Longman Paul Ltd.

New Zealand Soil Survey Bureau 1973. Map of parent rocks of New Zealand soils. 1:100000. 2 sheets. N.Z. Soil Survey Report 5. N.Z. Department of Scientific and Industrial Research.

New Zealand Soil Bureau 1954. General Survey of the Soils of North Island, N. Z. Soil Bureau Bulletin (n.s.) 5. N.Z. Department of Scientific and Industrial Research

Page, M., Trustrum, N., and Dymond, J. 1994. Sediment budget to assess the geomorphic effect of a cyclonic storm, New Zealand. Geomorphology 9, 169-188.

Page, M. and Reid, L. 1998. Storm rain - how many slips? how much sediment? Catchment Connections Issue 3, 1998, p1.

Painter, D. 1981. Steepland erosion processes and their assessment, in Erosion and Sediment transport in the Pacific Rim Steeplands. Symposium proceedings of the Christchurch Symposium organised under the auspices of the Royal Society of New Zealand, 25-31 January, 1981. international Association of Hydrological Sciences publication no. 132. International Association of Hydrological Sciences.

Pillans, B.; Trustrum, N. 1991 Fieldtrip guide: landscape evolution of Wanganui and Taranaki. p. 89-96 In: Joint annual conference, Geological Society of New Zealand and New Zealand Society of Soil Science: 25 November-1 December 1991: field trip guides. Lower Hutt: Geological Society of New Zealand. Geological Society of New Zealand miscellaneous publication 59B

Press, F. and Seiver, R. 2000. Understanding Earth, $3^{\text {rd }}$ edition p155-158, more. W.H Freeman and Company.

Rapp, A. 1960. Recent development of mountain slopes in Kärkevagge and surroundings, Northern Scandanavia. Geography Annaler 42: 184-187.

Rijkse, W.C. 1977. Soils of Pohangina County, North Island, New Zealand. Wellington: DSIR. Soil Bureau bulletin 42.70 p.

Selby, M. 1982. Hillslope materials and processes. Oxford University Press.

Slattery, M. and Burt, T. 1996. On the complexity of sediment delivery in fluvial systems: results from a small agricultural catchment, North Oxfordshire, United Kingdom, p635-656 in Advances in Hillslope Processes, Anderson, M. and Brooks, S. (eds). Wiley and Sons. 
Stevens, G.R. 1990 Rugged landscape: the geology of central New Zealand, including Wellington, Wairarapa, Manawatu, and the Marlborough Sounds. Wellington: DSIR Publishing. DSIR information series $169.286 \mathrm{p}$.

Suggate, E.P. 1982. The Geological Perspective in Landforms of New Zealand p1-13. Soons, J.M. and Selby, M.J. (eds). Longman Paul Ltd.

Terlien, M., De Louw, P., Van Asch, Th., Hetterschijt, R. 1996. The assessment and modelling of hydrological conditions of landslides in the Puriscal Region (Costa Rica) and the Manizales Region (Colombia), in Advances in Hillslope Processes p837. Anderson, M. and Brooks, S. (eds) Wiley and Sons.

Voelkerling, R.H. and Stewart, K.L. 1986. From Sand to Papa- a history of the Wanganui County (p 11-18,). Wanganui County Council.

Walton, E.K. Sedimentary Rocks in Holmes' Principles of Physical Geology, $4^{\text {th }}$ edition p 65-68. Duff P., McLean D. (eds). Chapman and Hall.

Water and Soil Division, Ministry of Works 1969 Land use capability survey handbook: a New Zealand handbook for the classification of land Wellington: Water and Soil Division, Ministry of Works.

Young, A. 1972. Slopes. Geomorphology Texts 3. Ed. Clayton, K. Oliver and Boyd.

Young, A and Saunders, I.1986. General section in Hillslope Processes, The Birmingham Symposia in Geomorphology International Series, no. 16, p9-17. Ed. Abrahamson, A.

\section{Web-Based references}

Natural Hazards Centre Online. Satellite image.

http://www.naturalhazards.net.nz/febfloods/mapgif/GMS_0402150430_SST.gif

accessed 1/9/2004

Natural Hazards Centre satellite loop

http://www.naturalhazards.net.nz/febfloods/sat/

accessed 12/10/2004

Natural Hazards Centre, I.G.N.S and NIWA.

http://www.naturalhazards.net.nz/febfloods/meta/niwa-rain.jpg/view

accessed 10/1/2005

Wanganui District Council Online

http://www.wanganui.govt.nz/civilDef/StormBrowser.asp

accessed 20/10/2004

Department of Conservation National Enterprise GIS

http://extranet.doc.govt.nz/bip/

accessed 10/12/2004 


\section{Appendix 1 Study Catchment Landslide Data}

\section{Landslide ID number: 1}

Scar Area: $537.1 \mathrm{~m}^{2} \quad$ Scar Depth: $0.6 \mathrm{~m} \quad$ Scar volume: $322.3 \mathrm{~m}^{3}$

Runout Area: $858.32 \mathrm{~m}^{2} \quad$ Runout Depth: $0.35 \mathrm{~m} \quad$ Runout volume: $300.4 \mathrm{~m}^{3}$

Material input to fluvial system: $21.8 \mathrm{~m}^{3}(6.8 \%)$

Slope setting: concave slope, middle part of slope

Landslide type and material type: translational slide and earthflow, regolith

Original slope angle: $34^{\circ}$

Scar angle: $\quad 46^{\circ} \quad$ Runout angle: $11^{\circ}$

Notes: reactivated on previous landslide scar, not fluvially coupled, turf relatively intact.

Photographs:
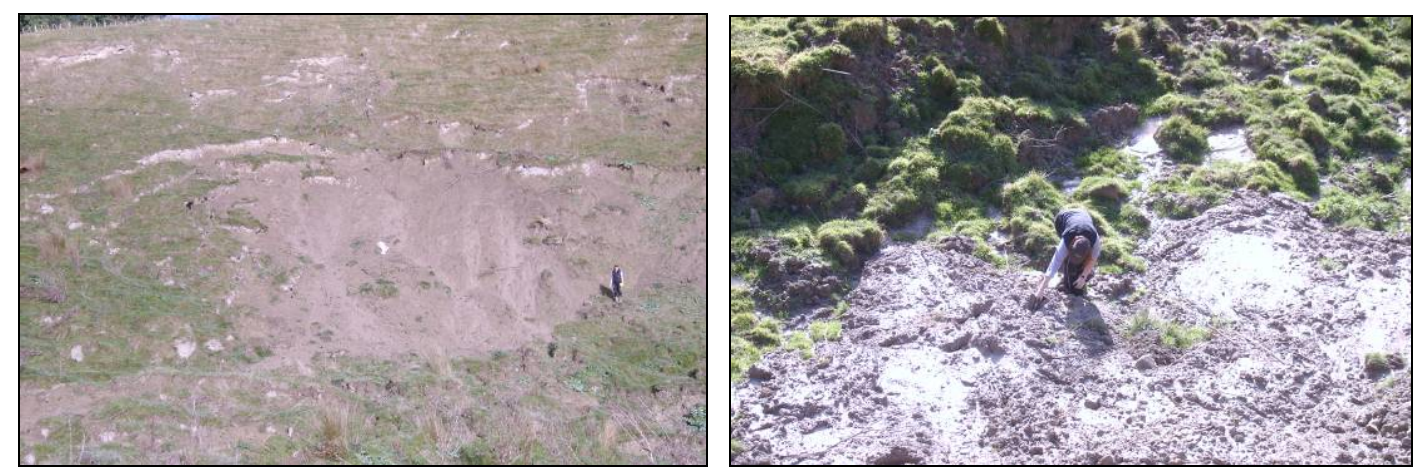

Landslide ID number: 2

Scar Area: $69.2 \mathrm{~m}^{2} \quad$ Scar Depth: $0.55 \mathrm{~m}$ Scar volume: $38.06 \mathrm{~m}^{3}$ Runout Area: $418 \mathrm{~m}^{2} \quad$ Runout Depth: $0.08 \mathrm{~m} \quad$ Runout volume: $33.44 \mathrm{~m}^{3}$

Material input to fluvial system: $4.7 \mathrm{~m}^{3}(12.3 \%)$

Slope setting: concave slope, upper part of slope

Landslide type and material type: translational slide and rapid earthflow

Original slope angle: $33^{\circ}$

Scar angle: $50^{\circ}$

Runout angle: $15^{\circ}$

Notes: contributing to alluvial fan, some scouring along flow path, at least $80 \%$ of flow path is original surface, some levee formation, not fluvially coupled

Photographs:

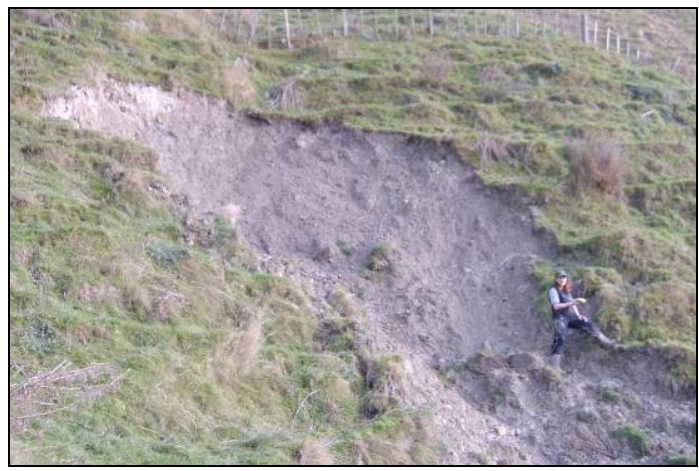

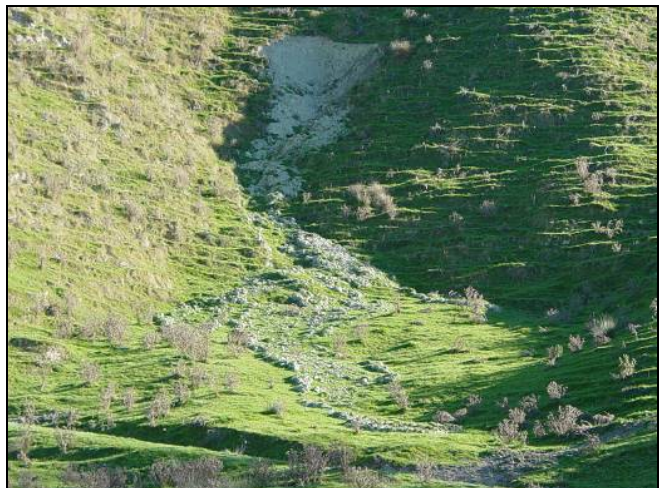


Landslide ID number: 3

Scar Area: $358.6 \mathrm{~m}^{2} \quad$ Scar Depth: $3.3 \mathrm{~m} \quad$ Scar volume: $1183.4 \mathrm{~m}^{3}$ Runout Area: $1737.7 \mathrm{~m}^{2} \quad$ Runout Depth: $0.48 \mathrm{~m} \quad$ Runout volume: $834.1 \mathrm{~m}^{3}$

Material input to fluvial system: $349.3 \mathrm{~m}^{3}(29.5 \%)$

Slope setting: concave slope, middle part of slope

Landslide type and material type: translational slide and earthflow, bedrock and regolith

Original slope angle: $30^{\circ}$

Scar angle: $51^{\circ}$

Runout angle: $23^{\circ}$

Notes: many cracks adjacent to scar head (ready to fail again), feeding into water course (fluvially coupled)

Photographs:
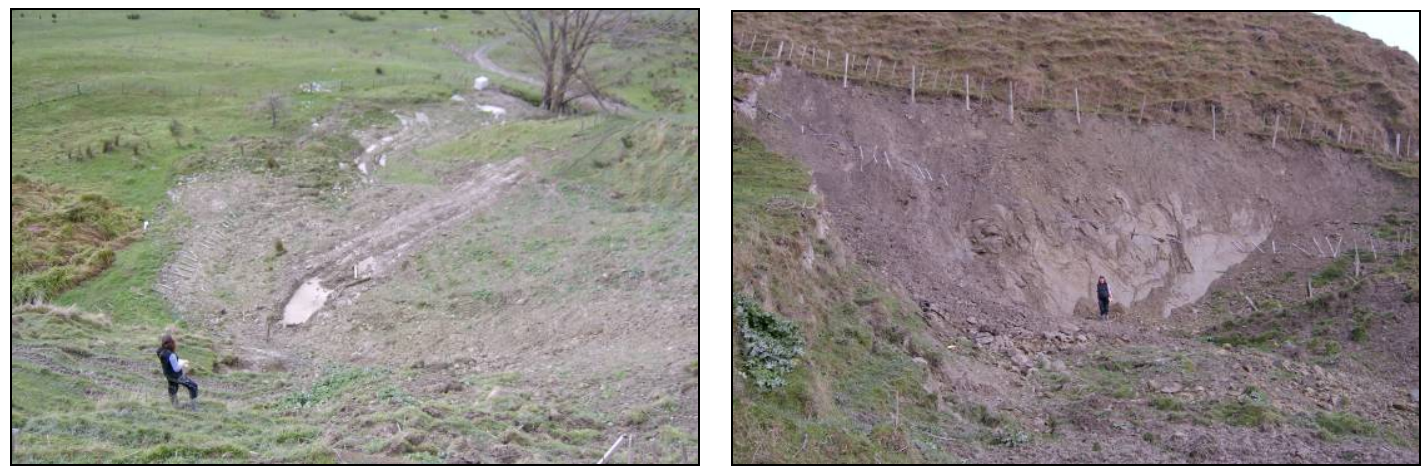

\section{Landslide ID number: 4}

Scar Area: $91.9 \mathrm{~m}^{2} \quad$ Scar Depth: $0.6 \mathrm{~m}$ Scar volume: $55.1 \mathrm{~m}^{3}$ Runout Area: $214.6 \mathrm{~m}^{2} \quad$ Runout Depth: $0.16 \mathrm{~m} \quad$ Runout volume: $34.3 \mathrm{~m}^{3}$

Material input to fluvial system: $21 \mathrm{~m}^{3}(38.1 \%)$

Slope setting: concave slope, middle part of slope

Landslide type and material type: translational slide and earthflow, colluvium and regolith

Original slope angle: $36^{\circ}$

Scar angle: $40^{\circ}$

Runout angle: $36^{\circ}$

Notes: upper region of old landslide scar, two shallow scars contributing to runout, 90 $\%$ original surface

Photographs:
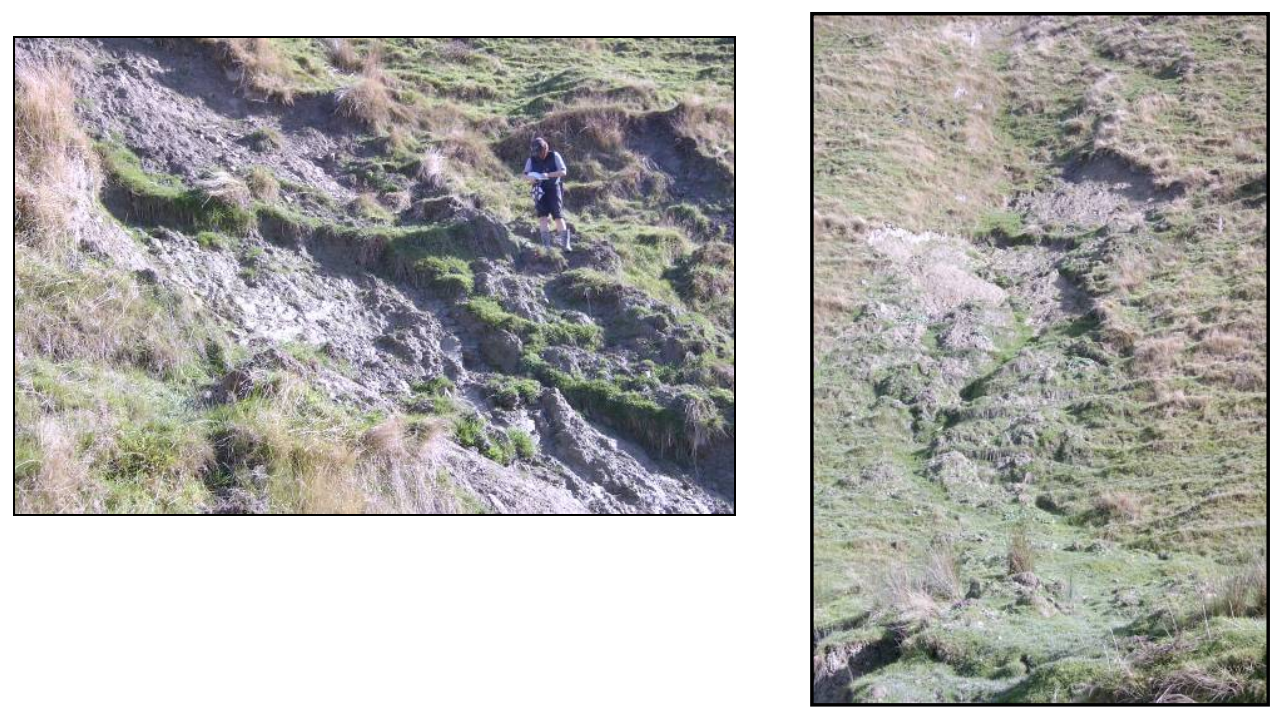
Landslide ID number: 5

Scar Area: $90.6 \mathrm{~m}^{2} \quad$ Scar Depth: $0.7 \mathrm{~m}$ Scar volume: $63.4 \mathrm{~m}^{3}$ Runout Area: $309.6 \mathrm{~m}^{2} \quad$ Runout Depth: $0.18 \mathrm{~m} \quad$ Runout volume: $55.7 \mathrm{~m}^{3}$

Material input to fluvial system: $7.7 \mathrm{~m}^{3}(12.1 \%)$

Slope setting: convex slope, middle part of slope

Landslide type and material type: translational slide and earthflow, colluvium and regolith

Original slope angle: $26^{\circ}$

Scar angle: $\quad 45^{\circ} \quad$ Runout angle: $15^{\circ}$

Notes: above road cut on old slip face, road cuts through deposit area, non-fluvially connected

Photographs:

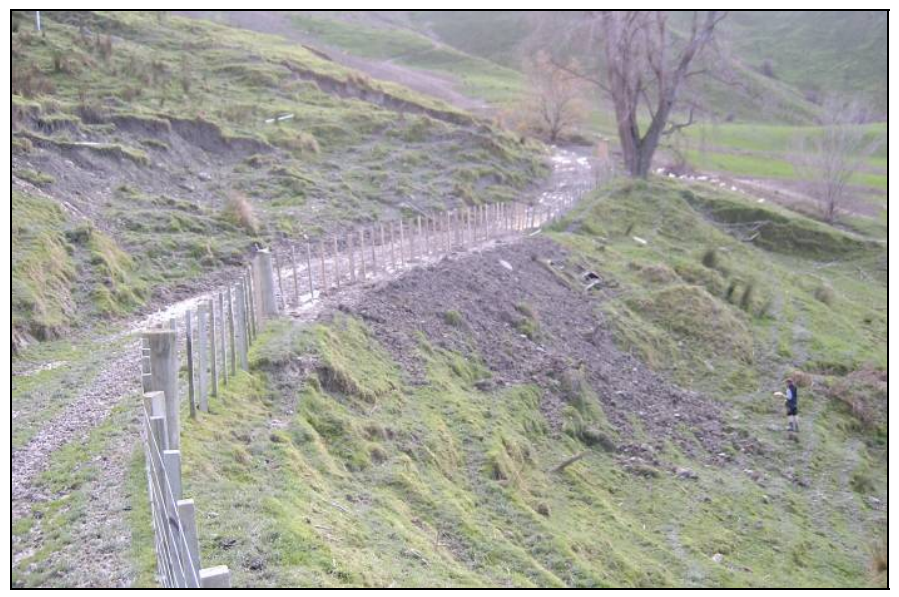

Landslide ID number: 6

Scar Area: $29.7 \mathrm{~m}^{2} \quad$ Scar Depth: $1.4 \mathrm{~m} \quad$ Scar volume: $41.6 \mathrm{~m}^{3}$ Runout Area: $55.4 \mathrm{~m}^{2} \quad$ Runout Depth: $0.4 \mathrm{~m} \quad$ Runout volume: $22.2 \mathrm{~m}^{3}$

Material input to fluvial system: $19.4 \mathrm{~m}^{3}(46.6 \%)$

Slope setting: convex slope, middle part of slope

Landslide type and material type: translational slide and rapid earthflow, regolith

Original slope angle: $24^{\circ}$

Scar angle: $55^{\circ}$

Runout angle: $15^{\circ}$

Notes: non-fluvially connected, runout toe removed by road clearing

Photographs:

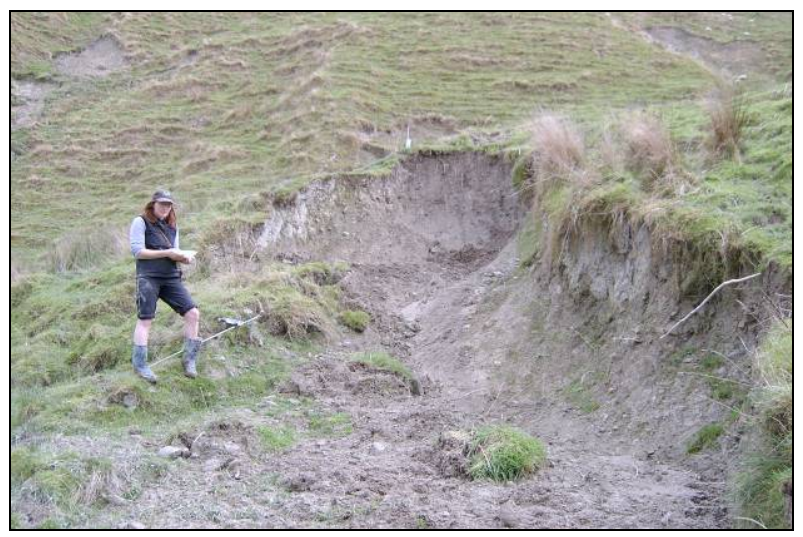


Landslide ID number: 7

Scar Area: $212.7 \mathrm{~m}^{2} \quad$ Scar Depth: $1.4 \mathrm{~m}$ Scar volume: $297.8 \mathrm{~m}^{3}$ Runout Area: $221.5 \mathrm{~m}^{2} \quad$ Runout Depth: $1.22 \mathrm{~m} \quad$ Runout volume: $270.2 \mathrm{~m}^{3}$

Material input to fluvial system: $27.6 \mathrm{~m}^{3}(9.3 \%)$

Slope setting: rectilinear slope, middle part of slope

Landslide type and material type: translational slide and earthflow, regolith Original slope angle: $21^{\circ}$

Scar angle: $\quad 50^{\circ} \quad$ Runout angle: $21^{\circ}$

Notes: part of toe removed by road clearing, very little evacuation, turf intact over most of deposit surface, non-connected to fluvial

Photographs:
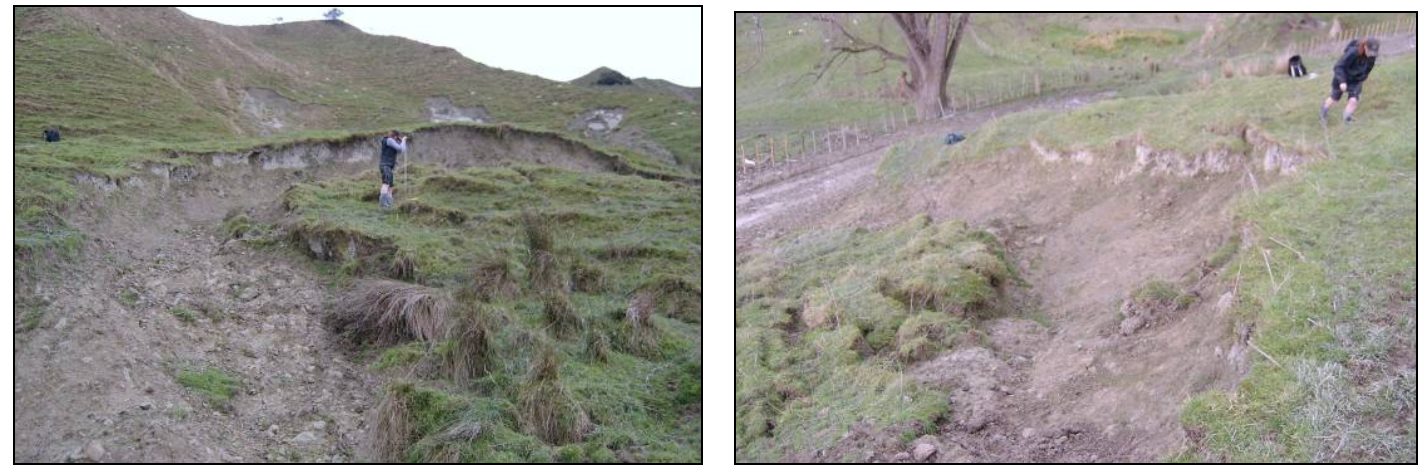

Landslide ID number: 8

Scar Area: $1112.8 \mathrm{~m}^{2}$ Scar Depth: $2.5 \mathrm{~m}$ Scar volume: $2782 \mathrm{~m}^{3}$ Runout Area: $6553.7 \mathrm{~m}^{2} \quad$ Runout Depth: $0.38 \mathrm{~m} \quad$ Runout volume: $2490.4 \mathrm{~m}^{3}$

Material input to fluvial system: $291.6 \mathrm{~m}^{3}(10.5 \%)$

Slope setting: convex slope, upper part of slope

Landslide type and material type: translational slide and rapid earthflow, bedrock and regolith

Original slope angle: $25^{\circ}$

Scar angle: $\quad 33^{\circ}$

Runout angle: $18^{\circ}$

Notes: three (slumpy) scars on true left flank, none of slumpy material has contributed to flow, non-connected to fluvial

Photographs:
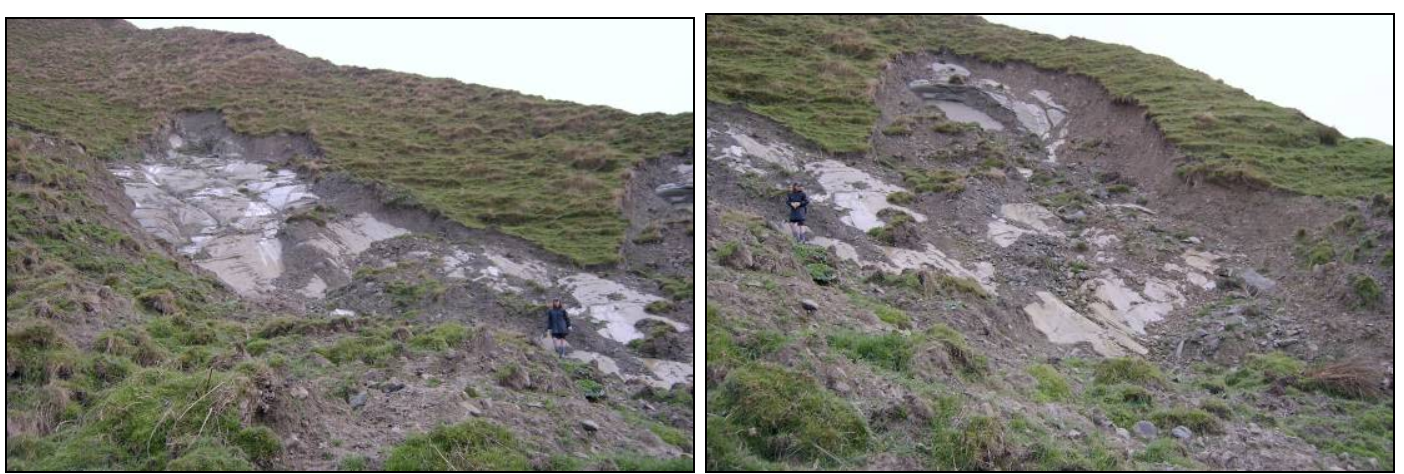
Landslide ID number: 9

Scar Area: $499.4 \mathrm{~m}$ Scar Depth: $0.7 \mathrm{~m}$ Scar volume: $349.6 \mathrm{~m}^{3}$ Runout Area: $1071.1 \mathrm{~m}^{2} \quad$ Runout Depth: $0.27 \mathrm{~m}$ Runout volume: $289.2 \mathrm{~m}^{3}$

Material input to fluvial system: $60.4 \mathrm{~m}^{3}(17.27 \%)$

Slope setting: rectilinear slope, upper part of slope

Landslide type and material type: translational slide and rapid earthflow, colluvium and regolith

Original slope angle: $24^{\circ}$

Scar angle: $\quad 37^{\circ} \quad$ Runout angle: $24^{\circ}$

Notes: multi-headed landslide with large runout lobe, toe partially cleared by road cut.

Photographs:
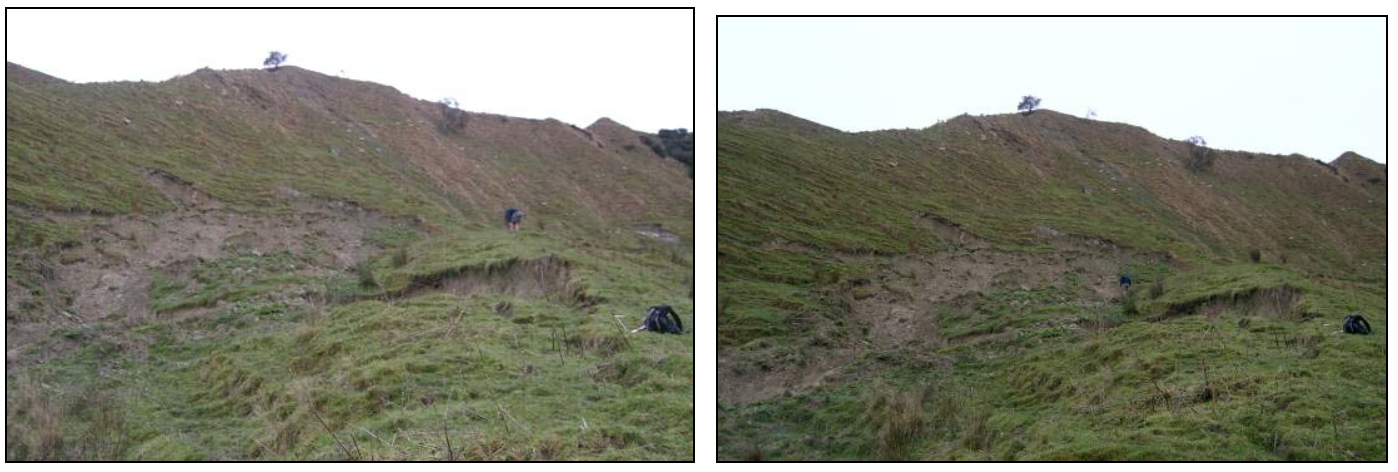

\section{Landslide ID number: 10}

Scar Area: $149.9 \mathrm{~m}^{2} \quad$ Scar Depth: $0.59 \mathrm{~m}$ Scar volume: $88.4 \mathrm{~m}^{3}$ Runout Area: $595.1 \mathrm{~m}^{2} \quad$ Runout Depth: $0.13 \mathrm{~m} \quad$ Runout volume: $77.4 \mathrm{~m}^{3}$

Material input to fluvial system: $11 \mathrm{~m}^{3}(12.4 \%)$

Slope setting: concave slope, upper part of slope

Landslide type and material type: translational slide and rapid earthflow, bedrock and regolith

Original slope angle: $28^{\circ}$

Scar angle: $40^{\circ}$

Runout angle: $25^{\circ}$

Notes: lower area $90 \%$ original surface, but upper part of runout intact, nonconnected with fluvial system

Photographs:
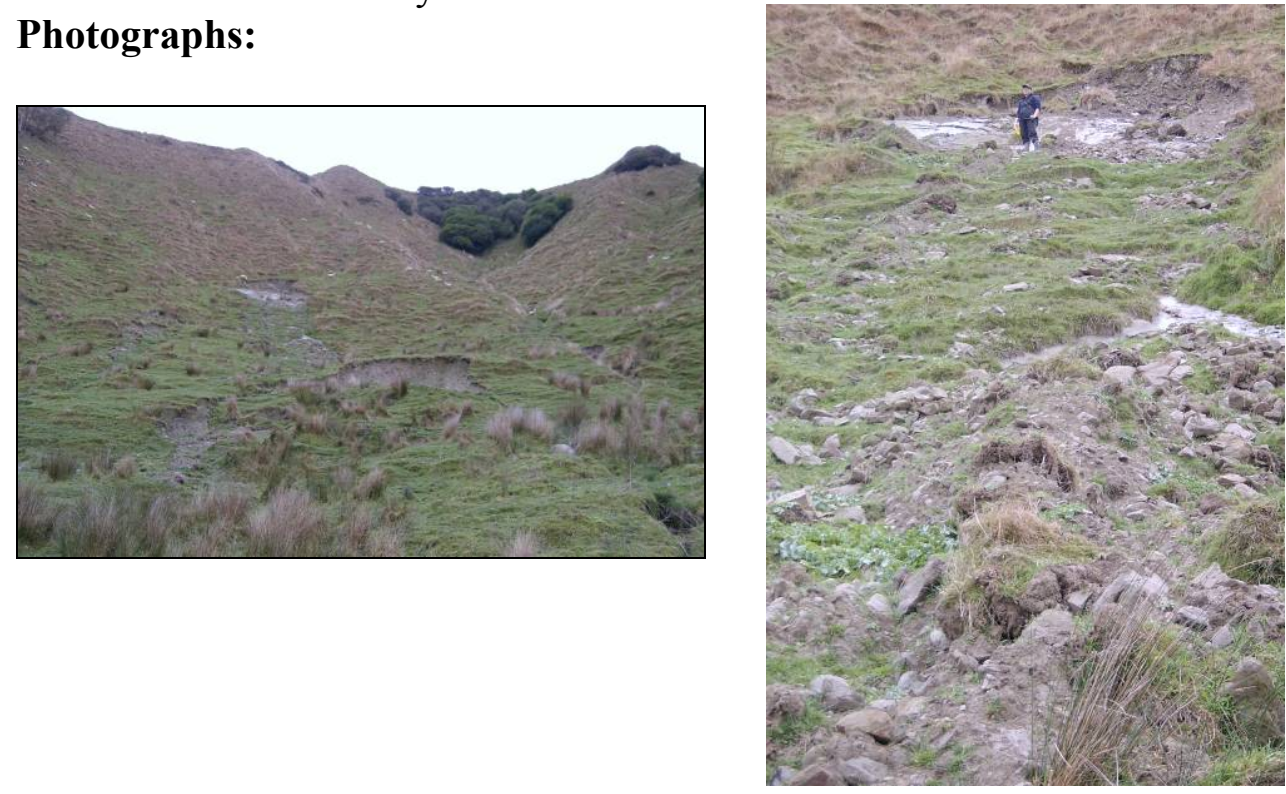
Landslide ID number: 11

Scar Area: $179.3 \mathrm{~m}^{2} \quad$ Scar Depth: $0.4 \mathrm{~m} \quad$ Scar volume: $71.7 \mathrm{~m}^{3}$ Runout Area: $252.2 \mathrm{~m}^{2} \quad$ Runout Depth: $0.27 \mathrm{~m} \quad$ Runout volume: $68.1 \mathrm{~m}^{3}$

Material input to fluvial system: $3.6 \mathrm{~m}^{3}(5.0 \%)$

Slope setting: concave slope, middle part of slope

Landslide type and material type: translational slide and earthflow, colluvium and regolith

Original slope angle: $23^{\circ}$

Scar angle: $\quad 41^{\circ} \quad$ Runout angle: $20^{\circ}$

Notes: large cracks on true left flank of scar but not evacuated, mainly slumpy at top than earthflow lower down, non-connected to fluvial

Photographs:
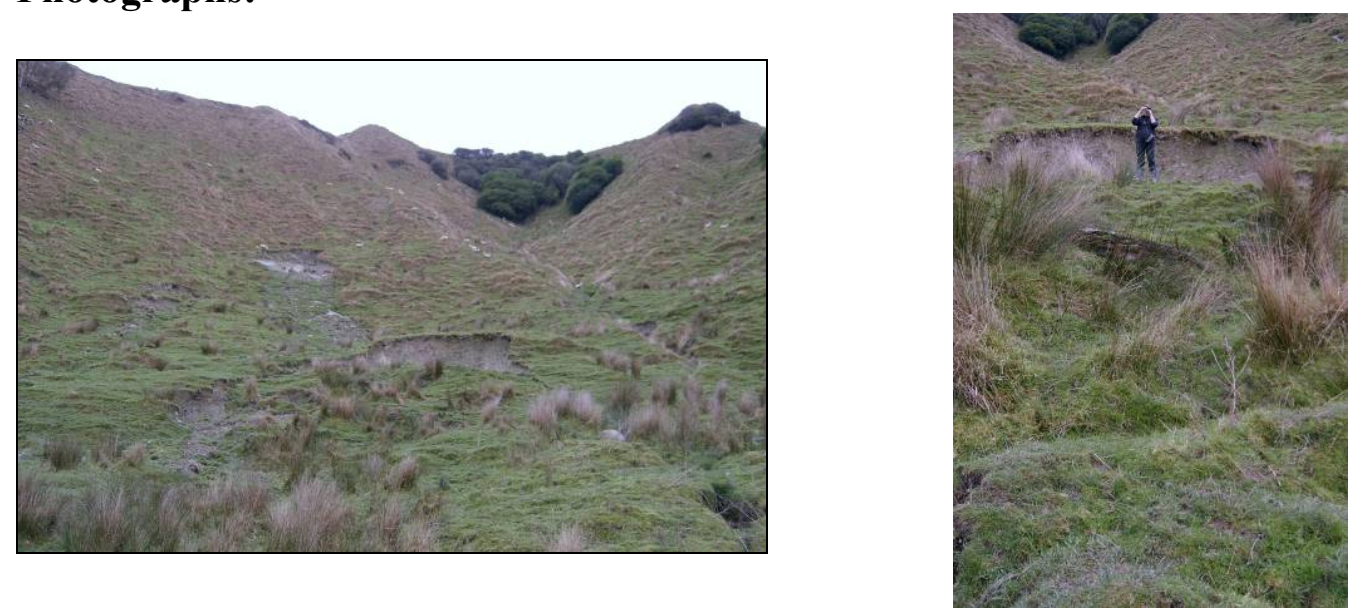

Landslide ID number: 12

Scar Area: $343.4 \mathrm{~m}^{2} \quad$ Scar Depth: $0.95 \mathrm{~m}$ Runout Area: $764.2 \mathrm{~m}^{2} \quad$ Runout Depth: $0.35 \mathrm{~m}$

Scar volume: $326.2 \mathrm{~m}^{3}$ Runout volume: $267.5 \mathrm{~m}^{3}$

Material input to fluvial system: $58.7 \mathrm{~m}^{3} \quad(18 \%)$

Slope setting: convex slope, lower part of slope

Landslide type and material type: translational slide and earthflow, regolith

Original slope angle: $31^{\circ}$

Scar angle: $\quad 46^{\circ} \quad$ Runout angle: $22^{\circ}$

Notes: connected to fluvial system, some scouring of flow path, toe washed away somewhat, blocky intact turf upper half, earthflow lower half

Photographs:

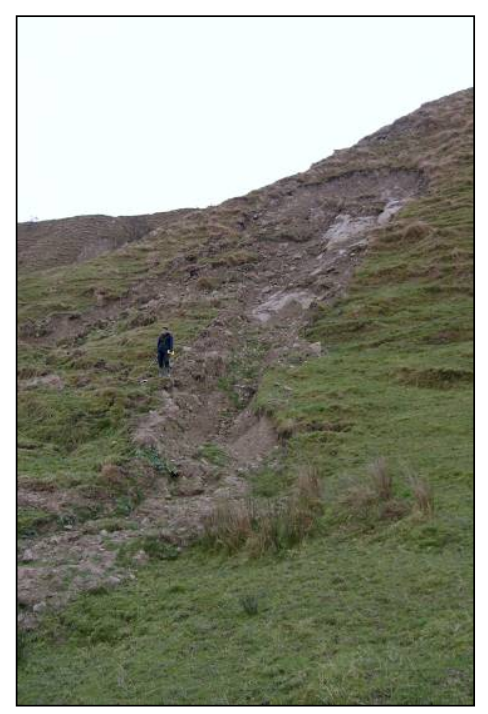


Landslide ID number: 13

Scar Area: $369.6 \mathrm{~m}^{2} \quad$ Scar Depth: $0.64 \mathrm{~m}$ Scar volume: $236.5 \mathrm{~m}^{3}$

Runout must be combined with landslide ID 14 as the runout areas meet

Material input to fluvial system: see landslide ID 14)

Slope setting: concave slope, upper part of slope

Landslide type and material type: translational slide and earthflow, regolith

Original slope angle: $26^{\circ}$

Scar angle: $\quad 45^{\circ} \quad$ Runout angle: $24^{\circ}$

Notes: large scar crack at top crest small scar lower down contributing to 13, connects with 14, connected to fluvial, saturated and unstable

Photographs:
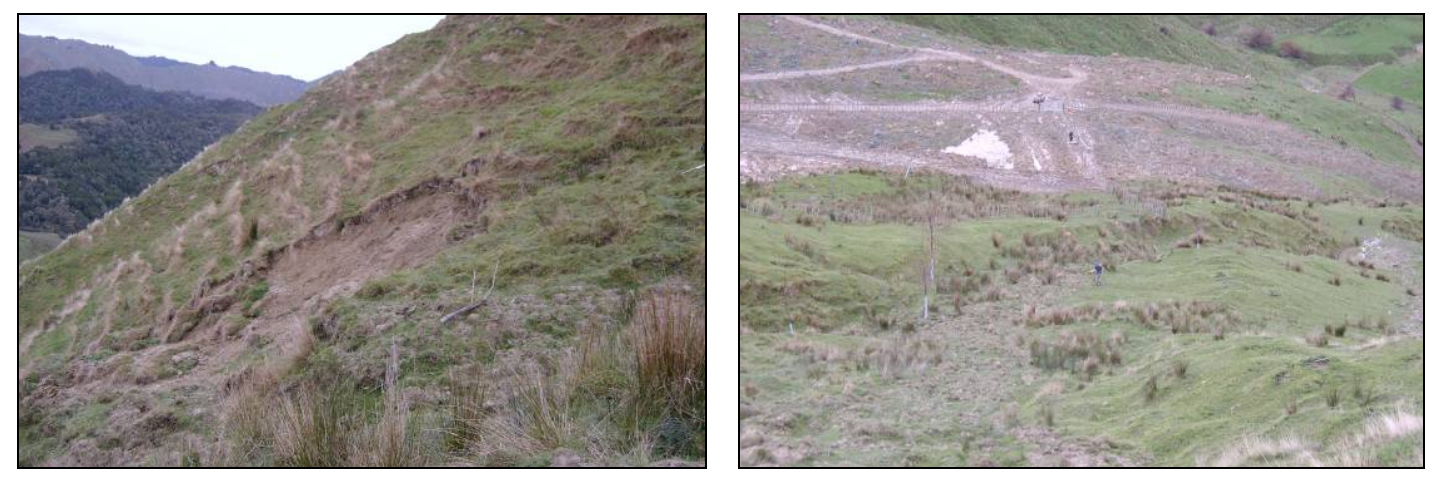

\section{Landslide ID number: 14}

Scar Area: $960.3 \mathrm{~m}^{2}$ Depth: $2 \mathrm{~m}$ Volume: $1920.6 \mathrm{~m}^{3}$ Combined: $2157.1 \mathrm{~m}^{3}$ Combined 13/14: Runout Area: $4417.4 \mathrm{~m}^{2}$ Depth: $0.36 \mathrm{~m}$ Volume: $1590.3 \mathrm{~m}^{3}$

Material input to fluvial system: $566.8 \mathrm{~m}^{3}$ (26.3\%)

Slope setting: convex slope, middle part of slope

Landslide type and material type: translational slide and earthflow

Original slope angle: $24^{\circ}$

Scar angle: $\quad 55^{\circ}$

Runout angle: $24^{\circ}$

Notes: large double-headed scar, flow converges than diverges, medium sized-scar in deposit area, below true right scar, fluvial connected and connected to 13

Photographs:
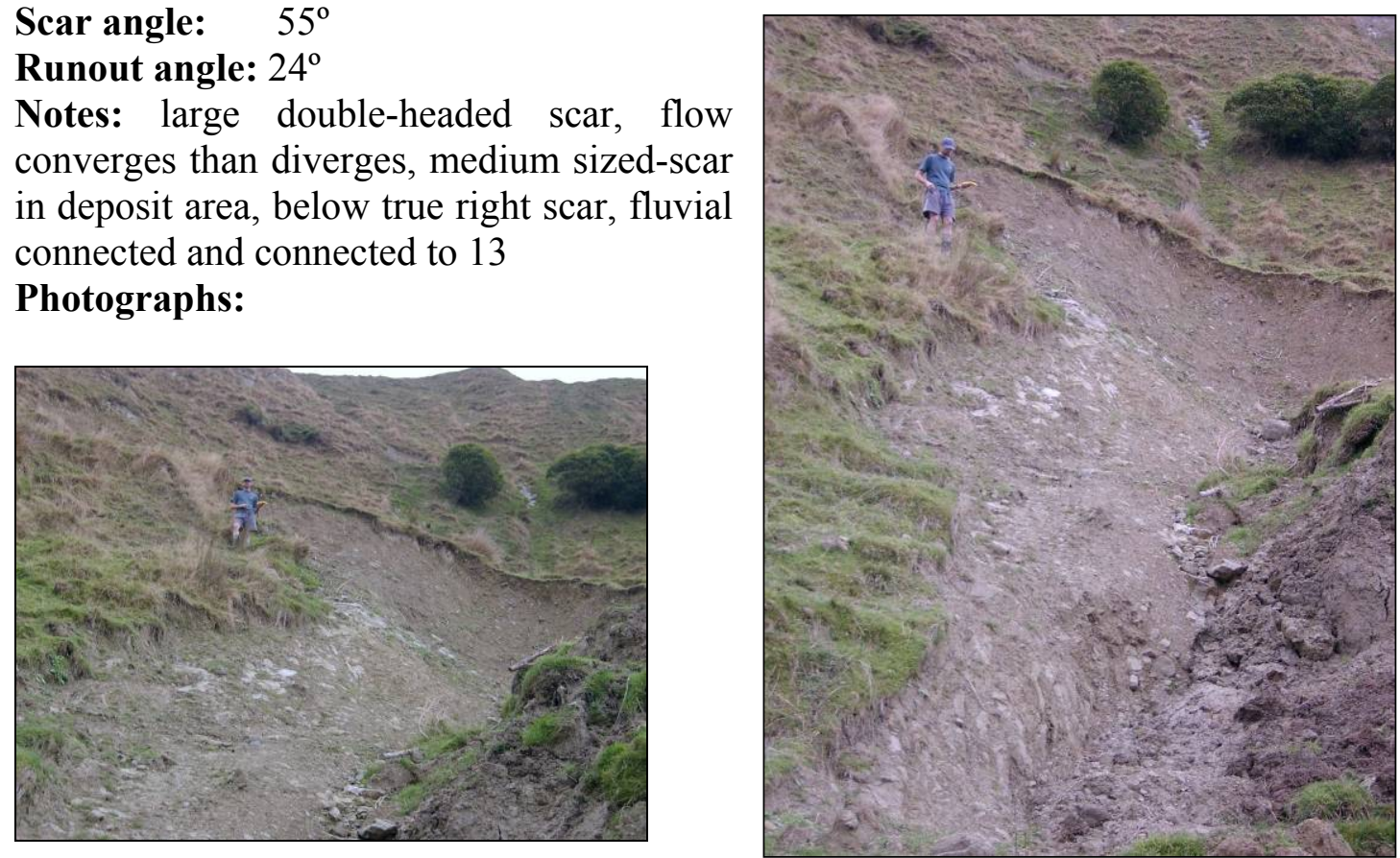
Landslide ID number: 15

Scar Area: unable to be measured

Runout Area: unable to be measured

Material input to fluvial system: unknown

Slope setting: concave slope, upper part of slope

Landslide type and material type: translational slide and rapid earthflow, regolith

Original slope angle: too steep to measure

Scar angle:

Runout angle:

Notes: uppermost part of catchment, high degree of scouring, fluvially connected but slope too steep and dangerous for measurements to be made, flow runs directly down drainage channel very fine material, not of significant size to be of concern

Photographs:
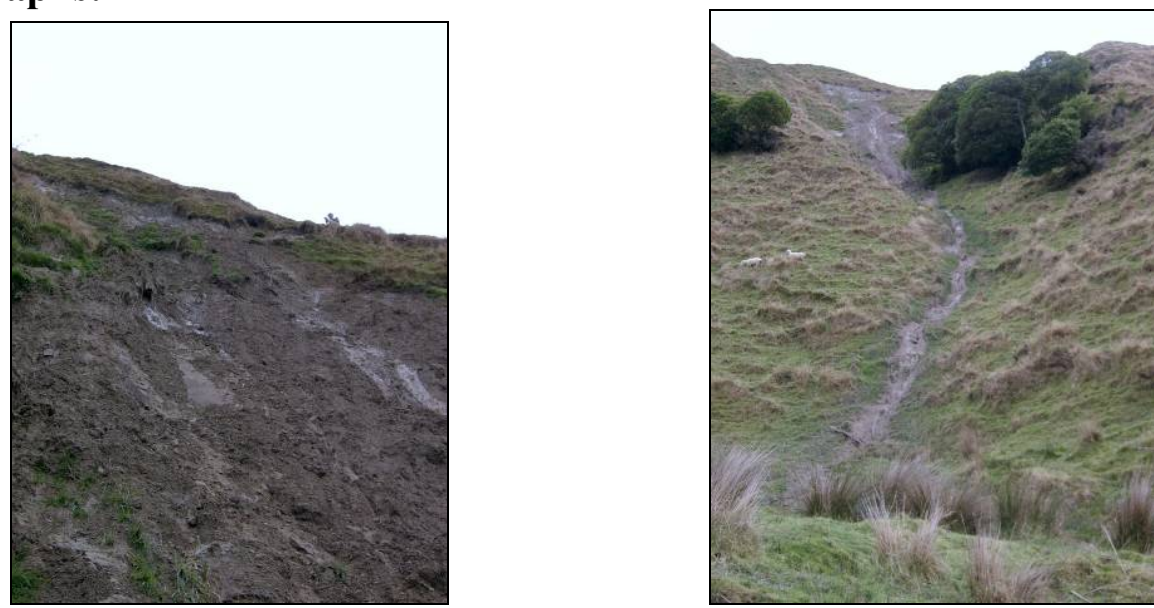

Landslide ID number: 16

Scar Area: $23.8 \mathrm{~m}^{2} \quad$ Scar Depth: $0.4 \mathrm{~m} \quad$ Scar volume: $9.7 \mathrm{~m}^{3}$ Runout Area: $52.4 \mathrm{~m}^{2} \quad$ Runout Depth: $0.18 \mathrm{~m}$ Runout volume: $9.4 \mathrm{~m}^{3}$

Material input to fluvial system: $0.3 \mathrm{~m}^{3}(3.1 \%)$

Slope setting: convex slope, middle part of slope

Landslide type and material type: translational slide and earthflow, regolith

Original slope angle: $24^{\circ}$

Scar angle: $\quad 60^{\circ}$

Runout angle: $23^{\circ}$

Notes: small slip, with blocky runout, non-connected to fluvial

Photographs:

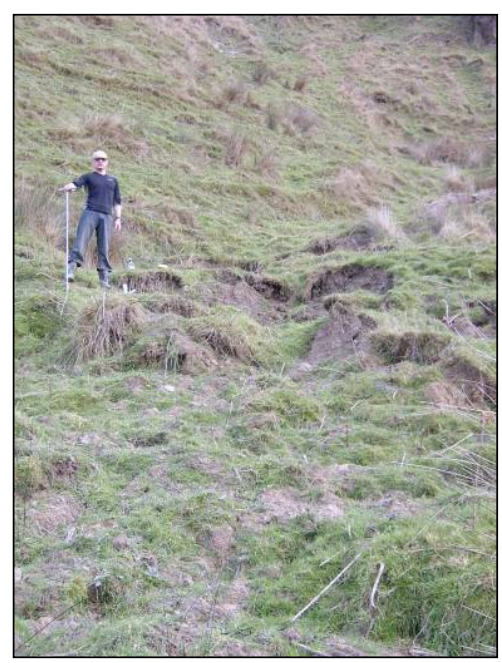


Landslide ID number: 17

Scar Area: $35.1 \mathrm{~m}^{2} \quad$ Scar Depth: $0.5 \mathrm{~m} \quad$ Scar volume: $17.6 \mathrm{~m}^{3}$ Runout Area: $57.8 \mathrm{~m}^{2} \quad$ Runout Depth: $0.28 \mathrm{~m}$ Runout volume: $14.5 \mathrm{~m}^{3}$

Material input to fluvial system: $3.1 \mathrm{~m}^{3}(17.6 \%)$

Slope setting: concave slope, upper part of slope

Landslide type and material type: translational slide and earthflow, regolith

Original slope angle: $34^{\circ}$

Scar angle: $55^{\circ} \quad$ Runout angle: $30^{\circ}$

Notes: connected with fluvial system, bedrock exposed but not removed

Photographs:

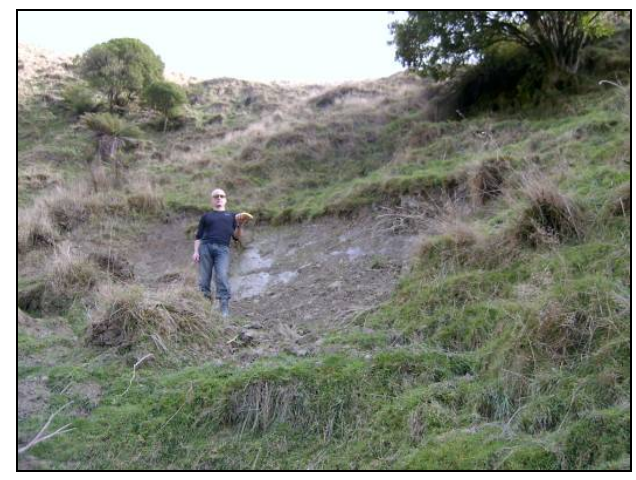

Landslide ID number: 18

Scar Area: $14265 \mathrm{~m}^{2} \quad$ Scar Depth: $14.1 \mathrm{~m} \quad$ Scar volume: $201137 \mathrm{~m}^{3}$

Runout Area: $53718 \mathrm{~m}^{2} \quad$ Runout Depth: $2.5 \mathrm{~m} \quad$ Runout volume: $134925 \mathrm{~m}^{3}$

Material input to fluvial system: $66212 \mathrm{~m}^{3}(32.9 \%)$

Slope setting: concave slope, upper part of slope

Landslide type and material type: rotational slide and earthflow, bedrock and regolith

Original slope angle: $34^{\circ}$

Scar angle: $\quad 52^{\circ} \quad$ Runout angle: $30^{\circ}$

Notes: largest sip in catchment and possible from event, many runout lobes and levees, connected to fluvial

Photographs:
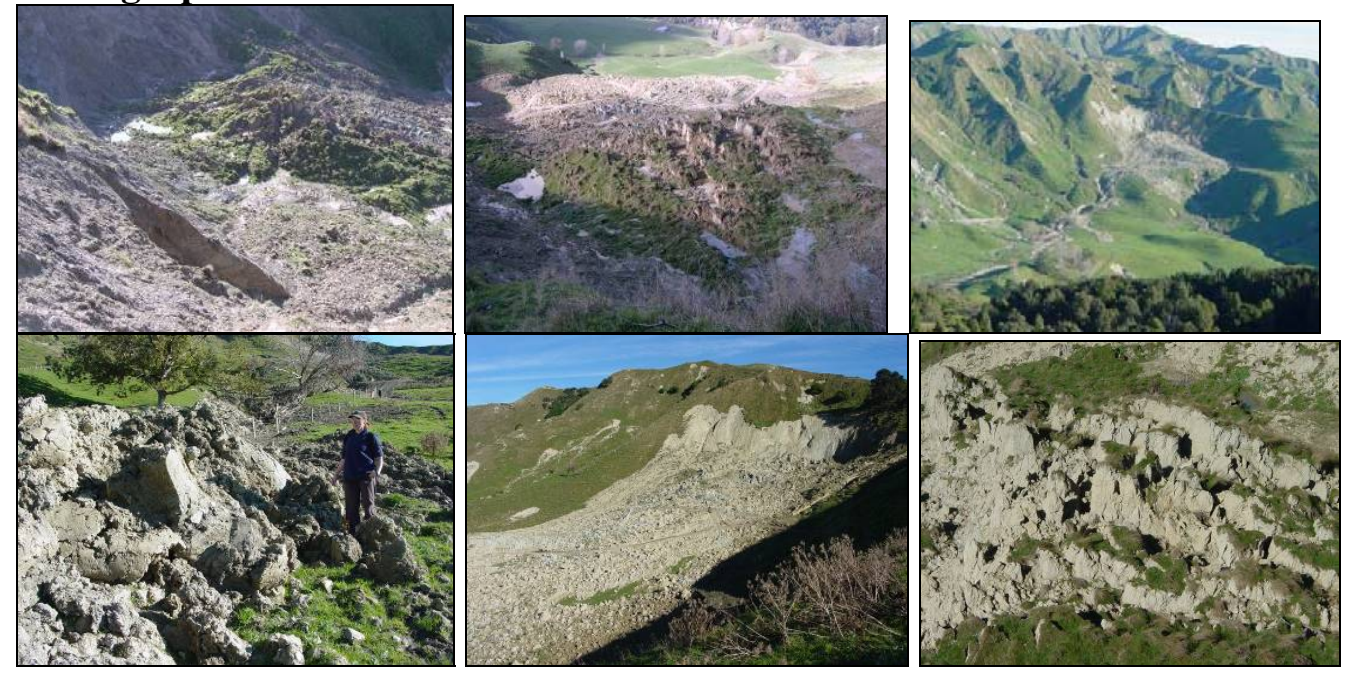
Landslide ID number: 19

Scar Area: $35.1 \mathrm{~m}^{2} \quad$ Scar Depth: $0.49 \mathrm{~m}$ Scar volume: $17.2 \mathrm{~m}^{3}$ Runout Area: $57.8 \mathrm{~m}^{2} \quad$ Runout Depth: $0.22 \mathrm{~m}$ Runout volume: $12.7 \mathrm{~m}^{3}$ Material input to fluvial system: $4.5 \mathrm{~m}^{3}(26.2 \%)$ Slope setting: convex slope, middle part of slope Landslide type and material type: translational slide Original slope angle: $27^{\circ}$

Scar angle: $\quad 35^{\circ} \quad$ Runout angle: $24^{\circ}$

Notes: connected to fluvial system, no flow developed, some material removed by road clearing

Photographs:

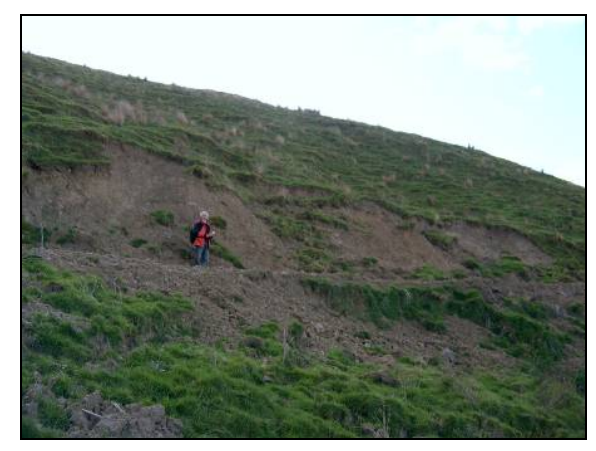

Landslide ID number: 20

Scar Area: $126.6 \mathrm{~m}^{2} \quad$ Scar Depth: $0.7 \mathrm{~m} \quad$ Scar volume: $88.6 \mathrm{~m}^{3}$ Runout Area: $324 \mathrm{~m}^{2} \quad$ Runout Depth: $0.18 \mathrm{~m} \quad$ Runout volume: $57.7 \mathrm{~m}^{3}$

Material input to fluvial system: $30.9 \mathrm{~m}^{3}(34.8 \%)$

Slope setting: concave slope, middle part of slope

Landslide type and material type: translational slide and earthflow, regolith Original slope angle: $36^{\circ}$

Scar angle: $40^{\circ}$

Runout angle: $46^{\circ}$

Notes: feeds into landslide 18 and connected with fluvial system

Photographs:

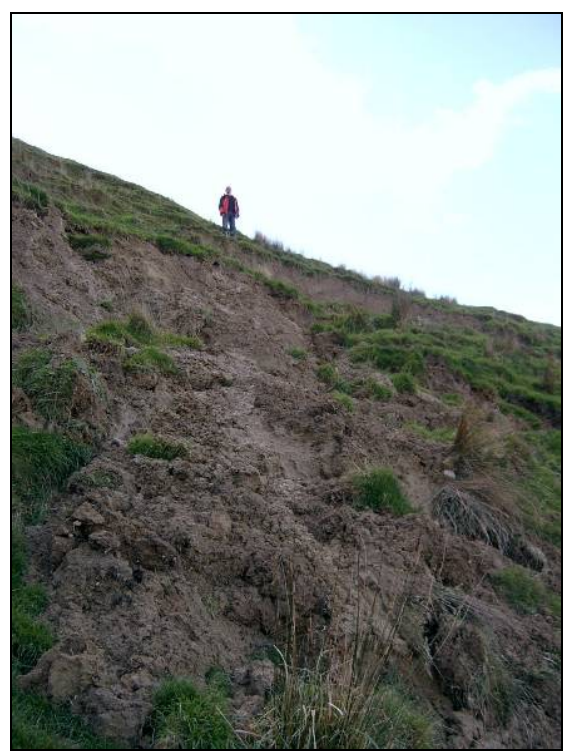


Landslide ID number: 21

Scar Area: $121.8 \mathrm{~m}^{2} \quad$ Scar Depth: $0.8 \mathrm{~m}$ Scar volume: $97.4 \mathrm{~m}^{3}$ Runout Area: $122.6 \mathrm{~m}^{2} \quad$ Runout Depth: $0.55 \mathrm{~m} \quad$ Runout volume: $66.7 \mathrm{~m}^{3}$

Material input to fluvial system: $30.7 \mathrm{~m}^{3}(31.5 \%)$

Slope setting: convex slope, lower part of slope

Landslide type and material type: translational slide, regolith

Original slope angle: $24^{\circ}$

Scar angle: $\quad 35^{\circ} \quad$ Runout angle: $18^{\circ}$

Notes: no flow formed, connected to fluvial system

Photographs:

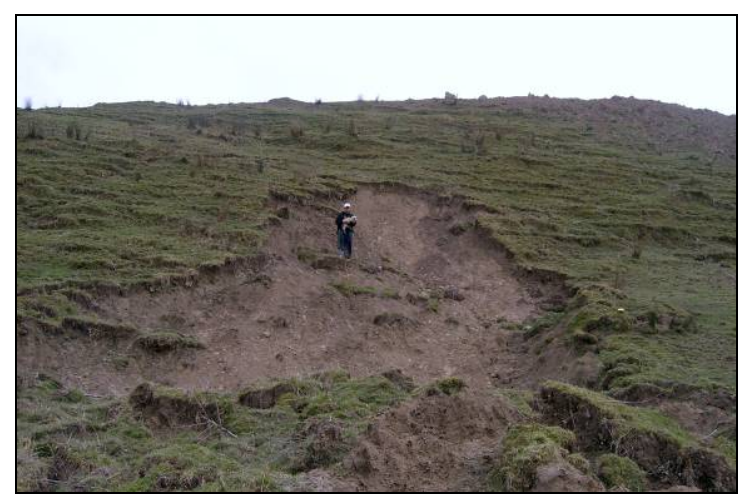

Landslide ID number: 22

Scar Area: $218.1 \mathrm{~m}^{2} \quad$ Scar Depth: $1.6 \mathrm{~m}$ Scar volume: $349 \mathrm{~m}^{3}$ Runout Area: $796.7 \mathrm{~m}^{2} \quad$ Runout Depth: $0.34 \mathrm{~m} \quad$ Runout volume: $270.8 \mathrm{~m}^{3}$

Material input to fluvial system: $78.2 \mathrm{~m}^{3}(22.4 .9 \%)$

Slope setting: concave slope, upper part of slope

Landslide type and material type: translational slide and rapid earthflow, bedrock and regolith

Original slope angle: $33^{\circ}$

Scar angle: $\quad 50^{\circ} \quad$ Runout angle: $15^{\circ}$

Notes: material quickly disperse to leave $90 \%$ original surface in lower deposit area, connected to fluvial

Photographs:

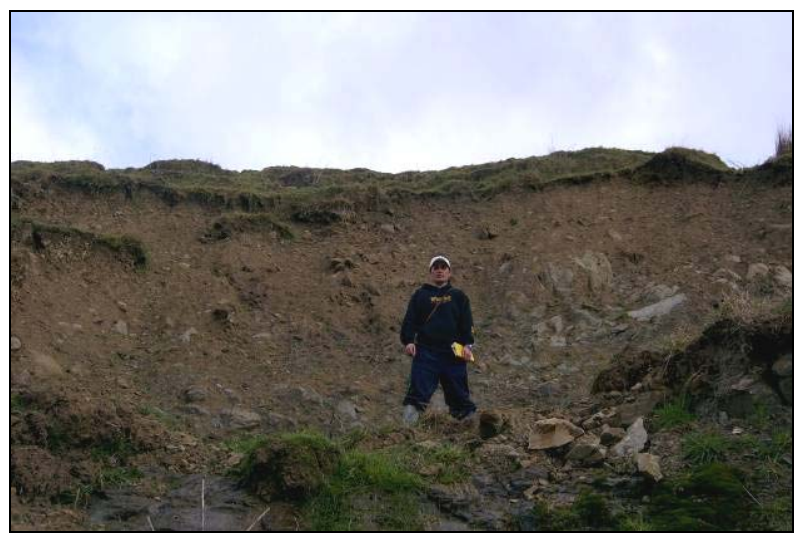


Landslide ID number: 23

Scar Area: $191.7 \mathrm{~m}^{2} \quad$ Scar Depth: $2.1 \mathrm{~m} \quad$ Scar volume: $406.8 \mathrm{~m}^{3}$ Runout Area: $1560.8 \mathrm{~m}^{2} \quad$ Runout Depth: $0.18 \mathrm{~m}$ Runout volume: $280.9 \mathrm{~m}^{3}$

Material input to fluvial system: $125.8 \mathrm{~m}^{3}(30.9 \%)$

Slope setting: concave slope, upper part of slope

Landslide type and material type: translational slide, regolith

Original slope angle: $25^{\circ}$

Scar angle: $\quad 43^{\circ} \quad$ Runout angle: $27^{\circ}$

Notes: multiple headed, non flow forming, connected with fluvial and 24

Photographs:
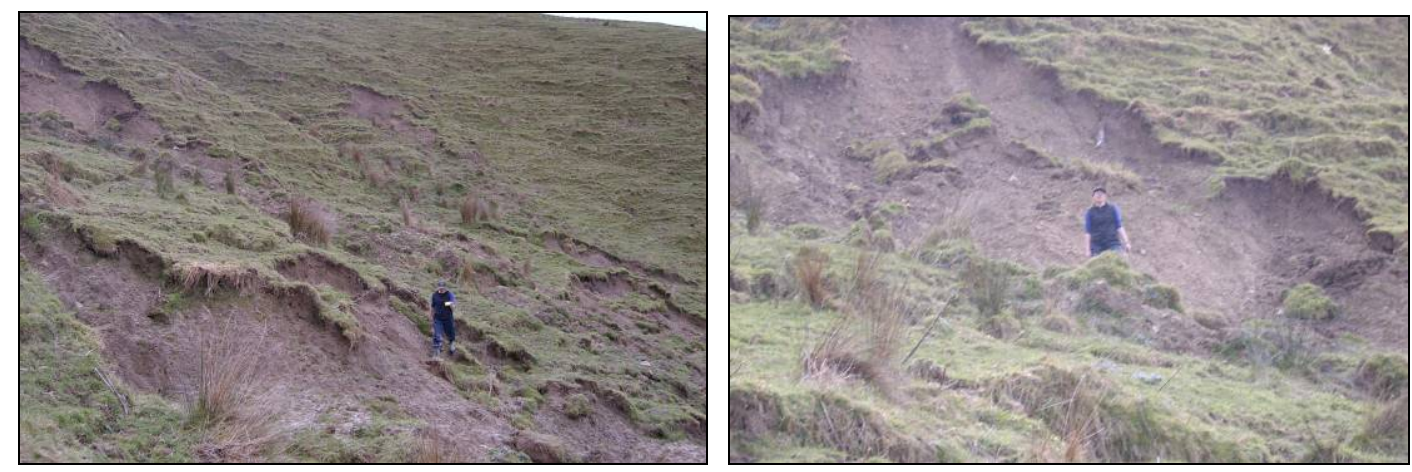

Landslide ID number: 24

Scar Area: $191.5 \mathrm{~m}^{2} \quad$ Scar Depth: $1.7 \mathrm{~m} \quad$ Scar volume: $325.6 \mathrm{~m}^{3}$

Runout Area: unable to be measured as no material in situ Runout volume: $0 \mathrm{~m}^{3}$

Material input to fluvial system: $325.6 \mathrm{~m}^{3}(100 \%)$

Slope setting: concave slope, middle part of slope

Landslide type and material type: translational slide, regolith

Original slope angle: $22^{\circ}$

Scar angle: $\quad 50^{\circ}$

Runout angle: N/A

Notes: connected to fluvial, all material lost to drainage channel

Photographs:

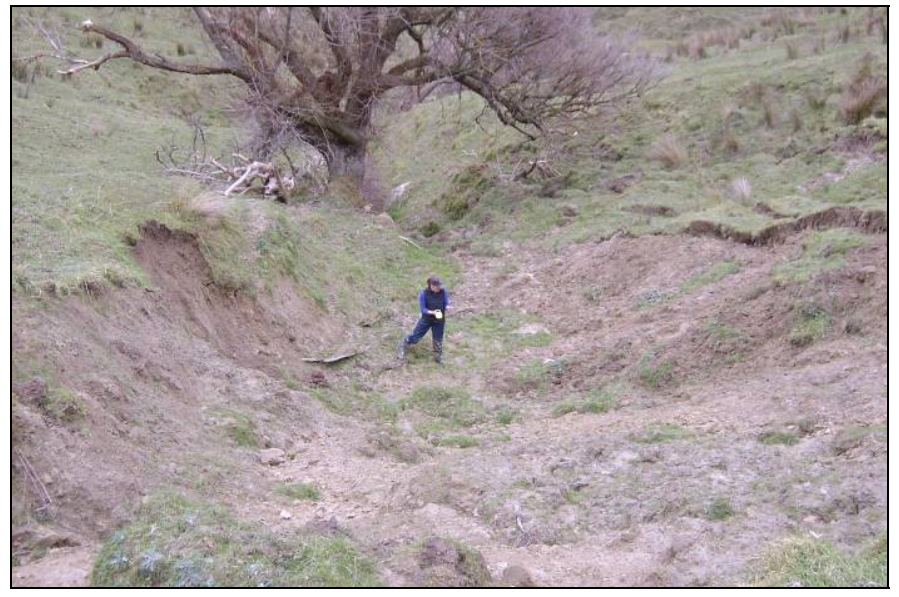


Landslide ID number: 25

Scar Area: $74.4 \mathrm{~m}^{2}$

Scar Depth: $0.6 \mathrm{~m}$

Scar volume: $44.6 \mathrm{~m}^{3}$

Runout Area: $122.5 \mathrm{~m}^{2}$

Runout Depth: $0.33 \mathrm{~m}$ Runout volume: $40.4 \mathrm{~m}^{3}$

Material input to fluvial system: $4.2 \mathrm{~m}^{3}(9.4 \%)$

Slope setting: concave slope, upper part of slope

Landslide type and material type: translational slide, regolith

Original slope angle: $35^{\circ}$

Scar angle: $\quad 42^{\circ} \quad$ Runout angle: $\quad 42^{\circ}$

Notes: very blocky hasn't flowed a lot, non-connected to fluvial

Photographs:

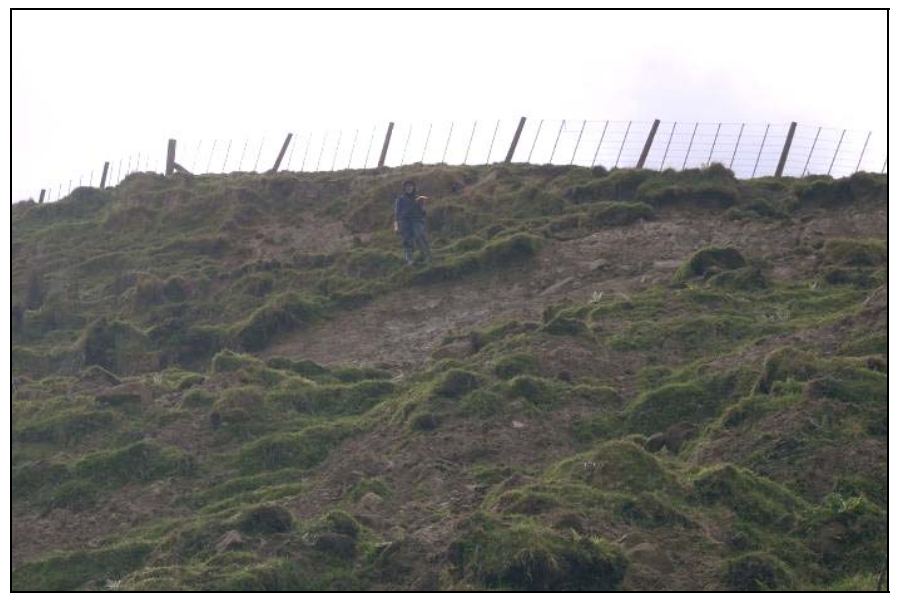

Landslide ID number: 26

Scar Area: $145.1 \mathrm{~m}^{2} \quad$ Scar Depth: $0.7 \mathrm{~m} \quad$ Scar volume: $101.6 \mathrm{~m}^{3}$ Runout Area: $472.2 \mathrm{~m}^{2} \quad$ Runout Depth: $0.16 \mathrm{~m} \quad$ Runout volume: $75.6 \mathrm{~m}^{3}$

Material input to fluvial system: $26 \mathrm{~m}^{3}(25.6 \%)$

Slope setting: convex slope, upper part of slope

Landslide type and material type: translational slide and earthflow, regolith

Original slope angle: $35^{\circ}$

Scar angle: $\quad 41^{\circ}$

Notes: connects with fluvial system

Runout angle: $33^{\circ}$

Photographs:
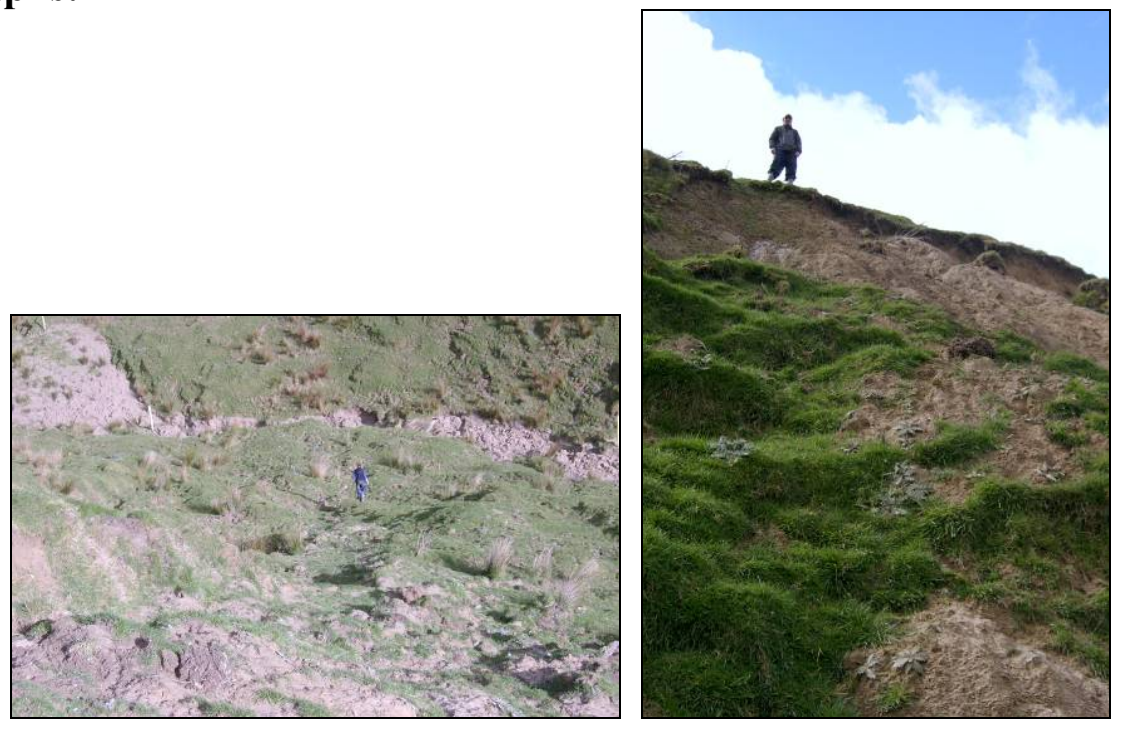
Landslide ID number: 27

Scar Area: $31.7 \mathrm{~m}^{2} \quad$ Scar Depth: $0.4 \mathrm{~m} \quad$ Scar volume: $12.7 \mathrm{~m}^{3}$

Runout Area: $188.7 \mathrm{~m}^{2} \quad$ Runout Depth: $0.65 \mathrm{~m} \quad$ Runout volume: $12.3 \mathrm{~m}^{3}$

Material input to fluvial system: $0.4 \mathrm{~m}^{3}(3.1 \%)$

Slope setting: concave slope, middle part of slope

Landslide type and material type: translational slide and rapid earthflow, regolith Original slope angle: $35^{\circ}$

Scar angle: $45^{\circ}$

Runout angle: $42^{\circ}$

Notes: material flowed very thinly, runout area $99 \%$ original regolith

Photographs:

No photograph available (camera issues) 


\section{Appendix 2 Slope aspect data summary}

\begin{tabular}{|c|c|c|c|c|c|}
\hline & & Mangawhero & & & landslide aspect as $\%$ of all slopes of orientation \\
\hline & $\begin{array}{l}\text { L/S } \\
\text { Slopes }\end{array}$ & $\%$ & All Slopes & $\%$ & \\
\hline West & 8.0 & 5.6 & 23.0 & 7.9 & 71.5 \\
\hline Northwest & 21.0 & 14.8 & 42.0 & 14.4 & 102.8 \\
\hline North & 25.0 & 17.6 & 39.0 & 13.4 & 131.8 \\
\hline Northeast & 37.0 & 26.1 & 40.0 & 13.7 & 190.2 \\
\hline East & 18.0 & 12.7 & 39.0 & 13.4 & 94.9 \\
\hline Southeast & 15.0 & 10.6 & 46.0 & 15.8 & 67.1 \\
\hline South & 13.0 & 9.2 & 35.0 & 12.0 & 76.4 \\
\hline Southwest & 5.0 & 3.5 & 28.0 & 9.6 & 36.7 \\
\hline \multirow[t]{3}{*}{ Total } & 142.0 & 100.0 & 292.0 & 100.0 & \\
\hline & & Whangaehu & & & landslide aspect as $\%$ of all slopes of orientation \\
\hline & $\begin{array}{l}\text { L/S } \\
\text { Slopes }\end{array}$ & $\%$ & All Slopes & $\%$ & \\
\hline West & 14 & 11.8 & 32.0 & 12.7 & 92.3 \\
\hline Northwest & 21 & 17.6 & 30.0 & 12.0 & 147.6 \\
\hline North & 28 & 23.5 & 30.0 & 12.0 & 196.9 \\
\hline Northeast & 24 & 20.2 & 37.0 & 14.7 & 136.8 \\
\hline East & 9 & 7.6 & 30.0 & 12.0 & 63.3 \\
\hline Southeast & 7 & 5.9 & 28.0 & 11.2 & 52.7 \\
\hline South & 6 & 5.0 & 31.0 & 12.4 & 40.8 \\
\hline Southwest & 10 & 8.4 & 33.0 & 13.1 & 63.9 \\
\hline \multirow[t]{3}{*}{ Total } & 119 & 100.0 & 251.0 & 100.0 & \\
\hline & & Turakina & & & landslide aspect as $\%$ of all slopes of orientation \\
\hline & $\begin{array}{l}\text { L/S } \\
\text { Slopes }\end{array}$ & $\%$ & All slopes & $\%$ & \\
\hline West & 5.0 & 4.0 & 25.0 & 9.2 & 43.4 \\
\hline Northwest & 27.0 & 21.6 & 31.0 & 11.4 & 188.8 \\
\hline North & 36.0 & 28.8 & 41.0 & 15.1 & 190.4 \\
\hline Northeast & 30.0 & 24.0 & 45.0 & 16.6 & 144.5 \\
\hline East & 14.0 & 11.2 & 29.0 & 10.7 & 104.7 \\
\hline Southeast & 2.0 & 1.6 & 34.0 & 12.5 & 12.8 \\
\hline South & 3.0 & 2.4 & 25.0 & 9.2 & 26.0 \\
\hline Southwest & 8.0 & 6.4 & 41.0 & 15.1 & 42.3 \\
\hline \multirow[t]{3}{*}{ Total } & 125.0 & 100.0 & 271.0 & 100.0 & \\
\hline & & Pohangina & & & landslide aspect as $\%$ of all slopes of orientation \\
\hline & $\begin{array}{l}\text { L/S } \\
\text { Slopes }\end{array}$ & $\%$ & All slopes & $\%$ & \\
\hline West & 32 & 18.5 & 52 & 15.3 & 120.6 \\
\hline Northwest & 44 & 25.4 & 44 & 13.0 & 196.0 \\
\hline North & 27 & 15.6 & 36 & 10.6 & 147.0 \\
\hline Northeast & 35 & 20.2 & 54 & 15.9 & 127.0 \\
\hline East & 9 & 5.2 & 41 & 12.1 & 43.0 \\
\hline Southeast & 7 & 4.0 & 35 & 10.3 & 39.2 \\
\hline South & 2 & 1.2 & 34 & 10.0 & 11.5 \\
\hline \multirow[t]{2}{*}{ Southwest } & 17 & 9.8 & 43 & 12.7 & 77.5 \\
\hline & 173.0 & 100.0 & 339.0 & 100.0 & \\
\hline
\end{tabular}


Appendix 3 Slope form data summary

\begin{tabular}{|l|c|c|l|c|c|}
\hline & \multicolumn{3}{|l|}{ Percentage of landside affected slope forms } & & \\
\hline & & $\%$ & & & $\%$ \\
\hline Mangawhero & Concave & 47 & Concave & Mangawhero & 47 \\
\hline & Convex & 24 & & Whangaehu & 48 \\
\hline & Mixed & 18 & & Turakina & 49 \\
\hline & Rectilinear & 11 & & Pohangina & 56 \\
\hline Whangaehu & Concave & 48 & Convex & Mangawhero & 24 \\
\hline & Convex & 24 & & Whangaehu & 24 \\
\hline & Mixed & 16 & & Turakina & 13 \\
\hline & Rectilinear & 12 & & Pohangina & 31 \\
\hline Turakina & Concave & 49 & Mixed & Mangawhero & 18 \\
\hline & Convex & 13 & & Whangaehu & 16 \\
\hline & Mixed & 17 & & Turakina & 17 \\
\hline Pohangina & Rectilinear & 21 & & Pohangina & 13 \\
\hline & Concave & 56 & Rectilinear & Mangawhero & 11 \\
\hline & Convex & 31 & & Whangaehu & 12 \\
\hline & Mixed & 13 & & Turakina & 21 \\
\hline & Rectilinear & 0 & & Pohangina & 0 \\
\hline
\end{tabular}

Appendix 4 Slope height data summary

\begin{tabular}{|c|c|c|c|}
\hline & & Height Range (m) & Average Height (m) \\
\hline \multirow[t]{5}{*}{ Mangawhero } & Concave & $80-220$ & 144 \\
\hline & Convex & $80-200$ & 139 \\
\hline & Mixed & $120-200$ & 158 \\
\hline & Rectilinear & $80-200$ & 129 \\
\hline & All slopes & $80-220$ & 144 \\
\hline \multirow[t]{5}{*}{ Whangaehu } & Concave & $80-280$ & 155 \\
\hline & Convex & $100-260$ & 141 \\
\hline & Mixed & $100-180$ & 150 \\
\hline & Rectilinear & $60-200$ & 136 \\
\hline & All slopes & $60-280$ & 148 \\
\hline \multirow[t]{5}{*}{ Turakina } & Concave & $80-200$ & 135 \\
\hline & Convex & $100-180$ & 130 \\
\hline & Mixed & $80-200$ & 141 \\
\hline & Rectilinear & $100-240$ & 147 \\
\hline & All slopes & $80-240$ & 138 \\
\hline \multirow[t]{5}{*}{ Pohangina } & Concave & $20-140$ & 66 \\
\hline & Convex & $20-120$ & 62 \\
\hline & Mixed & $40-100$ & 67 \\
\hline & Rectilinear & 0 & 0 \\
\hline & All slopes & $20-140$ & 64 \\
\hline \multicolumn{3}{|c|}{ NB: no rectilinear slopes in Pohangina } & \\
\hline
\end{tabular}


Appendix 5 Vegetation Data summary

\begin{tabular}{|l|l|r|r|r|r|}
\hline & Area measured & Pasture & Bush/Scrub & Pine & Poplar/Willow \\
\hline Mangawhero & $44.39 \mathrm{~km} 2$ & 49.6 & 4.7 & 6.5 & 12.5 \\
\hline Whangaehu & $51.77 \mathrm{~km} 2$ & 42.5 & 6.6 & 9.2 & 30.3 \\
\hline Turakina & $43.5 \mathrm{~km} 2$ & 31 & 6.5 & 7.1 & 7.4 \\
\hline Pohangina & $38.85 \mathrm{~km} 2$ & 35.9 & 11.6 & 7.9 & 18.4 \\
\hline Average & & 39.8 & 7.5 & 7.7 & 17.2 \\
\hline & & & & & \\
\hline
\end{tabular}

\begin{tabular}{|l|r|r|r|r|r|}
\hline & Mangawhero & Whangaehu & Turakina & Pohangina & Average \\
\hline Pasture & 49.6 & 42.5 & 31 & 35.9 & 39.8 \\
\hline Bush/Scrub & 4.7 & 6.6 & 6.5 & 11.6 & 7.5 \\
\hline Pine & 6.5 & 9.2 & 7.1 & 7.9 & 7.7 \\
\hline Poplar/Willow & 12.5 & 30.3 & 7.4 & 18.4 & 17.2 \\
\hline
\end{tabular}

Appendix 6 Landslide density data summary

\begin{tabular}{|c|c|c|c|c|}
\hline & & Area of grids (km2) & & \\
\hline & Mangawhero & Whangaehu & Turakina & Pohangina \\
\hline & 0.90 & 0.67 & 0.76 & 0.82 \\
\hline & 1.00 & 0.89 & 1.00 & 0.87 \\
\hline & 0.69 & 0.78 & 1.00 & 0.72 \\
\hline & 0.80 & 1.00 & 1.00 & 1.00 \\
\hline & 0.84 & 1.00 & 1.00 & 0.85 \\
\hline & 0.98 & 0.97 & 1.00 & 0.55 \\
\hline & 1.00 & 1.00 & 1.00 & 0.66 \\
\hline & 1.00 & 1.00 & 1.00 & 1.00 \\
\hline & 1.00 & 0.67 & 0.79 & 1.00 \\
\hline & 0.77 & 1.00 & 0.85 & 0.93 \\
\hline & 1.00 & 0.92 & 0.88 & 0.58 \\
\hline & 0.92 & 0.46 & 1.00 & 1.00 \\
\hline & 1.00 & 0.82 & 1.00 & 0.70 \\
\hline & 0.96 & 1.00 & 1.00 & 0.58 \\
\hline & 1.00 & 0.95 & 1.00 & 0.80 \\
\hline & 0.82 & 1.00 & 1.00 & 0.80 \\
\hline & 0.93 & 1.00 & 0.97 & 1.00 \\
\hline & 1.00 & 1.00 & 1.00 & 1.00 \\
\hline & & 1.00 & 1.00 & 1.00 \\
\hline & & 1.00 & 0.81 & 1.00 \\
\hline & & 0.84 & 0.80 & 1.00 \\
\hline & & 0.72 & 1.00 & 1.00 \\
\hline & & 0.50 & 0.90 & 1.00 \\
\hline & & & 0.97 & \\
\hline Density Values & Mangawhero & Whangaehu & Turakina & Pohangina \\
\hline Total slips (LS) & 721.00 & 723.00 & 730.00 & 748.00 \\
\hline Total km2 & 16.61 & 20.19 & 22.73 & 19.86 \\
\hline LS/km2 & 43.41 & 35.81 & 32.12 & 37.66 \\
\hline
\end{tabular}


Appendix 7 Runout length: scar length ratio data summary

\begin{tabular}{|l|r|r|r|r|}
\hline $\begin{array}{l}\text { Runout length: scar } \\
\text { length ratio }\end{array}$ & Mangawhero & Whangaehu & Turakina & Pohangina \\
\hline $1-1.99$ & 97 & 147 & 201 & 163 \\
\hline $2-2.99$ & 202 & 267 & 237 & 281 \\
\hline $3-3.99$ & 163 & 186 & 142 & 162 \\
\hline $4-4.99$ & 117 & 80 & 84 & 86 \\
\hline $5-5.99$ & 67 & 32 & 35 & 40 \\
\hline $6-6.99$ & 31 & 9 & 15 & 12 \\
\hline $7-7.99$ & 14 & 3 & 8 & 1 \\
\hline $8-8.99$ & 12 & 1 & 4 & 3 \\
\hline $9-9.99$ & 5 & 0 & 2 & 0 \\
\hline $10-10.99$ & 3 & 0 & 1 & 0 \\
\hline $11-11.99$ & 5 & 0 & 1 & 0 \\
\hline $12-12.99$ & 5 & 0 & 0 & 0 \\
\hline & & & & 748 \\
\hline Total & 721 & 725 & 730 & \\
\hline
\end{tabular}




\section{Appendix 8 Scar volume data by study area}
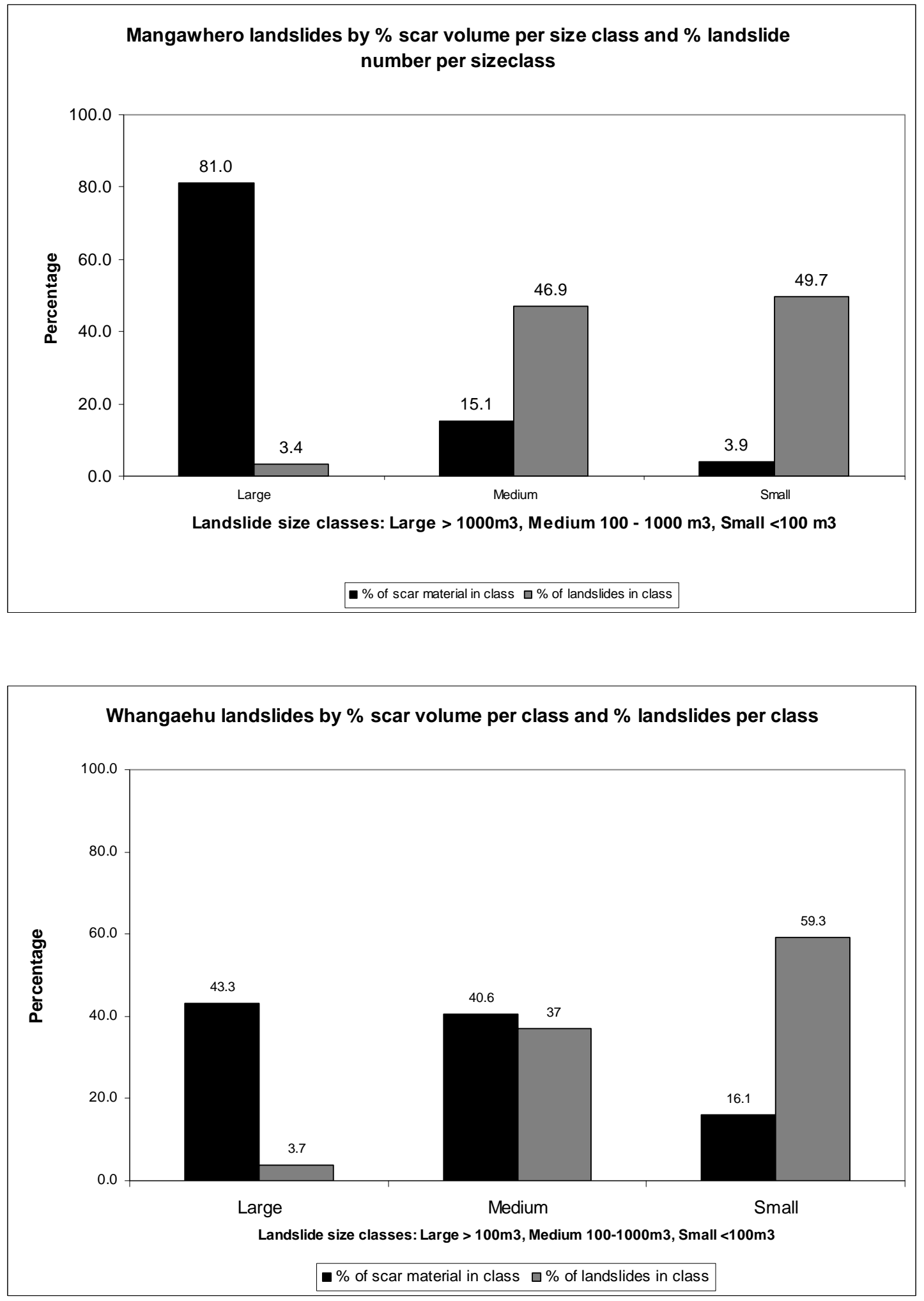

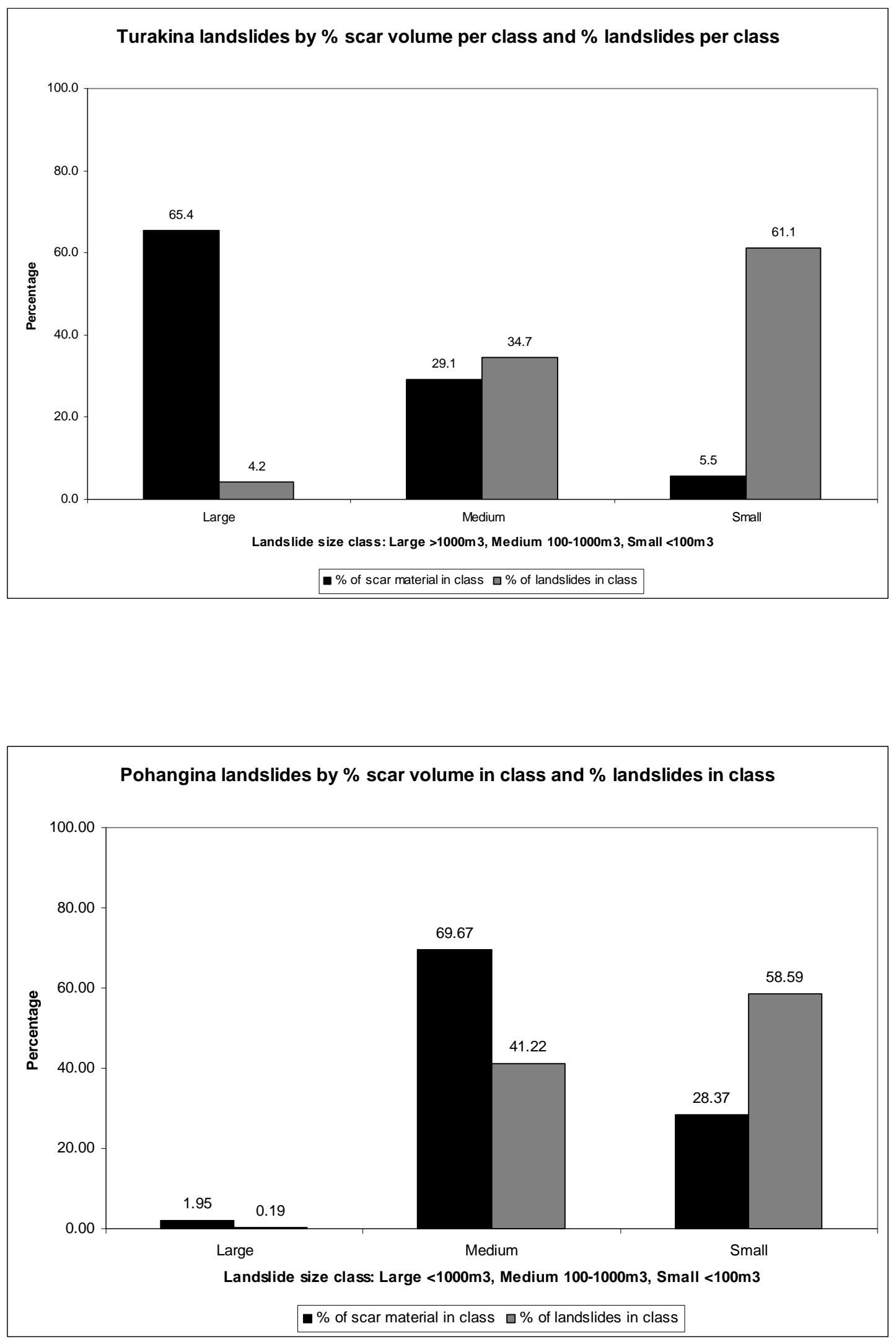
Appendix 9 Vertical aerial photo rectification data summary

\begin{tabular}{|c|c|c|c|c|c|c|c|}
\hline J5 length & K5 length & Difference & $\%$ change & K5 length & K6 length & Difference & $\%$ change \\
\hline 15.00 & 18.50 & -3.50 & 23.33 & 21.50 & 22.00 & -0.50 & 2.33 \\
\hline 13.00 & 12.00 & 1.00 & 7.69 & 13.00 & 13.00 & 0.00 & 0.00 \\
\hline 25.00 & 31.00 & -6.00 & 24.00 & 4.50 & 4.50 & 0.00 & 0.00 \\
\hline 9.00 & 10.00 & -1.00 & 11.11 & 8.50 & 8.50 & 0.00 & 0.00 \\
\hline 15.00 & 16.00 & -1.00 & 6.67 & 12.00 & 9.00 & 3.00 & 25.00 \\
\hline 15.00 & 16.50 & -1.50 & 10.00 & 6.00 & 6.00 & 0.00 & 0.00 \\
\hline 8.50 & 9.00 & -0.50 & 5.88 & 9.50 & 9.00 & 0.50 & 5.26 \\
\hline 7.50 & 7.50 & 0.00 & 0.00 & 12.50 & 13.50 & -1.00 & 8.00 \\
\hline 18.00 & 24.00 & -6.00 & 33.33 & 10.00 & 8.50 & 1.50 & 15.00 \\
\hline 7.00 & 7.00 & 0.00 & 0.00 & 15.00 & 15.00 & 0.00 & 0.00 \\
\hline 8.50 & 8.50 & 0.00 & 0.00 & 18.00 & 18.00 & 0.00 & 0.00 \\
\hline 9.00 & 10.00 & -1.00 & 11.11 & 15.50 & 15.50 & 0.00 & 0.00 \\
\hline 10.00 & 11.00 & -1.00 & 10.00 & 31.00 & 29.00 & 2.00 & 6.45 \\
\hline 15.00 & 15.00 & 0.00 & 0.00 & 21.00 & 22.00 & -1.00 & 4.76 \\
\hline 12.00 & 12.00 & 0.00 & 0.00 & 13.00 & 12.00 & 1.00 & 7.69 \\
\hline 12.00 & 14.00 & -2.00 & 16.67 & 26.00 & 28.00 & -2.00 & 7.69 \\
\hline 5.00 & 5.00 & 0.00 & 0.00 & 43.00 & 43.00 & 0.00 & 0.00 \\
\hline 11.00 & 12.00 & -1.00 & 9.09 & 13.00 & 12.00 & 1.00 & 7.69 \\
\hline 14.00 & 14.00 & 0.00 & 0.00 & 18.50 & 18.50 & 0.00 & 0.00 \\
\hline 4.00 & 4.00 & 0.00 & 0.00 & 24.50 & 22.00 & 2.50 & 10.20 \\
\hline 7.50 & 8.00 & -0.50 & 6.67 & 27.00 & 27.50 & -0.50 & 1.85 \\
\hline 10.00 & 10.00 & 0.00 & 0.00 & 15.00 & 16.50 & -1.50 & 10.00 \\
\hline 4.50 & 4.50 & 0.00 & 0.00 & 19.50 & 17.00 & 2.50 & 12.82 \\
\hline 19.00 & 17.00 & 2.00 & 10.53 & 12.00 & 13.00 & -1.00 & 8.33 \\
\hline 5.00 & 5.00 & 0.00 & 0.00 & 7.00 & 7.00 & 0.00 & 0.00 \\
\hline 6.50 & 7.00 & -0.50 & 7.69 & 15.50 & 15.00 & 0.50 & 3.23 \\
\hline 5.50 & 5.00 & 0.50 & 9.09 & 15.00 & 14.00 & 1.00 & 6.67 \\
\hline 9.00 & 9.00 & 0.00 & 0.00 & 21.00 & 17.00 & 4.00 & 19.05 \\
\hline 17.00 & 21.00 & -4.00 & 23.53 & 10.00 & 10.00 & 0.00 & 0.00 \\
\hline 22.00 & 23.00 & -1.00 & 4.55 & 7.50 & 7.00 & 0.50 & 6.67 \\
\hline 4.50 & 4.50 & 0.00 & 0.00 & 17.00 & 15.00 & 2.00 & 11.76 \\
\hline 6.50 & 6.00 & 0.50 & 7.69 & 21.00 & 18.00 & 3.00 & 14.29 \\
\hline 6.00 & 5.00 & 1.00 & 16.67 & 13.50 & 15.00 & -1.50 & 11.11 \\
\hline 16.00 & 12.00 & 4.00 & 25.00 & 10.00 & 10.00 & 0.00 & 0.00 \\
\hline 8.00 & 10.00 & -2.00 & 25.00 & 11.00 & 11.00 & 0.00 & 0.00 \\
\hline 12.00 & 13.00 & -1.00 & 8.33 & 6.50 & 6.50 & 0.00 & 0.00 \\
\hline 13.00 & 13.00 & 0.00 & 0.00 & 33.50 & 34.00 & -0.50 & 1.49 \\
\hline 12.00 & 12.00 & 0.00 & 0.00 & 42.00 & 40.00 & 2.00 & 4.76 \\
\hline 5.00 & 5.50 & -0.50 & 10.00 & 13.00 & 12.50 & 0.50 & 3.85 \\
\hline 5.00 & 5.00 & 0.00 & 0.00 & 29.00 & 27.50 & 1.50 & 5.17 \\
\hline 4.50 & 4.50 & 0.00 & 0.00 & 10.50 & 10.50 & 0.00 & 0.00 \\
\hline 16.00 & 15.00 & 1.00 & 6.25 & 10.00 & 12.00 & -2.00 & 20.00 \\
\hline 7.00 & 7.00 & 0.00 & 0.00 & 7.00 & 7.00 & 0.00 & 0.00 \\
\hline 5.00 & 6.00 & -1.00 & 20.00 & 23.00 & 19.00 & 4.00 & 17.39 \\
\hline 16.50 & 14.00 & 2.50 & 15.15 & 20.00 & 17.00 & 3.00 & 15.00 \\
\hline 3.50 & 4.00 & -0.50 & 14.29 & 12.50 & 12.50 & 0.00 & 0.00 \\
\hline 14.00 & 15.00 & -1.00 & 7.14 & 10.00 & 10.00 & 0.00 & 0.00 \\
\hline 6.00 & 6.50 & -0.50 & 8.33 & 20.50 & 20.50 & 0.00 & 0.00 \\
\hline 7.00 & 7.00 & 0.00 & 0.00 & 20.00 & 20.00 & 0.00 & 0.00 \\
\hline \multirow[t]{3}{*}{6.50} & 7.00 & -0.50 & 7.69 & 13.50 & 14.00 & -0.50 & 3.70 \\
\hline & & Total & 206.35 & & & Total & 118.68 \\
\hline & & Average & 4.13 & & & Average & 2.37 \\
\hline
\end{tabular}

